\title{
Antarctic ice sheet and climate evolution during the mid-Miocene
}

\section{Hannah Kate Chorley}

Antarctic Research Centre

Victoria University of Wellington

A thesis submitted to the Victoria University of Wellington in fulfillment of the requirements

for the degree of

Doctor of Philosophy

Geology

March 2021 

I would like to dedicate this thesis to my Mum and Dad - thanks for teaching me the meaning of unconditional love, to have confidence in myself, and to always speak up. This success is as much yours as it is mine and I will forever be grateful. 



\section{Acknowledgements}

Firstly, thank you to my supervisors, Tim Naish and Richard Levy, for this amazing opportunity and your support and guidance over the last few years. Thank you most of all for helping this thesis finally come to fruition.

To Ruthie, thanks for the friendship and support. I think together we have brought a little more life to the Miocene and I couldn't have made it through the last couple of years without you. It has been fun to see our thoughts and knowledge grow and develop with this project. Laurine, you are an amazing friend. These last 3 years have pushed us to our limits, and somehow, we have both come out the other side. A good (and inappropriate) sense of humour and someone else suffering alongside you is $100 \%$ a necessity for the completion of a $\mathrm{PhD}$. Here's to the future and to finding a lifelong friend. Marjo, thanks for pushing me to be the best I can be and your support when I've been feeling down. To all the friends at the Antarctic Research Centre and School of Geography, Environment and Earth Sciences I have made along the way, thanks for making this the experience it was and leaving me with many happy memories of my time here. Thanks to those that have also offered me help and support when I needed it, this thesis certainly wouldn't be where it is now without you.

To those that have contributed datasets and expertise that have helped with the analysis and interpretation of the Friis Hills cores: Warren Dickinson, Doug Kowalewski, Stephen Cox, Sidney Hemming, Christian Ohneiser, Margaret Harper, Joe Prebble, Aline Holmes, and Andrew Gorman. For all the other help and support along the way, thank you. To Antarctica New Zealand for logistical support in the field. To Webster Drilling, and in particular TK and Adam, for help collecting the cores and for not getting too frustrated when drilling was tough. Alex Pyne and Rebecca Pyne, for your core logging expertise. Also, thanks Rebecca for all the fun in the field and putting up with me and the 'dirty permafrost' at the ice core facility over the years, I hope we haven't traumatised you too much. To all those who have offered support and guidance in the labs - Jane Chewings at VUW, Andy Phillips at GNS, and again, Rebecca Pyne and Nancy Bertler at the ice core facility. This project has also been 
supported by multiple funding sources: the VUW Doctoral and Submission Scholarship and the ARC Endowed Development Fund.

To my family in the UK, the biggest thank you goes to you for your endless support and love. Zoe, thanks for always being the crazy one and sticking with me through everything, it doesn't matter the distance, you'll always be my best friend. Mum, Dad, and Alice, you are everything to me and I miss you every day. Thanks also goes to Mum and Alice for their patience with proof-reading, there's been a lot of it over the years! Grandad, thank you for starting me on this journey, I just wish you were here to see the result. Last but not least, Rich. Thank you for making life so wonderful and filled with love. On even the toughest days, it's hard not to smile. For listening to my many complaints, your help with figures, and for always staying calm, thank you. I'm looking forward to this next chapter of our lives, but first, I think we both deserve a holiday...

Finally, I would like to acknowledge the role my privilege has played in helping me to achieve this success. To those whose path has been rougher than mine, or whose path is still blocked - you are worthy. To those who share my privilege - only together can we break down the barriers to equality. 


\begin{abstract}
The mid-Miocene provides an important example relevant to the response of the East Antarctic Ice Sheet (EAIS) to future anthropogenic climate change. Geological observations and earth system modelling show a broad link between declining carbon dioxide $\left(\mathrm{CO}_{2}\right)$ concentrations and increasing size and sensitivity of ice sheets in the past. Future projections show $\mathrm{CO}_{2}$ concentrations could reach up to $1000 \mathrm{ppm}$ before the end of the century, with global temperatures $4-5^{\circ} \mathrm{C}$ warmer - a climate not seen since the mid-Miocene. This time period is therefore becoming increasingly important to understanding future Antarctic Ice Sheet (AIS) response, as $\mathrm{CO}_{2}$ concentrations are already at Pliocene levels ( $\left.\sim 400 \mathrm{ppm}\right)$. An improved, more detailed understanding of the response of the AIS to past climatic variability provides important context for interpreting how the AIS will respond to future climate change under high $\mathrm{CO}_{2}$ scenarios.
\end{abstract}

A dynamic EAIS characterised the mid-Miocene, with major variations in both volume and extent of terrestrial and marine ice sheets. While global climate remained warmer than present-day throughout, this interval was punctuated by an episode of unusual warmth within the Miocene Climatic Optimum (MCO, $17-15 \mathrm{Ma}$ ). The MCO is one of the warmest intervals since the onset of Antarctic glaciation, with $\mathrm{CO}_{2}$ concentrations of up to $840 \mathrm{ppm}$ during peak warmth and coastal regions characterised by temperate vegetation and mean summer temperatures (MST) of up to $\sim 10^{\circ} \mathrm{C}$. This warmth terminated with major cooling and ice expansion across the mid-Miocene Climate Transition (MMCT, 14.8-13.8 Ma).

$\mathrm{A} \sim 50 \mathrm{~m}$ thick ice-cemented terrestrial glacial sequence was recovered in drill cores from the Friis Hills, McMurdo Dry Valleys in 2016. A chronostratigraphic framework for the cores based on magnetostratigraphy, ${ }^{40} \mathrm{Ar} /{ }^{39} \mathrm{Ar}$ isotopic ages, and limited biostratigraphic constraints, revealed 15 sedimentary cycles of the advance and retreat of a temperate alpine glacier system between $\sim 15.1-13.8 \mathrm{Ma}$. Each cycle consists of traction tills and moraines deposited during ice advance and intervening glacio-fluvial to glacio-lacustrine lithofacies deposited during ice retreat. This record highlights the influence of increasing glacial- 
interglacial variability across the MMCT, with till facies becoming progressively thicker, drier and of wider provenance post $14.4 \mathrm{Ma}$, while interglacial sediments remained similar to those that characterised the late-MCO, sustaining tundra vegetation and MSTs of $6-7^{\circ} \mathrm{C}$.

An ensemble of model simulations were produced for a recently published mid-Miocene topography and a range of $\mathrm{CO}_{2}$ concentrations, Transantarctic Mountain (TAM) uplift scenarios, and glacial-interglacial orbits in order to better understand the mechanisms driving EAIS variability during the early to mid-Miocene. Sedimentological and palynological data for glacial-interglacial periods of the early to mid-Miocene provide the primary constraint on ice extent and temperature variability. Results of this model-data comparison were used to assess the likely boundary conditions for the MCO and MMCT, and inferred TAM elevations of 300-500 m lower than present-day, modelled $\mathrm{CO}_{2}$ concentrations up to $780 \mathrm{ppm}$ during periods of peak warmth, and a transition to lower $\mathrm{CO}_{2}$ across the MMCT. The onset of marine-based ice advance across the continental shelf was inferred between 280-460 ppm modelled $\mathrm{CO}_{2}$, however, the persistence of a significantly retreated, thick EAIS under even the highest modelled $\mathrm{CO}_{2}$ concentrations is not consistent with proxy data constraints and implies a strong hysteresis effect in the model. The presence of localised tundra vegetation under low $\mathrm{CO}_{2}$ concentrations in the model supports the persistence of higher plants in coastal lowlands post-MMCT, following their extinction at higher elevations after $\sim 13.8 \mathrm{Ma}$.

Terrestrial, marine, and far-field records were reconciled to assess glacial-interglacial variability and evolution of the EAIS across the mid-Miocene. While 15 cycles were identified within the Friis Hills record, only 7.5 of these are well enough constrained by the age model to be correlated to climate cycles in the $\delta^{18} \mathrm{O}$ record, spanning $\sim 160 \mathrm{ka}$ of the late-MCO and inferring a terrestrial-terminating AIS responding to local insolation controlled by precession. This is consistent with eccentricity modulated precession control implied in other coastal Antarctic and far-field records during the $\mathrm{MCO}$, but results presented here also support a two stepped climatic shift at $\sim 14.6$ and $\sim 13.8$ Ma during the MMCT. This stepwise shift in climatic cooling is attributed to declining $\mathrm{CO}_{2}$, with two boundaries in long-term atmospheric $\mathrm{CO}_{2}$ concentrations crossed during this time: (1) A shift to $\mathrm{CO}_{2}$ concentrations below 460 ppm in the model supported the growth of annual sea-ice and advance of small-scale marinebased ice into the Ross Sea. (2) At $13.8 \mathrm{Ma}$, a further decline in $\mathrm{CO}_{2}$ concentrations to below 280 ppm supported perennial sea-ice development, limiting the influence of warm, deepwater upwelling, resulting in large-scale marine-based ice advance, ultimately stabilising the AIS. This stepwise mid-Miocene cooling implies threshold behaviour of the AIS during a long-term 200-300 ppm general decline in $\mathrm{CO}_{2}$ proxy records. 


\section{Table of contents}

$\begin{array}{ll}\text { List of figures } & \text { xv }\end{array}$

$\begin{array}{ll}\text { List of tables } & \text { xix }\end{array}$

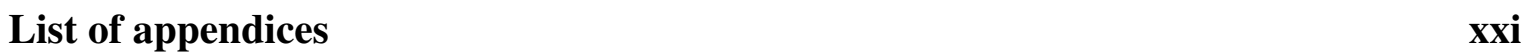

$\begin{array}{ll}\text { Nomenclature } & \text { xxiii }\end{array}$

1 Introduction 1

1.1 Rationale ............................. 1

1.2 Research questions .................... 5

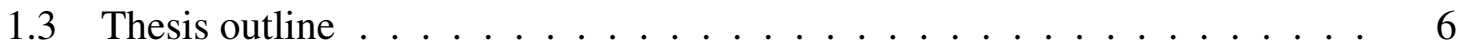

2 Background 9

2.1 Long term Cenozoic climate change . . . . . . . . . . . . . . . . 9

2.1.1 Ice sheet development from the oxygen isotope record . . . . . . 12

2.1.2 Ice sheet development from geologic and proxy records . . . . . 14

2.1.3 Drivers of ice sheet growth . . . . . . . . . . . . 17

2.2 Early to mid-Miocene climate change . . . . . . . . . . . . 28

2.2.1 Global climate variability during the Miocene . . . . . . . . . . 28

2.2.2 Miocene Climatic Optimum . . . . . . . . . . . . . . 30

2.2.3 Mid-Miocene Climate Transition . . . . . . . . . . . . . . 30 
2.2.4 Simulating Miocene glacial evolution with numerical modelling . . 32

2.2.5 Importance relative to present-day climate change . . . . . . . . . 33

2.3 Existing Miocene deposits in Antarctica - Marine . . . . . . . . . . . . . . 34

$2.3 .1 \quad$ ANDRILL-2A $\ldots \ldots \ldots \ldots \ldots \ldots \ldots$

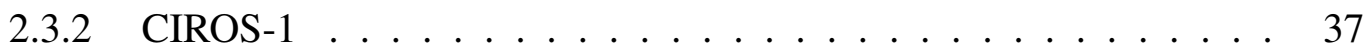

2.3.3 Cape Roberts Project-1 and $-2 / 2 \mathrm{~A} \ldots \ldots 38$

2.3.4 U1356 Wilkes Land . . . . . . . . . . . . . . . . . 39

2.3.5 Deep Sea Drilling Project $274 \ldots$. . . . . . . . . . . . . 40

2.4 Existing Miocene deposits in Antarctica - Terrestrial _ . . . . . . . . . 40

2.4.1 McMurdo Dry Valleys drill cores . . . . . . . . . . . . . . 41

2.4.2 Olympus Range and Wright Valley . . . . . . . . . . . . . 41

2.4 .3 Sirius Group . . . . . . . . . . . . . . . . . 42

2.4 .4 Friis Hills . . . . . . . . . . . . . . . . . . . 44

2.4 .5 Volcanic deposits . . . . . . . . . . . . . . . . . 48

2.5 Terrestrial glacial facies . . . . . . . . . . . . . . . . . 48

2.5.1 Wet-based glaciation ................ 50

2.5 .2 Cold-based glaciation . . . . . . . . . . . . . 53

2.5.3 Polythermal glaciation . . . . . . . . . . . . . 53

2.6 Modern analogues . . . . . . . . . . . . . . . . . . . 54

2.6.1 Greenland ........................ 54

2.6 .2 Kerguelen Islands . . . . . . . . . . . . . . . . . . . 55

2.6 .3 Patagonia ........................ 56

3 Antarctic Ice Sheet evolution and variability during the mid-Miocene Climate Transition ( 15.1-13.8 Ma), from the Friis Hills, Antarctica 57

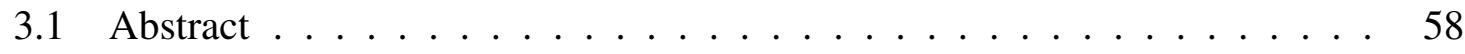

3.2 Introduction $\ldots \ldots \ldots \ldots \ldots \ldots \ldots$ 
3.3 Miocene terrestrial sediments in the Friis Hills . . . . . . . . . . . . . . . 62

3.4 This Study . . . . . . . . . . . . . . . . . . . . 65

3.5 Tectonic setting and topographic evolution . . . . . . . . . . . 66

3.6 Present day climate . . . . . . . . . . . . . . . . . . 69

3.7 Methods . . . . . . . . . . . . . . . . . . . 70

3.7 .1 Drilling ..................... 70

3.7.2 Core description and sampling . . . . . . . . . . . . 71

3.7.3 Grainsize analysis and clast counts . . . . . . . . . . . . 72

3.7.4 Core physical and chemical properties measurements . . . . . . 73

3.7 .5 Diatoms ......................... 73

3.7 .6 Palynology . . . . . . . . . . . . . . . . . 74

3.7 .7 Carbon analysis . . . . . . . . . . . . . . . . 74

3.7.8 Tephra characterisation and numeric dating . . . . . . . . . 75

3.7 .9 Paleomagnetic stratigraphy . . . . . . . . . . . . 76

3.8 Facies analysis and sequence stratigraphy . . . . . . . . . . . . . . . 77

3.8.1 Facies 1 - Mudstone and fine sandy-mudstone . . . . . . . . . . . 82

3.8.2 Facies 2 - Interstratified mudstone and sandstone . . . . . . . . 84

3.8.3 Facies 3 - Graded sandstone . . . . . . . . . . . . . 86

3.8.4 Facies 4 - Sandstone . . . . . . . . . . . . . . . . . . 88

3.8.5 Facies 5 - Cross stratified sandstone . . . . . . . . . . . . 89

3.8.6 Facies 6 - Breccia . . . . . . . . . . . . . . . . 91

3.8.7 Facies 7 - Stratified diamicton . . . . . . . . . . . . . 92

3.8.8 Facies 8 - Massive diamicton . . . . . . . . . . . . . . 93

3.8.9 Facies $9-$ Tephra . . . . . . . . . . . . . . . 96

3.8.10 Depositional architecture of a glacial-interglacial sedimentary cycle 99

3.9 Paleoecology . . . . . . . . . . . . . . . . . . . . . . . 104 
3.9.1 Pollen . . . . . . . . . . . . . . . . . . . . . 104

3.9 .2 Diatoms . . . . . . . . . . . . . . . 105

3.10 Age model and chronostratigraphic correlation . . . . . . . . . . 106

3.10 .1 Biostratigraphy . . . . . . . . . . . . . . . . 108

3.10.2 Tephrostratigraphy and tephrochronology . . . . . . . . . 108

3.10 .3 Paleomagnetism . . . . . . . . . . . . . . 110

3.10 .4 Magnetostratigraphy . . . . . . . . . . . . . . . 111

3.10 .5 Integrated chronostratigraphy $\ldots \ldots \ldots 112$

3.11 Updated composite stratigraphy for the Miocene Friis Hills deposits . . . 114

3.11 .1 Friis I drift . . . . . . . . . . . . . . . . . . . 114

3.11 .2 Friis II (lower) drift . . . . . . . . . . . . . . . . . 114

3.11 .3 Friis II (upper) drift . . . . . . . . . . . . . . . 116

3.12 Evolution of the Antarctic Ice Sheet in Southern Victoria Land through the mid-Miocene . . . . . . . . . . . . . . . . 116

3.13 Conclusions . . . . . . . . . . . . . . . . . 122

4 Carbon-dioxide and tectonic controls on Antarctic climate and ice sheet evolution in the mid-Miocene: a model-data integration 125

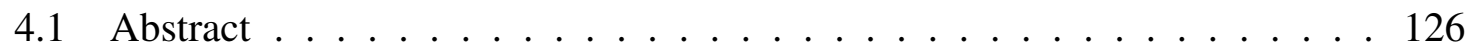

4.2 Introduction . . . . . . . . . . . . . . . . . 127

4.2.1 Transantarctic Mountain uplift scenarios . . . . . . . . . . . . . 130

4.2.2 Atmospheric carbon-dioxide concentrations . . . . . . . . . . 132

4.3 Methods . . . . . . . . . . . . . . . . . . . 134

4.3.1 Mid-Miocene paleo-records and model-data comparison . . . . . . 134

4.3.2 Model setup . . . . . . . . . . . . . . . . . . . . . . 138

4.3.3 Model boundary conditions . . . . . . . . . . . . . . . . 141

4.4 Results . . . . . . . . . . . . . . . . . . . . . . . . . . . 143 
4.4.1 Continent scale ice sheet reconstructions . . . . . . . . . . 143

4.4.2 Transantarctic Mountain ice sheet dynamics . . . . . . . . . . . . . 145

4.4 .3 Mid-Miocene climate . . . . . . . . . . . . . . . . . . . . . 147

4.4.4 Constraining model results with geologic data . . . . . . . . . . 148

4.4.5 Terrestrial records . . . . . . . . . . . . . . . . 151

4.4.6 Marine records . . . . . . . . . . . . . . . . 153

4.5 Discussion . . . . . . . . . . . . . . . . 156

4.5.1 Implications for Antarctic Ice Sheet dynamics . . . . . . . . . . 156

4.5.2 Implications for Antarctic climate and feedbacks $\ldots . . . . . .158$

4.5.3 Terrestrial records . . . . . . . . . . . . . . . . 160

4.5.4 Marine records . . . . . . . . . . . . . . . . . . 161

4.5.5 Characterising the mid-Miocene . . . . . . . . . . . . . . 164

4.6 Conclusions . . . . . . . . . . . . . . . . . . . . . 168

5 Glacial-interglacial variability and evolution of the Antarctic Ice Sheet across the mid-Miocene: reconciling terrestrial, marine, and far-field records 173

5.1 Introduction . . . . . . . . . . . . . . . 173

5.2 Reconciling mid-Miocene terrestrial, marine, and far field records $\ldots \ldots$. 178

5.2.1 Evolution of the Antarctic Ice Sheet through the mid-Miocene: evidence from coastal and offshore marine records . . . . . . . . . 178

5.2.2 Evolution of the Antarctic Ice Sheet in Southern Victoria Land through the mid-Miocene: evidence from terrestrial records . . . . 181

5.2.3 Reconciliation of marine and terrestrial records in Southern Victoria Land . . . . . . . . . . . . . . . . . . . 182

5.2.4 Reconciliation of Friis Hills glacial-interglacial cycles and far-field records for the mid-Miocene . . . . . . . . . . . . . . . . . . 184

5.3 The role of carbon dioxide on mid-Miocene climate variability $\ldots \ldots$. . . 187 
5.3.1 The role of carbon dioxide on stepwise climate cooling and thresholds in the Antarctic Ice Sheet during the mid-Miocene . . . . . . 192

5.4 Conclusions . . . . . . . . . . . . . . . . . . . . . . . . . . . . . 194

6 Conclusions and future work 


\section{List of figures}

1.1 Location map for early to mid-Miocene Antarctic records . . . . . . . . . . 4

2.1 Long-term Cenozoic climate variability . . . . . . . . . . . . . . . . 11

2.2 Cenozoic oxygen isotope record f . . . . . . . . . . . . . 13

2.3 Schematic diagram illustrating the three orbital parameters . . . . . . . . 19

2.4 Obliquity controls on Antarctic Ice Sheet evolution _ . . . . . . . . . . 21

2.5 Flexural cantilever hinge model . . . . . . . . . . . . . . 26

2.6 Reconstructed Antarctic topography for 34-3.5 Ma . . . . . . . . . . . . . 27

2.7 Reconstruction of early to mid-Miocene climate . . . . . . . . . . . . . . 29

2.8 Ice sheet reconstructions with modern vs. mid-Miocene topography . . . . 33

2.9 Location map for early to mid-Miocene Antarctic records . . . . . . . . . . 35

2.10 Mid-Miocene ice sheet evolution from the ANDRILL-2A record . . . . . . 36

2.11 Glacial-interglacial depositional environments from the Cape Roberts Project record . . . . . . . . . . . . . . . . . . . . 39

2.12 Generalised stratigraphic column for Miocene deposits in the Friis Hills from Lewis and Ashworth $(2015) \quad \ldots \ldots 45$

2.13 Typical facies associations for different glacial thermal regimes . . . . . . . 49

2.14 Terrestrial wet-based/polythermal glacial depositional model . . . . . . . . 51

2.15 Microstructures present in glacial sediments . . . . . . . . . . . 52

2.16 Southwest Greenland as a modern analogue for the Friis Hills . . . . . . . . 55 
3.1 Mid-Miocene ice sheet and climate variability . . . . . . . . . . . 60

3.2 Map of Southern Victoria Land and the Friis Hills drifts and drillsites _ . . 63

3.3 Geological cross sections through the Friis Hills central basin . . . . . . . . 66

3.4 Field site and drilling photos from the Friis Hills . . . . . . . . . . . . 71

3.5 Composite $\log$ of the FHDP-1A/1B core . . . . . . . . . . . . 78

3.6 Composite $\log$ of the FHDP-2A core . . . . . . . . . . . . . . 79

3.7 Composite $\log$ of the FHDP-3A core . . . . . . . . . . . . . . . 80

3.8 Mudstone and fine-sandy mudstone (facies 1) sedimentary features . . . . . 83

3.9 Diatom taxa observed in the FHDP record . . . . . . . . . . . . . 83

3.10 Interstratified mudstone and sandstone (facies 2) sedimentary features . . . 85

3.11 Graded sandstone (facies 3 ) sedimentary features $\ldots \ldots$. . . . . . . 87

3.12 Sandstone $($ facies 4$)$ sedimentary features $\ldots \ldots \ldots$. . . . . . . . . 88

3.13 Cross stratified sandstone (facies 5) sedimentary features . . . . . . . . . . 90

3.14 Breccia (facies 6 ) sedimentary features . . . . . . . . . . . . . . . 91

3.15 Stratified diamictite (facies 7) sedimentary features $\ldots \ldots$. . . . . . . 92

3.16 Friis II (upper and lower) drift sedimentary features . . . . . . . . . . . . . 94

3.17 Massive diamictite (facies 8) sedimentary features . . . . . . . . . . . 95

3.18 Tephra (facies 9) sedimentary features . . . . . . . . . . . . . . 97

3.19 Major element glass chemistry data for Friis Hills tephra . . . . . . . . . 98

3.20 Idealised sequence stratigraphic motif . . . . . . . . . . . . . . 100

3.21 Terrestrial depositional environment model for the Friis Hills . . . . . . . . 101

3.22 Composite age model for the FHDP drill cores . . . . . . . . . . . . . . . 107

$3.23{ }^{40} \mathrm{Ar} /{ }^{39} \mathrm{Ar}$ ages for the FHDP-2A/C and $-3 \mathrm{~A}$ tephra . . . . . . . . . . . 109

3.24 Glacial-interglacial reconstructions for the Frill Hills region . . . . . . . . . 118

4.1 Location map for model domain and mid-Miocene paleo-records . . . . . . 129

4.2 Flexural cantilever hinge model . . . . . . . . . . . . . . . . . 132 
4.3 Model ensemble design and boundary conditions . . . . . . . . . . . . . . 139

4.4 Asynchronous coupling of climate and ice sheet models . . . . . . . . . . . 140

4.5 Mid-Miocene (14 Ma) reconstructed topography . . . . . . . . . . . . . . . 143

4.6 Modelled ice sheet volume and extent . . . . . . . . . . . . . . . . . . . . 144

4.7 Flowlines and basal conditions for ice across the Transantarctic Mountain

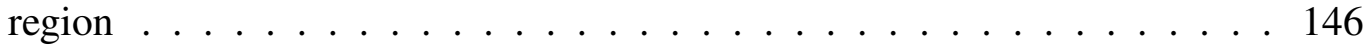

4.8 Flowlines and basal conditions for ice across the Friis Hills . . . . . . . . . 147

4.9 Modelled summer and winter precipitation in the Transantarctic Mountain region . . . . . . . . . . . . . . . . . . . 148

4.10 Modelled vegetation over the Transantarctic Mountain and Wilkes Land Subglacial Basin region . . . . . . . . . . . . . . . . . . . 150

4.11 Modelled minimum annual temperatures for paleodata sites . . . . . . . . . 151

4.12 Modelled mean summer temperatures for paleodata sites . . . . . . . . . . 152

4.13 ANDRILL-2A and Cape Roberts Project model-data comparison . . . . . . 154

4.14 Modelled mean annual temperatures for the Wilkes U1356 drill core . . . . 156

4.15 Hypothesised ice sheet configurations for the Miocene Climatic Optimum and mid-Miocene Climate Transition . . . . . . . . . . . . . . . . . . 171

5.1 Summary of glacial-interglacial variability across the mid-Miocene . . . . . 174

5.2 Location map for early to mid-Miocene Antarctic records . . . . . . . . . . 179

5.3 Mid-Miocene ice sheet evolution from the ANDRILL-2A record . . . . . . 180

5.4 Correlation of FHDP drill cores to the oxygen isotope record . . . . . . . 185 



\section{List of tables}

2.1 Friis Hills drifts and their interpretation f . . . . . . . . . . . . . . . 47

3.1 Summary of facies documented in the Friis Hills cores and their environmental interpretation . . . . . . . . . . . . . . . 81

4.1 Sedimentological and palynological proxy data for interglacial periods of the early Miocene and Miocene Climatic Optimum . . . . . . . . . . . . 135

4.2 Sedimentological and palynological proxy data for interglacial periods of the mid-Miocene Climate Transition . . . . . . . . . . . . . . . . . . 136

4.3 Sedimentological proxy data for glacial periods of the early to mid-Miocene 137

4.4 Circumpolar tundra biome classification . . . . . . . . . . . . . . 138

4.5 ANDRILL-2A environmental facies and model representation. . . . . . . . 154

5.1 Modelled glacial-interglacial Antarctic Ice Sheet variability . . . . . . . . . 187

5.2 Model-data comparison of carbon dioxide and sea level equivalent ice volume estimates for the mid-Miocene . . . . . . . . . . . . . . . . . . . . 189 



\section{List of appendices}

\section{Appendix A - Friis Hills sample list}

The sample list notes the samples taken from the drill cores, including drillers depth, actual depth, and the top depth (which has been used to subsequently plot and report data). This sample list also reports the facies and munsell colour assigned to each sample, moisture content, and percentage organics. The processed grain size data, including sample type, textural group, and percentage of mud/sand for each sample is also reported here, as is the processed XRF data used for further analysis.

\section{Appendix B - Raw grainsize data}

This appendix includes the raw grainsize data produced during grainsize analysis for each of the Friis Hills samples, including the samples tested for reproducibility and the LPS standard results.

\section{Appendix C - Clast counts}

This appendix reports clast counts taken in the field for every $10 \mathrm{~cm}$ of core. Where a clast is $>10 \mathrm{~cm}$ in size, this is reported as $100 \%$.

\section{Appendix D - Raw XRF data}

This appendix includes the raw XRF measurements for each of the Friis Hills samples, including the international XRF calibration standards. 
Appendix E - Down core variability in prevalent diatom species

This appendix shows the variability in the prevalent diatom species with depth.

\section{Appendix F - Palynology counts}

This appendix reports the data for palynology counts on 18 of the Friis Hills samples, including groups assigned to each of the samples and their definition.

\section{Appendix G - Down core variability in prevalent plant genera}

This appendix shows the variability in the prevalent plant genera with depth.

\section{Appendix H - Tephra classification data}

This appendix reports the data produced during tephra characterisation analysis, including the elemental abundance for each of the glass shards analysed and the normalisation standards used to assess accuracy.

\section{Appendix I - Paleomagnetic stratigraphy figures}

This appendix contains the figures and figure descriptions in supplement to sections 3.9.33.9.5 of the text. 


\title{
Nomenclature
}

\author{
Acronyms / Abbreviations
}

$\delta^{13} \mathrm{C}$ Deep-sea carbon isotope ratios

$\delta^{18} \mathrm{O}$ Deep-sea oxygen isotope ratios

$\%$ per mil, parts per thousand

ACC Antarctic Circumpolar Current

AIS Antarctic Ice Sheet

BWT Bottom Water Temperature

ChRM Characteristic Remanent Magnetisation

$\mathrm{CO}_{2}$ Carbon Dioxide

CRP Cape Roberts Project

CT Computed Tomography

DRM Detrital Remanent Magnetisation

DSDP Deep Sea Drilling Project

DVDP Dry Valley Drilling Project

EAIS East Antarctic Ice Sheet

EOT Eocene Oligocene Transition

EVP Erebus Volcanic Province 
FHDP Friis Hills Drilling Project

FORC First-Order Reversal Curve

GCM Global Climate Model

GPTS Global Polarity Time Scale

GSE Glacial Surface of Erosion

IODP Integrated Ocean Drilling Project

IRD Ice Rafted Debris

IRM Isothermal Remanence Magnetisation

ISM Ice Sheet Model

LOC Line of Correlation

LPS Laser Diffraction Particle Size Analyser

MAD Maximum Angular Deviation

MAT Mean Annual Temperature

MCO Miocene Climatic Optimum

MDV McMurdo Dry Valleys

MMCT Mid-Miocene Climate Transition

MST Mean Summer Temperature

ODP Ocean Drilling Project

OM Oligocene-Miocene boundary

PCA Principal Component Analysis

PETM Paleocene Eocene Thermal Maximum

PPM Parts Per Million

RCM Regional Climate Model 
SLE Sea Level Equivalent

SST Sea Surface Temperature

TAM Transantarctic Mountains

TAS Total Alkali vs. Silica

VRM Viscous Remanent Magnetisation

VUW Victoria University of Wellington

WAIS West Antarctic Ice Sheet

WLB Wilkes Land Subglacial Basin

XRF X-Ray Fluorescence 



\section{Chapter 1}

\section{Introduction}

\subsection{Rationale}

The combination of geological observations and earth system modelling shows a broad link between declining atmospheric carbon dioxide $\left(\mathrm{CO}_{2}\right)$ concentrations and increasing size and sensitivity of ice sheets in the past (Zachos et al., 2001; DeConto \& Pollard, 2003; Gasson et al., 2016). An improved, more detailed understanding of the response of the Antarctic Ice Sheet (AIS) to past climatic variability provides important context for understanding how the AIS will respond to future climate change under high $\mathrm{CO}_{2}$ scenarios. Future projections show atmospheric $\mathrm{CO}_{2}$ concentrations could reach $800 \mathrm{ppm}$ before the end of the century (Stocker et al., 2013) with associated global temperatures $4-5^{\circ} \mathrm{C}$ warmer - a climate not seen since the mid-Miocene (17-15 Ma; e.g. Herold et al., 2008; You et al., 2009; Gasson et al., 2016). This time period is becoming increasingly important for understanding future AIS response to warming because atmospheric $\mathrm{CO}_{2}$ has already reached Pliocene levels $(\sim 400$ ppm). Moreover, the paleogeography, and therefore atmospheric and oceanic circulation patterns during the mid-Miocene would have been broadly similar to those for the present-day configuration, providing boundary conditions for data-model comparisons in studying the sensitivity of the AIS to future warming. Improving current understanding of mid-Miocene climate in Antarctica will aid in interpreting the response of the AIS to future climate change.

Two different climatic states can be recognised in this time: (1) the Miocene Climatic Optimum (MCO, $\sim 17-15 \mathrm{Ma}$ ), which was characterised by temperatures warmer than presentday in the mid to high latitudes at atmospheric $\mathrm{CO}_{2}$ concentrations up to two times preindustrial levels (600 ppm; Foster et al., 2012; Goldner et al., 2014), and (2) the mid-Miocene 
climate transition (MMCT, $\sim 14.8-13.8 \mathrm{Ma}$ ), where the ice retreated and re-advanced into a larger than modern-day configuration (Hauptvogel \& Passchier, 2012). This marked the final transition into an icehouse climate, with a shift from a dynamic East Antarctic Ice Sheet (EAIS) to the more stable ice sheet of modern-day configurations (Denton et al., 1993; Stroeven \& Prentice 1997; Lewis et al., 2007).

A multi proxy approach to reconstructing the AIS extent, including the analysis of iceproximal marine sedimentary records (Naish et al., 2001; Barrett, 2009; Levy et al., 2016), deep sea oxygen isotope $\left(\delta^{18} \mathrm{O}\right)$ records (Shevenell et al., 2008; Lear et al., 2010; de Boer et al., 2010; Liebrand et al., 2011; Holbourn et al., 2014) and numerical models (Pekar \& DeConto 2006; Van Tuyll et al., 2007; DeConto et al., 2008; Gasson et al., 2016) indicates a highly dynamic AIS, with major variations in both volume and extent across the early to mid-Miocene. A continuous record of glacial-interglacial variability in the Transantarctic Mountains (TAM) will provide a vital terrestrial counterpart to marine records, providing an offshore-onshore transect of EAIS and climate variability during the mid-Miocene.

Changes in climate on the scale of millions of years have been attributed to a number of variables including, but not limited to, greenhouse gas concentrations, orbital forcing, and tectonic activity (Hays et al., 1976; Pearson \& Palmer 2000; DeConto \& Pollard 2003; Zachos et al., 2001; Raymo et al., 2006; Zachos et al., 2008; Ruddiman 2014). The origin of MCO warmth and the MMCT is still subject to debate, however both terrestrial (e.g. Goldner et al., 2014) and marine (e.g. Lear et al., 2000, Zhang et al., 2013) evidence support global temperatures up to $\sim{ }^{\circ} \mathrm{C}$ above modern. Changes in the poleward transport of moisture and heat have been attributed to ice growth during the MCO and MMCT, with intervals of glacial advance associated with warm surface and bottom water in the Southern Pacific, and vice versa during times of glacial retreat (Shevenell et al., 2008). A deepening of the Drake Passage, and subsequent strengthening of the Antarctic Circumpolar Current (ACC) and further thermal isolation of Antarctica could have contributed to the general cooling trend and stable AIS post-MMCT. This is corroborated by evidence for stepwise cooling in the Southern Pacific surface waters, interpreted as an increase in the ACC strength in the final interglacial prior to the termination of the MMCT (Shevenell et al., 2004).

The combination of geological observations and earth system modelling shows a broad link between declining atmospheric $\mathrm{CO}_{2}$ concentrations and increasing size and decreasing sensitivity of ice sheets in the past (Zachos et al., 2001; DeConto \& Pollard, 2003; Gasson et al., 2016; Levy et al., 2019). Elevated CO2 concentrations during the MCO have previously been attributed to Columbia River flood basalts, known to emit large volumes of $\mathrm{CO}_{2}$ over 
relatively short timescales (Kasbohm \& Schoene, 2018). A 200-300 ppm general decline in $\mathrm{CO}_{2}$ over the MCO and MMCT is inferred from geologic records (e.g. Foster et al., 2012; Zhang et al., 2013) and could explain the cooling trend across the MMCT. Declining $\mathrm{CO}_{2}$ concentrations across the mid-Miocene can be attributed to several mechanisms, including uplift of the Patagonian Andes and increased carbon sequestration rates (Blisniuk et al., 2005). Records of past climate change are essential in improving our understanding of the global response to rising atmospheric $\mathrm{CO}_{2}$ concentrations, however, this interpretation requires the identification of forcings and feedbacks and their relative role in the overall climate signal. Given the uncertainty regarding Transantarctic Mountain (TAM) uplift and atmospheric $\mathrm{CO}_{2}$ concentrations during the Miocene, this thesis evaluates the relative influence of these with respect to the glacial variability recorded in Miocene geologic data.

Analysis of new terrestrial permafrost drill cores are used to investigate climatic variability and glacial dynamics at the margin of the EAIS in the TAM of South Victoria Land during the mid-Miocene. The glacial history of this region has in the past relied heavily on coastlineproximal marine sedimentary records such as drill cores from CIROS-1, Cape Roberts Project-1 and 2/2A, ANDRILL-2A (Fig. 1.1) to reconstruct past environmental conditions (Barrett, 1987; Naish et al., 2001; Barrett, 2007; Fielding et al., 2011). The new mid-Miocene records were recovered by drilling a $\sim 50$-m thick deposit in the Friis Hills, located in the McMurdo Dry Valleys, Southern Victoria Land (Fig. 1.1). The glacio-fluvial and glaciolacustrine strata, which contain volcanic ash layers suggesting an age range of late-MCO ( $\sim 15.1 \mathrm{Ma})$ to MMCT $(\sim 13.8 \mathrm{Ma})$ comprise 15 cycles of glacial advance and retreat of an alpine glacier system at the margin of the EAIS through this time period. This well-dated record will provide an opportunity for the assessment of the role of orbital forcing on glacial deposition during this time and a comparison to the $\delta^{18} \mathrm{O}$ record and coastal and offshore marine records. 


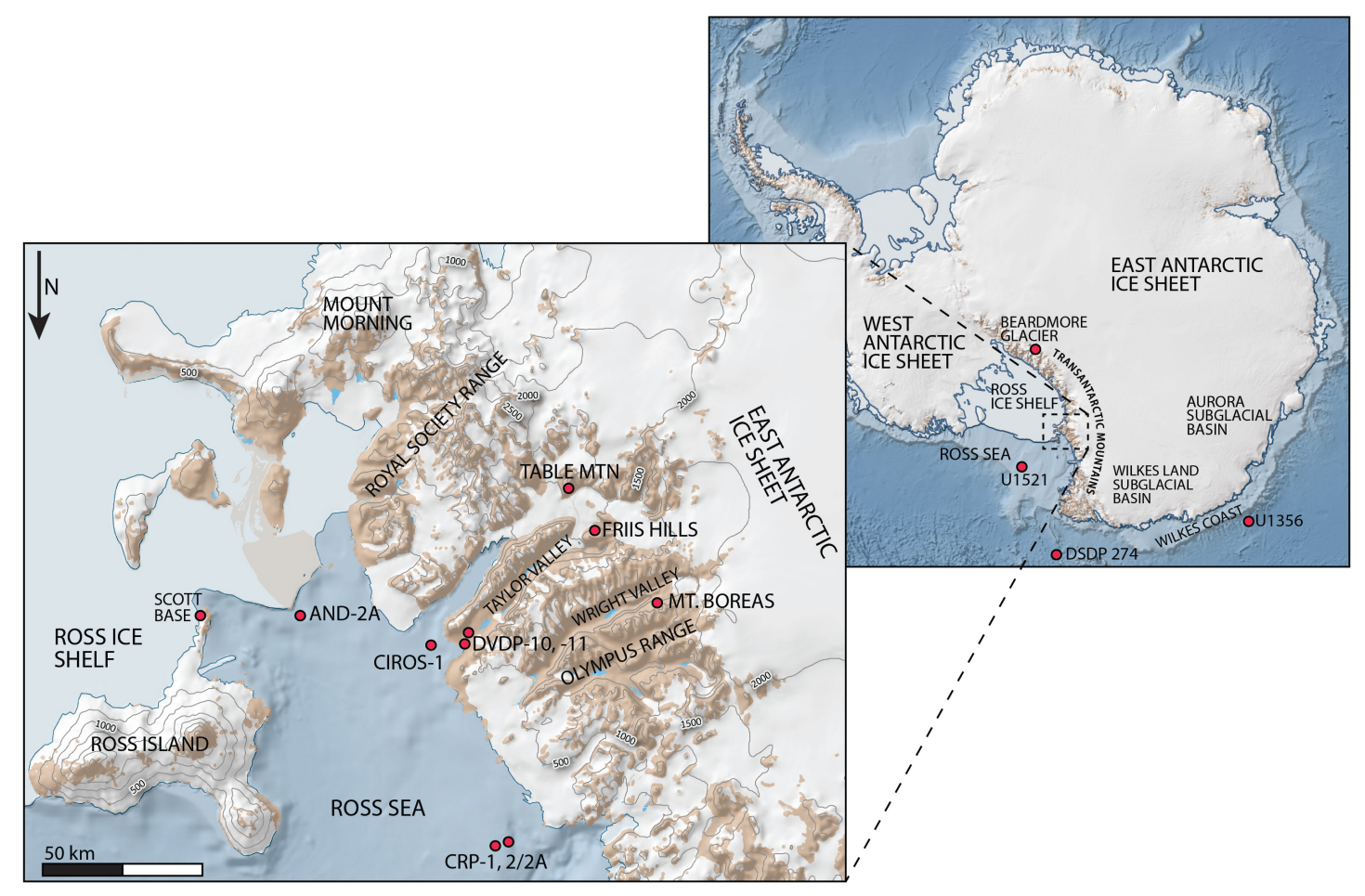

Fig. 1.1 Location map for early to mid-Miocene marine and terrestrial records and other locations discussed in the text, on a continental-scale, and, as the focus of this study, in more detail for the Southern Victoria Land sector of the Transantarctic Mountains. Base map from Quantarctica GIS package.

A model-data comparison using coupled numerical ice sheet and climate models in the context of constraints provided by the geological data was used to evaluate an ensemble of simulations for EAIS and climate variability for a range of plausible $\mathrm{CO}_{2}$ concentrations and TAM uplift scenarios during the mid-Miocene. Previous attempts to simulate the relative warmth of the Miocene have been hindered by a strong hysteresis, requiring $\mathrm{CO}_{2}$ concentrations considerably higher than those indicated by proxy records to initiate retreat (DeConto \& Pollard, 2003; DeConto et al., 2008; Gasson et al., 2016). Langebroek and others (2009) found that variations in orbital forcing, when combined with declining levels of atmospheric $\mathrm{CO}_{2}$, allowed for a hysteresis more closely aligned with $\mathrm{CO}_{2}$ reconstructions for the Miocene, with deglaciation of the EAIS initiated when $\mathrm{CO}_{2}$ declines to $\sim 725 \mathrm{ppm}$. These reconstructions, however, relied on modern-day topography, which is thought to have differed greatly during the Miocene. Using a new Miocene topography (Paxman et al., 2019b), and a range of $\mathrm{CO}_{2}$ concentrations and TAM elevations, this thesis reconciles model data with proxy environmental and sedimentological records both in the TAM and at the coast. 
Finally, glacial-interglacial variability and the long-term cooling trend across the midMiocene is discussed, with a focus on the role of $\mathrm{CO}_{2}$ during this time. An attempt to better reconcile model data, that corroborates geologic data from the continent, with far-field datasets such as global sea level reconstructions, the $\delta^{18} \mathrm{O}$ isotope record and $\mathrm{CO}_{2}$ records allows potential climate thresholds in the AIS system throughout the mid-Miocene to be assessed. An improved understanding of the response of the AIS and the general cooling trend across the mid-Miocene provides further knowledge that can be used to not only constrain the disparities between model and geologic data, but also provide insights into its response to projected global warming.

\subsection{Research questions}

1. What were the environmental, climatic and glacial conditions at the Friis Hills during the mid-Miocene and how did they evolve and vary?

Mid-Miocene paleoenvironmental reconstructions from geomorphic mapping and shallow pits in the Friis Hills terrestrial glacial deposits have previously been described by Lewis and Ashworth (2015) and indicate a considerably warmer and wetter climate than present day. However, a lack of chronological control and continuous stratigraphy has hindered efforts to interpret glacial evolution at the Friis Hills in a regional context. The relatively continuous record and analysis of these terrestrial glacial facies from the drill cores provides an opportunity for a more complete understanding of environmental conditions and how the EAIS and its glacial-interglacial variability, at the Friis Hills, evolved during the mid-Miocene.

2. How did different climate forcings and boundary conditions (e.g. atmospheric $\mathrm{CO}_{2}$, TAM elevation, and orbital forcing) influence EAIS evolution and variability during the mid-Miocene?

There is considerable uncertainty over the influence of different forcings on EAIS evolution during the Early to mid-Miocene. To date, modelling and data indicate a more dynamic EAIS at higher than present, yet still relatively low $\mathrm{CO}_{2}$ concentrations. $\mathrm{CO}_{2}$ reconstructions from proxy records indicate that values ranged anywhere between 300 to 840 ppm (Pagani et al., 1995; Pearson and Palmer, 2000; Kürschner et al., 2008; Retallack, 2009; Foster et al., 2012; Zhang et al., 2013; Greenop et al., 2014; Sosdian et al., 2018; Raitzsch et al., 2020). TAM uplift estimates since the mid-Miocene 
range from 0 to $1000 \mathrm{~m}$ (Clapperton and Sugden, 1990; Behrendt and Cooper, 1991; Fitzgerald, 1992; Wilch et al., 1993; Wilson, 1995; Kerr and Huybrechts, 1999; Sugden et al., 1999). Higher uplift estimates place many TAM geologic records considerably closer to sea level in the Miocene, influencing both ice over-riding extent and mean annual temperatures. By using climate and ice sheet models to investigate the relative influence TAM uplift and atmospheric $\mathrm{CO}_{2}$ concentrations, the glacial-interglacial variability recorded in terrestrial and marine sedimentary records can be evaluated. The relative attributions of climate forcing and boundary conditions that controlled the past ice sheet variability and may control future variability can in turn be more clearly assessed.

3. Can the mid-Miocene glacial history of the Friis Hills from geologic data and modelling studies (Questions $1 \& 2$ ), be reconciled with coastal drill core records and far-field climate records to better understand regional and global climate evolution during this time?

The mid-Miocene marks a fundamental change in long-term $\mathrm{CO}_{2}$ concentrations and orbital response of the EAIS (e.g. Levy et al., 2019). It is proposed this caused a major transition from a dynamic terrestrial AIS during MCO paced by eccentricity $(\sim 100$ kyr duration), modulated orbital precession ( $\sim 20$-kyr duration), to a highly dynamic marine-terminating ice sheet paced by changes in Earth's axial tilt ( $\sim 40$-kyr duration) during the MMCT. Following the MMCT, the AIS stabilised, with extensive marinebased ice during glacial periods and perennial sea ice. A well-constrained age model for the Friis Hills record allows for an assessment of the dominant orbital frequency influencing glacial variability and provides a comparison between EAIS variability in the terrestrial and marine sectors. Furthermore, the model-data comparison will allow for $\mathrm{CO}_{2}$ concentrations over glacial and interglacial periods across the mid-Miocene to be characterised, giving an indication of likely ice volume changes during this time. While it is acknowledged that multiple hypotheses exist for the origin of the MCO and MMCT, this thesis will utilise results from the model-data comparison (Question 2) to investigate the role long-term $\mathrm{CO}_{2}$ variability could have played during this time period.

\subsection{Thesis outline}

In order to address the questions above, this thesis is constructed in the following way: 


\section{Chapter 2 - Background}

This chapter provides a review of the literature and assesses current understanding of the main drivers of glacial-interglacial climate and AIS variability and evolution during the Cenozoic, and then focuses in detail on the Miocene. Previously described Miocene sedimentary deposits, their age, environmental and global significance are outlined. Previous simulations of AIS evolution during the Miocene are also outlined. Open questions and controversies are summarised. Finally, the literature on terrestrial glacial environments and the associated facies and their interpretation is outlined to provide context to the sediments that are described, analysed and interpreted in the FHDP drill cores.

\section{Chapter 3 - Antarctic Ice Sheet evolution and variability during the mid-Miocene Cli- mate Transition ( 15.1-13.8 Ma), from the Friis Hills, Antarctica}

This chapter presents the sedimentological descriptions, paleoenvironmental analyses, interpretations, and an age model for the mid-Miocene sediments in the Friis Hills drill cores. This includes facies analysis, sequence stratigraphy and a comparison of findings to existing studies from the Friis Hills. An assessment of how deposition in this glacial-fluvio-lacustrine polar alpine setting has changed through time both on glacial-interglacial and longer time scales is described and illustrated with depositional models. This chapter has been written as a manuscript for submission to the Bulletin of the Geological Society of America. While the introduction of this manuscript is relatively short, through necessity for a stand-alone paper, there is unavoidable overlap with Chapter 2 of this thesis. This chapter follows a similar outline to the paper manuscript, however, it has been reformatted and edited to fit with the structure of this thesis.

\section{Chapter 4 - Carbon-dioxide and tectonic controls on Antarctic climate and ice sheet evolution in the mid-Miocene: a model-data integration}

This chapter presents the results of a model-data integration to investigate the role of atmospheric $\mathrm{CO}_{2}$ concentrations and TAM elevations on Antarctic climate and ice sheet evolution in the mid-Miocene. An ensemble of model simulations are presented and evaluated for a recently published mid-Miocene topography (Paxman et al., 2019b) and a range of plausible $\mathrm{CO}_{2}$ concentrations, TAM uplift scenarios, and glacial-interglacial orbits. The model ensemble is constrained using ice extent and temperature variability inferred by sedimentological 
and palynological data, respectively. Finally, the data-constrained model boundary conditions are used to infer likely TAM elevations and $\mathrm{CO}_{2}$ concentrations for the MCO and MMCT. This chapter is based on a model/data comparison project carried out by $\mathrm{H}$. Chorley and A. Halberstadt, a PhD student at the University of Massachusetts, Amherst. The work presented in this chapter has been written as a manuscript for submission to a journal and is currently with co-authors for comment. While this chapter follows a similar outline to the paper manuscript, it has been reformatted and edited to fit with the structure of this thesis, with the addition of further analysis and interpretation of the geological data in the context of the model simulations. The introduction of this manuscript is relatively short, however through necessity for a stand-alone paper, there is unavoidable overlap with Chapter 2 of this thesis.

\section{Chapter 5 - Glacial-interglacial variability and evolution of the Antarctic Ice Sheet across the mid-Miocene: reconciling terrestrial, marine, and far-field records}

This chapter attempts to reconcile the mid-Miocene marine and terrestrial deposits discussed throughout this thesis to provide context into the differing response of the terrestrial and marine sectors of the EAIS to climate forcings. It presents a correlation of the Friis Hills drill core record to the $\delta^{18} \mathrm{O}$ isotope record, exploring the role of orbital forcing on glacialinterglacial variability at the Friis Hills. Finally, these records are compared to glacialinterglacial and long-term variability in proxies (e.g. sea level records, $\mathrm{CO}_{2}$ records, and the $\delta^{18} \mathrm{O}$ record), and the results of the model-data comparison presented in Chapter 4 to discuss the role declining $\mathrm{CO}_{2}$ concentrations across the mid-Miocene played on ice sheet and climate evolution. Unlike chapters 3 and 4, which are presented as distinct pieces of work, this chapter is written as a synthesis of findings and thoughts developed throughout this thesis. As a result, it often refers to previous chapters and figures to draw conclusions.

\section{Chapter 6 - Summary and conclusions}

This chapter provides a summary of the main conclusions of this thesis, highlighting areas for future work. 


\section{Chapter 2}

\section{Background}

The glacial evolution of the Transantarctic Mountains (TAM) and East Antarctic Ice Sheet (EAIS) through time is influenced by processes on both a local and global scale, in particular, the timing and amplitude of TAM uplift, orbital forcing, and atmospheric carbon dioxide $\left(\mathrm{CO}_{2}\right)$ variability. This chapter will begin by providing an overview of the long-term evolution of Cenozoic climate, examining the history and drivers of ice sheet growth in Antarctica. This will be followed by an overview of early to mid-Miocene climate in Antarctica, including both terrestrial and marine records and their implications. Here, existing work at the Friis Hills will be discussed, however this will be considered in greater detail in Chapter 3. Finally, this chapter will then assess terrestrial glacial facies, with a particular focus on the features and characteristics of wet-based, temperate glaciers and potential modern analogues for glaciation in the Friis Hills during the early to mid-Miocene.

\subsection{Long term Cenozoic climate change}

Over the last 65 million years, the Earth's climate has undergone continuous change, varying from the extremes of a greenhouse climate, through to the icehouse climate of present-day (Zachos et al., 2001; Zachos et al., 2008). During the Paleocene and Eocene (65-34 Ma), atmospheric $\mathrm{CO}_{2}$ concentrations were $>1000$ ppm (Fig. 2.1 e; Beerling \& Royer, 2011; Pross et al., 2012; Masson-Delmotte et al., 2013; Passchier et al., 2013) and Antarctica was warm and wet, with conditions not conducive to the development of large ice sheets. The early Cenozoic was characterised by a general warming trend, evident in deep-sea benthic foraminiferal oxygen isotope $\left(\delta^{18} \mathrm{O}\right)$ record (Fig. 2.1 a) and atmospheric $\mathrm{CO}_{2}$ records (Fig. 
$2.1 \mathrm{e})$. This warming was periodically punctuated by short-term ( $<200 \mathrm{ka})$ periods of extreme warmth such as the Paleocene-Eocene Thermal Maximum (PETM, 55.76, Fig. 2.1 a, Mudelsee et al., 2014).

The early Eocene Climatic Optimum (54-49 Ma) culminated this prolonged warming trend, with global temperatures $\sim 12^{\circ} \mathrm{C}$ warmer than present-day (Hollis et al., 2012; Huber \& Caballero, 2011; Mudelsee et al., 2014). Coastal regions in Antarctica had mild winters of $\sim 11^{\circ} \mathrm{C}$ that supported tropical forests, with high precipitation and temperate rainforests inland (Pross et al., 2012). A global cooling trend during the early-middle Eocene (Fig. 2.1 a) followed this peak warmth, marking the start of the decent into an icehouse world. A $2 \%$ increase in the $\delta^{18} \mathrm{O}$ record (Zachos et al., 2001) was coupled with the expansion of more temperate vegetation and a decline in tropical rainforests across the Antarctic continent (Pross et al., 2012). Several climate excursions punctuated this general cooling trend, including the middle-Eocene Climatic Optimum, an $\sim 500$ kyr period of warmth ( 40 Ma, Fig. 2.1 a, Shackleton \& Kennett, 1975; Bohaty \& Zachos, 2003; Zachos et al., 2008) and the Priabonian Oxygen Iotope Maximum ( $237.3 \mathrm{Ma}$ ), a short-lived cooling event thought to be associated with a period of ice-growth on Antarctica (Bohaty \& Zachos, 2003; Bohaty et al., 2009; Scher et al., 2014; Pascher et al., 2015).

At the Eocene-Oligocene transition (EOT, $\sim 34 \mathrm{Ma}$, Fig. $2.1 \mathrm{a}$ ), a decline in $\mathrm{CO}_{2}$ to $<750 \mathrm{ppm}$ (Fig. $2.1 \mathrm{e}$ ) and the tectonic isolation and aridification of Antarctica led to the development of large-scale Antarctic ice sheets (e.g. Pagani et al., 2011; Bijl et al., 2013; Passchier et al., 2013; Galeotti et al., 2016). Explanations for this include declining concentrations of atmospheric $\mathrm{CO}_{2}$ (DeConto \& Pollard, 2003; Pagani et al., 2011) and the thermal isolation of Antarctica via the opening of the Drake Passage and Tasmanian Seaway and associated changes in ocean circulation (e.g. Kennett \& Exon 2004). $\mathrm{CO}_{2}$ concentrations continued to decline during the Oligocene (Fig 2.1 e) and large-scale, orbitally-paced glacial advances on the order of 30-60 m sea level equivalent prevailed (Palike et al., 2006; Pagani et al., 2011; Miller et al., 2020). Modelling studies imply this volume of global ice during the Oligocene requires both East and West Antarctica to be ice-covered (DeConto \& Pollard, 2003), with topographic reconstructions of West Antarctica indicating it was above sea level (Wilson \& Luyendyk, 2009; Wilson et al., 2013), supporting the growth of terrestrial ice sheets in both regions. Declining temperatures, with mean summer temperatures (MST) of $\sim 10^{\circ} \mathrm{C}$, saw a shift from the subtropical forests that dominated the Eocene to widespread tundra (Askin \& Raine, 2000; Prebble et al., 2006). 


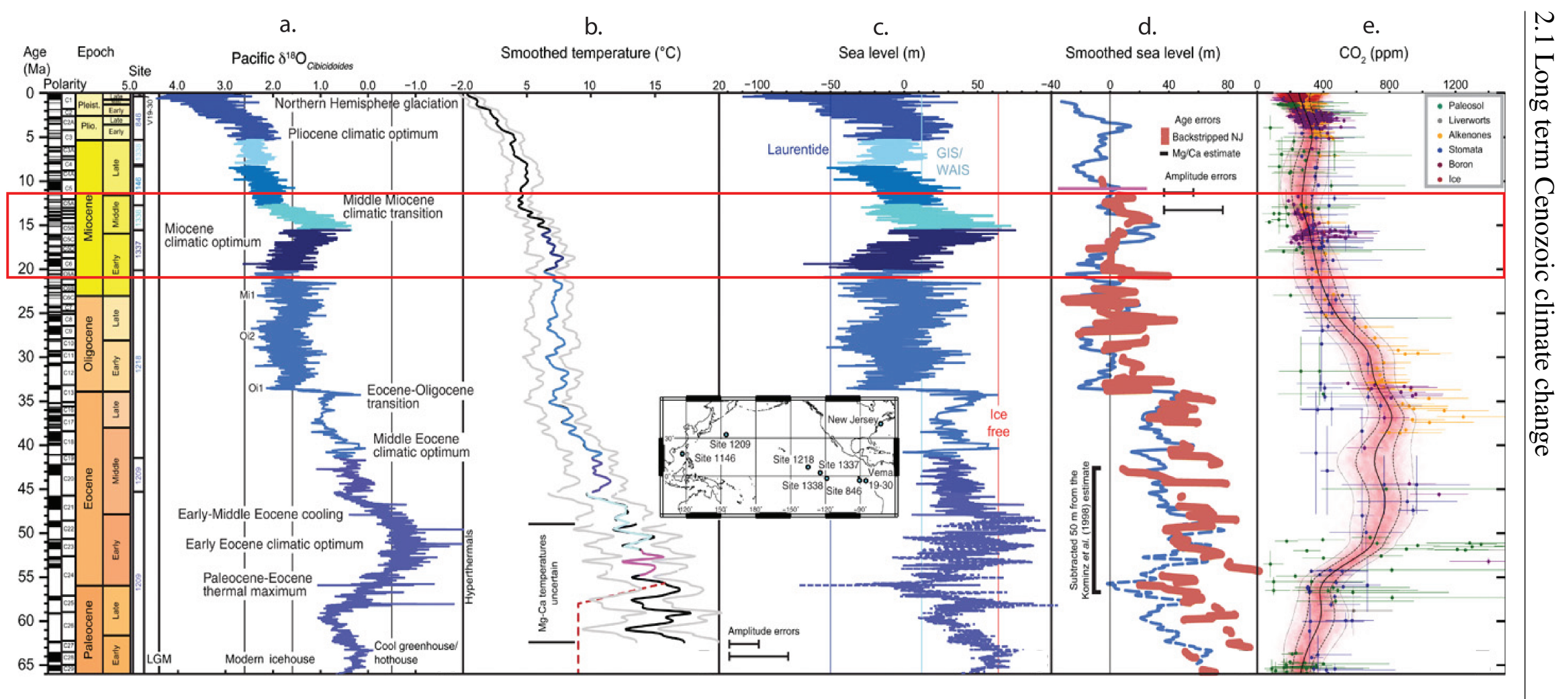

Fig. 2.1 Long term Cenozoic climate variability from (a) the $\delta^{18} \mathrm{O}$ record; icehouse climates with major ice sheets are determined by $\delta^{18} \mathrm{O}$ $>1.8 \%, \delta^{18} \mathrm{O}$ values of $-0.5 \%$ divide cool greenhouse climates (whereby Southern Hemisphere glaciation can occur) from hothouse climates. (b) temperature estimates from $\mathrm{Mg} / \mathrm{Ca}$ values in the Pacific (Cramer et al., 2011), the red line is the assumed temperature for the Paleocene-early Eocene. (c) sea level estimates from $\delta^{18} \mathrm{O}$ splice and $\delta^{18} \mathrm{O}$ seawater (Miller et al., 2020) using temperatures from $\mathrm{Mg} / \mathrm{Ca}$ (Shackleton \& Kennett, 1975). Ice-free line is drawn at $66 \mathrm{~m}$ above present-day, Greenland Ice Sheet and West Antarctic Ice Sheet line drawn at $12 \mathrm{~m}$ above present-day and the Laurentide Ice Sheet line is drawn at $-50 \mathrm{~m}$. (d) comparison of smoothed sea level estimates (Blue; Miller et al., 2020) and backstripped onshore New Jersey estimates (Red; Miller et al., 2005, Kominz et al., 2016). (e) $\mathrm{CO}_{2}$ compilation of Foster and others (2017) and measurements from Antarctic ice cores (Bereiter et al., 2015). The thick black line is modelled $\mathrm{CO}_{2}$, with dotted lines the associated errors. The map shows the locations of the Pacific and New Jersey records. The early to mid-Miocene, the focus of this study, is highlighted in red. Modified from Miller and others (2020). 


\subsubsection{Ice sheet development from the oxygen isotope record}

Over the Cenozoic, the general cooling trend is marked by a shift from a warm, ice-free, and vegetated Antarctica, to the permanently ice-covered Antarctic of present-day. During this time, $\delta^{18} \mathrm{O}$ values have increased by $\sim 5.4 \%$. Of this, $\sim 2.3 \%$ can be attributed to the development of ice sheets since $\sim 34 \mathrm{Ma}$ and the remaining, equivalent to $13^{\circ} \mathrm{C}$, from deep-sea cooling (Zachos et al., 2001; Cramer et al., 2009). Understanding of long-term climate variation is mostly from $\delta^{18} \mathrm{O}$ records, derived from the shells of deep-sea benthic foraminfera, and providing the most continuous and high resolution record for the Cenozoic (Zachos et al., 2001).

The $\delta^{18} \mathrm{O}$ record is a measure of oxygen of different isotopic values incorporated into, and preserved in, the tests of benthic foraminifera. These values can be potentially preserved for tens of millions of years, however, older records tend to be altered to some degree by diagenetic processes over time (Pearson et al., 2001). During periods of glacial expansion, ice sheets preferentially incorporate ${ }^{16} \mathrm{O}$ as more water is evaporated and precipitated as ice, in turn leaving oceans enriched in ${ }^{18} \mathrm{O}$ relative to interglacial periods. During these interglacial periods, ${ }^{16} \mathrm{O}$ enriched ice returns to the ocean, resulting in a lighter ocean isotopic composition (e.g. Hayes et al., 1976; Ravelo and Hillaire-Marcel, 2007). The $\delta^{18} \mathrm{O}$ ratio is influenced by the isotopic value of the water it is precipitated from, determined by global ice volume and the temperature of water at the time of calcification (Pearson, 2012). Distinguishing the relative contribution of these variables in the $\delta^{18} \mathrm{O}$ signature is a complication when using this record as a proxy of global ice volume (Zachos et al., 2001; Lisiecki \& Raymo, 2004; Pearson, 2012; Winnick \& Caves, 2015; Gasson et al., 2016). Despite this, relatively low values for the early Cenozoic ( $\sim 65-34 \mathrm{Ma})$ indicate minimal ice volume, with no major ice sheet at either pole (Zachos et al., 2001). This provides a far-field estimate of ice sheet history that corroborates geologic evidence from the Antarctic continental margin for the inception of continental scale ice sheets on Antarctica by $34 \mathrm{Ma}$ (Barrett, 1989; Hambrey et al., 1991; Zachos et al., 1992).

As is shown in Figure 2.2, the greenhouse climate of the early Cenozoic was followed by progressive cooling punctuated with three major steps in the extent and style of Antarctic glaciation:

1. The growth of dynamic continental ice sheets at the Eocene/Oligocene Climate Transition ( 34 Ma, Barrett, 1989; Zachos et al., 2001; Lear et al., 2008; Galeotti et al., 2016). This event occurred in two stages between $\sim 34-33.2 \mathrm{Ma}$; a positive $\delta^{18} \mathrm{O}$ 
excursion likely reflecting an initial decrease in temperature, and a second excursion that reflects maximum ice sheet extent (Lear et al., 2008).

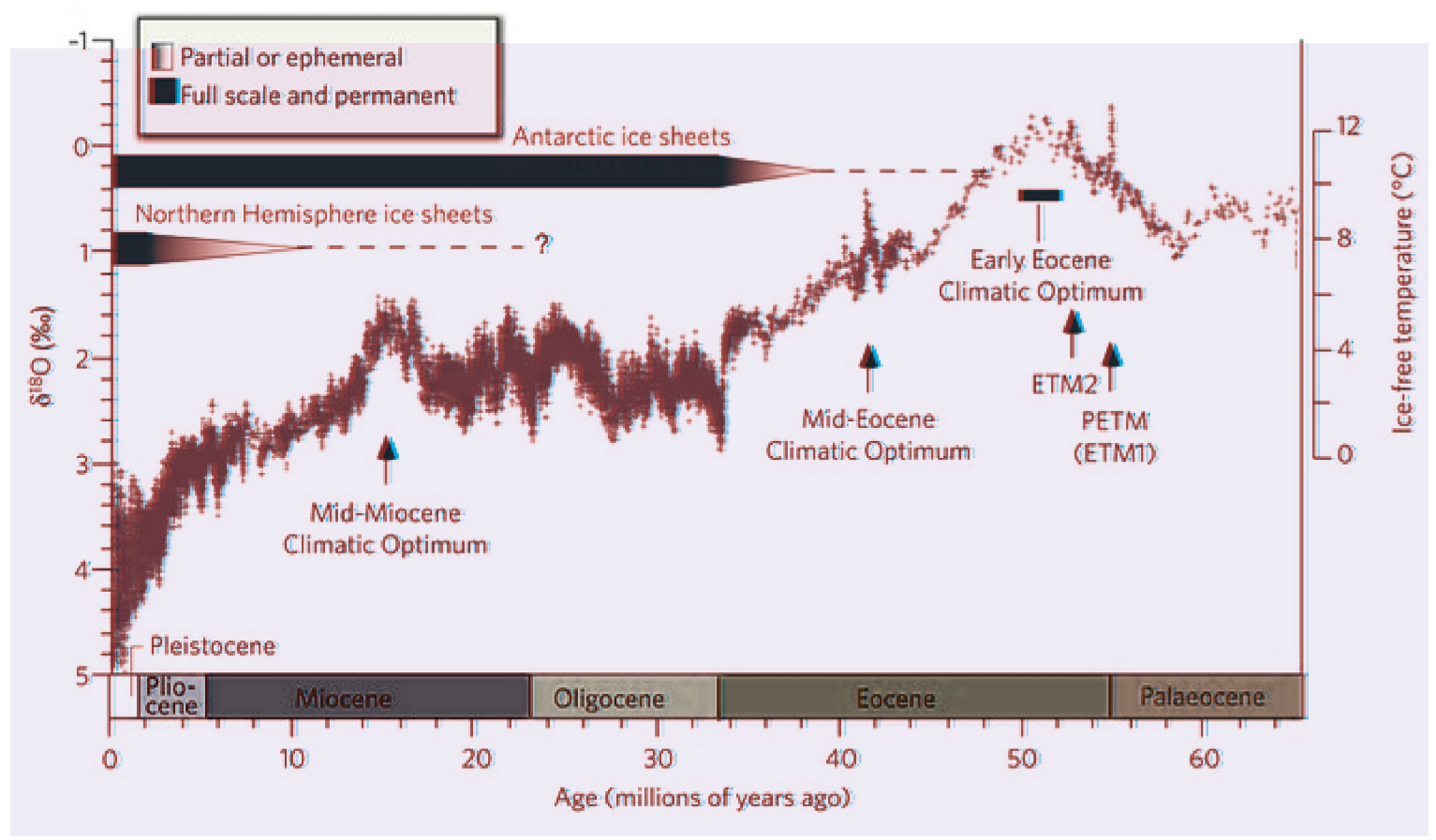

Fig. 2.2 Deep ocean benthic foraminiferal oxygen isotope record for the Cenozoic (65 Ma to present), highlighting periods of peak warmth and the proposed onset of ice sheets in the Southern and Northern hemispheres (Zachos et al., 2008).

2. Transient expansion of marine ice sheets occurred across the Oligocene/Miocene boundary ( 23 Ma, e.g. Naish et al., 2001; Sorlien et al., 2007; Bart \& De Santis, 2012), with a general warming trend and decreasing $\delta^{18} \mathrm{O}$ values indicating global ice remained relatively low until the mid-Miocene ( $\sim 15$ Ma, Flower \& Kennett, 1994; Zachos et al., 2001).

3. Climatic cooling and a shift to more stable terrestrial ice sheets occurred across the midMiocene Climate Transition (MMCT, e.g. Marchant et al., 1993; Sugden \& Denton, 2004; Lewis et al., 2008; Lewis \& Ashworth, 2015) while marine sectors remained highly variable through most of the late Neogene (e.g. Naish et al., 2009; Cooke et al., 2004; Patterson et al., 2014). Three major events are evident in this transition to a stable and more permanent EAIS in the $\delta^{18} \mathrm{O}$ record (Holbourn et al., 2013; Miller et al., 2020): at $14.8 \mathrm{Ma}\left(\sim 30 \mathrm{~m}\right.$ sea level fall and $\sim 0.7^{\circ} \mathrm{C}$ cooling), $13.8 \mathrm{Ma}(\sim 50 \mathrm{~m}$ sea level fall and $\sim 1.2^{\circ} \mathrm{C}$ cooling), and $12.8 \mathrm{Ma}\left(\sim 20-30 \mathrm{~m}\right.$ sea level fall and $\left.\sim 1.0^{\circ} \mathrm{C}\right)$ cooling. The general increase in $\delta^{18} \mathrm{O}$ values until $\sim 6 \mathrm{Ma}$ indicate cooling and ice 
sheet expansion persisted until the early Pliocene (Zachos et al., 2001; Mudelsee et al., 2014).

Formation of large Northern Hemisphere ice sheets and expansion of sea ice occurred during the Pliocene/Pleistocene Transition ( 2.7 Ma, McKay et al., 2009; Patterson et al., 2014). The modern Antarctic Ice Sheet (AIS), comprised of 27 million $\mathrm{km}^{3}$ of ice (Fretwell et al., 2013), holds the equivalent of $57 \mathrm{~m}$ sea level, 53 in the EAIS and 4 in the West Antarctic Ice Sheet (WAIS).

\subsubsection{Ice sheet development from geologic and proxy records}

Sea level estimates imply ice volumes of $>20 \mathrm{~m}$ sea level equivalent for much of the Cenozoic prior to the development of continental scale Antarctic glaciation (Miller et al., 2020). There is geologic evidence to suggest some degree of sea and land ice was present in Antarctica during the mid- to late-Eocene ( $\sim 55-35 \mathrm{Ma})$, primarily through the presence of ice-rafted debris (IRD) in deep-sea records (Ehrmann et al., 1992) and evidence for ice advance onto the continental shelf from geophysical and geological records at the Aurora Subglacial Basin (Gulick et al., 2017). Global sea level estimates imply largely ice-free conditions during the early Eocene (Browning et al., 1996; Miller et al., 2005; Miller et al., 2020), with the development of "cool greenhouse" ice sheets by the Mid Eocene (Fig. 2.1 a). Sea level changes on the scale of 15-40 $\mathrm{m}$ can be explained by the variability of small ice sheets equivalent to $25-35 \%$ present-day configuration (Miller et al., 2020).

Evidence for the onset of a continental scale AIS at the Eocene Oligocene Transition (EOT) include a major hiatus in the CIROS-1 drill core off the Victoria Land Coast between 34.5-30.5 Ma, associated with a regional unconformity in the Ross Sea (Barrett et al., 1989), iceberg calving at Ocean Drilling Project Leg 119 in Prydz Bay (Hambrey et al., 1991) and IRD on Kerguelen Plateau, Southern Indian Ocean (Ehrmann \& Mackensen, 1992; Zachos, 1992). A rapid reduction in bottom water temperatures from $10^{\circ} \mathrm{C}$ to $5^{\circ} \mathrm{C}$ recorded in Deep Sea Drilling Project (DSDP) Site 277 on the Campbell Plateau, in sub-Antarctic waters south of New Zealand, is thought to represent the formation of Antarctic bottom water and the onset of the present-day thermohaline circulation (Kennett \& Shackleton, 1976). Galeotti and others (2016) attribute the onset of continent-scale glaciation on Antarctica to a decline in atmospheric $\mathrm{CO}_{2}$ to below $750 \mathrm{ppm}$, coupled with minimums in eccentricity and obliquity that allowed for low seasonality and cooler MSTs. The variability and extent of glacial advance and retreat across the EOT is recorded in the Cape Roberts Project (CRP) -3 
drill core, a glacio-marine sediment core deposited off the coast of Victoria Land (Florindo et al., 2005). In the early stages of the EOT ( 34.1-31 Ma), the CRP-3 record shows orbitally controlled cyclicity (Galeotti et al., 2012, further detail in section 2.1.3) that was initially highly sensitive to local insolation forcing (Galeotti et al., 2016), contributing to $\sim 25 \mathrm{~m}$ global sea level variability (Miller et al., 2005). At $\sim 32.8 \mathrm{Ma}, \mathrm{CO}_{2}$ concentrations dropped below $600 \mathrm{ppm}$, the threshold at which ice sheets appear less sensitive to insolation forced melt, resulting in a relatively stable AIS until $\sim 29 \mathrm{Ma}$ as the terrestrial ice sheet thickened and advanced to the coast (Galeotti et al., 2016).

The EAIS was not permanently developed and remained unstable throughout the Oligocene and early Miocene, with large variability in ice sheet volume and extent on the scale of 50-60 m sea level equivalent (Palike et al., 2006; Miller et al., 2020). The late Oligocene AIS was strongly modulated by orbital forcing (Naish et al., 2001a). The Mi-1 event at the Oligocene-Miocene (OM) boundary ( $23 \mathrm{Ma}$ ) was characterised by a significant increase in Antarctic ice volume (Zachos et al., 1997; Lear et al., 2004), corroborated by the CIROS-1 and CRP-2/2A drill core records at the continental margin (Barrett et al., 1991; Naish et al., 2001a; Dunbar et al., 2008) and the DSDP Site 270 drill core (Kulhanek et al., 2019) to close to, or exceeding, present-day volume with unconformities in these records indicating marine ice advance into the Ross Sea. Prior to this event, glacimarine deposition recorded in the Ross Sea was the result of iceberg related activity, rather than grounded ice advance across the continental shelf (Leckie \& Webb, 1983). This event has been attributed to declining $\mathrm{CO}_{2}$ concentrations (Fig. 2.1 a) coupled with an eccentricity minimum and an obliquity node that resulted in low seasonality and relatively cool MSTs conducive to ice growth (Naish et al., 2001b; Zachos et al., 2001; Pagani et al., 2005). Tundra persisted on the continent, suggesting the event was not extensive or cold enough for the extinction of higher plants (Askin \& Raine, 2000).

The general cooling trend of the Oligocene and early-Miocene was punctuated by Miocene Climatic Optimum (MCO, 17-15 Ma), a period significantly warmer than presentday with dynamic ice sheet fluctuations (Miller et al., 2005; Gasson et al., 2016; Levy et al., 2016; Jovane et al., 2019) and relative sea level changes of up $50 \mathrm{~m}$ (Miller et al., 2005; John et al., 2011; Miller et al., 2020). The U1356 drill core record on the Wilkes Land continental margin suggest ice extent across the Wilkes Land Subglacial Basin (WLB) varied considerably on glacial-interglacial timescales and remained open during interglacial periods throughout the MCO (Sangiorgi et al., 2018). The AND-2A drill core record indicates large fluctuations in EAIS extent at the coast (Levy et al., 2016), while terrestrial records imply 
ice-free conditions during interglacial periods from the early Miocene through the MMCT ( 14.8-13.8 Ma; Lewis et al., 2006; Lewis et al., 2008; Lewis \& Ashworth 2015). Tundra vegetation persisted across the WLB and TAM, MSTs were $\sim 10^{\circ} \mathrm{C}$ (Warny et al., 2009) and mean global surface temperatures were $3-4{ }^{\circ} \mathrm{C}$ higher than present-day (You et al., 2009).

The MMCT saw global climate cool, in one of the largest and penultimate cooling steps of the Cenozoic. Marine ice re-advanced into the Ross Sea for the first time since the onset on the MCO (De Santis et al., 1999; Levy et al., 2016), while sea ice expanded off the Wilkes coast (Sangiorgi et al., 2018). An increase in glacial-interglacial amplitude marked in the $\delta^{18}$ O record (Holbourn et al., 2014) suggests the AIS expanded further during progressively cold glacial periods, while interglacial periods remained warm enough to support vegetation at high elevations of the TAM (Lewis et al., 2007; Lewis et al., 2008; Lewis \& Ashworth, 2015). The MMCT culminated in a shift from temperate climate wet-based glaciation and a dynamic ice sheet to the polar dry glacial style and more stable ice sheet of present-day Antarctica (Marchant et al., 1993; Sugden \& Denton, 2004; Lewis \& Ashworth, 2015). As the focus of this thesis, both the MCO and MMCT will be discussed further in section 2.2.

Continuing from this long-term Cenozoic cooling trend, the late Miocene ( 11.6-5.3 $\mathrm{Ma})$ is characterised by a general decline in global temperatures and relatively constant obliquity-paced sea level variability that rarely exceeded $20 \mathrm{~m}$ above present-day (Miller et al., 2020). Significant AIS expansions identified in the $\delta^{18} \mathrm{O}$ record at $\sim 9 \mathrm{Ma}$ and $\sim 7$ $\mathrm{Ma}$ are similar to the MMCT, in that they coincide with periods of prolonged eccentricity minima and high-amplitude obliquity variability (Holbourn et al., 2018). $\mathrm{CO}_{2}$ concentrations remained relatively stable throughout the late Miocene, at close to pre-industrial levels of $\sim 280$ ppm (Zhang et al., 2013). The early to mid-Pliocene ( $\sim 5.3-3 \mathrm{Ma}$ ) was a period of relative warmth following the MMCT and late Miocene, with sea level rising to highs not seen since the MCO at $\sim 4.7 \mathrm{Ma}$ (Miller et al., 2020). During the mid-Pliocene Warm Period ( 3.3-3 Ma), the diatom assemblage in the AND-1B drill core suggest open ocean conditions in the Ross Sea, with mean annual sea surface temperatures (SST) of $\sim 5^{\circ} \mathrm{C}$ (McKay et al., 2012), global average surface temperatures of $2-3^{\circ} \mathrm{C}$ above present-day (Dowsett et al., 2009) and $\mathrm{CO}_{2}$ concentrations of $\sim 400$ ppm, similar to present-day values (Seki et al., 2013; Martinez-Boti et al., 2015).

The glacial regime of the AIS during this time became subject to debate when possible Pliocene age marine diatoms were found in wet-based glacial deposits at the Sirius Formation in high elevations of the TAM (Webb et al., 1984). These Sirius Group deposits have been found as far south as Beardmore Glacier, at $86^{\circ} \mathrm{S}$ and imply wet-based glaciation occurred on 
the continent long after the stabilisation proposed at the MMCT. Furthermore, the presence of Nothofagus fossils implied tundra vegetation persisted at high elevations of the TAM at the time of deposition (Francis and Hills, 1996). The initial explanation for the deposition of these marine diatoms was the presence of open ocean in the WLB, with the reworking and transportation of these diatom-bearing sediment over the TAM as wet-based glaciers overrode the TAM during the mid-Pliocene, in an event similar to that proposed at the MMCT (Webb et al., 1984). This dynamic, wet-based EAIS during the Pliocene was inconsistent with geologic evidence in the Dry Valleys interpreted to reflect prolonged stability since the MMCT (Denton et al., 1993; Marchant et al., 1996; Summerfield et al., 1999) and the $\delta^{18} \mathrm{O}$ record, which did not support this scale of mass ice loss on Antarctica during the Pliocene (Kennett \& Hodell, 1993). Following further examination of these TAM deposits, it was determined that these Pliocene-age diatoms were contaminants, reworked or wind-blown into Miocene-age diamictites with higher porosity (Barrett et al., 1997; McKay et al., 2008).

After this period of relative warmth, the late Pliocene $(\sim 3.0-2.6 \mathrm{Ma})$ is characterised by global cooling and the onset of continental scale ice sheets in the Northern Hemisphere (Fig. 2.1, Haug \& Tiedmann, 1998; Ravelo et al., 2004). Mean annual SSTs in the Ross Sea declined to $\sim 1^{\circ} \mathrm{C}$ by $\sim 2.5 \mathrm{Ma}$ (McKay et al., 2012), perennial sea ice expanded in the Southern Ocean (Patterson et al., 2014) and the final transition to a cold, polar glacial regime by the late Pleistocene saw the persistence of the Ross Ice Shelf during interglacial periods (McKay et al., 2012).

\subsubsection{Drivers of ice sheet growth}

While it has been shown that present climate change is the result of increasing anthropogenic atmospheric $\mathrm{CO}_{2}$ concentrations, changes in climate on the scale of million of years have been attributed to a number of variables, including but not limited to, orbital forcing, greenhouse gas concentrations, and tectonic activity (Hays et al., 1976; Pearson \& Palmer, 2000; Zachos et al., 2001; DeConto \& Pollard, 2003; Raymo et al., 2006; Zachos et al., 2008; Ruddiman, 2014).

\section{Orbital Forcing}

Orbital parameters vary under a distinct and repetitive cyclicity, providing a relatively predictable pacing of climate over time (Zachos et al., 2001). Orbital forcing of the global 
climate is the link between the long term variations in these orbital parameters and the amount of incoming solar radiation (insolation). Milankovitch theory was developed in the $19^{\text {th }}$ century (Milankovitch, 1941) and defines the relationship between the varying levels of insolation and climate, with calculations of Earth's orbital geometry able to account for the $\sim 50$ million years of climate variability and predict variability millions of years into the future (Lasker et al., 2004).

There are three astronomical orbits responsible for climate variability: eccentricity, obliquity, and precession (Fig. 2.3). Changes in eccentricity, axial tilt (obliquity) and the longitude of perihelion (precession) combine to affect the magnitude of solar energy received at Earth's atmosphere and the seasonal and latitudinal distribution of this solar energy. This in turn influences the intensity and duration of seasons (Berger \& Loutre, 1991). Eccentricity is the variation in the Earth's orbit around the sun from circular to elliptical, the result of gravitational interactions with other planets. It occurs in two periodicities, one with an average of $100 \mathrm{kyr}$ and the other, $413 \mathrm{kyr}$. This variation in distance between the Earth and the Sun influences the total amount of insolation reaching the Earth's atmosphere. Eccentricity is greatest when the orbit is highly elliptical, with up to $30 \%$ more insolation reaching Earth at perihelion than at aphelion. While the impact on global and annual mean insolation is limited, the intra-annual changes in the distance between the Sun and the Earth modulate the seasonal effects induced by precession.

Obliquity refers to the tilt of the Earth's axis, which ranges between $22.1^{\circ}$ and $24.5^{\circ}$ with a periodicity of $41 \mathrm{kyr}$. This tilt has no effect on total global insolation, but controls the latitudinal gradient of insolation and therefore the degree of seasonality; a greater tilt increases insolation at the poles, increasing the amplitude of the seasonal cycle. The variability of insolation is greatest at high latitudes and is in-phase in both hemispheres. Obliquity also acts to modulate annual mean insolation at all latitudes and the extent of the polar circles. 

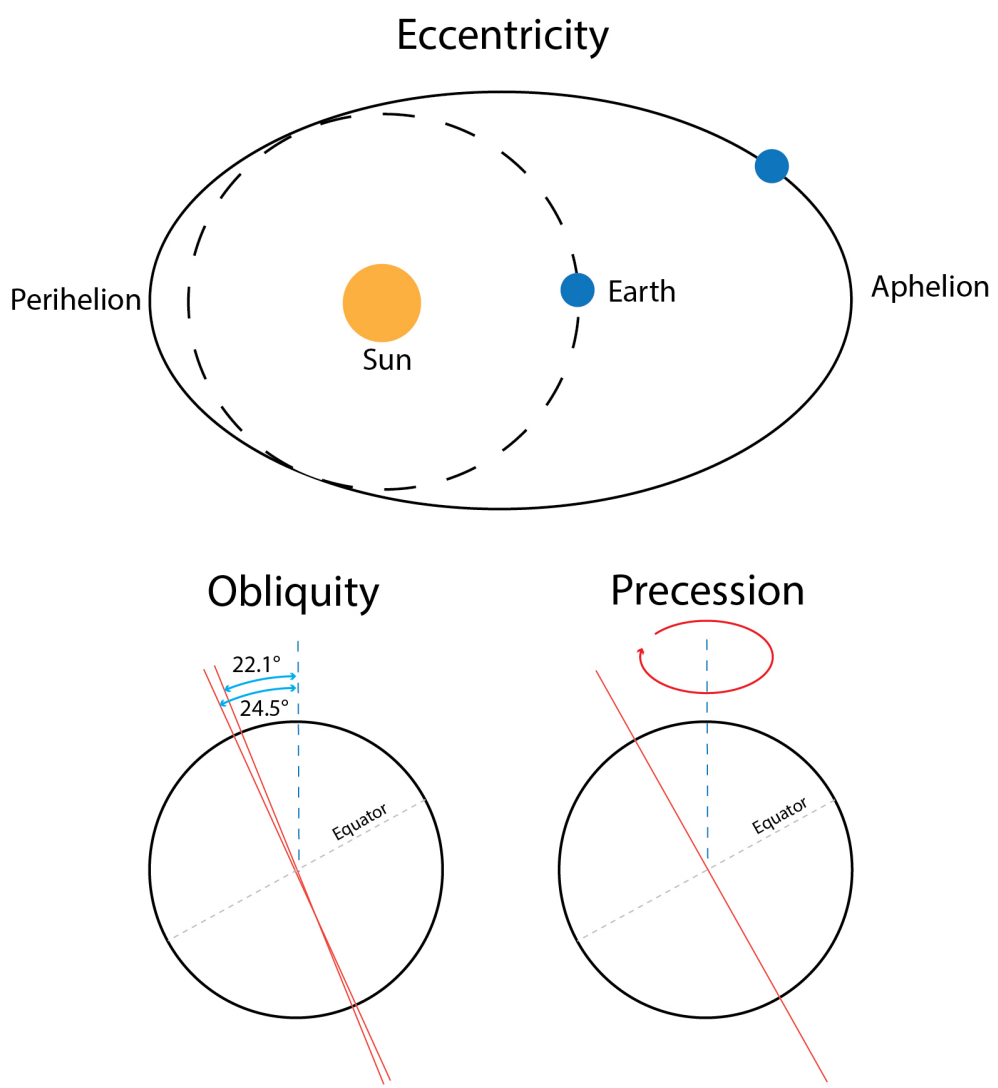

Fig. 2.3 Schematic diagram illustrating the three orbital parameters: eccentricity, obliquity, and precession.

Precession is the motion of the Earth's axis of rotation, with a periodicity of $19 \mathrm{kyr}$ and $23 \mathrm{kyr}$. It has long been recognised that precession influences the annual insolation cycle, but unlike eccentricity, does not alter the average annual insolation at a given latitude (Herschel, 1832). The change in the direction of the Earth's tilt towards the sun controls the duration and intensity of the seasons and mean summer insolation relative to when the Earth is closer to (perihelion) or further away from (aphelion) the sun. Precession is out of phase between hemispheres and therefore, when the Earth's orbit is in aphelion, the Southern Hemisphere should experience long austral summers. On the other hand, when the Earth's orbit is in perihelion, the Northern Hemisphere will experience warmer summer temperatures. The amplitude of precession forcing is dependent on eccentricity; when eccentricity is low, the frequency of precession undergoes large variations, and the seasonal insolation changes induced by precession is weaker than during periods of high eccentricity (Huybers \& Aharonson, 2010). 
These orbital cycles cause long-term variations in daily insolation at Earth's surface at precession frequencies, modulated by both obliquity and eccentricity. Insolation variability at high latitudes influences the extent of polar ice sheets, whereby the number and intensity of positive degree days during summer influences conditions that are favourable for ice sheet growth. The $\delta^{18} \mathrm{O}$ record from deep sea sediment cores was the first evidence that Earth's climate was controlled by orbital cycles (Emiliani, 1966; Shackleton \& Opdyke, 1973; Hays et al., 1976). The growth and decay of global ice volume observed in these records was modulated by orbital cycles of $\sim 100, \sim 40$, and $\sim 20$-kyrs (Hays et al., 1976).

Following the work of Hays and others (1976) and the first observation of orbital variability in marine sediment cores, the identification of Milankovitch orbital periodicities in Cenozoic and Mesozoic proxy records has become a foundation for paleoclimate research. Records that preserve a response to these variations can be used to better understand controls on past climate change, with the orbital tuning of records quickly becoming common practice (e.g. Imbrie et al., 1984; Shackleton et al., 1990; Naish et al., 2001; Lisieki \& Raymo, 2005). Ice-volume variability in the $\delta^{18} \mathrm{O}$ record shows that the frequency of glacial-interglacial cycles has evolved over the past 34 Ma (Palike et al., 2006; Holbourn et al., 2013; Liebrand et al., 2016; Vleeschouwer et al., 2017), when continental scale ice sheets first developed over Antarctica. These cycles were primarily paced by short- and long-term eccentricity through the Oligocene and early Miocene (Fig 2.4 a), with obliquity paced variations during the MMCT and late Miocene (Fig 2.4 b,c). Some of this variable ice sheet response to orbital forcing can be attributed to the sensitivity of marine-based ice to obliquity forcing (Levy et al., 2019).

It has been hypothesised that orbital configuration was a primary driver of climatic variation during the early to mid-Miocene (Holbourn et al., 2005; Langebroek et al., 2009; Levy et al., 2016; Levy et al., 2019). Benthic foraminiferal $\delta^{18} \mathrm{O}$ records are characterised by high amplitude variability during the MCO with a periodicity of the short-term $\sim 100$ kyr cycle (Holbourn et al., 2007; Holbourn et al., 2014), a pacing that is also identified in the AND-2A sedimentary record from the Antarctic margin (Passchier et al., 2013; Levy et al., 2016). During the early Miocene and MCO climate was driven by 400 and 100 kyr eccentricity modulated precession cycles, while the terrestrially-terminating AIS was sensitive to local insolation controlled by precession (Fig. 2.4 b, Levy et al., 2019).

As the AIS advanced into the marine realm and sea ice grew in response to declining $\mathrm{CO}_{2}$ concentrations, ice sheet growth and decay was paced by obliquity (Fig. 2.4 b). A marked shift from $\sim 40$ kyr obliquity paced between 14.7-13.9 Ma to $\sim 100 \mathrm{kyr}$ eccentricity paced 
climatic variations between 13.8-13.1 Ma, together with a $200 \mathrm{ppm}$ drop in $\mathrm{CO}_{2}$ is thought to have triggered the MMCT (Holbourn et al., 2014). Levy and others (2019) suggest that orbital variations were the primary driver of glacial cycles, with the extent to which the ice sheet retreated during warm interglacial periods and the mean climate state controlled by atmospheric $\mathrm{CO}_{2}$ concentrations.

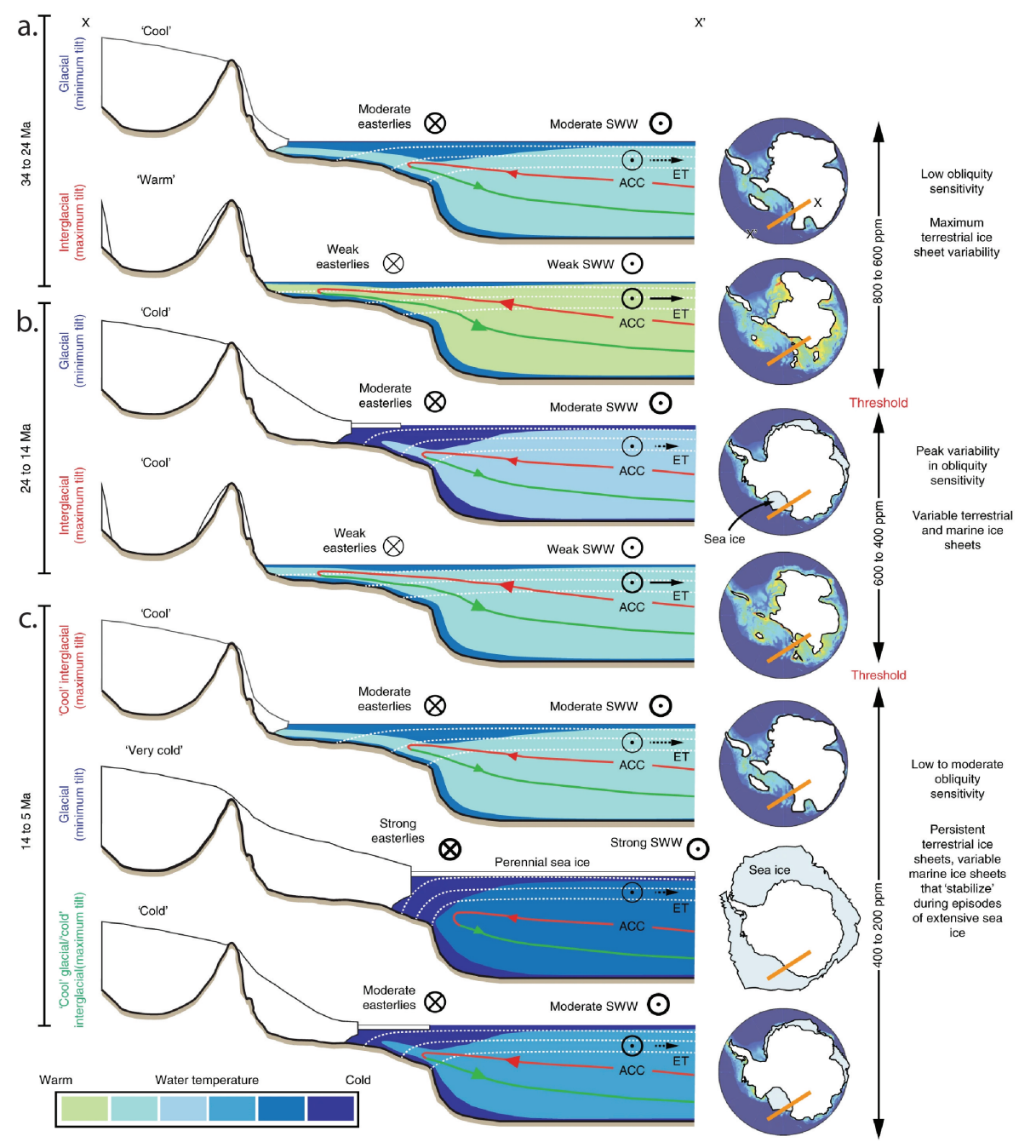

Fig. 2.4 Conceptual model developed by Levy and others (2019) outlining the influence of obliquity on Antarctic Ice Sheet glacial-interglacial variability for 34-4 Ma. (a) 34-24 Ma under the high $\mathrm{CO}_{2}$ concentrations of the Oligocene, temperatures were too warm to support marine ice; (b) 24-14 Ma, where a decline in $\mathrm{CO}_{2}$ concentrations supported marine ice advance but glacial-interglacial variability remained high; (c) 14-5 Ma, where further $\mathrm{CO}_{2}$ decline supported extensive sea ice and marine ice sheet growth. Cross sections indicated by orange lines on the maps. General positions and strength of zonal wind systems indicated by circles with crosses and dots. Overturning circulation indicated by red and green lines. ACC $=$ Antarctic Circumpolar Current, ET $=$ Ekman transport, SWW = south westerly winds. 


\section{Atmospheric carbon dioxide concentrations}

Atmospheric $\mathrm{CO}_{2}$ reconstructions pre-Quaternary are sparse and long-term reconstructions are lacking, limiting the full analysis of their role in controlling climate variability (Greenop et al., 2014; Sosdian et al., 2018). $\mathrm{CO}_{2}$ concentrations vary naturally and through time have been shown to be a key parameter driving Earths Cenozoic climate, including the growth and decay of ice sheets (e.g. Raymo, 1991; Berner \& Kothavala, 2001; DeConto \& Pollard, 2003; Pagani et al., 2011; Zhang et al., 2013; Galeotti et al., 2016). In general, dynamic and long term changes to the carbon cycle have been attributed to these variations in $\mathrm{CO}_{2}$, including changes in volcanic emissions, silicate weathering and the organic carbon subcycle (e.g. Raymo \& Ruddiman, 1992; Derry \& France-Lanord, 1996; Foster et al., 2012).

Climate models corroborate proxy records, providing an estimate of glaciation thresholds similar to those in proxy reconstructions, with Antarctic glaciation triggered when atmospheric $\mathrm{CO}_{2}$ levels are $<750 \mathrm{ppm}$ and Northern Hemisphere glaciation at $<280 \mathrm{ppm}$ (DeConto et al., 2008). $\mathrm{CO}_{2}$ decreased at the Eocene/Oligocene transition, 34 Ma. At this point, atmospheric $\mathrm{CO}_{2}$ concentrations likely declined from $>1000 \mathrm{ppm}$ to below the threshold, resulting in the onset of glaciation in Antarctica (Zhang et al., 2013).

Greenop and others (2014) suggest $\mathrm{CO}_{2}$ fluctuated on glacial-interglacial timescales during the mid-Miocene, although the mechanism of such geologically short, high-amplitude, variations in $\mathrm{CO}_{2}$ is more difficult to identify. Periods of decreased $\mathrm{CO}_{2}$ in proxy records coincides with the major glaciations of the early to mid-Miocene and elevated $\mathrm{CO}_{2}$ during the $\mathrm{MCO}$ and interglacial periods (Kurschner et al., 2008). Large increases in $\mathrm{CO}_{2}$ concentrations during interglacial periods, on the scale of an up to $100 \mathrm{ppm}$ increase in a few thousand years (Luthi et al., 2008), can be attributed to the ocean carbon cycle (e.g. Stephens and Keeling, 2000; Martinez-Garcia et al., 2009; Menviel et al., 2018), however $>100$ ppm variability is more difficult to explain.

While atmospheric $\mathrm{CO}_{2}$ concentrations impact global temperatures, the uptake of $\mathrm{CO}_{2}$ by the oceans plays an important role in regulating long term climate (e.g. Broekcer \& Peng 1982; Falkowski et al., 2000; Luthi et al., 2008). Oceans are a significantly greater carbon reservoir than the atmosphere and atmospheric $\mathrm{CO}_{2}$ exchanges rapidly with the ocean depending on a number of factors. Atmospheric $\mathrm{CO}_{2}$ is often higher during interglacials due to the increased exchange of $\mathrm{CO}_{2}$ between the atmosphere and ocean, however there are a number of hypotheses for how this process occurs that will now be discussed in further detail. 
During warm interglacials, the poleward movement of westerlies increases upwelling of deep, carbon-rich water to the surface in the Antarctic Circumpolar Current (ACC), where it will exchange with the atmosphere (Toggweiler, 1999; Menviel et al., 2018). Reduced sea ice around the Antarctic continent during interglacials also allows for increased deep-water ventilation and ocean-atmosphere $\mathrm{CO}_{2}$ exchange on the scale of $\sim 59 \mathrm{ppm}$ (Stephens \& Keeling, 2000). Variable marine biosphere productivity and shifts in the net organic matter export in the Southern Ocean can attribute up to 40-50 ppm atmospheric $\mathrm{CO}_{2}$ variability over glacial-interglacial cycles (Martinez-Garcia et al., 2009). Furthermore, the ability of the ocean to sequester atmospheric $\mathrm{CO}_{2}$ is lower during interglacials when SSTs are warmer, as $\mathrm{CO}_{2}$ is more soluble in cold and saline waters (Volk \& Hoffert, 1985).

DeConto and others (2012) attribute high $\mathrm{CO}_{2}$ concentrations during interglacial periods in the Paleogene to carbon release from thawing terrestrial permafrost. When the AIS was still dynamic and large areas of the Antarctic continent remained ice-free, these open ice-free areas were a large carbon source and sink (DeConto et al., 2012). Once a $\mathrm{CO}_{2}$ threshold of $900 \mathrm{ppm}$ is reached, these carbon sinks become sensitive to increased solar insolation during periods of high obliquity and eccentricity, which is hypothesised as a driver of hyperthermal events, such as the PETM, during the early Cenozoic (DeConto et al., 2012).

Carbon isotope $\left(\delta^{13} \mathrm{C}\right)$ records imply orbital forcing also influences the carbon cycle, with a $400 \mathrm{kyr}$ oscillation observed in these records through most of the Cenozoic (Cramer et al., 2003; Billups et al., 2004; Pälike et al., 2006; Wang et al., 2010; Sexton et al., 2011). An eccentricity-paced variability in $\mathrm{CO}_{2}$ between 300-500 ppm during the MCO (Greenop et al., 2014), is a likely driver in the dynamic ice sheet observed at this time (Miller et al., 2005; Gasson et al., 2016; Levy et al., 2016; Sangiorgi et al., 2018; Jovane et al., 2019; Levy et al., 2019).

Through the early to mid-Miocene, reconstructions derived from plant stomata (Royer et al., 2001; Kurschner et al., 2008; Beerling et al., 2009), paleosols (Cerling, 1992; Ekart et al., 1999; Retallack, 2009), phytoplankton (Badger et al., 2013; Zhang et al., 2013; Super et al., 2018), boron isotopes (Foster et al., 2012; Greenop et al., 2014), B/Ca (Badger et al., 2013) have produced a wide range of $\mathrm{CO}_{2}$ estimates. Values for this time period range from 280 to 840 ppm (Kurschner et al., 2008; Retallack, 2009; Foster et al., 2012; Zhang et al., 2013; Greenop et al., 2014), with general agreement that atmospheric $\mathrm{CO}_{2}$ concentrations were higher than pre-industrial values and that a decline in $\mathrm{CO}_{2}$ coincided with the MMCT (Fig. $2.1 \mathrm{e})$. 
A shift from an obliquity to eccentricity forced climate is not considerable enough to account for the changing climate across the MMCT, so $\mathrm{CO}_{2}$ variability could have been a driving force for changes in climate across the MCO and MMCT. The MCO interglacials that coincide with the most ice retreat, as indicated by marine sedimentary records (Acton et al., 2008; Warny et al., 2009; Feakins et al., 2012; Fielding et al., 2011; Passchier et al., 2011; Levy et al., 2016; Levy et al., 2019), correspond to high amplitude variability in obliquity and atmospheric $\mathrm{CO}_{2}$ (Greenop et al., 2014), suggesting multiple factors are responsible for long term ice sheet development.

The low temporal resolution of $\mathrm{CO}_{2}$ records during the early to mid-Miocene suggest these records may not capture the full scale of orbitally-paced changes in $\mathrm{CO}_{2}$ (Greenop et al., 2014). Furthermore, the low resolution of $\mathrm{CO}_{2}$ records during this period and the evidence for $\mathrm{CO}_{2}$ levels varying on a glacial-interglacial level, could suggest that during these times, $\mathrm{CO}_{2}$ concentrations were significantly higher but remain to be reconstructed in the sparse records that represent this time period. Understanding the direct role of $\mathrm{CO}_{2}$ in ice sheet development over the Cenozoic is complicated, with the dynamics and drivers of the carbon cycle still poorly understood and likely all acting in tandem to contribute to longer-term and glacial-interglacial variability of atmospheric $\mathrm{CO}_{2}$ concentrations through the Cenozoic.

\section{Tectonics}

The opening of Southern Ocean gateways is thought to have also been a contributor to the initiation of ice sheet development in Antarctica. The opening of the Drake (South America and Antarctica) and Tasmanian (Australia and Antarctica) passages coincides with the start of the general cooling trend and the onset of glaciation at the early Eocene Climatic Optimum ( $\sim 52-50 \mathrm{Ma}$ ) (Bijl et al., 2013). The isolation of Antarctica led to the reorganisation of the ACC and heat distribution (Kennett, 1977; DeConto \& Pollard, 2003; Bijl et al., 2013). While the thermal isolation of the Antarctic continent can explain the onset of widespread glaciation across the continent, subsequent termination of these ice sheets indicate another forcing, such as those discussed above, is responsible for the variability of these ice sheets through time.

Antarctic bedrock topography plays a key role in determining where ice flows and erodes (Gasson et al., 2016) and TAM uplift is thought to have significantly contributed to changes in the basal thermal character of the ice sheet, resulting in the more stable ice sheet that 
exists in Antarctica today (Marchant et al., 1993; Sugden \& Denton, 2004; Lewis et al., 2006, 2008; Lewis \& Ashworth, 2015). Despite this, paleotopography is poorly constrained and there is considerable uncertainty over uplift rates since the Miocene which limits current understanding of the role of tectonics on the evolution of the EAIS.

The present-day TAM, with elevations exceeding $4000 \mathrm{~m}$, are a >3000 km long mountain range dividing the West Antarctic Rift System from East Antarctica. With 15\% of EAIS discharge draining through the outlet glaciers of the TAM (Golledge et al., 2014), the mountain chain acts as a buttress to EAIS flow into the Ross Sea. The result of repeated tectonism and magmatism (Fitzgerald, 2002; Goodge et al., 2004), the formation of the TAM occurred in three main episodes of uplift during the early Cretaceous, late Cretaceous, and early Cenozoic (Fitzgerald, 2002). More recently, a re-evaluation of thermochronology data combined with observations in geologic records and thermal history modelling indicate this uplift was far more complex, varying spatially and in timing within individual blocks along the mountain range (Lisker \& Laufer, 2013; Lisker et al., 2014).

TAM uplift has been attributed to several mechanisms: thermal conduction or advection (ten Brink \& Stern, 1992; ten Brink et al., 1993; Stern et al., 2005), isostatic rebound in response to normal faulting (Bott \& Stern, 1992), and erosional based rebound from valley incisions (Stern \& ten Brink, 1989). The most accepted mechanism responsible for the uplift of the TAM is a 'flexural cantilever hinge model' (Fig. 2.5, Stern and ten Brink, 1989). This model explains the high elevations of the TAM while also accounting for a WLB up to $1 \mathrm{~km}$ below sea level. In this case, the WLB is a flexurally controlled basin, the result of regional compensation for the significant uplift of the TAM (Stern \& ten Brink, 1989). Uplift estimates vary from up to $1 \mathrm{~km}$ (Behrendt \& Cooper, 1991; Fitzgerald, 1992; Wilch et al., 1993; Kerr \& Huybrechts, 1999) to major uplift of the TAM occurring prior to the Miocene (Clapperton \& Sugden, 1990; Wilson, 1995; Sugden et al., 1999). Higher estimates of uplift place many TAM geologic records considerably closer to sea level, influencing both ice over-riding, and given an adiabatic lapse rate of $0.5^{\circ} \mathrm{C} / 100 \mathrm{~m}$ (Lewis \& Ashworth, 2015), the mean annual temperature at given $\mathrm{CO}_{2}$ concentrations. 


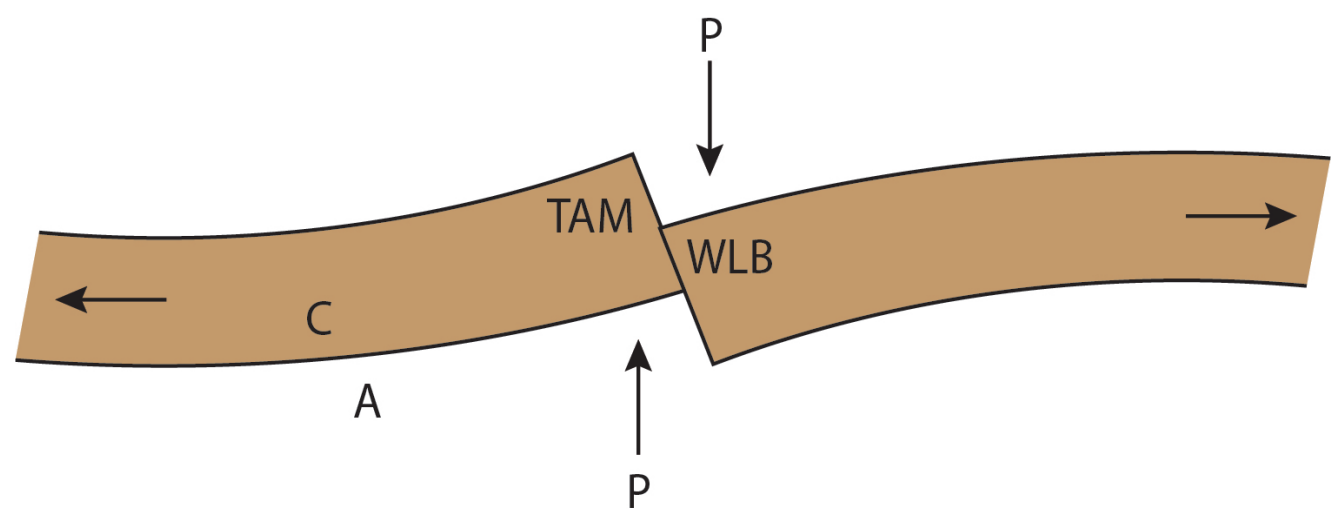

Fig. 2.5 Cantilever style hinged deflection shows how TAM elevations continued to rise while elevations of the WLB were lowered, with the WLB explained as a flexurally controlled basin produced as a form of regional compensation for TAM uplift. $\mathrm{C}$ is the elastic plate, which is buoyantly supported by a displaced, fluid substratum, A. Each limb of the plate acts as an independent, cantilevered beam and the load ' $\mathrm{P}$ ' acting equally but in opposite directions on each side of the inclined fault arises from buoyancy forces. As the lithosphere is buoyantly supported by the asthenosphere, the limb of the footwall of unloaded and will flex upward. The hanging wall now has extra mass and will flex downward in response. Figure adapted from Stern and ten Brink (1989).

Modelling studies by Kerr and Huybrecht (1999) suggest that the surface elevation of particular mountain blocks only has a local effect on ice sheet dynamics. It is important to investigate whether evidence for wet based glaciation within geologic records are the signals of a localised change in glaciation style or representative of the AIS as a whole. The Dry Valleys are an individual block in the TAM that provides a particularly interesting region to focus on, not only because of the abundance of geologic records (Marchant et al., 1993; Lewis et al., 2006, 2007, 2008; Lewis \& Ashworth, 2015), but also because evidence indicates the block has uplifted as one unit since the early Tertiary (Fitzgerald et al., 1986).

Poor constraints for Miocene topography has required scaling between modern day isostatically rebounded and Eocene-Oligocene topography when investigating AIS variability during the Miocene (Gasson et al., 2016). The most recent topographic reconstruction of Miocene surface elevation by Paxman and others (2019b) uses a back-stripping method to estimate and restore glacially eroded material to the topography, adjusting elevation for flexural isostatic responses in response to increased loading (Fig. 2.6). 

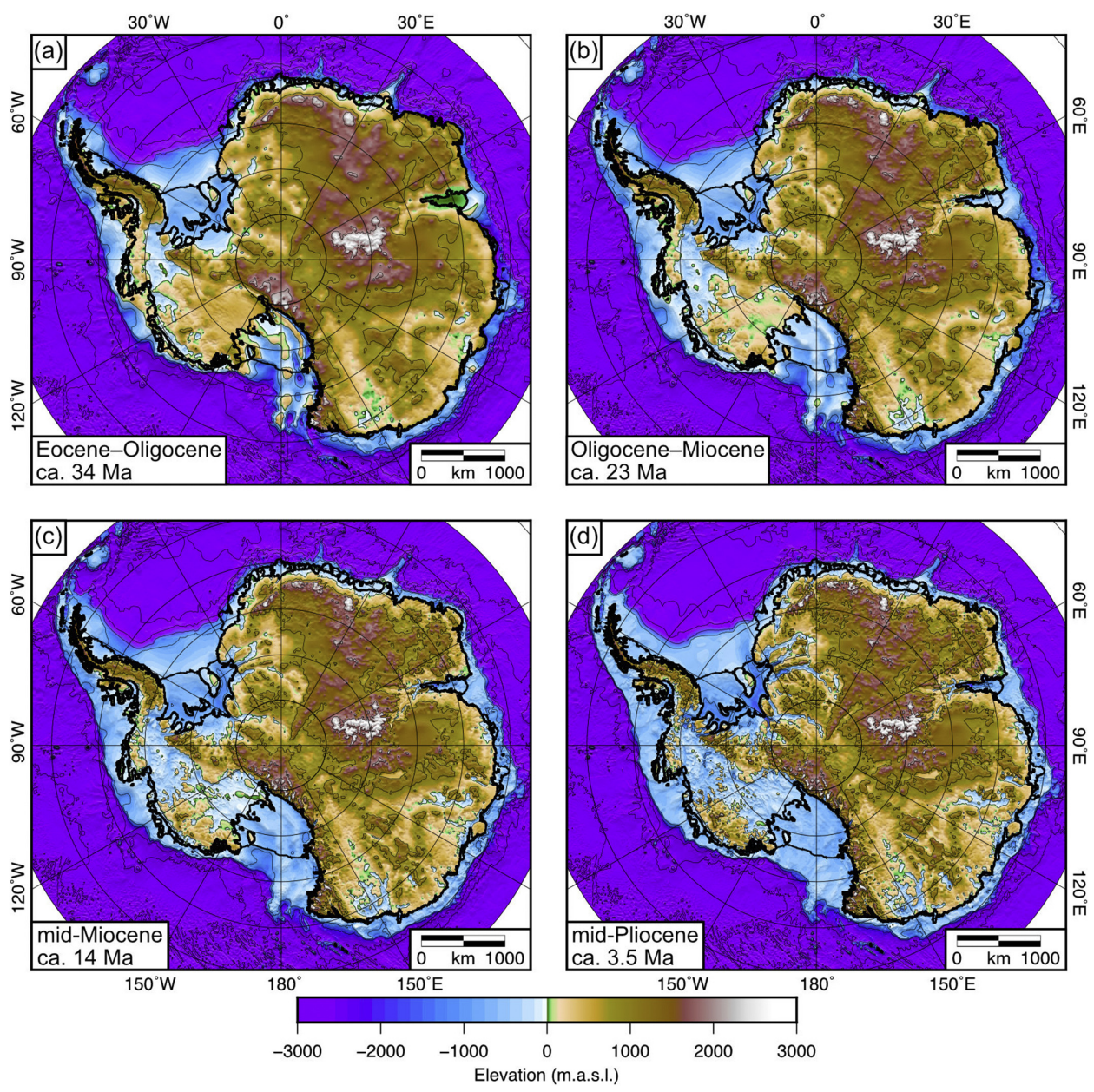

Fig. 2.6 Reconstructed Antarctic topography for 34-3.5 Ma from Paxman et al., (2019b). (a) Antarctic topography at the Eocene-Oligocene boundary (34 Ma). (b) Antarctic topography at the Oligocene-Miocene boundary (23 Ma). (c) Antarctic topography at the mid-Miocene climate transition (14 Ma). (d) Antarctic topography at the mid-Pliocene (3.5 Ma). Elevations are relative to present-day sea level at $1 \mathrm{~km}$ intervals and are for fully isostatically relaxed ice-free conditions.

The continual evolution of topography from $34 \mathrm{Ma}$ to present is calculated using a history of sediment deposition from drill core records from the Wilkes Land Margin and western Ross Sea (Paxman et al., 2019b). It is apparent that between 34-14 Ma, topographic change is by the subsidence of West Antarctica and Subglacial Basins of East Antarctica (e.g. Wilkes) and erosion around the East Antarctic Margin, while erosion from marine ice advance lowered elevations on the Ross Sea continental shelf. Post-MMCT, erosion and sedimentation accelerated in West Antarctica, but decreased in East Antarctica (Paxman et al., 2019b), as a shift from temperate climate wet-based glaciation and a dynamic ice sheet to the polar dry glacial style and more stable ice sheet of present-day Antarctica resulted in an 
ice sheet with less erosive power (Marchant et al., 1993; Sugden \& Denton, 2004; Lewis \& Ashworth, 2015). These topographic reconstructions highlight the role tectonics play in ice sheet growth and decay, with the formation of large interior basins below sea level due to subsidence creating regions of Antarctic particularly vulnerable to ocean warming.

\subsection{Early to mid-Miocene climate change}

The early to mid-Miocene (23-14 Ma) is characterised by a dynamic AIS with major variations in both volume and extent of terrestrial and marine ice sheets (Miller et al., 2005; Gasson et al., 2016; Levy et al., 2016). This interval was punctuated by an episode of unusual warmth within the MCO ( 17-15 Ma; Flower \& Kennett, 1993), one of the warmest intervals since the onset of Antarctic glaciation (Zachos et al., 2008) and terminated with major cooling and ice expansion across the MMCT ( $\sim 13.8 \mathrm{Ma})$.

\subsubsection{Global climate variability during the Miocene}

While global climate during the Miocene remained warmer than present-day throughout, a marked increase in $\delta^{18} \mathrm{O}$ in benthic foraminiferal records (Holbourn et al., 2005; Shevenell et al., 2008; Lear et al., 2010; Holbourn et al., 2014) indicates global cooling during the MMCT $\sim 14.6 \mathrm{Ma}$ (Fig. 2.7). An increase in $\delta^{18} \mathrm{O}$ in benthic foraminiferal records is the result of either a decrease in bottom water temperatures, an increase in global ice volume, or a combination of each of these. $\mathrm{Mg} / \mathrm{Ca}$ ratios, taken from the same foraminiferal calcite, are directly related to ocean temperature and relatively independent of fluctuations in ice volume and therefore act as a proxy for bottom water temperatures. A comparison of $\delta^{18} \mathrm{O}$ and $\mathrm{Mg} / \mathrm{Ca}$ ratios indicates that Antarctic ice growth can account for $\sim 0.85 \%$, coupled with a $2-3^{\circ} \mathrm{C}$ cooling in the deep ocean across the MMCT (Lear et al., 2000; Billups \& Schrag, 2003).

Multi-proxy studies of the AIS behaviour, including the analysis of ice-proximal marine

sedimentary records (Naish et al., 2001; Barrett, 2009; Levy et al., 2016), deep sea $\delta^{18} \mathrm{O}$ records (Shevenell et al., 2008; Lear et al., 2010; de Boer et al., 2010; Liebrand et al., 2014; Holbourn et al., 2014) and numerical models (Pekar \& DeConto, 2006; Van Tuyll et al., 2007; DeConto et al., 2008; Gasson et al., 2016) indicate a highly dynamic AIS during the early to mid-Miocene. 


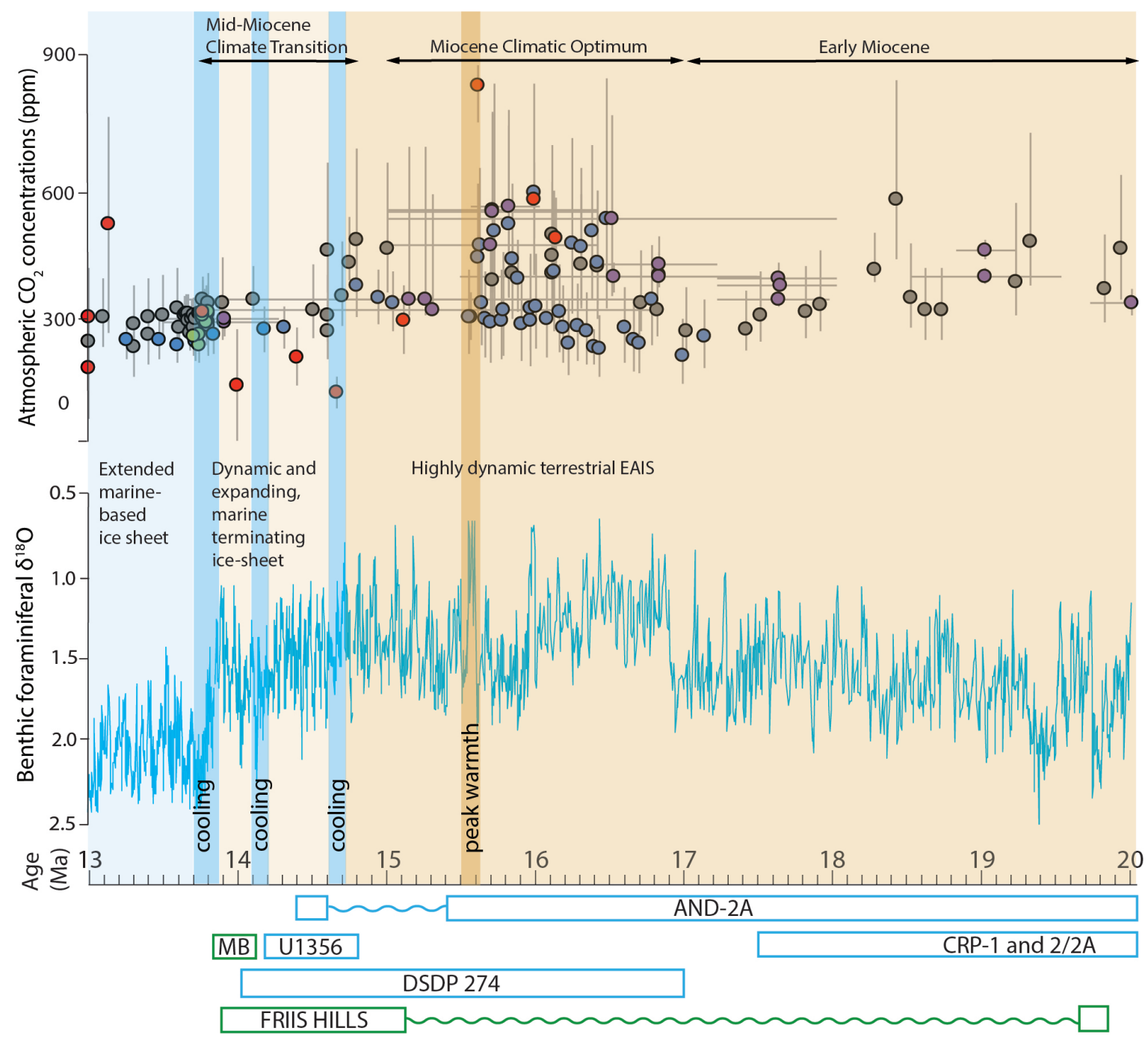

Fig. 2.7 Reconstruction of early to mid-Miocene climate from atmospheric $\mathrm{CO}_{2}$ concentrations, global sea level estimates and the $\delta^{18} \mathrm{O}$ record. $\mathrm{CO}_{2}$ data from paleosols (red: Cerling, 1992; Ekart et al., 1999; Retallack, 2009), phytoplankton (grey: Badger et al., 2013; Zhang et al., 2013; Super et al., 2018), boron isotopes (blue: Foster et al., 2012; Greenop et al., 2014), B/Ca (green: Badger et al., 2013), stomata (purple: Royer et al., 2001 and Kurschner et al., 2008, updated by Beerling et al., 2009). Global sea level estimates from Miller and others (2005) and oxygen isotope data from Holbourn and others (2014; 2015). Existing marine records for this period are noted in blue and terrestrial in green. MB $=$ Mount Boreas. The relative time over which different forcings influence climate is also indicated. 


\subsubsection{Miocene Climatic Optimum}

The MCO is the warmest period since the end of the early Eocene, with initiation of the general global cooling trend and subsequent onset of wide-spread glaciation in Antarctica (Fig. 2.1). During the MCO, benthic $\delta^{18} \mathrm{O}$ values vary between $\sim 0.67$ and $1.93 \%$ (Fig. 2.7) and suggest the AIS ice sheet was at times 30\% (Liebrand et al., 2011; Holbourn et al., 2013) to $80 \%$ (Shevenell et al., 2008; Lear et al., 2010; de Boer et al., 2010) smaller than today. These estimates are further corroborated by reconstructions of sea level, which indicate relative changes of up to $50 \mathrm{~m}$ (Fig. 2.1, Miller et al., 2005; Webb et al., 2008; John et al., 2011; Miller et al., 2020). Proxy data indicates atmospheric $\mathrm{CO}_{2}$ concentrations varied between 300 and 600 ppm at glacial-interglacial time scales during the MCO (Greenop et al., 2014) but may have reached values as high as 840 ppm during peak warmth (Fig. 2.7, Retallack, 2009), far lower than those required by models to simulate a similar level of ice sheet retreat, indicative of a climate far more sensitive to changes in $\mathrm{CO}_{2}$ than present-day (e.g. Gasson et al., 2016).

SSTs in the Ross Sea and Wilkes Land margin reached $\sim 10^{\circ} \mathrm{C}$, with coastal regions characterised by temperate vegetation and ice-free marine sectors (Warny et al., 2009; Sangiorgi et al., 2018). The EAIS advanced and retreated through the TAM (Hauptvogel \& Passchier, 2012) during the MCO and did not advance beyond the coastline during interglacial episodes. Sediments collected at Site U1356, off-shore Wilkes Land, suggest deposition occurred in open-water conditions (Sangiorgi et al., 2018). The WLB, was likely subaerial during the early to mid-Miocene (Gasson et al., 2016; Paxman et al., 2019a) and evidence suggests that ice only rarely advanced into the marine setting, with a marine-based ice sheet developing post-MCO (Sangiorgi et al., 2018). MSTs during MCO peak warmth from terrestrial palynomorphs imply MSTs of $\sim 10^{\circ} \mathrm{C}$, while the persistence of tundra vegetation provides some constraint on minimum annual temperatures, although estimations of this vary between $-22^{\circ} \mathrm{C}$ (Sakai et al., 1981; Hill et al., 1996) and $-60^{\circ} \mathrm{C}$ (Chapin, 1987; Billings \& Mooney, 1968).

\subsubsection{Mid-Miocene Climate Transition}

Global climate began to cool after 14.8 Ma (Holbourn et al., 2014; 2015). Glacial-interglacial amplitudes recorded in oxygen isotopes increased and higher $\delta^{18} \mathrm{O}$ values suggest the AIS expanded during successively larger glacial episodes (Fig. 2.7). Disconformities in the AND-2A record (Fig. 2.7, Levy et al., 2016) and across the Ross Sea (De Santis et al., 1999), 
a major increase in Earth system sensitivity to obliquity (Levy et al., 2019), an increase in sea ice indicators (Sangiorgi et al., 2018), and major turnover in Southern Ocean diatom species (Crampton et al., 2016), suggest marine ice sheets once again expanded across the Ross Sea during glacial intervals. This major expansion of the EAIS during the MMCT coincides with a shift from temperate climate wet-based glaciation and a dynamic ice sheet to the polar dry glacial style and more stable ice sheet of present-day Antarctica (Marchant et al., 1993; Sugden \& Denton, 2004; Lewis et al., 2015). Relative to past events of major ice sheet growth, such as that at the EOT, there was a relatively small decline in atmospheric $\mathrm{CO}_{2}$ across the MMCT (Langebroek et al., 2009). Despite this, the MMCT can be characterised by progressive cooling and an expansion of the EAIS on a continental scale, with a grounded ice sheet overriding the TAM and extending onto the continental shelf.

Significant expansion of the EAIS is evident in the Dry Valleys, where sedimentary records indicate large meltwater outburst floods occurred as a warm-based ice sheet advanced over the TAM (Denton \& Sugden, 2005). The transition from the highly erosive wet-based ice sheet to a less erosive cold-based ice sheet is evident in a reduction in sediment supply to sedimentary records off the coast (Passchier, 2011; Gulick et al., 2017; Kim et al., 2018), while volcanoes $>15$ Myr in Marie Byrd Land show no evidence of glacial erosion (Rocchi et al., 2006). ${ }^{40} \mathrm{Ar} /{ }^{39} \mathrm{Ar}$ dating of volcanic ashes in the Olympus Range of the Dry Valleys indicate this transition occurred between 13.94 and $13.62 \mathrm{Ma}$ (Lewis et al., 2007). During this time, Southern Ocean SSTs cooled by $6-7^{\circ} \mathrm{C}$ (Holbourn et al., 2007), accompanied by a $\sim 2^{\circ} \mathrm{C}$ cooling of deep water, inferred to be the result of an eccentricity-paced intensification of the Antarctic Circumpolar Current in response to a tectonically-induced reorganisation of the climate system as the Eastern Tethys Ocean became constricted and there was a further decline in $\mathrm{CO}_{2}$ concentrations (Shevenell et al., 2004; Shevenell et al., 2008). As the EAIS advanced, summer temperatures in the TAM declined by $>8^{\circ} \mathrm{C}$ (Denton $\&$ Sugden, 2005), and global sea level lowered by up to $60 \mathrm{~m}$ (John et al., 2011).

Surface melt of terrestrial ice sheets due to local insolation is greatest when the ice sheet does not terminate in the marine realm (Huybers, 2006). Climate cooling over the MMCT and the expansion of marine-based sectors of the AIS decreased the influence of local insolation on the surface melt by increasing the insolation melt threshold (Levy et al., 2019). This reduced the magnitude of terrestrial ice sheet variability that was typical of the mid-Miocene and resulted in the expansion of marine-based sectors, subsequent tectonic subsidence and erosion of the continental shelf increased the sensitivity of the ice sheet to oceanic influences (Levy et al., 2019). Increased sensitivity to ocean forcing and excursions 
of warm water onto the continental shelf influence the dynamic state of the AIS since the MMCT.

Ultimately, the shift that occurred across the MMCT led to the demise of remaining terrestrial plants in the Dry Valleys and high elevations of the TAM by $\sim 13.85 \mathrm{Ma}$ (Lewis et al., 2007, 2008). The exact cause for this remains unclear but could include climatic cooling and the loss of refugia due to glacial overriding through the final phases of the MMCT. While plants went extinct at the higher elevations of the TAM, there is evidence from Dry Valley Drilling Project (DVDP) -10 and -11 records for the persistence of higher plants at lower elevations of the Taylor Valley through the early Pliocene (Fielding et al., 2012; Ohneiser et al., 2020).

\subsubsection{Simulating Miocene glacial evolution with numerical modelling}

Previous attempts to simulate the relative warmth of the Miocene have been hindered by a strong hysteresis, which requires surface temperatures to warm by $15-20^{\circ} \mathrm{C}$ for retreat to occur from a fully glaciated state, and the need for atmospheric $\mathrm{CO}_{2}$ concentrations considerably higher than those indicated by proxy records (DeConto \& Pollard, 2003; DeConto et al., 2008; Gasson et al., 2016). This well-known hysteresis occurs due to surface elevation-mass balance feedbacks (Oerlemans, 2002), an albedo feedback (Pollard \& DeConto, 2005) and the cooling effect of the ice sheet on the surrounding Southern Ocean (DeConto et al., 2007).

Efforts to resolve this hysteresis have focused on marine-based regions of the AIS (Mengel \& Levermann, 2014; Pollard et al., 2015), however only a third of the AIS is currently marine-based (Fretwell et al., 2013), suggesting that evidence for a dynamic AIS during the mid-Miocene also included variability in terrestrial ice sheet extent (Gasson et al., 2016). Langebroek and others (2009) found variations in orbital forcing when combined with declining levels of atmospheric $\mathrm{CO}_{2}$ allowed for a hysteresis more closely aligned with $\mathrm{CO}_{2}$ reconstructions for the Miocene, with deglaciation of the EAIS at $\sim 725 \mathrm{ppm}$. These reconstructions, however, relied on modern-day topography, which is thought to have differed greatly during the Miocene.

Gasson and others (2016) reconstructed Miocene topography using a scaling between modern day isostatically rebounded and Eocene-Oligocene topography. Results indicate that Miocene topography (Fig. 2.8, scenario B) was required to reconstruct patterns of grounded ice at the AND-2A site in the Ross Sea, the result of an expanded continental ice sheet that likely overrode the TAM and the Friis Hills, rather than the result of increased output 
from outlet glaciers. The addition of a Miocene topography and a 2-way coupled regional climate model to simulations in this paper appears to resolve previous discrepancies between modelling and geological data, which implied a stable EAIS during warm intervals of the mid-Miocene.

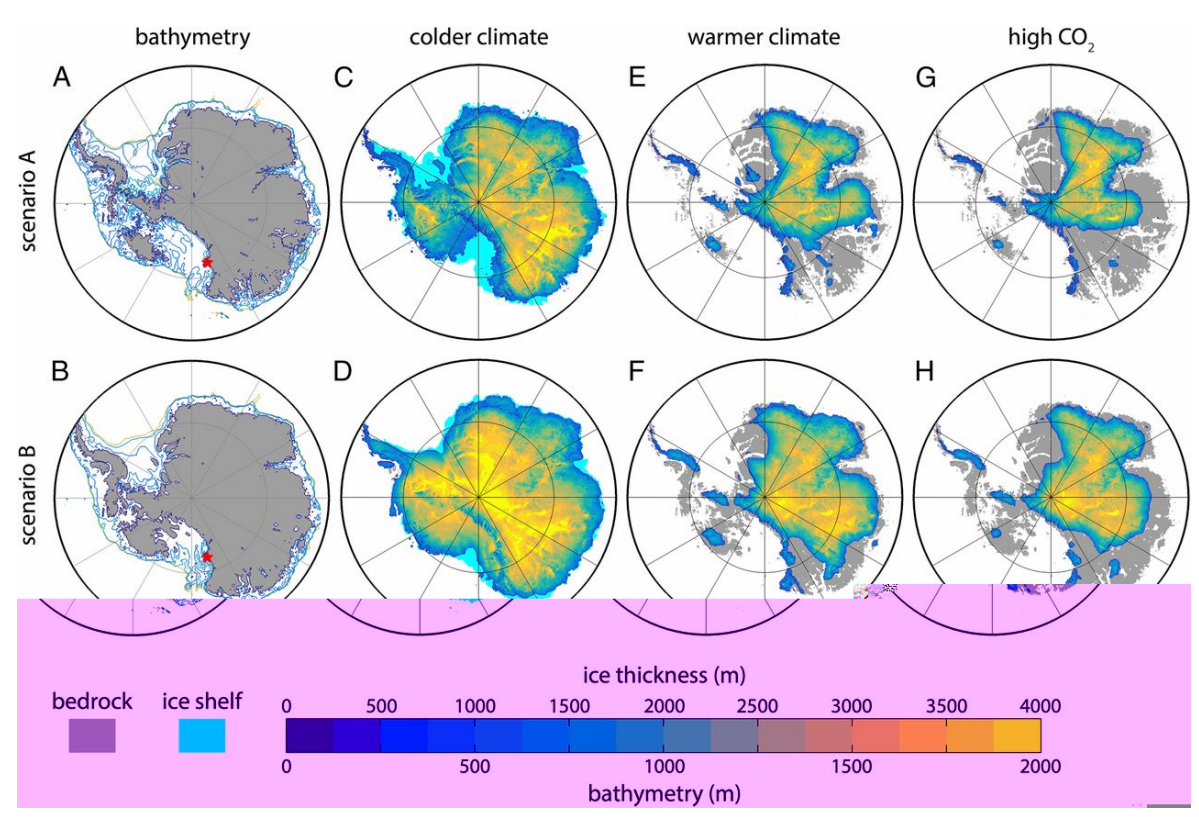

Fig. 2.8 Ice sheet thickness in response to different climate forcing and varying topography, whereby scenario A uses modern Bedmap2 bedrock topography, scenario B uses midMiocene bedrock topography, cold climate simulations have atmospheric $\mathrm{CO}_{2}$ of $280 \mathrm{ppm}$ with an astronomical configuration favourable for glaciation, warm climate simulations have atmospheric $\mathrm{CO}_{2}$ of $500 \mathrm{ppm}$ with an astronomical configuration favourable for deglaciation, and high $\mathrm{CO}_{2}$ scenarios have the same configurations as warm climate simulations but atmospheric $\mathrm{CO}_{2}$ of 840 ppm. AND-2A location marked by red stars (Gasson et al., 2016).

\subsubsection{Importance relative to present-day climate change}

The mid-Miocene provides an important analogue for the response of the EAIS to future anthropogenic climate change. The combination of geological observations and earth system modelling shows a broad link between declining atmospheric $\mathrm{CO}_{2}$ concentrations and increasing size and sensitivity of ice sheets in the past (Zachos et al., 2001; DeConto \& Pollard, 2003; Gasson et al., 2016). An improved, more detailed understanding of the response of the AIS to past climatic variability provides important context for understanding how the ice sheet will respond to future climate change under high $\mathrm{CO}_{2}$ scenarios. 
Future projections show atmospheric $\mathrm{CO}_{2}$ concentrations could reach $800 \mathrm{ppm}$ before the end of the century (Stocker et al., 2013) with associated global temperatures $4-5^{\circ} \mathrm{C}$ warmer a climate not seen since the mid-Miocene (Herold et al., 2008; You et al., 2009; Gasson et al., 2016). This time period is therefore becoming increasingly important for understanding future AIS response to warming because atmospheric $\mathrm{CO}_{2}$ has already reached Pliocene levels ( $\sim 400 \mathrm{ppm}$ ). Moreover, the paleogeography, and therefore, atmospheric and oceanic circulation patterns during this time would have been similar to those for the present-day configuration, providing boundary conditions for data-model comparisons in studying the sensitivity of the Antarctic Ice Sheet to future warming.

\subsection{Existing Miocene deposits in Antarctica - Marine}

\subsubsection{ANDRILL-2A}

The AND-2A core was recovered in 2007 as part of the ANDRILL project in the Ross Sea, spanning $1138.54 \mathrm{~m}$ of sediments at $\sim 98 \%$ recovery, it included a well preserved expanded early to mid-Miocene sequence with a near continuous record for 20.2-14.4 Ma (Fig. 2.9, Levy et al., 2016). Magnetic minerals preserved in the core corroborate the theory of a highly dynamic and variable environment (Jovane et al., 2019), with the Ross Ice Shelf retreating inland during warm interglacials and advancing beyond its present-day extent and across the continental shelf during cold glacial periods. 


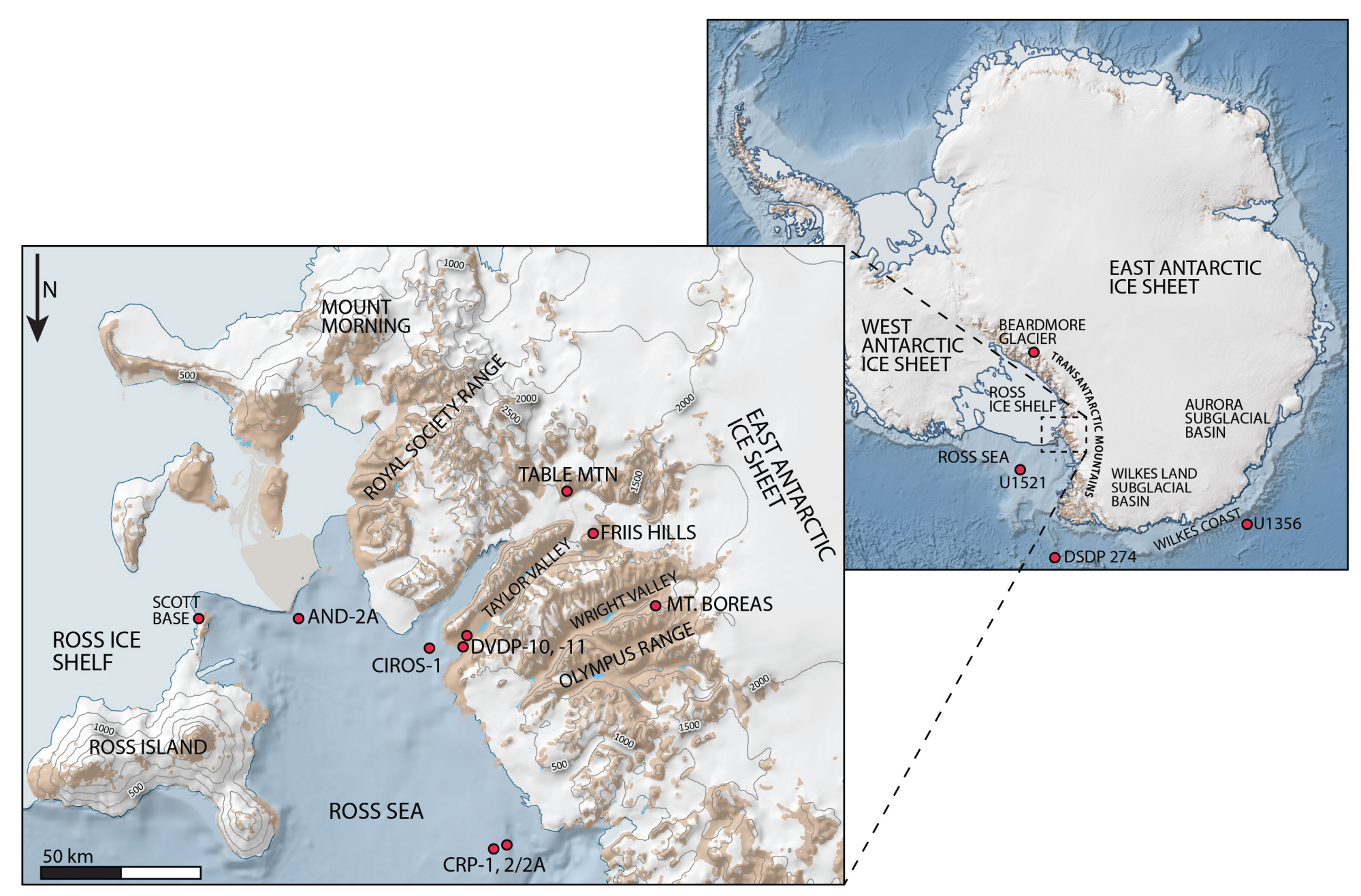

Fig. 2.9 Location map for early to mid-Miocene marine and terrestrial records and other locations discussed in the text, on a continentalscale, and, as the focus of this study, in more detail for the Southern Victoria Land sector of the Transantarctic Mountains. Base map from Quantarctica GIS package. 
Paleoenvironmental data define four environmental motifs (Fig. 2.10, Levy et al., 2016): ice advance over the drill site (EM I maximum ice), minimum grounding line variability and persistent floating ice shelves and/or coastal fast ice (EM II cold polar), tidewater glaciers calving into the ocean (EM III cold temperate), and open ocean with terrestrial terminating ice and abundant tundra vegetation (EM VI minimum ice). The AND-2A record captures four periods of maximum ice sheet advance over the drill site and five episodes of peak warmth and minimum ice, indicating significant variability in ice sheet extent during the early to mid-Miocene. Three periods of peak warmth occurred during the MCO (Figs. 2.7, 2.10). This peak warmth and EAIS retreat through the TAM occurred during intervals with eccentricity maxima, with SSTs of $6-10^{\circ} \mathrm{C}$ warmer than present-day (Levy et al., 2016) and MSTs of $\sim 10^{\circ} \mathrm{C}$ at the coast (Warny et al., 2009). This significant EAIS retreat occurred at elevated $\mathrm{CO}_{2}$ concentrations of $>500 \mathrm{ppm}$, implying a terrestrial ice sheet sensitive to $\mathrm{CO}_{2}$ concentrations lower than those implied by climate models (Goldner et al., 2014; Levy et al., 2016).

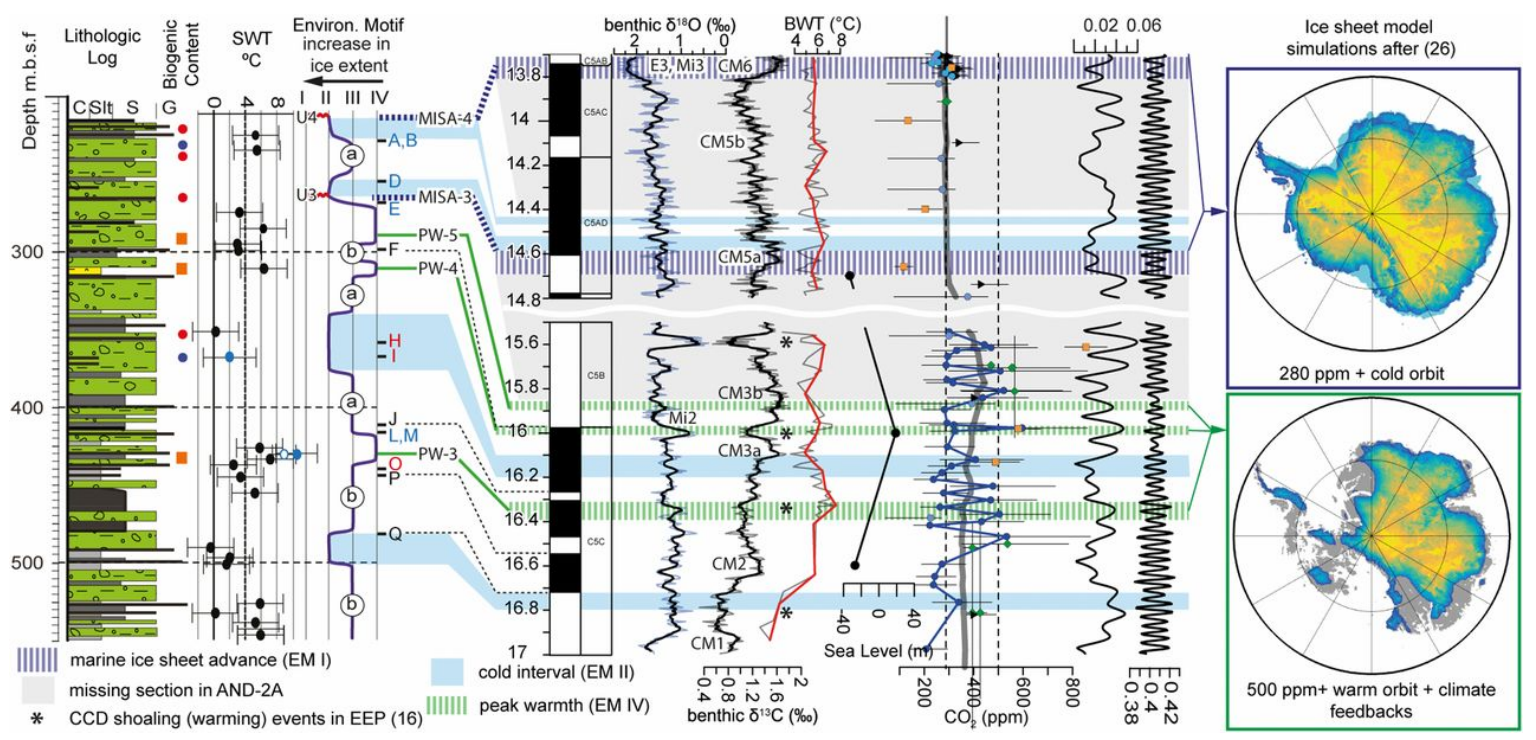

Fig. 2.10 Mid-Miocene ice sheet variability from the ANDRILL-2A record correlated to the geomagnetic polarity timescale, $\delta^{18} \mathrm{O}$ and $\delta^{13} \mathrm{C}$ Holbourn et al., 2014; Holbourn et al., 2015), bottom water temperatures (BWT; Shevenell et al., 2008), sea level estimates (John et al., 2011), and atmospheric $\mathrm{CO}_{2}$ concentrations from boron isotopes (blue circles; Foster et al., 2012; Badger et al., 2013; Greenop et al., 2014), alkenones (black triangles; Zhang et al., 2001; Badger et al., 2013), stomata (green diamonds; Kurschner et al., 2008), and paleosols (orange squares; Cerling, 1992; Ekart et al., 1999; Retallack, 2009). Environmental motifs reported by Levy and others (2016) highlighted in the record and time missing in unconformities. Orbital eccentricity and obliquity forcing from Laskar and others (2011) and ice sheet simulations from Gasson and others (2016). Figure from Levy and others (2016). 
Periods of marine ice advance correlate with global sea level lowering, increasing $\delta^{18} \mathrm{O}$ and $\delta^{13} \mathrm{C}$ values, eccentricity minima, and a decline in $\mathrm{CO}_{2}$ concentrations to $<300 \mathrm{ppm}$ (Fig. 2.10, Levy et al., 2016). Unconformities in the AND-2A core suggest no ice advance over the drillsite between 18-14.6 Ma (Fig. 2.10, Levy et al., 2016), implying variability in the $\delta^{18} \mathrm{O}$ record is the result of the growth and decay of the terrestrial EAIS. The re-advance of the EAIS into the Ross Sea during the MMCT, thought to reflect continent-wide ice sheet advance, marked the onset of a cold climate and persistent marine-based ice sheets (Levy et al., 2016) until $\sim 10 \mathrm{Ma}$, when the AND-1B core records ice sheet retreat to the terrestrial margins (McKay et al., 2009).

\subsubsection{CIROS-1}

CIROS-1 was drilled in 1986, $12 \mathrm{~km}$ offshore of the Ferrar Glacier, on the Western edge of the Victoria Land Basin to a depth of $702 \mathrm{~m}$ below the sea floor (Fig. 2.9). Sediment recovered ranged from late Eocene to early Miocene and contains a record of glacial and tectonic evolution of the Antarctic margin and EAIS variability through the TAM since the onset of a continental-scale AIS (Robinson et al., 1987). Fourteen unconformity-bound sequences are recorded in the cores consisting mainly of shallow marine mudstones, sandstones, and diamictites deposited by a glacio-marine deltaic system between $~ 38-22 \mathrm{Ma}$ (Barrett, 1989).

During the late Eocene and early Oligocene, the CIROS-1 drill core implies the EAIS was yet to be permanently developed with a low ice volume that varied on orbital timescales and westward flowing glaciers through the TAM (Barrett, 2009). During this period of relative warmth, sediments imply deposition in a fluvial and shallow marine environment during the advance and retreat of distal glaciers that terminated on land (Barrett, 2009; Van de Ven, 2010). An increase in ice volume during the early Oligocene is marked by a $\sim 9 \mathrm{Myr}$ unconformity in the CIROS-1 record, thought to be the result of erosion and overriding of the drill site by an expanded EAIS (Roberts et al., 2003).

The early Miocene interval of the core is predominantly diamictite and sandstone, with brecciated mudstone units deposited in ice proximal conditions and span the OligoceneMiocene transition and Mi-1 glaciation ( $24 \mathrm{Ma}$ ). The presence of a Nothofagus (Southern beech) leaf and pollen within this upper section of the core suggest that Antarctic MSTs remained $>5^{\circ} \mathrm{C}$ in the early Miocene, with temperate to warm conditions supporting forests along the coastline (Mildenhall, 1989). The occurrence of this pollen in clumps alongside 
the partial leaf fossil suggest these coastal forests persisted beyond the Mi-1 glaciation, with a climate characteristic of present-day high altitude Patagonia and Tasmania (Hill, 1989).

\subsubsection{Cape Roberts Project-1 and -2/2A}

CRP also recovered sediment cores off the coast of Victoria Land (Fig. 2.9), spanning 34-17 Ma and sampling sediment deposited by the McKay Glacier, an EAIS outlet glacier, that records advance and retreat of the EAIS into the Ross Sea (Naish et al., 2001b). Faunal and floral evidence suggests deposition on the continental shelf in a relatively shallow marine environment under a cool temperate climate, with MSTs at the coast of $10-12^{\circ} \mathrm{C}$ and low diversity woody flora throughout deposition (Raine \& Askin, 2001).

The CRP drill cores note a significant increase in glacial influence at $\sim 33 \mathrm{Ma}$, as a continental-scale AIS developed (Barrett, 2007). Diamictites, with sharp lower contacts that represent glacial surfaces of erosion, indicate the McKay glacier advanced onto the continental shelf during glacial periods (Fig. 2.11 a; Fielding et al., 2000; Naish et al., 2001b). During periods of glacial retreat, mudstones with ice rafted debris, indicate open marine deposition over the core site with both marine-terminating glaciers and deposition from glacier-fed river deltas (Fig. 2.11 b). Records indicate a dynamic ice sheet prior to the Mi-1 glaciation, with significant cooling, and ice sheet expansion post Mi-1 glaciation. Orbitally-paced variability of the ice sheet occurred on the scale of 40-50 m relative sea level change (Dunbar et al., 2008), indicating a highly dynamic AIS at the time of deposition. 

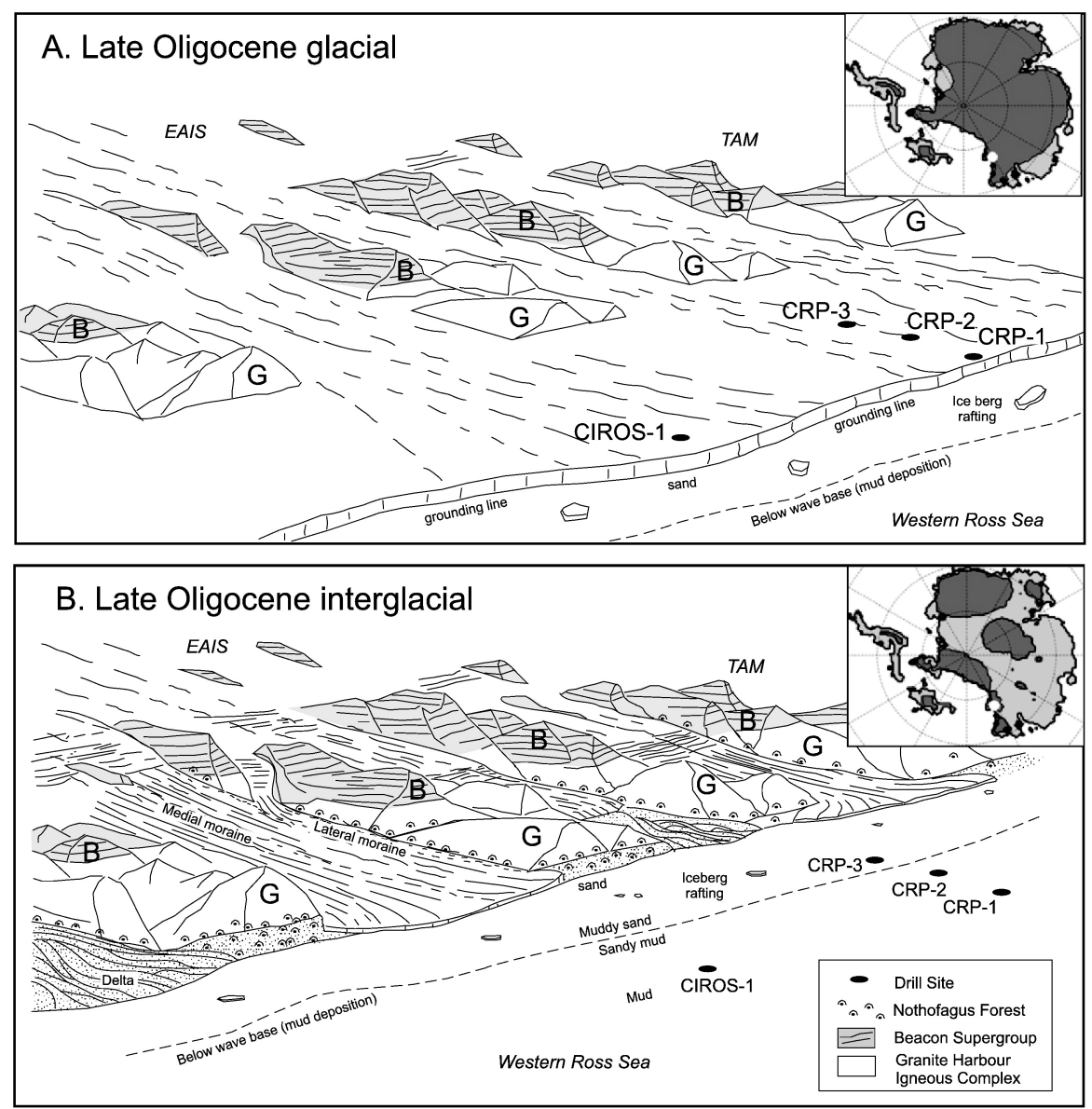

Fig. 2.11 Depositional environments and modelled ice configuration (DeConto et al., 2007) during glacial (a) and interglacial (b) periods of the late Oligocene from the Cape Roberts Project drill core record. $\mathrm{G}$ = granite, $\mathrm{B}=$ beacon supergroup (Dunbar et al., 2008, modified from Barrett 2007).

\subsubsection{U1356 Wilkes Land}

The Integrated Ocean Drilling Project Site U1356 drill core recovered Eocene and midMiocene sequence $\sim 350 \mathrm{~km}$ offshore the Adelie Coast along the Wilkes Land Margin (Fig. 2.9), providing insight into EAIS dynamics across the WLB during the time of deposition (Sangiorgi et al., 2018). During the MCO, a lack of IRD and sedimentation in open-water conditions suggests that ice only rarely advanced into the marine realm, with the high contribution of soil erosion material indicating extensive ice free regions along the Wilkes coast and the WLB between 16.4-14.8 Ma (Sangiorgi et al., 2018). Terrestrial fossil pollen assemblages from U1536 suggest MCO mean annual temperatures (MAT) of $5.8-13^{\circ} \mathrm{C}$ (MATs of $10-12^{\circ} \mathrm{C} \pm 5^{\circ} \mathrm{C}$ are also reconstructed from branched tetraether lipids), and MSTs 
$>10^{\circ} \mathrm{C}$ (Sangiorgi et al., 2018) suggest warmer temperatures at the Adelie Coast than other locations in Antarctica. Terrestrial palynomorphs indicate woody tundra vegetation with boreal forests and occasional Cyathea (tree ferns) in sheltered coastal areas between 17-14.8 Ma (Paashier et al., 2013; Sangiorgi et al., 2018). A third proxy for paleotemperatures, based on inorganic chemical weathering, reconstructs MATs of $6-8^{\circ} \mathrm{C} \pm 4^{\circ} \mathrm{C}$ (Passchier et al., 2013), which are more in line with other MCO records from the Dry Valleys and TAM coast.

Post-MCO, temperatures remained relatively warm, but saw a shift in vegetation to shrub tundra and peat lands, dominated by Nothofagus and Podocarpidites, along the sheltered coastal lowlands. While the AND-2A record reports maximum ice advance at $14.6 \mathrm{Ma}$, with extensive marine-based ice, slightly cooler marine and terrestrial temperatures reported at Site U1356 allowed for episodic ice-rafted debris, suggest ice expansion and the development of sea ice, but mild ocean and continental conditions at the site maintained cold temperate rather than maximum ice conditions (Sangiorgi et al., 2018). These cooler temperatures were punctuated by episodes of ice sheet retreat into the WLB during interglacial periods, leading to a reduced margin relative to present-day (Pierce et al., 2017; Sangiorgi et al., 2018).

\subsubsection{Deep Sea Drilling Project 274}

DSDP 274 was drilled into the Northwestern Ross Sea (Fig. 2.9), $250 \mathrm{~km}$ off the coast of Cape Adare and currently in the path of a major outflow of Antarctic Bottom Water that flows over the continental shelf of the Ross Sea (Orsi \& Wiederwohl, 2009). The core spans the late Eocene through to the Quaternary, with a number of unconformities (Hayes et al., 1975). An increase in IRD at the MMCT indicate marine terminating ice at the Wilkes coast and a drop in accumulation rate interpreted as stronger ocean currents winnowing the material as the extent of the ice shelf in the Ross Sea increased (Hayes et al., 1975).

\subsection{Existing Miocene deposits in Antarctica - Terrestrial}

Marine geological records such as those previously discussed provide direct evidence of the variability of the EAIS to global climate change (Barrett, 1987; Naish et al., 2001; Barrett, 2007; Naish et al., 2009; Fielding et al., 2011). While these nearshore and deep-marine records allow for a better understanding of the extent of glaciation at the coast during the Miocene, they provide limited insight into inland climatic conditions and glacial variability (cf. Lewis \& Ashworth, 2015). 


\subsubsection{McMurdo Dry Valleys drill cores}

The Dry Valley Drilling Project (DVDP), extending from 1971-76, was the first drilling project in Antarctica, resulting in 15 boreholes ranging in depth from 4 to $381 \mathrm{~m}$ (Fig. 2.9, Talalay \& Pyne, 2017). Prior to this, glacial landforms and outcrops along the TAM and Dry Valleys had been used to reconstruct the history of the EAIS (e.g. Barrett \& Treves, 1981). DVDP cores $-10,-11$, and -12 were taken from the permafrost layer in the deglaciated eastern end of the Taylor Valley at varying distances in land: site $10(50 \mathrm{~m}$ inland and 2.8 metres above sea level (masl)), site 11 (3 km inland and 80.2 masl), and site 12 (18 km inland and 75 masl; McKelvey, 1981).

The present-day floor of the Taylor Valley consists of Cenozoic age hummocky moraines, frozen glacial lakes and basaltic cinder cones (McCraw, 1967), however geological evidence indicates a fjord ecosystem in Taylor Valley during the Miocene, when seawater extended into the valley beyond the current extent of the Taylor Glacier (Elston \& Bressler, 1981; Sugden et al., 1995). DVDP-11 records late Miocene sedimentation with diamictites indicating periods of subglacial deposition and sandy mudstones indicating deposition in a glacio-fluvial and glacio-lacustrine environment (McKelvey, 1981). While both cores 10 and 11 reflect this variability, they vary considerably in facies assemblage, suggesting a large variability of the sediment deposited on a local scale (McKelvey, 1981). Late Miocene and early Pliocene sediments infer a warmer than present-day climate, with obliquity-paced AIS variability and retreat of the EAIS to its terrestrial margins during interglacial periods (Niash et al., 2009). More recent work on DVDP cores -10 and -11 infers that while plants went extinct at higher elevations of the TAM and Dry Valleys, higher plants may have persisted at lower elevations of the Taylor Valley until the early Pliocene (Fielding et al., 2012; Ohneiser et al., 2020) .

\subsubsection{Olympus Range and Wright Valley}

Deposits at Mt. Boreas in the Olympus Range, Dry Valleys (Fig. 2.9) record some of the last phases of wet-based glaciation, dated at $14.07 \pm 0.05 \mathrm{Ma}$ (Lewis et al., 2008). The well-preserved lacustrine and terrestrial fossils recovered include diatoms, palynomorphs, mosses, ostracods, and insects, revealing the last remnants of vegetation at high altitudes in Antarctica, with sediments indicating a local mountain glacier and associated small alpine lake (Lewis et al., 2008). Modern analogues for the species present indicate an MST of $\sim 5^{\circ} \mathrm{C}$ and conditions at the limit of plant growth during sedimentation, before being infilled by debris flows and fluvial sands (Lewis et al., 2008). Following this, overlying tills dated at 
$13.85 \pm 0.03$ Ma represent the first stages of cold-based glaciation and the final disappearance of plants in the high elevations of the TAM (Lewis et al., 2008).

Evidence from the upper Wright Valley, in the western Dry Valleys, supports overriding of the TAM by a wet-based EAIS in the final phases of the MMCT. An $\sim 50 \mathrm{~km}$ long network of glacially-scoured features known as the Labyrinth emerges from under the margin of EAIS (Lewis et al., 2006). Tephra ages indicate the Labyrinth formed between 14.4 and 12.4 Ma when large subglacial outburst floods occurred beneath an expanded and thickened EAIS (Lewis et al., 2006). The incised Labyrinth platform is at a similar present-day elevation as a glacially-moulded surface at the head of the Pearse Valley, which is also incised with a similar network of outburst drainage channels (Lewis \& Ashworth, 2015).

The traditional view based on geomorphic studies (Denton et al., 1993; Sugden et al., 1995; Marchant et al., 1996; Sugden \& Denton, 2004; Lewis et al., 2008) implies landscape modification of the TAM from the EOT to $\sim 15$ Ma occurred due to warm-based glaciers and rivers in the Dry Valleys. By the end of the MMCT ( $\sim 13.8 \mathrm{Ma})$, a shift from a cool temperate to polar climate coincided with a maximum overriding EAIS across the TAM, major outburst flood meltwater features (e.g. Labyrinth) at high altitudes, and scoured coastal bedrock (Sugden \& Denton, 2004; Lewis et al., 2008). Since this time, the landscape across the Dry Valleys was considered to have remained relatively stable, with little erosion occurring under the hyper-arid polar climate of modern-day Antarctica. A 15.5 Ma volcanic ash within surficial deposits in the Dry Valleys was some of the first evidence to suggest the present-day landscape may have existed since the mid-Miocene, and the unconsolidated Miocene terrestrial sediments were unlikely to have remained in-situ without considerably low rates of denudation (Marchant et al., 1996). The geomorphic evidence discussed has been used to suggest the Dry Valleys had largely reached their present form by the mid-Miocene (Denton et al., 1993; Sugden et al., 1995).

\subsubsection{Sirius Group}

The Sirius Group can be found at high elevations throughout the TAM, as far south as $86^{\circ} \mathrm{S}$ (Webb et al., 1996) and mostly at elevations higher than $1600 \mathrm{~m}$ (Goff et al., 2002) containing leaves, pollen, and fragments of Nothofagus that are indicative of a warmer Antarctica than present-day (Webb et al., 1984). The marine diatoms in the sediment are interpreted to have been deposited in marine basins east and west of the TAM and then transported by the glacial sediments in which they were found by a fjord and tidewater glacier system extending 
through the TAM (Webb et al., 1996). The Sirius Group records marine, glacio-marine, glacio-lacustrine, lacustrine, and periglacial facies (e.g. Webb et al., 1996), representing three phases of glaciation (Hambrey et al., 2003), with glaciers fluctuating in fjords with similar conditions to present-day Greenland (Hambrey et al., 2007).

The age of these sediments is important in constraining the transition from a predominantly wet-based AIS to the cold-polar AIS of present-day. The glacial regime of the AIS during the time of deposition became subject to debate when Pliocene age marine diatoms were found in wet-based glacial deposits in the Sirius Group at the Beardmore, Reedy, and Ferrar glaciers (Webb et al., 1984). Sirius Group deposits at Table Mountain, Dry Valleys, comprise of a gravelly sandstone, sandstone, and sandy conglomerate, with the glacio-fluvial and glacio-lacustrine facies of sandstone dominating and suggesting wetter conditions than present-day (Fig. 2.9, Goff et al., 2002).

Overall, it is thought that Table Mountain deposits are the result of the advance and retreat of wet-based ice, likely part of a local alpine system rather than an overriding EAIS. Similar to this, deposits at Beardmore glacier include diamictites, fluvial, and lacustrine sediments, representing the advance and retreat of a dynamic valley glacier (Webb et al., 1996). Tetraether lipids and terrestrial palynomorphs such as Nothofagus, Podocarpidites and vascular plants indicate MSTs of $5^{\circ} \mathrm{C}$ at the time of deposition (Francis et al., 2007; ReesOwen et al., 2018). It was noted that marine diatoms were rare, and occurred most abundantly in diamictites with higher porosity, and subsequently determined that these Pliocene-age diatoms were contaminants, reworked into Miocene-age wet-based glacial deposits (Barrett et al., 1997; McKay et al., 2008).

Sirius Group deposits in Allan Hills occur in compact, matrix-supported diamictites in low paleovalleys that has been overridden by a cold-based EAIS post-deposition (McKay et al., 2008). Marine diatom concentrations in this deposit are rare relative to other sites, attributed to the low porosity of the diamictites (McKay et al., 2008). Further analysis of processes at this site implied these diatoms were transported by wind onto the EAIS and subsequently deposited on the Allan Hills by katabatic winds (McKay et al., 2008). Modelling studies corroborate this theory, with isostatic uplift exposing marine deposits in the Wilkes and Aurora Basins (Scherer et al., 2016). These marine deposits were subsequently vulnerable to wind erosion, with prevailing winds in the model inferring deposition of these wind-blown sediments in the TAM could have been likely (Scherer et al., 2016).

The evidence for a cold arid climate in the TAM and coastal Dry Valleys during the Pliocene despite many periods when the Ross Sea was ice free (Barrett, 2013), coupled 
with evidence for the decline and proposed extinction of terrestrial biota at high elevations (Lewis et al., 2008; Ashworth \& Lewis, 2011; Lewis \& Ashworth, 2015), suggest an unstable EAIS and extensive tundra vegetation at the high elevations of the Sirius deposits during the Pliocene was unlikely. The marine diatoms found in the deposits have now been attributed to aeolian deposition and subsequent recycling (Stroeven \& Prentice, 1997) and the majority of evidence now favours the deposits being mid-Miocene or older in age (Barrett, 2013), with the MMCT representing the shift from a dynamic wet-based to stable polar EAIS.

\subsubsection{Friis Hills}

The Friis Hills are located at the head of the Taylor Valley, in the McMurdo Dry Valleys, Southern Victoria Land, Antarctica. At an average elevation of $1325 \mathrm{~m}$ above sea level, the Friis Hills is an isolated inselberg up to $1100 \mathrm{~m}$ above the surrounding topography. Its unique position has allowed for Neogene terrestrial glacial-fluvial-lacustrine sediments to be preserved in basins and be protected from subsequent EAIS ice sheet expansions and overriding of the TAM during and after the MMCT. The glacially-molded platform extends 8 $\mathrm{km}$ east to west and $4 \mathrm{~km}$ north to south with three rounded hills that rise 150-250 $\mathrm{m}$ above the surface (Lewis \& Ashworth, 2015). The elevation of this surface has been correlated on geomorphic observations with a bedrock platform on Solitary Rocks, $4 \mathrm{~km}$ to the south, and several benches in the Asgard Range to the north (Lewis \& Ashworth, 2015). Previous work by Lewis and Ashworth (2015) at the Friis Hills indicate a considerably warmer and wetter climate, characteristic of temperate alpine glacial environments, during the early to mid-Miocene.

A composite stratigraphy based on surface pits dug into sequences of glacial, glacialfluvial, and glacial-lacustrine sediments in the Friis Hills reveal environmental snapshots through the early to mid-Miocene (Lewis \& Ashworth, 2015). Lewis and Ashworth (2015) identified three stratigraphic units: the Friis I, Friis II, and Cavendish drifts (Fig. 2.12, Table 2.1). The Friis I drift includes an upper and lower diamictite of up to $1.8 \mathrm{~m}$ thick with an intervening layer of interbedded sands, gravels and a volcanic ash. Diamicts within the Friis I drift are predominantly light grey in colour with dolerite, sandstone and granite clasts, with evidence indicating SW flowing ice that flowed across the region prior to formation of Taylor and Pearse Valleys, and represents an early alpine phase. During this phase, locally derived wet-based, sub-polar glaciers flowed inland, away from the Ross Sea (Lewis \& Ashworth 2015). 


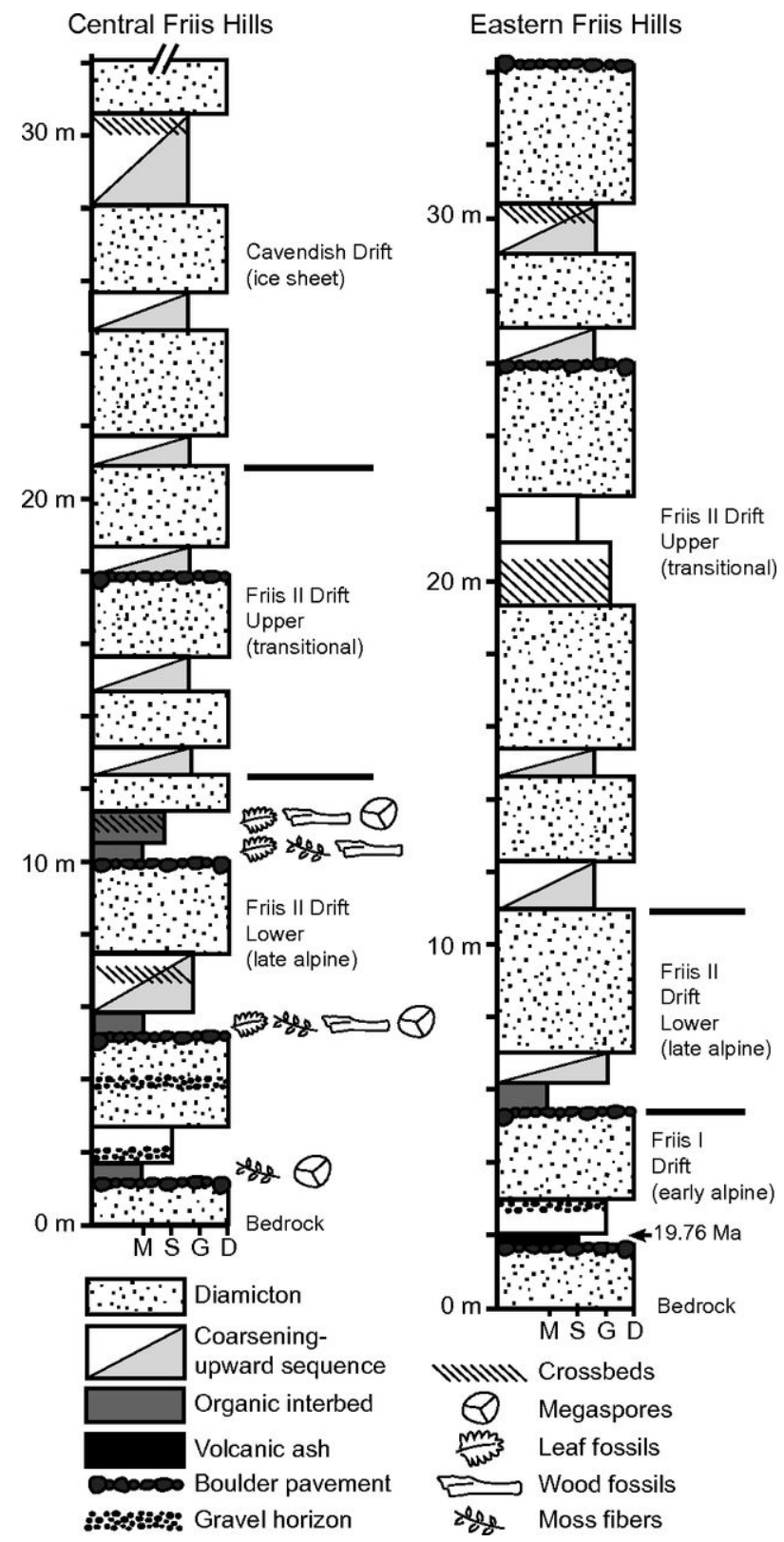

Fig. 2.12 Generalised stratigraphic column for Miocene glacial deposits in the Friis Hills. Thicknesses are based on average measurements from excavations and erosional truncations. Abbreviations for grain size: $\mathrm{M}-$ mud, $\mathrm{S}-$ sand, $\mathrm{G}-$ gravel, $\mathrm{D} —$ diamicton. Figure from Lewis and Ashworth (2015).

Friis II drifts were deposited by ice flowing to the SE and E/SE and represent the transition from a late alpine phase where sediments record advance and retreat of local wet-based glaciers (Friis II lower drift) through to a transitional phase (Friis II upper drift). These drifts include multiple diamictites deposited over at least five episodes of glaciation with interbeds 
of well- sorted, fine grained interglacial deposits. Fossiliferous beds in Friis II (lower) drift lower record abundant fossil assemblages, indicative of a Nothofagus shrub tundra present on the Friis Hills during the absence of ice and MSTs of $\sim 6-7^{\circ} \mathrm{C}$ (Lewis \& Ashworth, 2015).

A shift to granite-rich diamictites along the southern margin of the Friis Hills indicates an increasingly dominant and expanding continental ice sheet recorded by sediments of the Cavendish drift. Overall, nine cycles of glacial advance and retreat are recorded in the Friis Hills sequence constructed by Lewis and Ashworth (2015). A 19.76 Ma tephra found at the base of the deposits in an adjacent basin provide a maximum age for deposition (Fig. 2.12, Lewis \& Ashworth, 2015), while analysis of ${ }^{10} \mathrm{Be}$ in surface deposits indicates the surface has remained exposed for the last $14 \mathrm{Ma}$, providing some constraint on the minimum age of deposition (Valletta et al., 2015). 
Table 2.1 Description of the Friis Hills drifts reported in Lewis and Ashworth (2015) and their interpretation. FH = Friis Hills.

\begin{tabular}{|c|c|c|c|}
\hline Drift & Phase & Description & Interpretation \\
\hline Friis I & $\begin{array}{l}\text { Early } \\
\text { alpine }\end{array}$ & $\begin{array}{l}\text { Up to } 5.5 \mathrm{~m} \text { depth exposed, rests on molded and polished } \\
\text { bedrock, upper and lower diamict with intervening bed of } \\
\text { sand and gravel, with tephra dated at } 19.76 \mathrm{Ma} \text {. Diamic- } \\
\text { tons are light grey in colour, matrix supported, composed } \\
\text { of dolerite, sandstone, and granite clasts with matrix of } \\
\text { gravelly muddy sand. }\end{array}$ & $\begin{array}{l}\text { More widespread glaciation, lodgement tills, clasts and } \\
\text { lack of erratics suggests deposition predates downcutting } \\
\text { of surrounding valleys, brief ice-free periods, deformation } \\
\text { from ice readvance, local topographic low, ice was alpine, } \\
\text { no continental ice sheet flowed over FH at this time, ice } \\
\text { flow to SW. }\end{array}$ \\
\hline $\begin{array}{ll}\text { Friis } & I I \\
\text { (lower) } & \end{array}$ & $\begin{array}{l}\text { Late } \\
\text { alpine }\end{array}$ & $\begin{array}{l}\text { Diamictons mostly composed of dolerite, less than } 0.25 \% \\
\text { granite. Matrix grading from olive brown to light-olive } \\
\text { grey. Basal diamict consists of mainly cobble-sized, well- } \\
\text { rounded clasts. Interbeds finer grained and thicker than } \\
\text { upper unit, fossiliferous lacustrine and fluvial beds, up } \\
\text { to } 4.5 \mathrm{~m} \text { thick. Red to dark-red structureless sandy-silt } \\
\text { interbeds, fossil rich. Most interbeds are well-bedded, } \\
\text { sand coarsens overall but individual beds fine upwards. } \\
\text { Dropstones rare but more common up unit. Sand beds } \\
\text { below diamictons often deformed. }\end{array}$ & $\begin{array}{l}\text { Erosive wet-based glaciers, at least four episodes of glacia- } \\
\text { tion, locally sourced glaciers based on absence of erratic } \\
\text { clasts. Fossil assemblages indicate vegetation and rich } \\
\text { biota during ice absence. As ice readvanced, lakes formed } \\
\text { between glacier margin and hillslopes. Dropstones sug- } \\
\text { gest iceberg influence. Nothofagus dominated shrub tun- } \\
\text { dra. Became a topographic high during this phase due } \\
\text { to glacial doncutting, westward extension of Kukri Hills, } \\
\text { drainage divide between Ferrar and Taylor, ice flow to SE. }\end{array}$ \\
\hline $\begin{array}{ll}\text { Friis } & I I \\
\text { (upper) } & \end{array}$ & Transitional & $\begin{array}{l}\text { Diamictons contain more granite clasts than lower unit, } \\
\text { lacustrine and fluvial beds devoid of fossils. Upper unit } \\
\text { comprises at least three diamictons, ranging from 0.6- } \\
4.3 \mathrm{~m} \text { in depth, and composed of glacially molded clasts } \\
\text { within loose matrix of light grey to light brown gravelly } \\
\text { muddy sand. } 12 \% \text { granite clasts in upper sections. In- } \\
\text { terbeds composed of silt and fine sand, uppermost sands } \\
\text { cross bedded, most are well-sorted. }\end{array}$ & $\begin{array}{l}\text { Erosive wet-based glaciers, at least five episodes of glacia- } \\
\text { tion, erratic clasts suggests source area of considerable } \\
\text { relief to the WNW. Topography previously directed ice } \\
\text { from high elevations, ice now flowed past and over FH. } \\
\text { Changes in till characteristics attributed to change from } \\
\text { local system to overtopping local topographic divides, first } \\
\text { evidence of ice thick enough to overtop TAM. No evidence } \\
\text { vegetation recolonised during ice free periods. Ice flow to } \\
\text { E/SE. }\end{array}$ \\
\hline Cavendish & ice sheet & $\begin{array}{l}\text { Granite rich diamictons and well-sorted sandy interbeds, } \\
\text { only along southern margin of central FH. Diamictons } \\
\text { compose of dolerite, granite and sandstone clasts with pale } \\
\text { yellow to light olive brown gravelly muddy sand. Large } \\
\text { boulders of granite and dolerite, rare in previous drifts. } \\
\text { Fine grained interbeds up to } 2.6 \text { m thick of well-sorted } \\
\text { silt, sands, and gravel. }\end{array}$ & $\begin{array}{l}\text { Ablation tills and debris flows at lateral moraines of } \\
\text { glacier, deposited by glacier in adjacent trough. Fine } \\
\text { grained interbeds from melting along glacier margins dur- } \\
\text { ing retreat phases. }\end{array}$ \\
\hline
\end{tabular}




\subsubsection{Volcanic deposits}

Cenozoic volcanism is common both in and adjacent to the Dry Valleys (Kyle, 1990), occurring predominantly in the Royal Society Range and the Taylor and Wright Valleys (Di Roberto et al., 2012). Mount Morning (Fig. 2.9) is part of a $2000 \mathrm{~km}$ long chain of extrusive, Cenozoic-age volcanic centres known as the McMurdo Volcanic Group, with the Melbourne and Hallett volcanic provinces in Northern Victoria Land (Kyle, 1990). The oldest and southern-most eruptive complex in the Erebus Volcanic Province (EVP) in Southern Victoria Land (Martin et al., 2010; Di Roberto et al., 2012), its position on the active West Antarctic Rift System plays a key factor in the long eruptive history (Martin et al., 2010). Volcanism occurs in two distinct phases: Phase I activity (18.7-11.4 Ma) is defined by a mildy alkaline, trachytic to rhyolitic composition, and phase II activity (6.13-0.15 Ma) is defined by strongly alkaline, phonolitic to basinite compositions (Martin et al., 2010).

CRP cores provide some of the oldest evidence for volcanism in the EVP, with ${ }^{40} \mathrm{Ar} /{ }^{39} \mathrm{Ar}$ ages of 24.1, 23.7, 21.4, and 18.4 Ma (Martin et al., 2010). The provenance of these volcanics is attributed to the Southern Victoria Land EVP, and in particular Mount Morning, as a Northern Victoria Land source would require mechanisms to transport the debris that are currently not understood (Smellie, 1998; Martin et al., 2010). Miocene volcanic activity is evident in the AND-2A core between 17.1-11.5 Ma (Di Roberto et al., 2012), the AND-1B core at $13.57 \pm 0.13 \mathrm{Ma}$ (Martin et al., 2010), and in volcanic deposits re-dated by Martin et al., (2010) at Gandalf Ridge (18.7 \pm 0.3 and $15.5 \pm 0.5 \mathrm{Ma}$ ), Pinnacle Valley (15.4 \pm 0.1 and $13.0 \pm 0.3 \mathrm{Ma}$ ), and Mason Spur (12.9 \pm 0.1 and 11.4 $\pm 0.2 \mathrm{Ma}$ ). Other volcanic deposits and ages reported in the Friis Hills, the Olympus Range, and new terrestrial volcanic deposits in the Dry Valleys could also likely be attributed to Mount Morning, however this would require further analysis of the chemical composition of these tephras.

\subsection{Terrestrial glacial facies}

The thermal regime of a glacier is principally determined by environmental and climatic conditions, which in turn dictates the process of ice movement, the nature of sediment transport, and the different sedimentary facies laid down by the glacier (e.g. Fig. 2.13. Hambrey \& Glasser, 2012). The topographic setting plays a large role in determining the sedimentary facies that will be preserved, for example, in high relief areas, subglacial deposits are often reworked by glacio-fluvial processes and are therefore rarely preserved. 
The advance and retreat cycles of glaciers responds to variations in ablation and velocity, which is subject to seasonal variations, and on a longer timescale, climatic fluctuations such as those discussed in section 2.1.3.

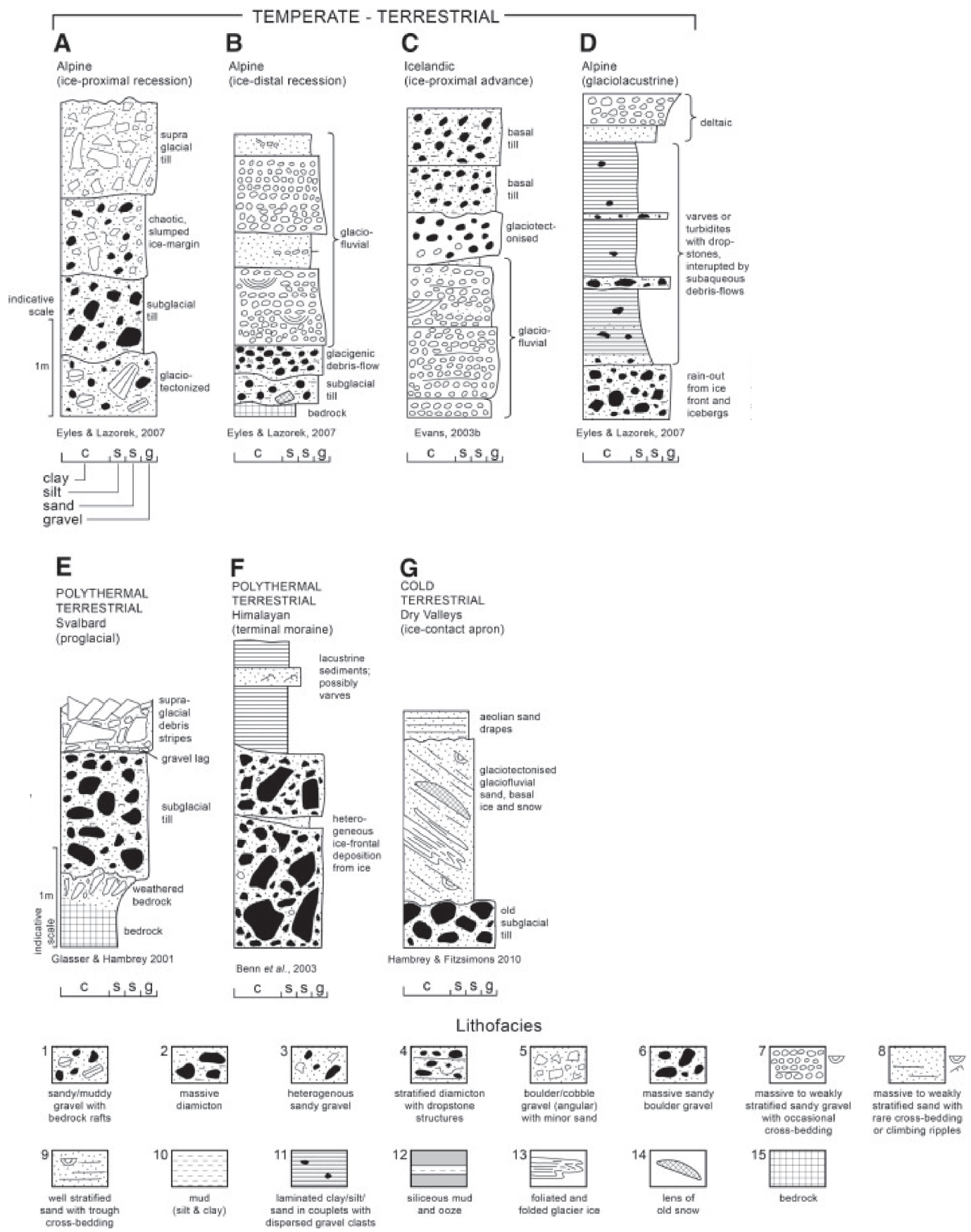

Fig. 2.13 Typical facies association for different glacial thermal regimes in terrestrial environments and interpretations of the associated depositional environment. Grain size indicators: clay (c), silt (s), sand (s), and gravel (g). Modified from Hambrey and Glasser (2012). 
Figure 2.13 gives an example of the typical associations with different thermal regimes, however as previously discussed, these are also subject to a number of different variables. There is no stereotypical facies assemblage for each style of glaciation, with wide range of sedimentary processes acting to different degrees depending on these variables. By constraining the nature of the facies deposited by different types of glaciers and the relative proportions of these different facies, it is possible to make assumptions regarding the thermal and dynamic regimes of former glaciers. The different types of glaciation, classified by thermal regimes as temperate (wet-based), polythermal, and cold-based, and the associated facies will now be discussed in greater detail.

\subsubsection{Wet-based glaciation}

Temperate, wet-based glaciers, such as those in Antarctica during the early to mid-Miocene, are those where ice at the bed is at pressure melting point throughout. This style of glaciation is typical of alpine regions with a maritime climate and high snow accumulation rates, but can also be present in regions with strongly seasonal climates (Hambrey \& Glasser, 2012). While known as wet-based glaciation, ablation occurs through melting on the surface, internally, and at the base, however the majority of water discharges from the base. As a result of this, wet-based glaciers carry little debris at the base, with englacial and basal sediment loads of these glaciers typically low. The continual basal melting and significant amount of meltwater leads to the rapid removal of debris and removal of sediment. Till deposits can therefore represent considerably large periods of time, particularly when compared to the retreat moraines associated with recent climatic changes (Hambrey \& Glasser, 2012).

The reworking of sediments post deposition by subglacial meltwater is an important process in temperate alpine environments (Benn \& Evans, 2010; Hambrey \& Glasser, 2012). The most common facies in these environments is sandy gravel, with grain size decreasing with increasing distance from the ice margin (Hambrey \& Glasser, 2012). Diamicton, interpreted as subglacial traction till, is a relatively rare deposit in alpine environments, particularly where steep valleys restrict the process of sediment deposition. Regions with low relief and relatively flat proglacial areas such as Norway and Iceland, where sediment is deposited directly below the glaciers, have the highest chance of surviving glacio-fluvial reworking and preserving large sheets of diamict (Hambrey \& Glasser, 2012). Due to the highly varied nature of sediments deposited by temperate, wet-based glaciers, no uniform landsystem model or facies association can be applied to all temperate environments (Ham- 
brey \& Glasser, 2012), however general depositional models exist (e.g. Fig. 2.14). While modern ice-marginal environments may not necessarily be close analogues for the geological record, descriptions of modern day processes and sediments can be used to reconstruct and better understand former glacial environments such as the Friis Hills. An idealised example of facies deposited in this environment is shown in Figure 2.13 a-d.

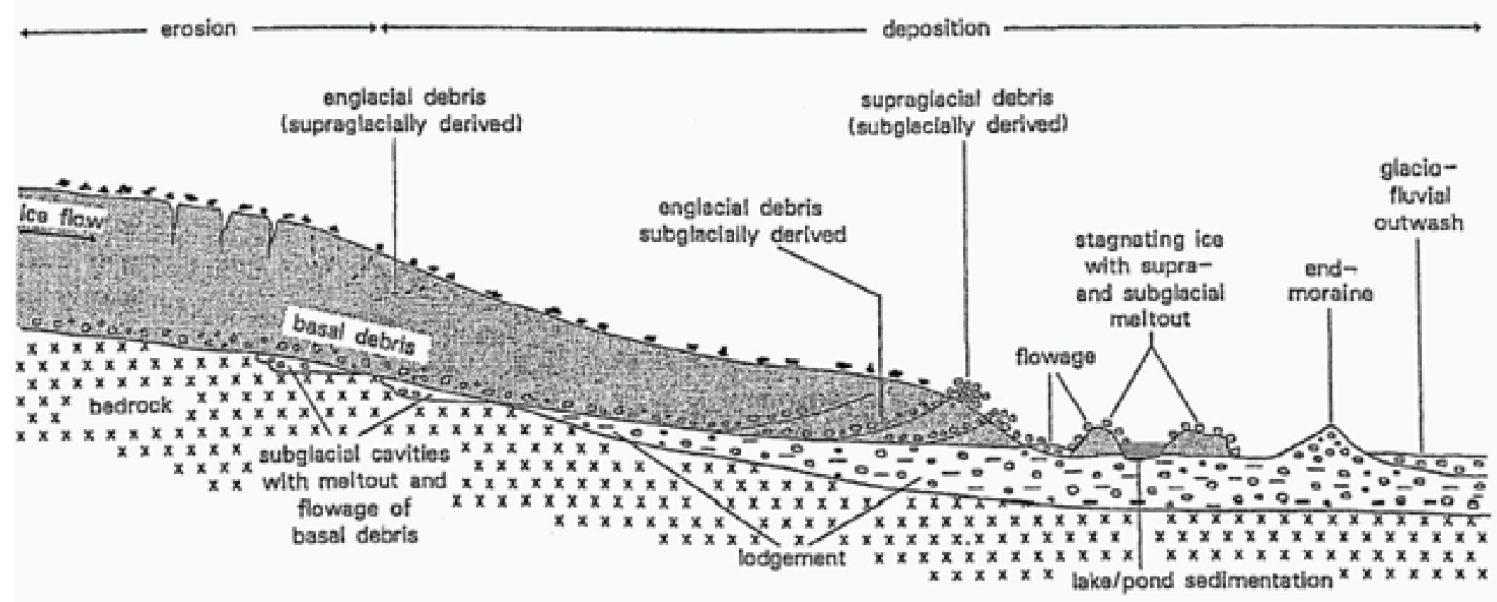

Fig. 2.14 An example of a glacial depositional model for wet-based/polythermal landterminating glaciers (from Hambrey \& Glasser 1978).

Meltstreams play a large role in deposition and reworking of sediments and glaciofluvial processes produce a wide range of facies associations (Miall, 1992). Ice marginal environments saturated with water in the form of subglacial or proglacial meltwater streams and standing water allow for saturated sediments that are easily liquefied and displaced by processes of pushing and squeezing from the pressure of the overriding glacier or the glacier behind. These sediments exhibit microstructures that are typical of shearing and movement, such as rotational structures, water escape structures, and fold structures (Fig. 2.15).

Given the dominance of diamictite in sediments deposited at the Friis Hills, as indicated by Lewis and Ashworth (2015), it could be assumed that during the early to mid-Miocene this was a relatively low relief landscape, limiting glacio-fluvial reworking and removal of diamictite deposits. Modern analogues for the paleoenvironment of the Friis Hills will be considered in section 2.6. 


\section{Microfabrics and Microstructures within the Plasma and S-Matrix of Glacial Sediments}

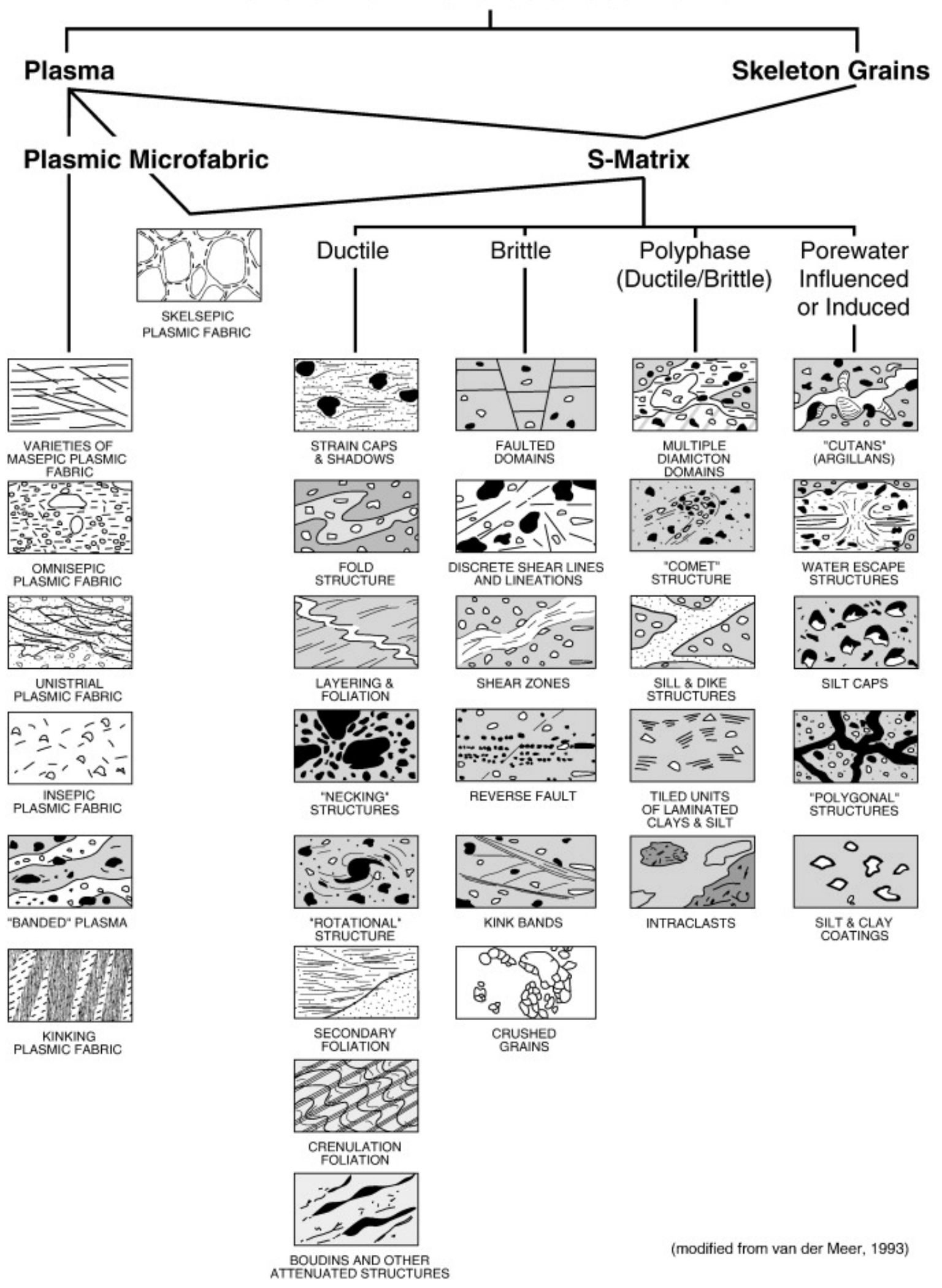

Fig. 2.15 Summary of microstructures present in glacial sediments (from Van der Meer 2003). 


\subsubsection{Cold-based glaciation}

Cold-based glaciers are where ice remains below the pressure melting point throughout, resulting in the absence of free-flowing basal meltwater. These glaciers exist only in cold, arid climates, or at high altitudes with low rates of snow accumulation and mean annual temperature (MAT) $<0^{\circ} \mathrm{C}$. Movement is predominantly through internal deformation in the lowermost parts of the glacier and the underlying bedrock, but can also move through basal sliding, with this process occurring at $-17^{\circ} \mathrm{C}$ in the Dry Valleys, Antarctica (Cuffey et al, 2000).

While it has been thought that cold-based glaciers lack erosive power, they are still capable of erosion and deposition (Atkins et al., 2002; Hambrey \& Glasser, 2010). The dominant process in cold based glaciers is basal debris entrainment, with little modification of sediments from the source material, which usually consists of coarser sediments and sands (Hambrey \& Fitzsimons, 2010). Debris aprons and fans form at the margins of cold-based glaciers (Benn \& Evans, 2010) and the incorporation of these frontal aprons during overriding, results in glaciers with large basal debris loads and debris-rich ice up to $5 \mathrm{~m}$ thick at the base. Subsequent deposition of this material is dominated by ice removal through sublimation (Hambrey \& Glasser, 2012).

Glaciers in the Dry Valleys today are considered some of the coldest glaciers globally, with basal temperatures between -18 to $-15^{\circ} \mathrm{C}$ and subglacial meltwater produced by pressure melting refreezes within the ice (Holdsworth \& Bull, 1970). An idealised example of facies deposited in this environment is shown in Figure $2.13 \mathrm{~g}$.

\subsubsection{Polythermal glaciation}

Polythermal glaciers are an intermediate form of glaciation, with a complex thermal structure These glaciers each have distinct flow characteristics, with a number of disjointed regions consisting of both cold and warm-based glaciation (Blatter \& Hutter, 1991). The Greenland and Antarctic ice sheets were once considered to be cold-based, however there is now evidence to show that much of the base is at pressure melting point. Geothermal heat flow raises the basal temperature of thick glaciers and ice sheets to the pressure melting point, despite MATs of $-60^{\circ} \mathrm{C}$. In polar regions, only the margins of the ice sheet or thin glaciers are cold-based, and much of these ice sheets can therefore be considered polythermal. Up to 55\% of the grounded part of the Antarctic Ice Sheet is at pressure melting point (Pattyn, 2010), 
with wet-based areas including outlet glaciers, ice streams, subglacial lakes and areas with basal drainage (Siegert et al., 2005; Stearns et al., 2008; Smith et al., 2009). An idealised example of facies deposited in this environment is shown in Figure 2.13 e-f.

\subsection{Modern analogues}

\subsubsection{Greenland}

Southwest Greenland is an environment particularly sensitive to fluctuations, with changes in sea ice extent and duration greatly influencing both the marine and terrestrial realms (Mienert et al., 1992; Andrews et al., 1997). Climate variability dominated by the balance between southward-flowing currents that bring cold polar water into the region and currents that carry warmer Atlantic waters. Glaciers are fed by smaller, localised ice caps with no connection to the main Greenland ice sheet, ice advance is subject to more local variability in response to these climate forcings (Geirsdottir et al., 2000).

Southwest Greenland constitutes land terminating ice during warm periods, with advance into fjords and the marine realm during colder periods, which in the case of recent history, includes the Little Ice Age ( 1600-1900 AD; Geirsdottir et al., 2000). Fjords in the Kangerlussuaq region, such as Kangerlussuaq Fjord, could be considered typical of Taylor Valley during the Miocene (Fig. 2.16). Mountains up to $1280 \mathrm{~m}$ high surround the fjord, with extensive cirques and valley glaciers of a polythermal nature that calve into the fjord or terminating in the terrestrial realm (Geirsdottir et al., 2000).

Land terminating outlet glaciers, such as Russell Glacier in Southeast Greenland, have considerably lower velocities of tens of metres per year than tidewater outlet glaciers, which can have velocities of up to thousands of metres per year (Benn \& Evans, 2010). Analysis of pollen data from the AND-2A core indicates an environment similar to the Pleistocene boreal coniferous forest expansion in southern Greenland during the peak warmth of the MCO in the TAM (Warny et al., 2009). 

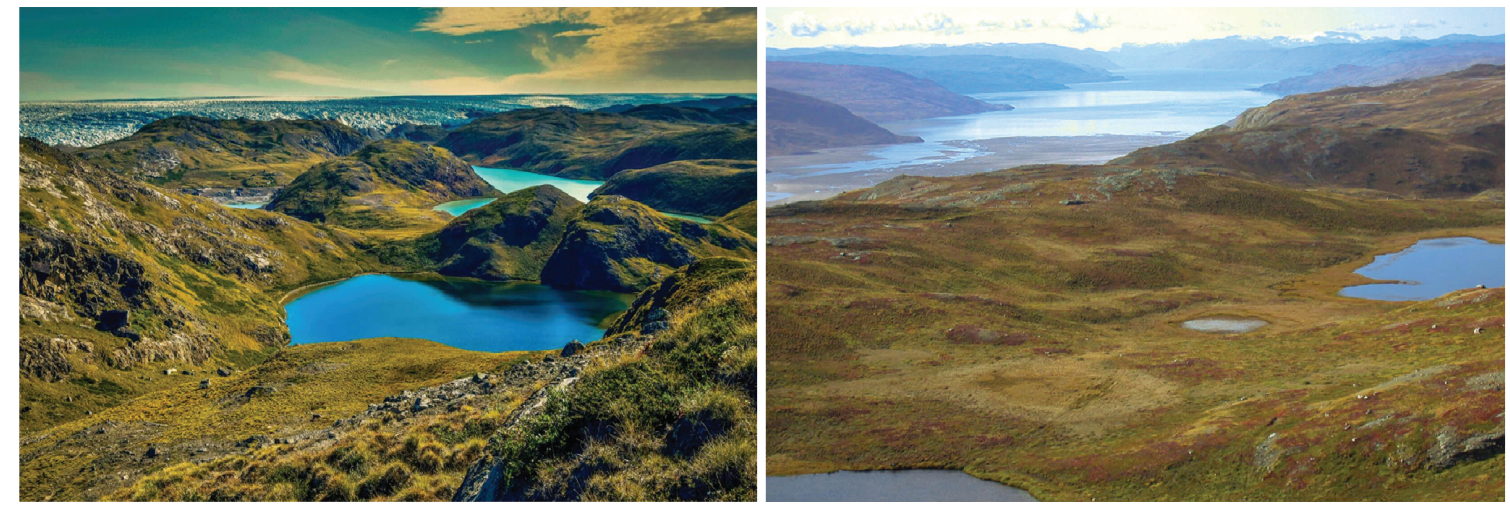

Fig. 2.16 The Kangerlussuaq region in southwest Greenland provides a modern analogue for interglacials at the Friis Hills during the mid-Miocene, with expansive tundra vegetation, small lakes and ponds, and flowing water. Large valleys such as the Ferrar and Taylor were being down cut during this time, with ice from the EAIS flowing around and over the Friis Hills during glacial periods. (Source: University of Maine).

\subsubsection{Kerguelen Islands}

Located just south of the Antarctic Convergence Zone at $49^{\circ} \mathrm{S}$, the Kerguelen Islands are situated at the polar front, where Antarctic and temperate air masses meet. The western part of the main island, with an average elevation of $800 \mathrm{~m}$ above sea level, is dominated by a small icecap with outlet glaciers, while the eastern side is characterised by flat landscapes and expansive glacial and glacio-fluvial deposits (Van der Putten et al., 2015). The general climate of this sub-Antarctic island is cool-oceanic and is therefore greatly influenced by the surrounding oceanic mass (Frenot et al., 1995), with mean annual temperatures of $4.6^{\circ} \mathrm{C}$ (Van der Putten et al., 2015) and little daily or seasonal temperature variation such as that most likely seen at the Friis Hills during the Miocene.

Present-day glaciers in Kerguelen are unique, directly influenced by both atmospheric and oceanic variability due to their location at low altitudes and on islands (Verfaillie et al., 2015). Measured albedo values in Kerguelen are higher than snow line albedo values recorded in typical alpine glacial environments (Dumont et al., 2011), thought to be the result of a relatively small number of rock outcrops relative to alpine glaciers which are often surrounded by rock outcrop and frequent snowfall all year round (Verfaillie et al., 2015). Ampere glacier is one of the largest outlet glaciers draining the Calotte Cook ice sheet with regular cycles of glacial advance and retreat in response to climatic fluctuations (Frenot et al., 1993). The Ampere glacier terminates into Lac Ampere, a proglacial lake with 7 distinct 
retreat moraines interspersed with large, flat areas of glacio-fluvial deposits with pebbles and very sparse vegetation (Frenot et al., 1993).

Monitoring and measurements are sparse in the Kerguelen Islands, and therefore a full understanding of present-day glaciation is difficult. What is apparent is the rapid response of those glaciers measured to climate perturbations (Berthier et al., 2009), likely due to the homogeneous nature of the climate and the influence of large scale processes in the Southern Ocean.

\subsubsection{Patagonia}

The outlet glaciers in Patagonia extend to lower latitudes than any other substantial ice mass, characterised by the high precipitation and ablation, high ice velocities, and steep mass balance gradients that are typical of temperate glaciers (Rott et al., 1998). As a result, when combined with distinct localised topographic and climatic contrasts, these dynamic glaciers are extremely sensitive to temperature and precipitation change (Kerr \& Sugden, 1994). Long term variations are driven by climatic changes as the result of mountain range uplift, SSTs of the Southern Oceans and the strength of the circum-Antarctic ocean circulation (Villalba et al., 1997).

The dominant lithofacies in these environments and their interpretation are sandy boulder gravel (ice-marginal), sandy gravel (glacio-fluvial), angular gravel (supraglacial) and diamicton (basal glacial) (Glasser \& Hambrey, 2004). The deformation of sand and laminites in moraine ridges suggest periods of glacial advance over a proglacial lake, similar to deposits from studied temperate glaciers in New Zealand and Iceland (Glasser \& Hambrey, 2004). Fluvial reworking and aeolian processes also play a role in the reworking and distribution of sediment post-deposition (Glasser \& Hambrey, 2004). 


\section{Chapter 3}

\section{Antarctic Ice Sheet evolution and variability during the mid-Miocene Climate Transition ( 15.1-13.8 Ma), from the Friis Hills, Antarctica}

Author contributions are as follows: Sediments in the FHDP cores were described by H. Chorley (VUW), R. Levy (VUW/GNS Science), and T. Naish (VUW). H. Chorley subsequently undertook the analyses and interpretation of the data and wrote the first draft. R. Levy and T. Naish helped in both the data interpretation and writing of the manuscript. S. Hemming (Lamont-Doherty Earth Observatory) and S. Cox (Lamont-Doherty Earth Observatory) undertook the ${ }^{40} \mathrm{Ar} /{ }^{39} \mathrm{Ar}$ numeric dating of the two tephras from the cores, while F. Florindo (National Institute of Geophysics and Volcanology), C. Ohneiser (University of Otago), P. Lurcock (National Institute of Geophysics and Volcanology) provided the paleomagnetic analysis and magnetostratigraphy interpretation. J. Hopkins (VUW) assisted with tephra classification and interpretation of the data. J. Prebble (GNS Science) and A. Holmes (VUW) carried out the palynological analyses and interpretation and diatom analysis of the FHDP cores was conducted by M. Harper (VUW). A. Gorman (University of Otago) provided seismic data for the Friis Hills basin. M. Verret (VUW) provided the organic carbon fraction data for lake facies of the FHDP cores and assisted with core sampling. 
Antarctic Ice Sheet evolution and variability during the mid-Miocene Climate Transition

\subsection{Abstract}

A 50 m thick ice-cemented terrestrial glacial sequence was recovered in drill cores from the Friis Hills, McMurdo Dry Valleys in 2016. These cores provide new insights into the variability and extent of glaciation through the Transantarctic Mountains (TAM) during the mid-Miocene, between $\sim 15.1-13.8 \mathrm{Ma}$. The early stage of this interval was characterised by a period of warmth within the Miocene Climatic Optimum (MCO, 17-15 Ma), when global average temperature was $3-4^{\circ} \mathrm{C}$ warmer than today and atmospheric carbon dioxide $\left(\mathrm{CO}_{2}\right)$ levels up to $600 \mathrm{ppm}$ - one of the warmest intervals since the onset of Antarctic glaciation. The MCO was terminated by major global cooling and Antarctic wide ice sheet expansion across the Miocene Climatic Transition (MMCT, 14.8-13.8 Ma).

A chronostratigraphic framework for the cores based on magnetostratigraphy, ${ }^{40} \mathrm{Ar} /{ }^{39} \mathrm{Ar}$ isotopic ages for two interbedded silicic tephra, and limited biostratigraphic constraints revealed 15 sedimentary cycles of the advance and retreat of a temperate alpine glacier system between $\sim 15.1-13.8 \mathrm{Ma}$. Each cycle consists of traction tills and moraines deposited during advances of a temperate alpine glacier system, and intervening glacio-fluvial to glaciolacustrine sediments deposited during interglacial retreat, indicating a much warmer and wetter environment in the TAM than exists today. Using the characteristic facies within these sequences and associated environmental interpretations, an idealised sequence stratigraphic motif and a conceptual depositional model for a cycle of glacial advance and erosion, interglacial retreat and subsequent glacial advance is presented.

After 14.4 Ma till facies in the Friis Hills cores become progressively thicker, less muddy, more pervasively deformed and are punctuated by thinner intervals of organic rich fluviallacustrine interglacial sediments that display similar facies to the underlying organic-rich interglacials. This suggests that glaciation progressively became colder, drier and more regionally-extensive during glacial periods heading into the MMCT. However, interglacials remained warm enough to sustain tundra-style vegetation including Nothofagus at high elevations where mean summer temperatures (MST) were $6-7^{\circ} \mathrm{C}$.

\subsection{Introduction}

The combination of geological observations and earth system modelling shows a broad link between declining atmospheric $\mathrm{CO}_{2}$ concentrations and increasing size and sensitivity of ice 
sheets in the past (Zachos et al., 2001; DeConto \& Pollard, 2003; Naish et al., 2009; Pollard \& DeConto, 2009; Gasson et al., 2016; Levy et al., 2019). An improved, more detailed understanding of the response of the Antarctic Ice Sheet (AIS) to past climatic variability provides important context for understanding how the ice sheet will respond to future climate change under high $\mathrm{CO}_{2}$ scenarios. Future projections show atmospheric $\mathrm{CO}_{2}$ concentrations could reach 800 ppm well before the end of the century (Stocker et al., 2013), with associated global temperatures $4-5^{\circ} \mathrm{C}$ warmer than pre-industrial values - a climate not seen since the mid-Miocene (e.g. Flower \& Kennett, 1993; White et al., 1997; Zachos et al., 2001; Böhme, 2003; Mosbrugger et al., 2005; Kürschner et al., 2008; Herold et al., 2008; You et al., 2009; Henrot et al., 2010; Krapp \& Jungclaus, 2011; Utescher et al., 2011; Herold et al., 2012; Holbourn et al., 2015; Hobbs \& Parrish, 2016; Prebble et al., 2017). This time-period is becoming increasingly important as a guide to Antarctica's response to future climate because atmospheric $\mathrm{CO}_{2}$ concentrations have already reached Pliocene levels and look likely to continue to increase. Moreover, global paleogeography, and therefore, atmospheric and oceanic circulation during this time were broadly similar to the present-day configuration (e.g. Herold et al., 2008; 2012) providing a representative "test-bed" for understanding future AIS change. However, local geographic differences in the Ross Sea region affected the volume of ice that fluctuated across West Antarctica (Wilson et al., 2012; Gasson et al., 2016; Paxman et al., 2019a). While the Miocene AIS cannot be used as a direct analogue for potential response of the modern ice sheet to future climate change, records can be used to examine the influence of a warmer climate on the processes that govern ice sheet dynamics and ice sheet sensitivity in general.

Geological archives provide direct records of past ice sheet response under these warmer than present-day conditions. The early to mid-Miocene ( $\sim 23-14 \mathrm{Ma})$ is characterised by a dynamic AIS with major variations in both volume and extent of terrestrial and marine ice sheets (Miller et al., 2005; Gasson et al., 2016; Levy et al., 2016; Sangiorgi et al., 2018; Jovane et al., 2019; Levy et al., 2019). This interval was punctuated by an episode of unusual warmth within the $\mathrm{MCO}$, one of the warmest intervals since the onset of Antarctic glaciation (Zachos et al., 2001; Zachos et al., 2008), and was terminated by major cooling and ice expansion across the MMCT (Flower \& Kennett, 1993). 
Antarctic Ice Sheet evolution and variability during the mid-Miocene Climate Transition

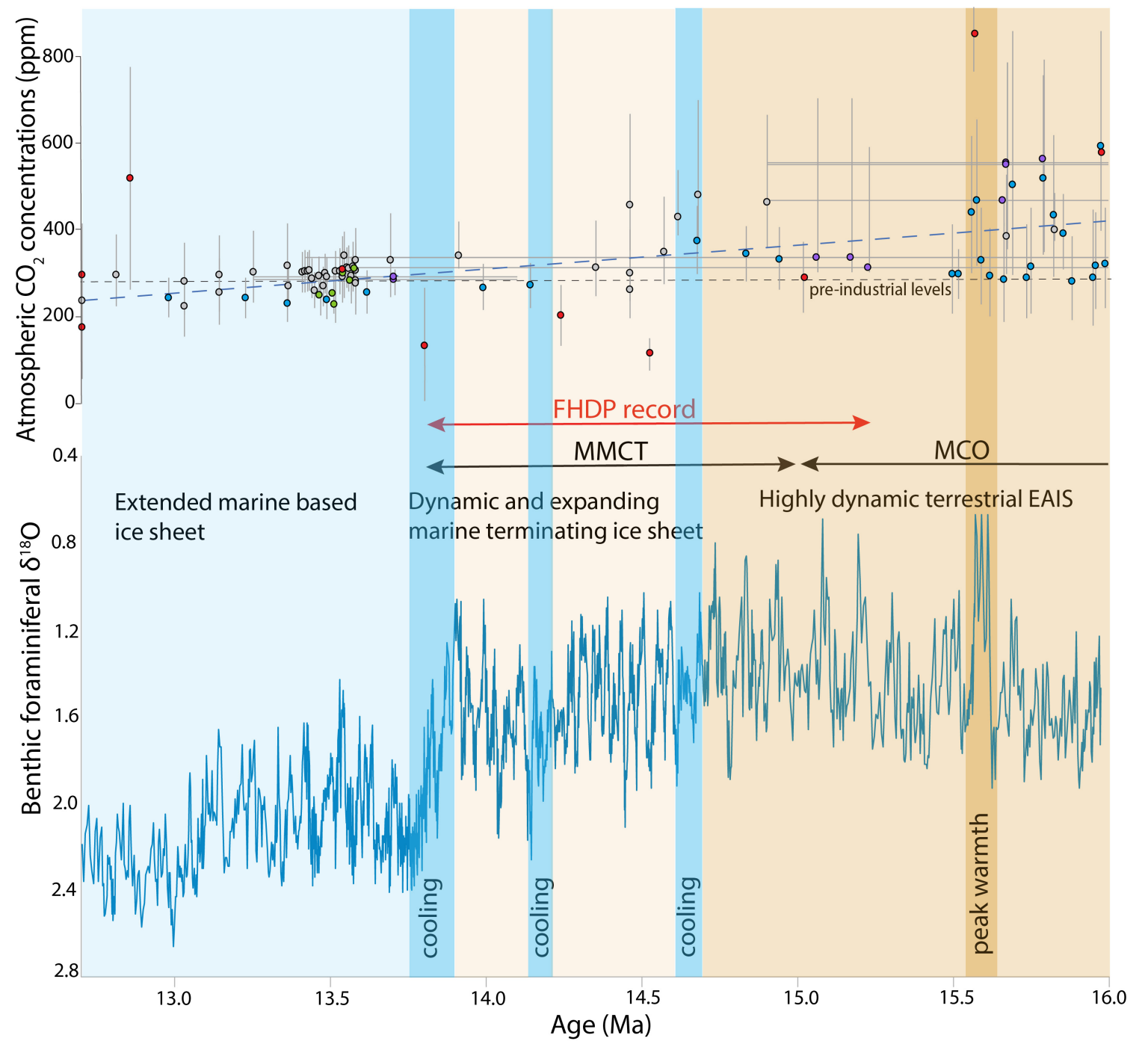

Fig. 3.1 Mid-Miocene atmospheric $\mathrm{CO}_{2}$ concentrations correlated to global sea level estimates and the benthic $\delta{ }^{18} \mathrm{O}$ record. $\mathrm{CO}_{2}$ data from paleosols (red: Cerling, 1992; Ekart et al., 1999; Retallack, 2009), phytoplankton (grey: Badger et al., 2013; Zhang et al., 2013; Super et al., 2018), boron isotopes (blue: Foster et al., 2012; Greenop et al., 2014), B/Ca (green: Badger et al., 2013), Stomata (purple: Royer et al., 2001 and Kurschner et al., 2008, updated by Beerling et al., 2009). Average change through time is marked by the blue dashed line an pre-industrial levels are $280 \mathrm{ppm}$. Oxygen isotope data from Holbourn and others (2014). $\mathrm{MCO}=$ Miocene Climate Transition, $\mathrm{MMCT}=$ mid-Miocene Climate Transition, FDHP = Friis Hills Drilling Project.

Miocene coastal environmental history in the Ross Sea region is captured in proximal glacimarine sedimentary records including CIROS-1 (Barrett et al., 1989), CRP-1 and 2/2A (Naish et al., 2001; Levy et al., 2012), ANDRILL-2A (Fielding et al., 2011; Passchier et 
al., 2011; Levy et al., 2016), DSDP Leg 28 (Kulhanek et al., 2019) and IODP 374 (McKay et al., 2019) and 379 (Gohl et al., 2019). These coastal records can be correlated with well-dated terrestrial deposits from the Olympus and Asgard Ranges, in the TAM, which include changes in both glacial dynamics, vegetation, and hydroclimate (Marchant et al., 1993; Lewis et al., 2007).

During the MCO, benthic foraminiferal oxygen isotope $\left(\delta^{18} \mathrm{O}\right)$ values vary between $\sim 0.67$ and $1.93 \%$ (Fig. 3.1) and suggest the AIS was at times 30\% (Liebrand et al., 2011; Holbourn et al., 2013) to 80\% (Shevenell et al., 2008; Lear et al., 2010; De Boer et al., 2010) smaller than today. These estimates are further corroborated by reconstructions of sea level, which indicate relative changes of up to $50 \mathrm{~m}$ (Miller et al., 2005; John et al., 2011). Geological proxy data indicate atmospheric $\mathrm{CO}_{2}$ concentrations varied between $300 \mathrm{ppm}$ and 600 ppm on glacial-interglacial (orbital) time scales during the MCO (Kürschner et al., 2008; Foster et al., 2012; Greenop et al., 2014), but may have reached values as high as 840 ppm (Retallack, 2009). These concentrations are smaller than those required by models to simulate a similar level of ice sheet retreat, indicative of a climate far more sensitive to changes in $\mathrm{CO}_{2}$ than present-day (Gasson et al., 2016). The East Antarctic Ice Sheet (EAIS) advanced and retreated through the TAM (Hauptvogel \& Passchier, 2012) during the MCO and did not advance beyond the coastline during interglacial episodes (Levy et al., 2016). Sediments collected at Site U1356, off-shore Wilkes Land sector of the EAIS, suggest deposition occurred in open-water conditions (Sangiorgi et al., 2018). The Wilkes Land Subglacial Basin (WLB) was likely subaerial during the early to mid-Miocene (Gasson et al., 2016; Paxman et al., 2019a) and evidence suggests that ice only rarely advanced into the marine setting, with a marine-based ice sheet developing post-MCO (Sangiorgi et al., 2018; Levy et al., 2019).

Global climate began to cool after 14.8 Ma (Flower \& Kennett, 1993; Böhme, 2003; Shevenell et al., 2008; Holbourn et al., 2014). Disconformities in the AND-2A record (Levy et al., 2016) and across the Ross Sea (De Santis et al., 1999), together with an increase in sea ice indicators (Sangiorgi et al., 2018), and major turnover in Southern Ocean diatom species (Crampton et al., 2016), suggest marine ice sheets advanced across the Ross Sea during glacial intervals for the first time since the onset of the MCO. An increase in glacial-interglacial amplitude in the $\delta^{18} \mathrm{O}$ record suggest the AIS expanded further during successively colder glacial phases. This interval of progressive glacial expansion culminated in a major step in the $\delta^{18} \mathrm{O}$ record (Fig. 3.1), that based on glacial geomorphic studies in the TAM, has been linked with a shift from temperate climate wet-based glaciation and a dynamic ice sheet to 
Antarctic Ice Sheet evolution and variability during the mid-Miocene Climate Transition

the polar dry glacial style and more stable ice sheet of present-day Antarctica (Marchant et al., 1993; Sugden \& Denton, 2004; Lewis \& Ashworth, 2015).

Mean atmospheric $\mathrm{CO}_{2}$ across the MMCT declined by $\sim 100$ ppm relative to pre- industrial levels (Langebroek et al., 2009; Foster et al., 2012; Badger et al., 2013; Zhang et al., 2013; Greenop et al., 2014). The MMCT is characterised by increasingly large glacial periods together with episodic expansion and retreat of the EAIS through the TAM outlet valleys and across the continental shelf (Levy et al., 2016). During this time, Southern Ocean sea surface temperatures cooled by $6-7^{\circ} \mathrm{C}$ (Holbourn et al., 2007), bottom water temperatures decreased by $6-7^{\circ} \mathrm{C}$ (Shevenell et al., 2008), summer temperatures in the TAM declined by $>8^{\circ} \mathrm{C}$ (Denton \& Sugden, 2005), and global sea level lowered by $\sim 60 \mathrm{~m}$ (John et al., 2011). ${ }^{40} \mathrm{Ar} /{ }^{39} \mathrm{Ar}$ dating of volcanic ashes in the Olympus Range of the Dry Valleys indicate extensive glaciation in TAM occurred between 13.94 and 13.62 Ma (Lewis et al., 2007). Ultimately, this shift led to the demise of remaining terrestrial plants in the Dry Valleys by $\sim 13.85 \mathrm{Ma}$, and potentially extinction across the entire continent (Lewis et al., 2006; 2008).

\subsection{Miocene terrestrial sediments in the Friis Hills}

Early to mid-Miocene terrestrial records in the Dry Valleys have been described from shallow surface pits above the permafrost and sporadic outcrops rather than continuous sequences, such as those in the coastal marine drill core records (e.g. Levy et al., 2016). Terrestrial records from the Olympus and Asgard Ranges (Fig. 3.2), also in the Dry Valleys, are indicative of the transition from wet-based to a cold polar style of glaciation across the MMCT (Lewis et al., 2006; Lewis et al., 2008). Thus far, evidence for relatively warm continental conditions and the presence of vegetation within the continental interior during the MCO are recorded at Mount Boreas in the Olympus Range (Lewis et al., 2008). A composite stratigraphy based on surface pits dug into sequences of glacial, glacio-fluvial, and glacio-lacustrine sediments in the Friis Hills reveal a terrestrial environmental record through the early to mid-Miocene (Lewis \& Ashworth, 2015). 

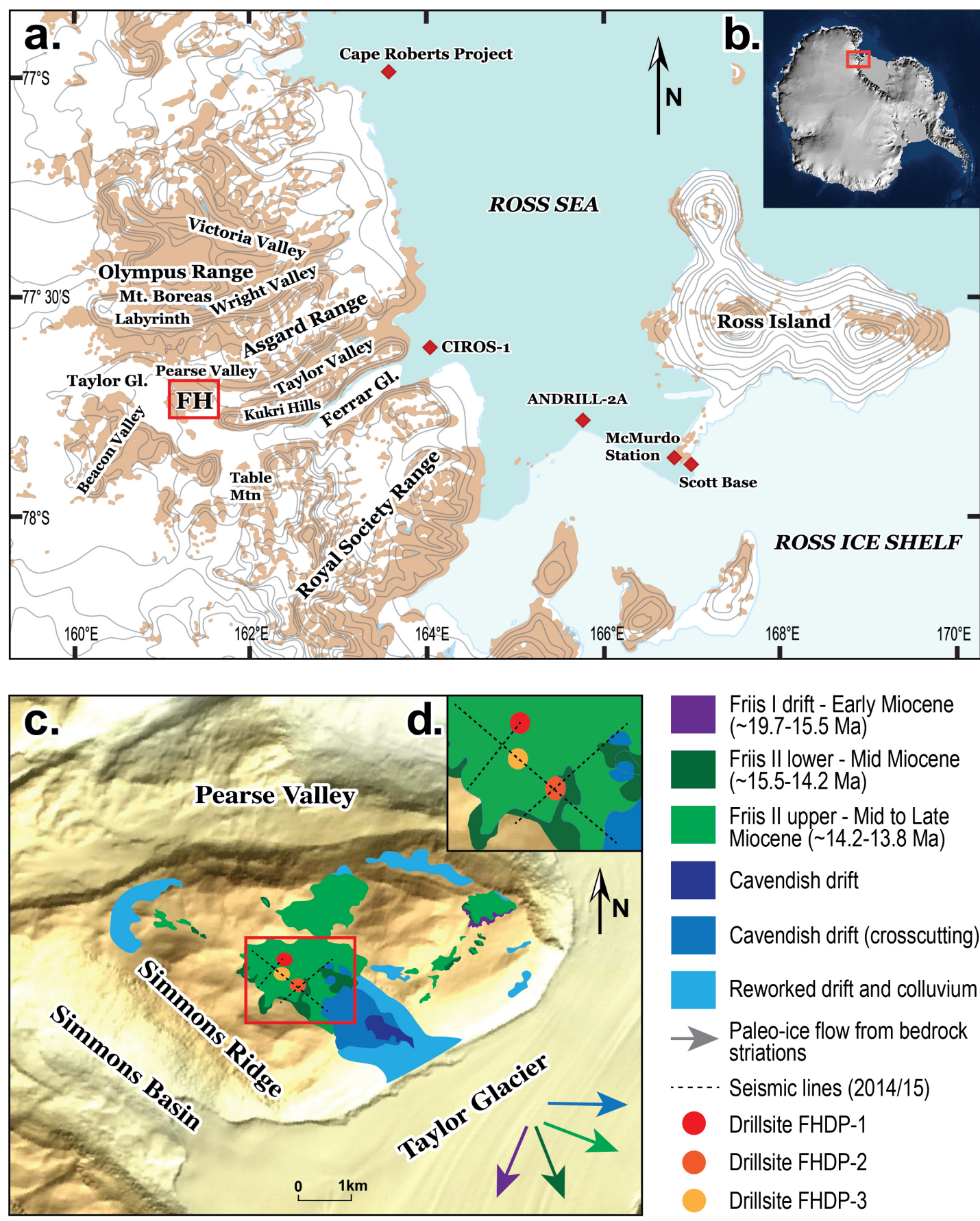

Friis I drift - Early Miocene ( 19.7-15.5 Ma)

Friis II lower - Mid Miocene $(\sim 15.5-14.2 \mathrm{Ma})$

Friis II upper - Mid to Late Miocene ( 14.2-13.8 Ma)

Cavendish drift Cavendish drift (crosscutting) Reworked drift and colluvium Paleo-ice flow from bedrock striations

-... Seismic lines (2014/15)

Drillsite FHDP-1

Drillsite FHDP-2

Drillsite FHDP-3

Fig. 3.2 Locations maps for (a) The Friis Hills (FH) and other locations discussed in the text red box is inset for figure c. (b) Friis Hills on a continent wide scale - red box indicates the area shown in figure a. (c) Surface drift deposits and paleo-ice flow over the Friis Hills as mapped by Lewis and Ashworth (2015) (d) Drill sites relative to seismic lines taken in the 2014/15 field season. 
Antarctic Ice Sheet evolution and variability during the mid-Miocene Climate Transition

The Friis Hills $\left(77^{\circ} 45^{\prime} \mathrm{S}, 161^{\circ} 3^{\prime} \mathrm{E} ; 3.2 \mathrm{a}, \mathrm{b}\right)$ are located at the head of the Taylor Valley, in the MDV, Southern Victoria Land, Antarctica. At an average elevation of 1325 metres (m) above sea level, the Friis Hills is an isolated inselberg up to $1100 \mathrm{~m}$ above the surrounding topography. Its unique position has allowed Neogene terrestrial glacio-fluvial and glaciolacustrine sediments to be preserved in basins and be protected from subsequent EAIS ice sheet expansions and overriding of the TAM during and after the MMCT. The glaciallymolded platform extends $8 \mathrm{~km}$ east to west and $4 \mathrm{~km}$ north to south with three rounded hills that rise 150-250 $\mathrm{m}$ above the surface (Lewis \& Ashworth, 2015). The elevation of this surface has been correlated on geomorphic observations with a bedrock platform on Solitary Rocks, $4 \mathrm{~km}$ to the south, and several benches in the Asgard Range to the north (Lewis \& Ashworth, 2015). Previous work by Lewis and Ashworth (2015) at the Friis Hills indicate a considerably warmer and wetter climate, characteristic of temperate alpine glacial environments during the early to mid-Miocene. Lewis and Ashworth (2015) identified three stratigraphic units: the Friis I, Friis II, and Cavendish drifts (summarised in Table 2.1).

The Friis I drift is restricted to the eastern most part of the Friis Hills and includes an upper and lower diamicton interpreted as subglacial (lodgement/traction) tills of up to 1.8 $\mathrm{m}$ thick, separated stratigraphically by an interval of interbedded fluvio-lacustrine muds, sands, gravels and a volcanic ash with a ${ }^{40} \mathrm{Ar} /{ }^{39} \mathrm{Ar}$ age of $19.76 \mathrm{Ma}$. Although no clear stratigraphic correlation could be established, the Friis I drift was assumed to be older than the Friis II drifts mapped to the west, by Lewis and Ashworth (2015). Generally, the drifts contain locally-derived faceted and striated clasts of dolerite, sandstone and granite overlying a polished and striated basement, providing evidence of southwest flowing ice across the region and representing an early alpine glacial phase. During this phase, locally derived wet-based, sub-polar glaciers flowed inland, away from the Ross Sea. There is no evidence for plant growth at the Friis Hills during the early Miocene (Lewis \& Ashworth, 2015).

Friis II drifts were interpreted as locally derived till sheets representing advance and retreat of wet-based temperate style glaciers flowing to the southeast (Friis II (lower) drift), and then transitioning to a more regionally expansive eastward directed glaciation (Friis II (upper) drift). Friis II drifts include multiple diamictons deposited over at least five episodes of glaciation with interbeds of well-sorted, fine grained interglacial fluvial and lacustrine deposits. Fossiliferous beds in Friis II (lower) drift record a rich biota, indicative of a Nothofagus shrub tundra in the Friis Hills during the absence of ice and MST of $\sim 6-7^{\circ} \mathrm{C}$ (Lewis \& Ashworth, 2015). During interglacials small fluvial systems linked retreated ice margins to small lakes separated by interfluves characterised by soils and peats. The observed 
decrease in fossiliferous sediments, weathering, and an increase in granite clasts upsection in the Friis II drift suggested a cooling in glacial regime and onset of more regional glaciation prior to the MMCT. Finally, a shift to non-fossiliferous granite-rich massive diamictons, lacking evidence of water-borne transport, recorded as the Cavendish drift along the southern margin of the Friis Hills, indicates development of the cold continental ice sheet overriding and downcutting in the TAM.

\subsection{This Study}

Previous work mapping the Friis Hills drifts (Lewis \& Ashworth, 2015) and their geomorphic expression suggested a more extensive stratigraphic record lay buried in the central portions of the Friis paleovalleys. Plans were developed to recover a more complete and continuous record through the Friis Hills sediments using a helicopter-transportable, permafrost-capable wireline diamond drill system (Fig. 3.4). A seismic refraction survey conducted in the austral summer of 2014-2015 revealed a low-velocity sequence up to $60 \mathrm{~m}$ thick in the central Friis Basin overlying significantly higher velocity, seismically-opaque material interpreted as basement (Fig. 3.3). In the austral summer of 2016-2017, sediment cores were collected from three locations in the Friis Hills, based on geometry of the basin elucidated in the seismic data (Figs. $3.2 \mathrm{c}, \mathrm{d}, 3.3$ ). These cores provide the first relatively continuous stratigraphic record (72\% recovery) through the succession, with an opportunity to improve age control and to evaluate and build on the stratigraphic, climatic, and glaciological evolution implied by Lewis and Ashworth (2015).

This chapter reports the sedimentologic and paleoenvironmental significance of cores recovered from three sites (Figs. $3.2 \mathrm{c}, \mathrm{d}, 3.3$ ). The cores reveal up to $50.4 \mathrm{~m}$ of cyclic fining-upwards facies successions comprising diamicton, sand and mud facies, bounded by glacial surfaces of erosion (GSE), recording regular oscillations from subglacial to fluvial-deltaic lacustrine environments. Numeric ages on two interbedded tephra within the magnetostratigraphic framework, provide new chronologic constraints that allow improved correlation with the mid-Miocene global climate records, such as the $\delta^{18} \mathrm{O}$ record, and the relationship to existing proximal marine records to be further explored. 
Antarctic Ice Sheet evolution and variability during the mid-Miocene Climate Transition

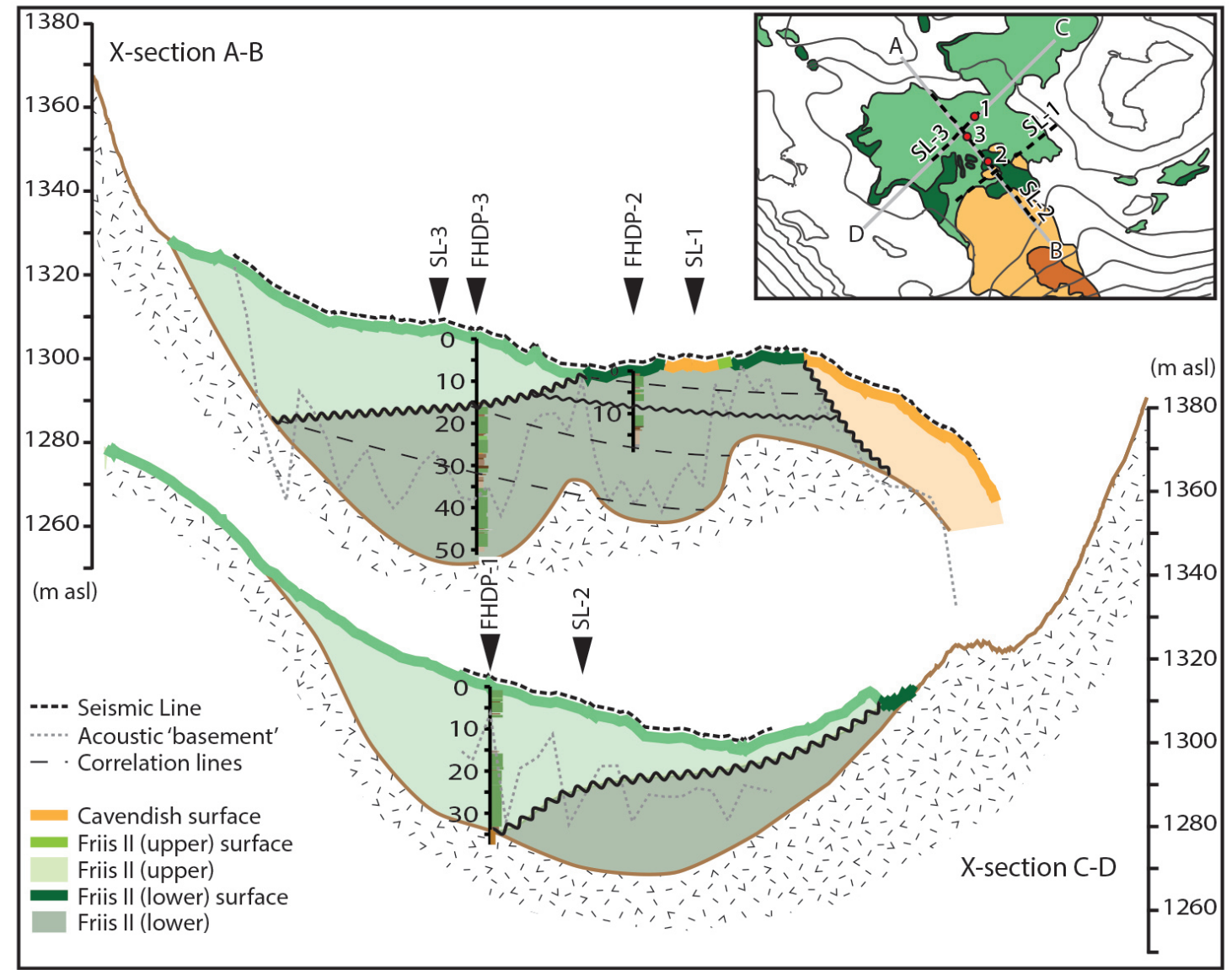

Fig. 3.3 Geological cross sections through the Friis Hills central basin. Depth to basement is based on seismic refraction (grey dashed line) and drill core data. Surface extent of the Friis Hills II (upper and lower) and Cavendish drift from Lewis and Ashworth (2015). Arrows indicate location of drill cores and seismic lines. Inset: Location of cross sections indicated by blue, red, and green lines, thicker lines indicate extent of seismic refraction survey lines 1 , 2 , and 3 .

\subsection{Tectonic setting and topographic evolution}

The present-day TAM is $3000 \mathrm{~km}$ long, and with peaks reaching $>4000 \mathrm{~m}$ high, is the highest uplifted continental rift-flank on Earth (Stern and ten Brink, 1989; Sugden \& Denton, 2004). The TAM formed in an extensional environment (Fitzgerald, 1992; Fitzgerald, 2002; Goodge et al., 2004), during three main episodes of rifting - the early Cretaceous, late Cretaceous, and early Cenozoic (Fitzgerald, 2002). Uplift initially began in the Cretaceous, most exhumation, based on fission-track data, took place after 55 Ma (Fitzgerald, 1992) due 
to glacial downcutting by outlet glaciers. Timing of the incision is unknown, although there is evidence from offshore drill cores that $2000 \mathrm{~m}$ of unroofing had occurred by the earliest Oligocene, thereafter, glacial incision and isostatic rebound caused $2000 \mathrm{~m}$ of subsequent uplift (Stern et al., 2005). However, the roles of thermal, erosional, tectonic and mantle-driven processes in driving TAM uplift remain poorly understood (Stern et al., 2005; Brenn et al., 2017; Paxman et al., 2019a).

Adjacent to the Ross Embayment, the TAM is characterised by a steep, high front, with the inland boundary submerged beneath the present-day EAIS (Marchant et al., 1993). Transverse valleys carry ice from the EAIS through outlet glaciers towards the coast, with the main transverse valleys in the Dry Valleys region the Taylor, Wright and Victoria valleys, separated by the Asgard and Olympus Ranges (Fig. 3.2). Lower Paleozoic igneous and metamorphic basement rocks are overlain by the Devonion to Triassic aged sandstones, siltstones and conglomerates that form the Beacon Supergroup, with Jurassic age Ferrar Dolerite intrusions and Cenozoic volcanics.

Early work (Behrendt \& Cooper, 1991; Denton et al., 1993; Webb et al., 1994; Sugden et al., 1995) suggested that these rising surface elevations could have played a key role in the changing ice sheet dynamics seen across the early to mid-Miocene, contributing to the shift in basal thermal character. There is, however, considerable uncertainty over uplift rates since the Miocene that limits current understanding of the role of tectonics on the evolution of the EAIS. Surface uplift estimates suggest less than $800 \mathrm{~m}$ since the MMCT (Wilch et al., 1993; Miller et al., 2010; Levy et al., 2012), with subaerial volcanic remnants at low altitudes indicating uplift of $>300 \mathrm{~m}$ since the late Miocene is highly unlikely (Wilch et al., 1993). However, rates of up to $100 \mathrm{~m} \mathrm{my}^{-1}$ have been inferred on the basis on fissiontrack thermochronology (Fitzgerald, 1992), which could place the Friis Hills considerably closer to sea level during the time of deposition of sediments discussed herein. More recent paleotopographic reconstructions using 3-D flexural modelling indicate that the removal of eroded material from the TAM and WLB alone has driven 600-900 $\mathrm{m}$ of uplift across the TAM since $34 \mathrm{Ma}$, and 100-300 m since the early Miocene (Stern et al., 2005; Paxman et al., 2019a).

The traditional view based on geomorphic studies (Denton et al., 1993; Sugden et al., 1995; Marchant et al., 1996; Sugden \& Denton, 2004; Lewis et al., 2008) implies landscape modification of the TAM from the Eocene/Oligocene transition, until approximately 15 $\mathrm{Ma}$, occurred due to warm-based glaciers and rivers in the Dry Valleys. By the end of the MMCT ( $\sim 13.8 \mathrm{Ma})$, a shift from a cool temperate to polar climate coincided with 
Antarctic Ice Sheet evolution and variability during the mid-Miocene Climate Transition

maximum overriding of the EAIS across the TAM, major outburst flood meltwater features (e.g. Labyrinth, Fig. 3.2 a) at high altitudes, and scoured coastal bedrock (Sugden \& Denton, 2004; Lewis et al., 2008). Since this time, the landscape across the Dry Valleys was considered to have remained relatively stable, with little erosion occurring under the hyper-arid polar climate of modern-day Antarctica. In-situ volcanic ash within surficial deposits in the Dry Valleys dated at 15.15 Ma (Marchant et al., 1996) were some of the first evidence to suggest this "old" landscape may have existed from mid-Miocene, and the unconsolidated Miocene terrestrial sediments were unlikely to have remained in-situ without considerably low rates of denudation. Overall, the geomorphic evidence has been used to suggest landscape evolution, including the development of some major troughs, within the Dry Valleys had largely reached its present form by the mid-Miocene, with the main forms of erosion both rivers and glaciers (Denton et al., 1993; Sugden et al., 1995).

Cenozoic volcanism is common both in and adjacent to the Dry Valleys region (Kyle, 1990), predominantly in the Royal Society Range and Taylor and Wright Valleys (Di Roberto et al., 2012). Mount Morning is the oldest volcanic complex within the Erebus volcanic province in Southern Victoria Land (Di Roberto et al., 2012), with Phase I activity occurring 18.7-11.4 Ma. Most deposits vary from Miocene to Pliocene in age, with ${ }^{40} \mathrm{Ar} /{ }^{39} \mathrm{Ar}$ ages ranging between 15.15-4.33 Ma. Along with limited evidence for volcanic activity in the AND-2A core between 17.1-11.5 Ma (Di Roberto et al., 2012), Martin and others (2010) have dated Miocene volcanic deposits at Gandalf Ridge $(18.7 \pm 0.3$ and $15.5 \pm 0.5 \mathrm{Ma})$, Pinnacle Valley $(15.4 \pm 0.1$ and $13.0 \pm 0.3 \mathrm{Ma})$, and Mason Spur (12.9 \pm 0.1 and $11.4 \pm 0.2$ Ma).

${ }^{40} \mathrm{Ar} /{ }^{39} \mathrm{Ar}$ dating of a widespread $35 \mathrm{~cm}$ thick tephra deposit in the Eastern Friis Hills revealed an age of 19.76 $\pm 0.11 \mathrm{Ma}$ (Lewis and Ashworth, 2015) which thus far, is the oldest reported volcanic ash deposited in a terrestrial setting along the Victoria Land sector of the TAM. The in-situ occurrence of this tephra indicates, at the very least, this region of the Friis Hills was ice-free during the early Miocene (Lewis \& Ashworth, 2015). A study of meteoric cosmogenic nuclid, beryllium-10 in the Friis Hills surficial sediments revealed that ancient terrestrial lake sediments were deposited between 17.5-14 Ma and have been isolated from meteoric water since this time (Valletta et al., 2015). 


\subsection{Present day climate}

The MDV region, with a combined area of over $4800 \mathrm{~km}^{2}$ is classified a severe polar desert, constitutes the largest ice-free area in Antarctica. The Friis Hills is subject to subfreezing temperatures, low precipitation, and strong winds throughout the year. The present-day EAIS flows towards the Ross Sea via the Taylor and Ferrar glaciers. Taylor Valley is $900-1100 \mathrm{~m}$ below the Friis Hills.

Annual temperature and precipitation records in the Dry Valleys date back to the mid1980s, however these records are predominately located in the valleys and coastal regions (Parish \& Bromwhich, 1987; Fountain et al., 1999; Doran et al., 2002). Meterological observations in the Friis Hills were recorded from 2005 to 2010 (Bliss et al., 2011). During this 5-year period, MSTs were $-13.2^{\circ} \mathrm{C}$ with average wind speeds of $4.7 \mathrm{~ms}^{-1}$. Winter mean temperatures were considerably lower, at $-29.7^{\circ} \mathrm{C}$, with a lower average wind speed of 4.2 $\mathrm{ms}^{-1}$ (Bliss et al., 2011). The valleys run transverse to the major katabatic winds from the Ross Ice Shelf (Parish \& Bromwich 1987), and steep sided valleys result in strong localised glacier drainage winds (Doran et al., 2002). Lake Fryxell, at the foot of the Taylor Valley, has some of the highest recorded wind speeds in the region, reaching $37.8 \mathrm{~m} / \mathrm{s}$ during a katabatic event (Doran et al., 2002).

Precipitation rates at Lake Bonney are $<15 \mathrm{~cm} /$ year (Fountain et al., 1999), however since the Friis Hills are at higher elevations and further inland, it is likely that precipitation in the hills is less than this (Doran et al., 2002). While mean annual temperature is strongly controlled by altitude under normal alpine conditions, the driving force on temperature locally within the Dry Valleys is exposure to the warming effect of the katabatic winds. This influence can result in temperature variations of $30^{\circ} \mathrm{C}$ in the Taylor Valley during winter months (Doran et al., 2002). Low precipitation, low surface albedo, and the warm, dry katabatic winds from the Polar Plateau result in the extremely arid conditions in the modern-day Dry Valleys. 
Antarctic Ice Sheet evolution and variability during the mid-Miocene Climate Transition

\subsection{Methods}

\subsubsection{Drilling}

Three sites (Figs. $3.2 \mathrm{c}, \mathrm{d}, 3.3$ ) were drilled to a maximum depth of $50.48 \mathrm{~m}$ during the austral summer season of 2016/17, using a bespoke air chilled and flushed wire-line diamond drill system (Fig. 3.4 b-d). Drill sites were located based on previous mapping (Lewis \& Ashworth, 2015, summarised in Table 2.1), and the seismic refraction survey. Drilling objectives were to sample the deepest part of the basin and recover continuous sections through the Friis Hills II drifts (Fig. 3.3).

Sites were numbered Friis Hills Drilling Project (FHDP) 1, 2, and 3, with the suffixes $\mathrm{A}, \mathrm{B}$, and $\mathrm{C}$ used where more than one hole was drilled at a site. A total of $73.26 \mathrm{~m}$ of permafrost (ice-cemented) sediment was recovered, with an average recovery rate of $71.9 \%$. Core $2 \mathrm{~A}$ had the highest recovery at $75.9 \%$, with cores $1 \mathrm{~A}$ and $3 \mathrm{~A}$ both recovering $70.2 \%$. Site 1 was located to recover core from what was initially inferred to be the thickest part of the basin based on seismic refraction data. However, basement was intersected at $33.5 \mathrm{~m}$. Site 2 was selected to core into known outcrop of Friis II (lower) drift, to ensure recovery of this fossil-rich sequence. Site 3 was located near the intersection of seismic lines 2 and 3 to enhance stratigraphic correlation between each site and attempt to recover Friis I drift and intersect basement, which was not reached, and this hole was terminated due to technical difficulties. Core was unable to be recovered between 7.3 to $15.1 \mathrm{~m}$ at FHDP-1A and from the surface down to $15.02 \mathrm{~m}$ in FHDP-3A, due to a lack of ice cement. For these intervals, cuttings were sampled every $50 \mathrm{~cm}$. 
a.

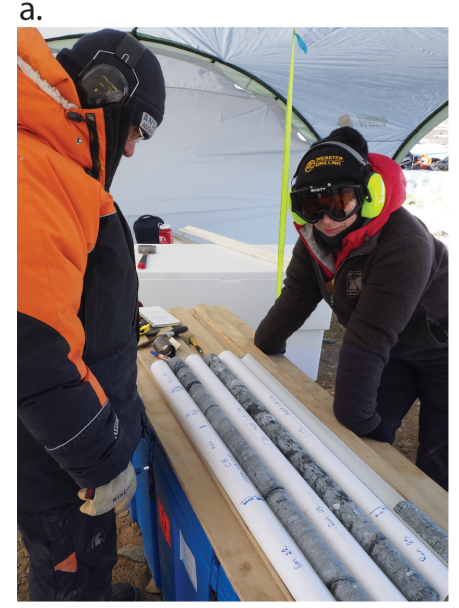

C.

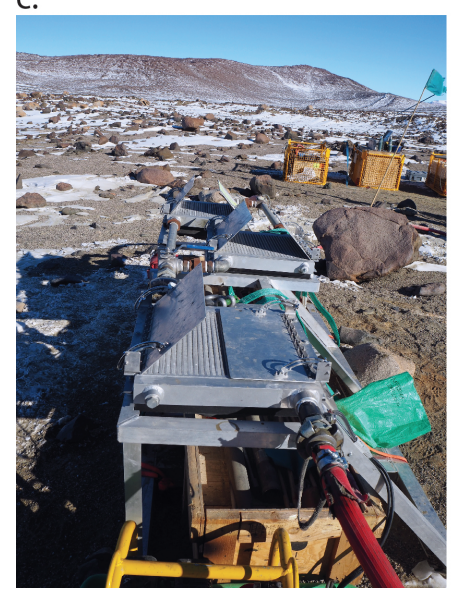

b.

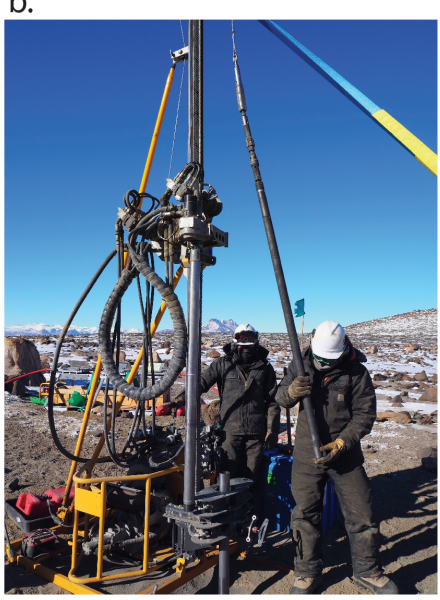

d.

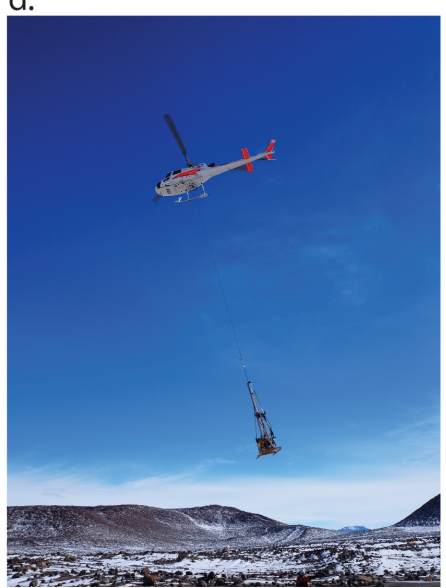

Fig. 3.4 Photos of 2016-17 field season. (a) Logging of the cores, (b) Drill rig and core retrieval process, (c) Electric fan cooling system, (d) Shifting of the drill rig by helicopter between drill sites.

\subsubsection{Core description and sampling}

Initial visual lithological descriptions were undertaken in the field (Fig. 3.4 a), with descriptions cross-checked and, in some cases, subsequently modified following re-description of the core prior to sampling at the National Ice Core Facility at GNS Science. Lithological descriptions for fine-grained and poorly-sorted terrigenous sediments were based on definitions established for the Cape Roberts Project and ANDRILL Programme (Hambrey et al., 1997; Naish et al., 2008; McKay et al., 2009) and terrestrial glacial environments (e.g Walker \& James, 1992; Benn \& Evans, 2010; van der Meer \& Menzies, 2011). A preliminary lithofacies scheme was defined based on the identification of lithology, sedimentary structure and texture, clast abundance, composition and density, deformation features, fossil 
Antarctic Ice Sheet evolution and variability during the mid-Miocene Climate Transition

content, colour, and nature of contact with underlying beds. Cores were shipped to and are currently stored at the National Ice Core Facility in polyethylene bags and thermally insulated core boxes at $-28^{\circ} \mathrm{C}$. A total of 168 samples were taken from the cores, at regular one metre intervals through diamictons and at higher resolution through the thinner and more variable lacustrine and fluvial deposits (see Appendix A). Samples were taken using a 2.2 $\mathrm{mm}$ diamond blade tile cutter. Samples were thawed, weighed, centrifuged to separate water (for ground ice analysis) and dried for $48-72$ hours at $85^{\circ} \mathrm{C}$ to meet Ministry for Primary Industries standards for the release of biosecurity risk samples from quarantine. A munsell colour was assigned to each of the thawed and dried samples prior to further analysis to investigate changes throughout the cores (Appendix A). Each sample was divided into an archival sample that remains frozen in the core tube and thawed subsamples for analysis of grainsize, XRF, lipid biomarkers, diatoms, and pollen.

\subsubsection{Grainsize analysis and clast counts}

Grain size analysis was carried out on all 168 samples and was measured on an Aqueous Liquid Module of the Beckman-Coulter LS 13320 Laser Diffraction Particle Size Analyser to provide quantitative data to support visual core descriptions. An $\sim 5 \mathrm{~cm}^{3}$ sub-sample was crushed using wooden blocks to remove aggregates produced during the drying process, and then passed through a $2 \mathrm{~mm}$ sieve and split into 3 subsamples of $\sim 0.1-1 \mathrm{~g}$ depending on lithology, with less material required for mud-rich and finer samples. Samples were treated with $\sim 10 \mathrm{ml}$ of $27 \%$ hydrogen peroxide at $70^{\circ} \mathrm{C}$ to remove organic material and centrifuged and washed three times for 10 minutes each with $\sim 40-45 \mathrm{ml} \mathrm{DI} \mathrm{H}_{2} \mathrm{O}$. Samples were examined under a microscope to check for carbonate and biogenic silica and treatment for the removal of these was deemed unnecessary given such low concentrations. All samples were then disaggregated by adding $50 \mathrm{ml}$ of $1 \mathrm{~g} / \mathrm{L}$ calgon and leaving in an ultrasonic bath for 30 minutes. Samples were then analysed using the LS 13320 Laser Diffraction Particle Size Analyser (LPS) at Victoria University of Wellington (VUW). 10\% of samples were measured three times to check the reproducibility of the results and consistency of process (reported in Appendix B). An LPS standard of $68 \mu \mathrm{m}$ glass beads were also run prior to each round of analysis to check for reproducibility. The GRADISTAT package developed by Blott and Pye, (2001) was used to further analyse results produced by the LPS. Grain size parameters were defined as clay $(<8 \mu \mathrm{m})$, silt $(8-63 \mu \mathrm{m})$, and sand $(63-2000 \mu \mathrm{m})$. Gravel $(>2 \mathrm{~mm})$ clasts exposed on the core surface were counted and summed every $10 \mathrm{~cm}$ interval along the core to quantify gravel content. These data can provide a measure of glacial proximity (e.g. Fielding 
et al., 2000; Naish et al., 2001). Grain size data and clast counts are reported in Appendix B and $\mathrm{C}$ respectively.

\subsubsection{Core physical and chemical properties measurements}

Along-core elemental abundances were measured using a handheld M-series Vanta Olympus portable X-Ray Fluorescence (XRF) spectrometer (50 KV) at VUW. Samples were calibrated at the start and end of each sample run using international standards from the USGS and Geological Survey of Japan and raw data were corrected using the international XRF calibration standard (reported in Appendix D). $\sim 1-2 \mathrm{~g}$ of each sample was crushed to provide homogenous material for measurements. Measurements were taken using two built in methods: Soil and Geochem. The Soil method used three beams at 15, 40, and $50 \mathrm{kv}$ to measure heavier elements (e.g. Ba and Sr). The Geochem method used beams at 10 and 40 $\mathrm{kv}$ to measure lighter elements (e.g. $\mathrm{Ca}, \mathrm{Si}, \mathrm{Al}$ ). Some elements were captured by both of these methods in this case, the most appropriate method is the data presented in Appendix A. For example, Ca recorded in higher concentrations is more accurately measured using the Geochem method, whereas lower concentrations are more accurately measured by the Soil method.

High-resolution three-dimensional images of the cores were collected at Pacific Radiology, Boulcott Hospital, Lower Hutt using X-Ray computed tomography (CT) conducted on a GE BrightSpeed medical CT scanner set to $120 \mathrm{kV}, 250 \mathrm{~mA}$, pitch of $0.625 \mathrm{~mm}$ and a $100 \mathrm{~cm}^{2}$ window. These data were used for detailed examination of sedimentary structures, textures, deformation features and lithologies.

\subsubsection{Diatoms}

A subset of 133 samples, to include at least one from each sedimentary facies, were examined for diatom content. 52 samples from fluvial-lacustrine facies were examined in detail. Samples were immersed in hydrogen peroxide to remove organic matter. Biogenic silica was concentrated by flotation in Sodium Polytungstate (specific gravity $2.20 \mathrm{~g} \mathrm{~cm}^{2}$ ). Material separates were rinsed and mounted on permanent slides for light microscopy using Naphrax ${ }^{\circledR}$ mountant (refractive index 1.65). Assemblage composition for each sample was determined by counting diatoms under a Leitz Diaplan differential interference contrast microscope at x400 magnification. At least 90 (usually 200) whole and significant fragments of diatom 
Antarctic Ice Sheet evolution and variability during the mid-Miocene Climate Transition

valves (including ends or centres of valves) were identified to genus level in each sample. Down core variability in prevalent diatom species is shown in Appendix E.

\subsubsection{Palynology}

Nineteen samples were collected from mudstone and sandstone intervals for palynological study. These samples were processed at GNS Science using standard palynological methods: $10 \%$ cold $\mathrm{HCl}$ wash, $50 \% \mathrm{HF}$, a further $10 \% \mathrm{HCl}$, a brief 20-60 second disaggregation in an ultrasonic bath, followed by filter through a $6 \mu \mathrm{m}$ mesh. A single Lycopodium tablet (batch 1031) was added to each sample at the start of processing, to enable calculation of absolute palynomorph abundance. Organic residues were mounted on two $\mathrm{cm}$ square glass cover slips in glycerin jelly. A complete scan of the cover slip was made for each sample using a Zeiss Axioplan2 light microscope. Results are reported in Appendix F. The coarse fraction ( $>90)$ remaining from diatom sample preparation were used to assess organic microfossil remains in FHDP samples, the down core variability in prevalent plant genera is shown in Appendix G.

\subsubsection{Carbon analysis}

Organic carbon concentrations within samples was determined using an Elemental VarioEl Cube instrument (Jan Veizer Laboratory, University of Ottawa). To prepare the samples, they were first acidified with $10 \% \mathrm{HCl}$ to remove inorganic carbon and isolate the organic carbon fraction. $100 \mathrm{mg}$ of material was measured, along with $100 \mathrm{mg}$ of tungstic oxide $\left(\mathrm{WO}_{2}\right)$, a combustion catalyst and a binder. Calibrated standards of Sulfanilic Acid were prepared in a range of weights and ran to ensure instrument precision while blind standards were run for calibration. $20 \%$ of samples were ran as duplicates to ensure of the reproducibility of results. The capsules were flash combusted at $1800^{\circ} \mathrm{C}$ with the addition of oxygen. The resulting gases were carried through the columns of reducing and oxidising chemical to obtain $\mathrm{N}_{2}$, $\mathrm{CO}_{2}, \mathrm{H}_{2} \mathrm{O}$ and $\mathrm{SO}_{2}$. Gases were then separated by the trap and purge method and measured with a thermoconductivity detector. The analytical precision for the analysis was $\pm 0.1 \%$. Results are reported in Appendix A. 


\subsubsection{Tephra characterisation and numeric dating}

Tephra deposits in the cores were identified during visual core description and McMurdo Volcanic Group origin was confirmed via preliminary XRF analysis of the cores, which identified intervals of relatively high Niobium (Roser \& Pyne 1989). Two tephra deposits were found at $5.6 \mathrm{~m}$ in cores $2 \mathrm{~A} / \mathrm{C}$ and $27 \mathrm{~m}$ in core $3 \mathrm{~A}$. The tephra horizon in core $2 \mathrm{C}$ comprised a yellow/light grey, mm-scale, cross-bedded fine sandstone with volcaniclastic material and dispersed clasts, while the horizon in $3 \mathrm{~A}$ was a grey/brown massive mudstone with volcaniclastic grains and dispersed clast and pebble lenses.

Glass shards from each tephra horizon were extracted and analysed for their major element composition at VUW on a JEOL JXA 8230 Superprobe (EMPA), for chemical characterisation, including population homogeneity. A beam size of $10 \mu \mathrm{m}$ at $8 \mathrm{nA}$ was used to analyse major elements as oxides, whose concentrations were calculated using the ZAF correction method. Matrix matched standards VG-568 and VG-A99 were used as bracketing standards and run three times between every sample, with VG-568 used as the normalisation standard and VG-A99 run as the secondary standard. Accuracy of the analyses was within $\leq$ $4.6 \%$ of the recommended values for the VG-A99 except for $\mathrm{TiO}_{2}(13.6 \%), \mathrm{MnO}(30.1 \%)$ and $\mathrm{Cl}(11.5 \%)$, precision for all the elements was $\leq 0.76$ (2sd). Analytical totals were between 93-100 wt $\%$ with the deviations from $100 \%$ attributed to variable degrees of post eruption hydration, these deviations were corrected to $100 \%$ and are reported in Appendix $\mathrm{H}$.

Two samples were prepared for radiometric dating. Each sample was disaggregated in water and wet-sieved at $63 \mu \mathrm{m}$. After disaggregation and dry sieving at $150 \mu \mathrm{m}$, feldspars were concentrated with heavy liquids, to isolate the $2.55-2.65 \mathrm{~g} / \mathrm{cc}$, and hand-picked under a binocular microscope for clarity and absence of visible inclusions. Samples were coirradiated with Fish Canyon sanidine monitor standard in two separate batches (irradiations USGS78 and USGS90), each with an 8-hour duration, with Cd-shielding and rotation in the USGS TRIGA Reactor. The second batch was irradiated because of the inadequate precision for distinguishing the ages of the two samples in the first. An analytical delay required us to omit the use of the ${ }^{37} \mathrm{Ar}$ for nuclear interference corrections on the second batch, so a fixed K/Ca with a large uncertainty was used. The magnitude of this correction is small for sanidine, allowing the good age precision using this approach to be retained. To further minimise the impact of the nuclear interference corrections and to filter out measurements with large uncertainties, the analyses were filtered to exclude samples with $<80 \%$ radiogenic ${ }^{40}$ Ar before plotting. 
Antarctic Ice Sheet evolution and variability during the mid-Miocene Climate Transition

Irradiated samples from irradiation USGS90 were analysed using the fully automated LDEO-AGES Isotopx NGX multiple collector mass spectrometer. Individual crystals were fused using a Teledyne 70 Watt $\mathrm{CO}_{2}$ laser at $15 \%$ power and gases released from the heating of samples were scrubbed of reactive gases by exposure to $\mathrm{Zr}$-Al sintered metal alloy getters. Isotopic ratios were determined using Pychron, an open source software package led by developer Jake Ross (New Mexico Tech). Measurements were made in multiple-collector mode with ${ }^{40} \mathrm{Ar},{ }^{39} \mathrm{Ar},{ }^{38} \mathrm{Ar}$, and ${ }^{37} \mathrm{Ar}$ on faraday detectors outfitted with ATONA amplifiers (Cox et al., 2020), and ${ }^{36} \mathrm{Ar}$ in ion counting mode on a secondary electron multiplier. At these conditions, the ${ }^{40} \mathrm{Ar}$ signal was approximately $455 \mathrm{mV}$ for $8.5 \times 10^{-13}$ moles of atmospheric Ar.

In all cases, ${ }^{40} \mathrm{Ar} /{ }^{39} \mathrm{Ar}$ data were corrected for backgrounds, mass discrimination and nuclear interferences (except for the NGX analyses, a correction for Ca interference was not made because it was more than a year between irradiation and analysis). Background and mass discrimination corrections were based on time series of blanks and air pipettes (respectively) run throughout the interval of the analyses (isotopic abundance of atmospheric Ar are from Lee et al., 2006). The nuclear interference corrections were based on production ratios from Dalrymple and others (1981). Individual dates are reported with $\pm 1 \sigma$ analytical uncertainties relative to Fish Canyon monitor age of 28.201 (Kuiper et al., 2008) and using the decay constants of Min and others (2000). J-values were calculated from Fish Canyon sanidine monitor co-irradiated in the same irradiation pit as the unknowns and other monitor standards.

\subsubsection{Paleomagnetic stratigraphy}

A total of 72 discrete samples (48 from 3A, 14 from 2A, 10 from $1 \mathrm{~A}$ ), ranging in volume between 4 and $8 \mathrm{~cm}^{3}$, were cut from frozen core sections for paleomagnetic analysis. Samples were oriented only with respect to the up direction because cores are not azimuthally oriented. In polar regions the geomagnetic field has a steep inclination, which was $83^{\circ}$ at the drill sites $\left(77^{\circ} \mathrm{S}\right)$, enabling identification of polarity in the absence of declination. Fine-grained intervals were targeted for sampling and regions around clasts in diamicton-dominated lithofacies were avoided due to the potential for post and syn-depositional realignment of the magnetic fabric.

Frozen samples were transported to the Otago Paleomagnetic Research Facility, where they were stored in a sample freezer at $-25^{\circ} \mathrm{C}$. Magnetic moment measurements were made 
using the 2G Enterprises DC 760-3.5 pass-through superconducting rock magnetometer housed in a $150 \mathrm{nT}$ magnetically shielded laboratory. All samples were demagnetised in an alternating field increasing in $5 \mathrm{mT}$ increments to $50 \mathrm{mT}$ and then at $60 \mathrm{mT}, 70 \mathrm{mT}, 80 \mathrm{mT}$ and $100 \mathrm{mT}$. Isothermal Remanence Magnetisation (IRM), hysteresis, loops and First-Order Reversal Curve (FORC) (Roberts et al., 2014) analyses were performed to characterise the remanence-carrying mineralogy on $\sim 0.10 \mathrm{~g}$ crushed samples using a Princeton Measurements Corporation Vibrating Sample Magnetometer (MicroMag 3900). FORCs were measured with a field spacing of $2 \mathrm{mT}$, an interaction field $(\mathrm{Hu})$ ranging between $-60 \mathrm{mT}$ to $+60 \mathrm{mT}$, and coercivity field (Hc) between $0 \mathrm{mT}$ to $100 \mathrm{mT}$. The FORCinel software package (Harrison \& Feinberg, 2008) was used to process data and smoothing factors of between 3 and 5 (Roberts et al., 2000) were used. Orthogonal component vector plots of the paleomagnetic data were produced, and paleomagnetic directions calculated by principal component analysis (PCA) (Kirschvink, 1980), using the PuffinPlot software package (Lurcock \& Wilson, 2012).

\subsection{Facies analysis and sequence stratigraphy}

Fifteen terrestrial glacially influenced sedimentary cycles have been identified in the FHDP cores (Figs. 3.5-3.7). The cycles are defined as vertically stacked repetitive facies successions identified by lithologic core descriptions, grain-size analyses, and fossil content. Each sedimentary cycle is bounded at its base by a GSE, associated with advance of a landterminating alpine glacier system. The vertical occurrence of the facies within cycles are shown for each drillsite in Figs. 3.5, 3.6, and 3.7 and in detail for Cycle 5 from Core FHDP3A (Fig. 3.20). A 3-dimensional (3D) visualisation of the changing glacial and depositional setting during a cycle of glacial advance and retreat is shown in Fig. 3.21.

Typically, cycles fine-upwards from diamictons and breccia, to sandstone and mudstone representing retreat along the Friis Hills paleo-valley. Subglacial environments at the drill sites transition to a pro-glacial fluvio-lacustrine setting during warming intervals of deglaciation. Coarse-grained lithologies were deposited in subglacial and grounding zone proximal environments, while sandstones and mudstones represent fluvial-deltaic and lacustrine deposition under progressively lower energy depositional conditions. The tops of some cycles coarsen as glacier terminus proximal and fluvio-deltaic sediments prograde over lacustrine facies during subsequent re-advance of the glacier forming the next GSE. Proglacial facies immediately underlying GSEs and subglacial facies above GSEs display a range of ductile, and brittle deformation features, discussed below. Table 3.1 summarises the nine recurring 
Antarctic Ice Sheet evolution and variability during the mid-Miocene Climate Transition 78 ( 15.1-13.8 Ma), from the Friis Hills, Antarctica

facies, their characteristics and their interpretation along a depositional continuum from subglacial ice-proximal to proglacial and distal lacustrine environments.

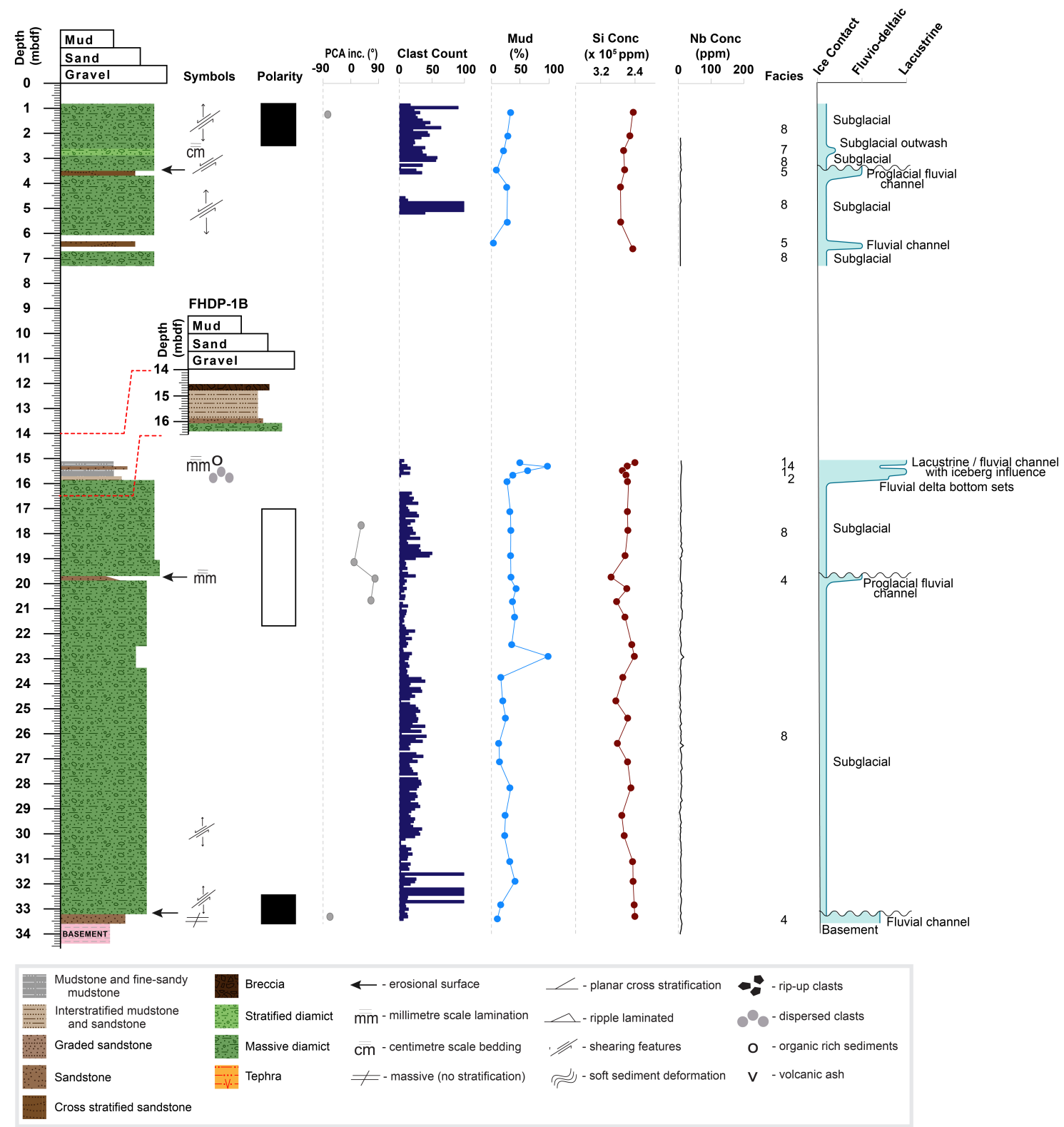

Fig. 3.5 Composite log of the FHDP-1A and -1B core, showing from left to right, lithostratigraphy, paleomagnetic stratigraphy, sedimentology, geochemistry, and facies interpretation. Facies numbers are given in Table 3.1. Glacial surfaces of erosion define sequence boundaries. The glacial proximity curve (ice contact to lacustrine) was determined using models discussed in Figure 3.20. 


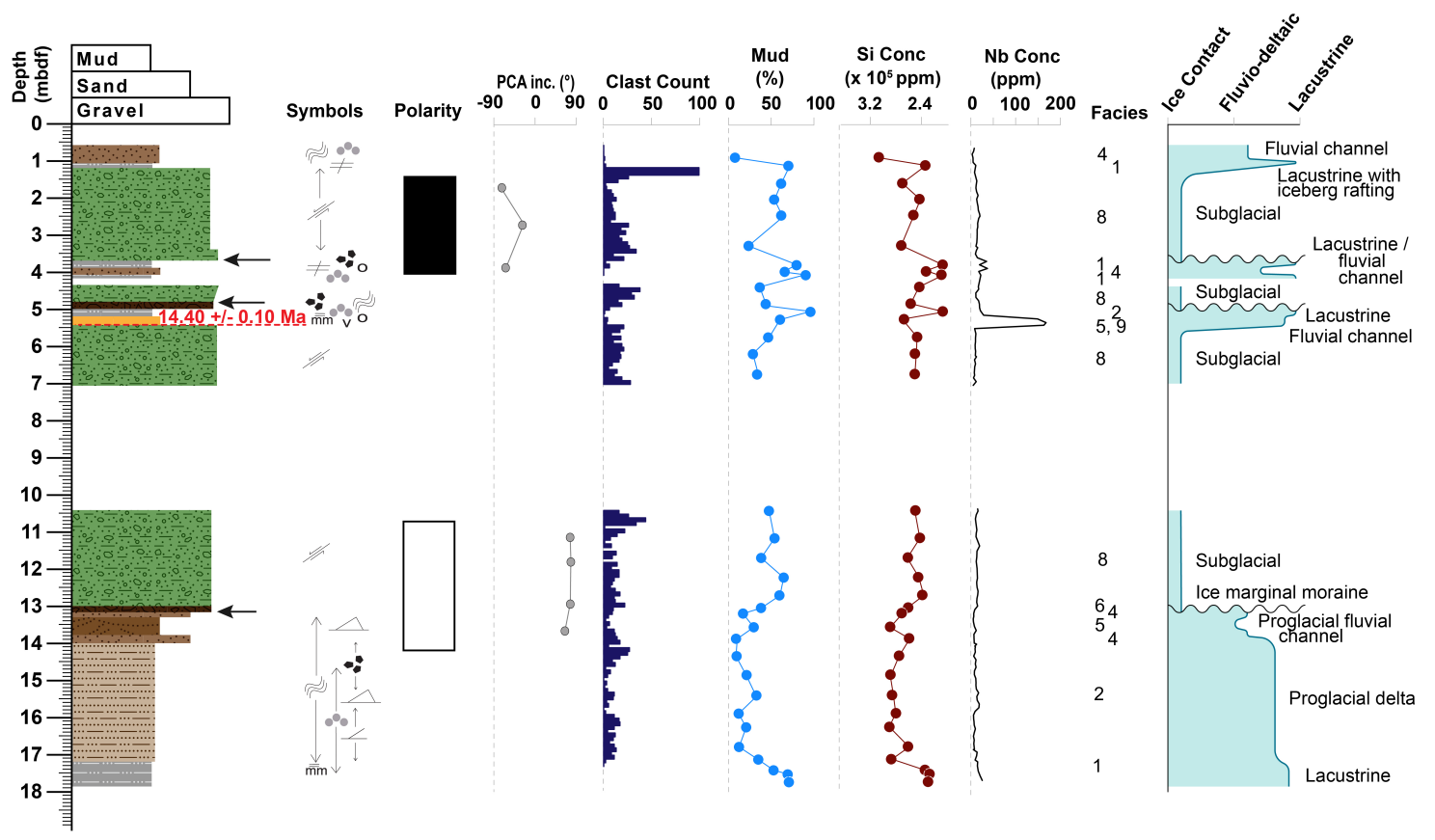

Fig. 3.6 Composite log of the FHDP-2A core, showing from left to right, lithostratigraphy, paleomagnetic stratigraphy, sedimentology, geochemistry, and facies interpretation. Facies numbers are given in Table 3.1. Key to symbols and lithologies is provided in Figure 3.5. Glacial surfaces of erosion define sequence boundaries. The glacial proximity curve (ice contact to lacustrine) was determined using models discussed in Figure 3.20. 
Antarctic Ice Sheet evolution and variability during the mid-Miocene Climate Transition

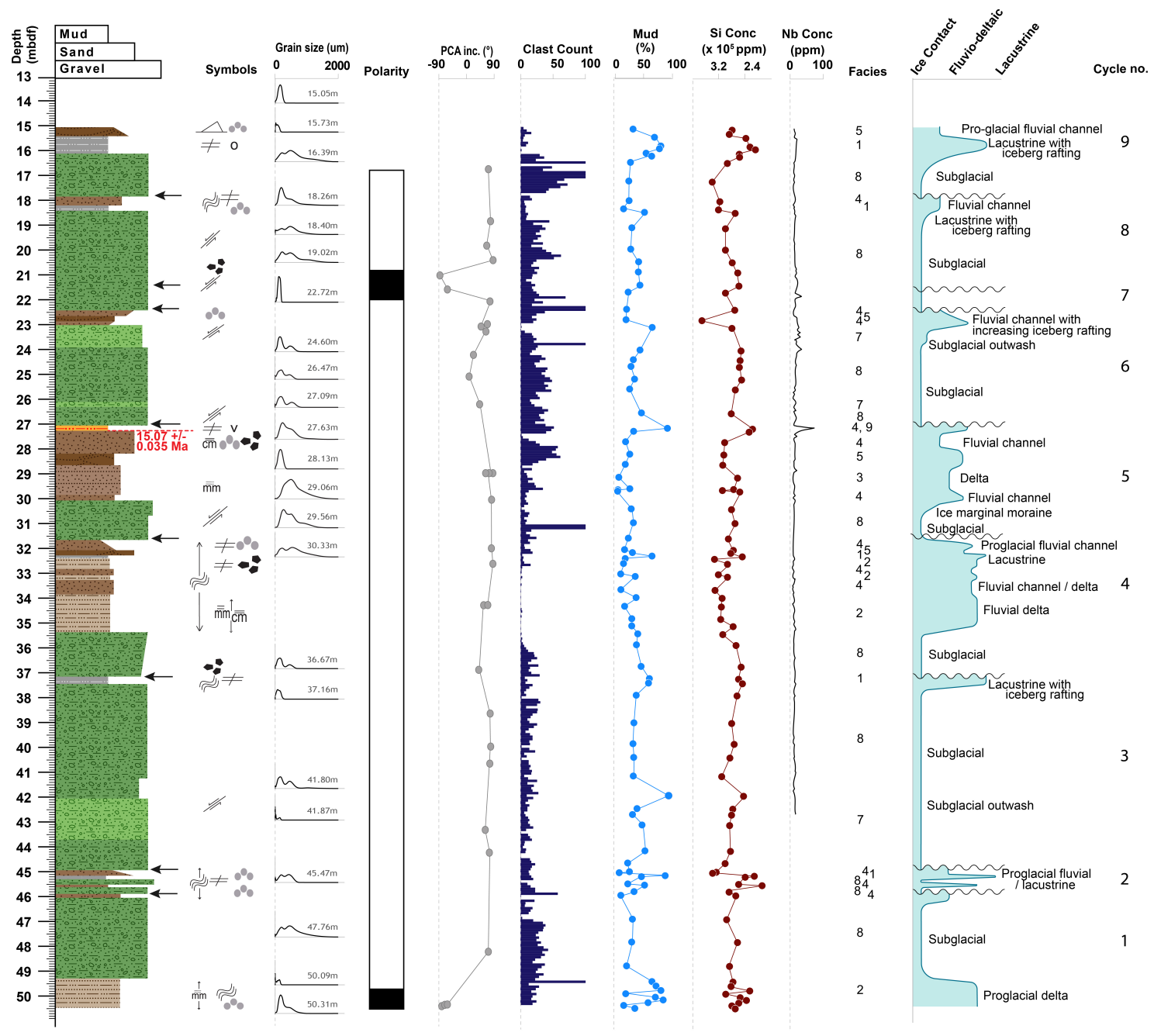

Fig. 3.7 Composite log of the FHDP-3A core, showing from left to right, lithostratigraphy, paleomagnetic stratigraphy, sedimentology, geochemistry, and facies interpretation. Key to symbols and lithologies is provided in Figure 3.5. Facies numbers are given in Table 3.1. Glacial surfaces of erosion define sequence boundaries. The glacial proximity curve (ice contact to lacustrine) was determined using models discussed in Figure 3.20. 
Table 3.1 Summary of facies present in the cores, the percentage of each facies that contributes to total core recovered, and an environmental interpretation.

\begin{tabular}{|c|c|c|c|c|c|}
\hline Facies & Name & Description & Interpretation & core $\%$ & References \\
\hline 1 & $\begin{array}{lr}\text { Mudstone } & \text { and } \\
\text { fine-sandy } & \text { mud- } \\
\text { stone } & \end{array}$ & $\begin{array}{l}\text { Light-brown to dark-olive brown, organic- } \\
\text { rich, massive to horizontally-stratified, lam- } \\
\text { inated and bedded, dispersed clasts of do- } \\
\text { lerite and granite. }\end{array}$ & $\begin{array}{l}\text { Lacustrine bog under variable influ- } \\
\text { ence of iceberg or lake ice rafting }\end{array}$ & 3.92 & $\begin{array}{l}\text { Fitzsimons (1992), Hiemstra and van der Meer } \\
\text { (1997), van der Meer and Menzies (2011) }\end{array}$ \\
\hline 2 & $\begin{array}{l}\text { Interstratified } \\
\text { mudstone and } \\
\text { sandstone }\end{array}$ & $\begin{array}{l}\text { Grey to brown, laminated and bedded (up to } \\
5 \mathrm{~cm} \text {-thick), carbonaceous horizontally inter- } \\
\text { stratified, mudstone and fine sandstone with } \\
\text { dispersed clasts of dolerite and granite. }\end{array}$ & $\begin{array}{l}\text { Proglacial delta bottom set with ice- } \\
\text { berg or lake ice rafting (with dis- } \\
\text { persed clasts) }\end{array}$ & 9.27 & $\begin{array}{l}\text { McCabe and Eyles (1988), Fitzsimons (1992), } \\
\text { Walker and James (1992), Bennett et al., (2002) }\end{array}$ \\
\hline 3 & Graded sandstone & $\begin{array}{l}\text { Dark grey to olive and light grey, nor- } \\
\text { mally graded beds up to } 30 \mathrm{~cm} \text {-thick, contain } \\
\text { poorly sorted, pebbly coarse sandstone that } \\
\text { fines upwards into well sorted, laminated } \\
\text { fine sandstone. }\end{array}$ & $\begin{array}{l}\text { Delta foreset, sediment gravity } \\
\text { flows }\end{array}$ & 1.94 & $\begin{array}{l}\text { Miall (1978), Eyles et al., (1987), Tye and Cole- } \\
\text { man (1989), Horton and Schmidt (1996), Bennett } \\
\text { et al., (2002) }\end{array}$ \\
\hline 4 & Sandstone & $\begin{array}{l}\text { Grey to yellow brown, massive to horizon- } \\
\text { tally bedded (up to } 30 \text {-cm thick), moderately } \\
\text { to poorly sorted muddy-fine to pebbly coarse } \\
\text { sandstone. }\end{array}$ & Fluvial channel/delta & 6.91 & Eyles et al., (1987), McCarroll and Harris (1992) \\
\hline 5 & $\begin{array}{l}\text { Cross stratified } \\
\text { sandstone }\end{array}$ & $\begin{array}{l}\text { Yellow-brown to grey, well sorted, cross } \\
\text { stratified fine to coarse sandstone. }\end{array}$ & $\begin{array}{l}\text { Proglacial fluvial channel (with dis- } \\
\text { persed clasts }\end{array}$ & 2.85 & $\begin{array}{l}\text { Miall (1977), Porter and Beget (1981), Eyles and } \\
\text { Eyles (1983), Thomas et al., (2004), Benn and } \\
\text { Evans (2010) }\end{array}$ \\
\hline 6 & Breccia & $\begin{array}{l}\text { Light olive brown, clast rich, poorly sorted } \\
\text { breccia with a muddy sand matrix. }\end{array}$ & $\begin{array}{l}\text { Sediment redeposition by mass } \\
\text { flow, ice marginal moraine }\end{array}$ & 0.45 & Benn and Evans (1998), Atkins et al., (2002) \\
\hline 7 & Stratified diamict & $\begin{array}{l}\text { Grey clast rich to clast poor, sandy or muddy, } \\
\text { subhorizontal to high-angle weakly stratified } \\
\text { (beds up to } 20 \mathrm{~cm} \text {-thick) diamictite. }\end{array}$ & $\begin{array}{l}\text { Proximal subglacial outwash, sed- } \\
\text { iment gravity flow, moraines, rain } \\
\text { out of debris from ice }\end{array}$ & 4.26 & $\begin{array}{l}\text { Hart (1987, 1990), Menzies (1989), McCarroll } \\
\text { and Harris (1992) }\end{array}$ \\
\hline 8 & Massive diamict & $\begin{array}{l}\text { Grey to yellow-brown, massive clast rich to } \\
\text { clast poor, sandy to intermediate diamictite. }\end{array}$ & $\begin{array}{l}\text { Deposition by flowing ice, sub- } \\
\text { glacial }\end{array}$ & 69.84 & Fitzsimons (1992), Van der Meer (2003) \\
\hline 9 & Tephra & $\begin{array}{l}\text { White/grey, deformed, massive to laminated, } \\
\text { vitric, sandy mud to mud. }\end{array}$ & $\begin{array}{lr}\text { Volcaniclastic, remobilised } & \text { in } \\
\text { fluvial-lacustrine environment } & \end{array}$ & 0.56 & \\
\hline
\end{tabular}


Antarctic Ice Sheet evolution and variability during the mid-Miocene Climate Transition

In the next sections a detailed analysis of each facies and its environmental interpretation is provided, which form the building blocks of a sequence stratigraphic interpretation and a depositional model for recurrent advance and retreat of mountain glacier system in the Friis Hills during glacial-interglacial climate cycles of the mid-Miocene.

\subsubsection{Facies 1 - Mudstone and fine sandy-mudstone}

\section{Description}

Light-brown to dark-olive brown, organic-rich, massive to horizontally-stratified, laminated and bedded, mudstone and fine-sandy mudstone with dispersed extraformational clasts of dolerite and granite. Stratification is expressed by bedding up to $1.5 \mathrm{~cm}$ and sub $\mathrm{mm}$-scale laminae of siltstone or very fine sandstone, however stratification is highly disturbed near erosional contacts (GSE, Fig. 3.8 b). This facies is organic-rich, with total organic carbon up to $13.27 \%$. Organic material is fine-grained and disseminated, with some macrofossils of woody material, leaves, moss mats and seeds. Palynomorphs include pollen, spores, and Botryococcus, an algae characteristic of freshwater environments. Siliceous microfossils are commonly present and include freshwater diatoms such as Staurosirella spp., Staurosira spp., Aulacoseria and chrysophycean cysts (Fig. 3.9). This facies commonly preserves soft-sediment deformation structures in discrete intervals, as convolute bedding and folding, sedimentary intrusions (clastic sills and dykes, with fills of mud, sand or diamicton) and load structures, especially when it occurs stratigraphically below a GSE (Fig. 3.8 a,b). Additionally, brittle deformation is expressed by mineralised fractures, microfaults, highangle reverse and low-angle, concordant with bedding, physical mixing/shearing as well as brecciation. Some brittle deformation features cross-cut soft-sediment deformation features. 


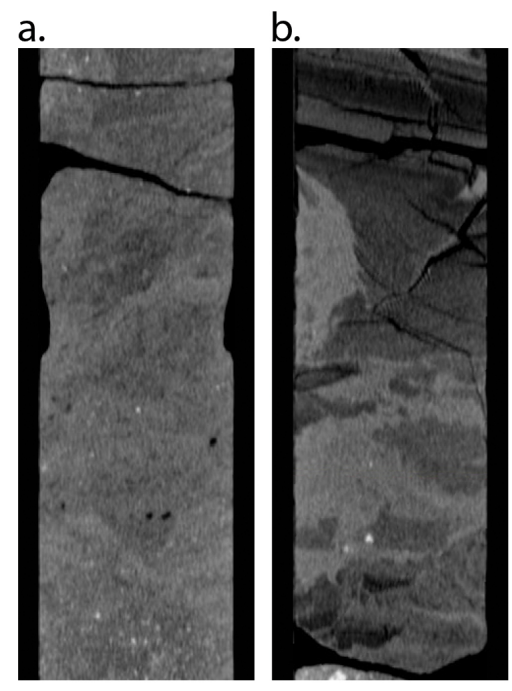

Fig. 3.8 Mudstone and fine-sandy mudstone (facies 1) sedimentary features. (a) 3A 32.17$32.32 \mathrm{~m}$ - ductile deformation below GSE. (b) 3A 37.17-37.31 m - highly sheared and deformed, with physical intermixing of lithologies, sediment injections, and brittle deformation. Images are CT scans, with shading representing a materials relative density. High density material such as clasts appear in lighter shades.
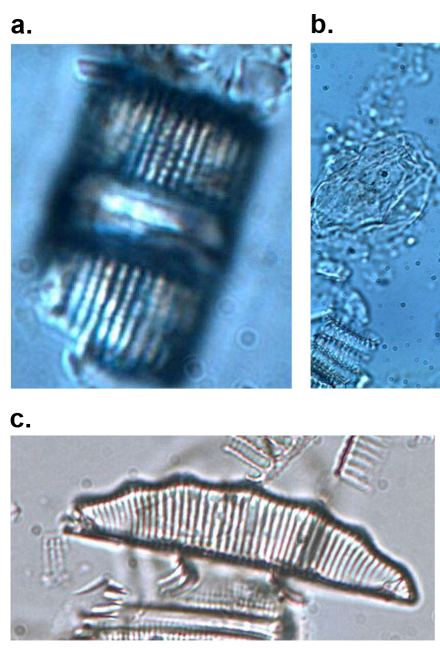

b.

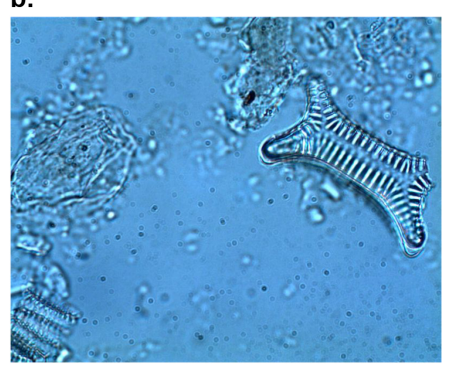

d.

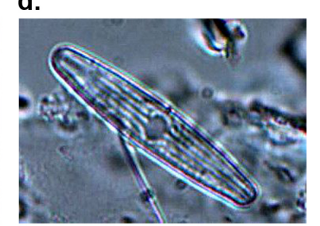

Fig. 3.9 Examples of diatom taxa observed in facies 1 (mudstone and fine-sandy mudstone) (a) Aulacoseria spp., (b) A new Staurosirella species observed in Friis Hills Miocene sediments, Staurosirella tigris, and facies 4 (sandstone) (c) Eunotia spp., (d) Brachysira spp. 
Antarctic Ice Sheet evolution and variability during the mid-Miocene Climate Transition

\section{Interpretation}

Facies 1 represents the lowest energy and most ice distal deposits in the Friis Hills sediment cores and consist of hemipelagic sediments. The lack of bioturbation, high organic matter content, and rare to abundant organic macrofossils together with freshwater diatoms, indicate a terrestrial lacustrine setting (Fitzsimmons, 1992). Staurosirella spp. and Staurosira spp. are typical flora in alpine lakes with benign turbulence and low water turnover (Rimet et al., 2019). The occasional occurrence of rare dispersed sub-angular to sub-round extra clasts and sag and drape features indicate deposition from episodic ice-berg rafting from a lake-terminating glacier. The occurrence of subtle horizontal stratification may represent episodic and seasonal to sub-seasonal fluctuations in meltwater/sediment discharge and/or the presence and absence of lake ice. The latter due to wind-blown fine sand released to the lake floor as lake-ice melts. Convolute bedding and slump features may represent the effects of downslope instability from small seismic events, sediment overloading or glacio-tectonics. Intraformational softsediment and brittle deformation together with an increased abundance of ice-berg rafting typically occurs where this facies immediately underlies a sharp-based diamicton and is interpreted as subglacial deformation associated with subsequent ice advance, grounding and overriding (discussed below) in a pro-glacial lacustrine environment (van der Meer \& Menzies, 2011). Brittle deformation cross-cutting folded and convolute soft-sediments and vertically fractured lonestones imply post-depositional ice overriding of this lacustrine facies (Hiemstra \& van der Meer, 1997).

\subsubsection{Facies 2 - Interstratified mudstone and sandstone}

\section{Description}

Grey to brown, laminated and bedded (up $5 \mathrm{~cm}$ thick) carbonaceous horizontally-interstratified, mudstone and fine sandstone with dispersed extraclasts of dolerite and granite. Unlike facies 1 , stratification is generally moderate to strong and is defined by up to $5 \mathrm{~cm}$ thick units of brown laminated mudstone or sandy fine mudstone and grey fine sandstone (Fig. 3.10 b,d). Sandstones are typically sharp based and in some cases beds are normally graded. Organic material is fine-grained and disseminated, but occasional macrofossils of woody material, leaves, moss mats and seeds present. This facies generally contains less organic material than facies 1 , however, some samples have up to $11.77 \%$ total organic carbon. Freshwater diatoms are sometimes present and assemblages include Staurosirella 
spp. and Eunotia spp. Soft-sediment deformation structures occur in discrete intervals and include convolute bedding and folding (Fig. $3.10 \mathrm{~d}$,e), sedimentary intrusions such as clastic sills and dykes with fills of mud, sand or diamicton (Fig. 3.10 a), and load structures (Fig. $3.10 \mathrm{f}$ ). Brittle deformation is expressed by mineralised fractures (Fig. $3.10 \mathrm{c}$ ), high angle reverse microfaults (Fig. 3.10 e), physical mixing/shearing as well as brecciation (Fig. 3.10 b,c,f), and occasional lonestones (Fig. 3.10 a-f). Some brittle deformation features cross-cut soft-sediment deformation features. Deformation is more pervasive in this facies than facies 1. Facies 2 accounts for $9.27 \%$ of the total facies assemblage.
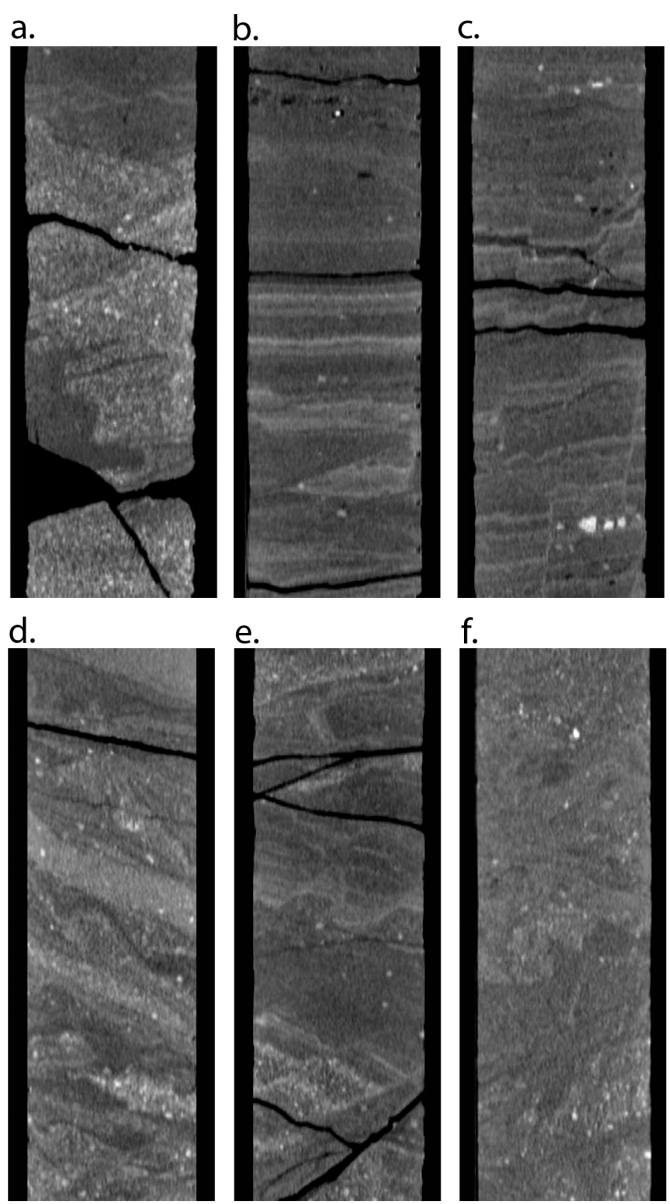

Fig. 3.10 Interstratified mudstone and sandstone (facies 2) sedimentary features. (a) 2A 13.65-13.80 m - sedimentary intrusions, (b) 2A 14.85-15.00 m - laminations with shearing, (c) 2A 15.12-15.27 m - brittle deformation, (d) 2A 15.0-15.95 $\mathrm{m}$ - shearing and slumping, (e) 2A 16.19-16.35 m - sharp and high angle reverse faults, (f) 32.64-32.79 m -load structures. Images are CT scans, with shading representing a materials relative density. High density material such as clasts appear in lighter shades. 
Antarctic Ice Sheet evolution and variability during the mid-Miocene Climate Transition

\section{Interpretation}

Facies 2 represents subaqueous depositional conditions in which sand supply was greater than for facies 1 and is interpreted to have formed in a shallow ice-proximal proglacial lacustrine environment. The thinly interbedded nature of the facies suggests conditions where fine sediment settled out of suspension for much of the time, punctuated by discrete depositional events. During these events, sand was deposited rapidly from decelerating flows perhaps at the base of subaqueous fan receiving glacial outwash sand from a subglacial fluvial conduit, or via a fluvial delta system in the proglacial environment (e.g. McCabe \& Eyles, 1988; Walker \& James, 1992). The occurrence of normally graded units and intraclast breccias implies an unstable sloping substrate, but not steep or high-energy enough to deliver reverse-graded deposits. The lack of gravel and relative thinness of the units $(<5 \mathrm{~cm})$ implies a distal setting and/or a relatively small delta in a small lake. The more pervasive occurrence of both brittle and ductile deformation features (Fig. $3.10 \mathrm{~g}$ ) is consistent with a more proximal glacial and depositional setting and is interpreted as a combination syn-depositional slumping and post-deposition sub-glacial deformation.

\subsubsection{Facies 3 - Graded sandstone}

\section{Description}

Dark grey to olive and light grey, normally graded beds up to 30cm-thick, contain poorlysorted, pebbly coarse sandstone that fines upwards into well-sorted, laminated fine sandstone. Pebbly sandstones are sharp-based and truncate underlying laminated fine sandstones (Fig. 3.11 b,c), which may be low angle cross- or convolute bedded. Pebble clasts are angular to sub-rounded. This facies contains intervals of convolute folded and sheared physicallyintermixed strata (Fig. 3.11 d). Facies 3 accounts for $31.94 \%$ of the total facies assemblage. 


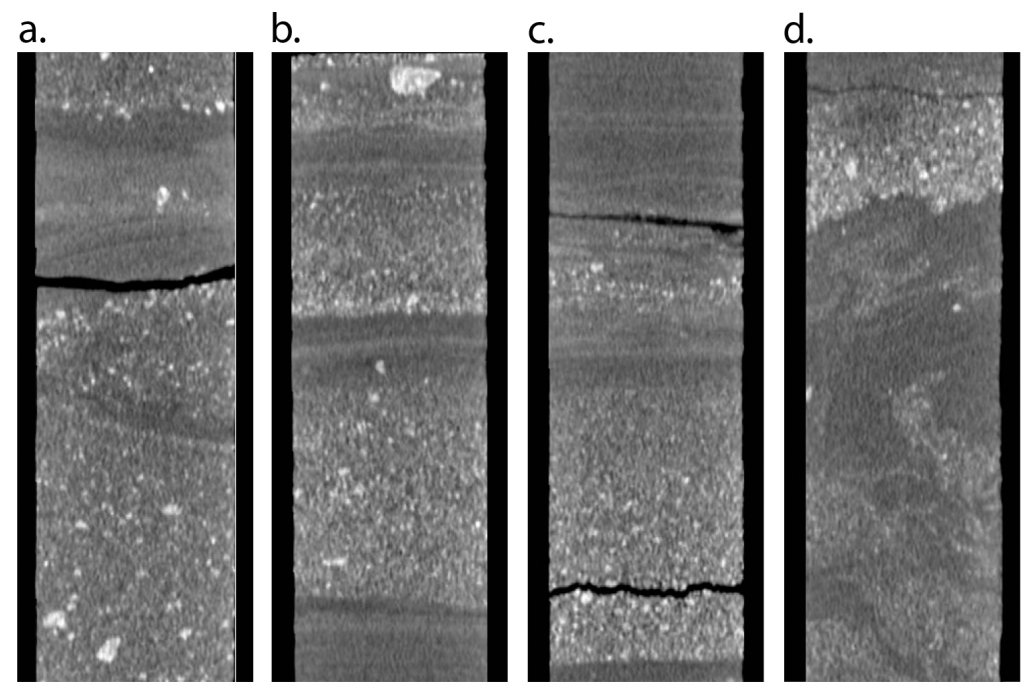

Fig. 3.11 Graded sandstone (facies 3) sedimentary features. (a-c) 3A 29.07-29.22 m, 3A 29.42-29.57 m, 3A 29.56-29.71 m - graded bedding with sharp based pebbly sandstone passing up into laminated fine sandstones, (d) sheared and physically intermixed as a result of slumping. Images are CT scans, with shading representing a materials relative density. High density material such as clasts appear in lighter shades.

\section{Interpretation}

Facies 3 includes graded-sandstone beds that are similar to facies 2 but lack hemipelagic mudstone beds that commonly sit above sandstone beds in facies 2 . Vertical amalgamation of up to 12 normally graded sandstone beds between 28.40-40.00 m in Core 3A (Fig. $3.11 \mathrm{a}-\mathrm{c}$ ) implies rapid deposition by sediment gravity flows on a delta front or toe in a more shoreline proximal environment than facies 2. Convex-upwards and convolute lamination in the top of each graded unit is consistent with settling of fine sand out of a turbid plume under declining flow such as in a turbidite. These features also resemble hummocky cross-stratification deposited as a result of declining return flow from storm surge (Plint, 1988; Walker \& James, 1992). However, the lack of mud and normally graded nature of this facies is more consistent with a non-cohesive subaqueous debris flow (Postma, 1986; Nemec, 1990), such as grain-flows (Nemac \& Steel, 1984). The lack of outsized clasts in laminated sandstones indicates limited or no occurrence of ice-berg rafting suggesting time between deposition of successive units was short and/or the glacier was land-terminating with a river/stream delivering well-sorted sand to a small fluvial-lacustrine delta (e.g. Tye \& Coleman, 1989; Fielding, 1994; Horton \& Schmidt, 1996; Walker \& James, 1992; Bennett et al., 2002). 
Antarctic Ice Sheet evolution and variability during the mid-Miocene Climate Transition

\subsubsection{Facies 4 - Sandstone}

\section{Description}

Grey to yellow brown massive to horizontally bedded (up to $30 \mathrm{~cm}$ thick) moderately- to poorly-sorted muddy-fine to pebbly coarse sandstone. Varieties of poorly sorted, mudrich, fine- to coarse grained sandstones generally lacking in internal sedimentary structure characterise facies 4 . Thin mudstone (facies 1 ) intervals up to 3-cm thick separate many of the sand beds (Fig. 3.12 a,d). Sedimentary structure is poorly developed, and horizontal stratification is often weak and defined by intervening mud beds with no evidence of tractional deposition by currents (Fig. 3.12 d). Some beds are normally-graded and may represent variants on facies 2 and 3. Many of the beds include extraformational mud clasts "floating" within a muddy sand matrix (Fig. 3.12 a), while in a few cases concentrations of clasts occur either at the base or at the top of beds (Fig. 3.12 c). Soft-sediment deformation structures were noted only locally (Fig. 3.12 b). Benthic diatom species are prevalent, including Brachysira spp. and Eunotia spp (Fig. 3.9), with low proportions of Staurosirella spp. and Staurosira spp. Facies 4 accounts for $6.91 \%$ of the total facies assemblage.
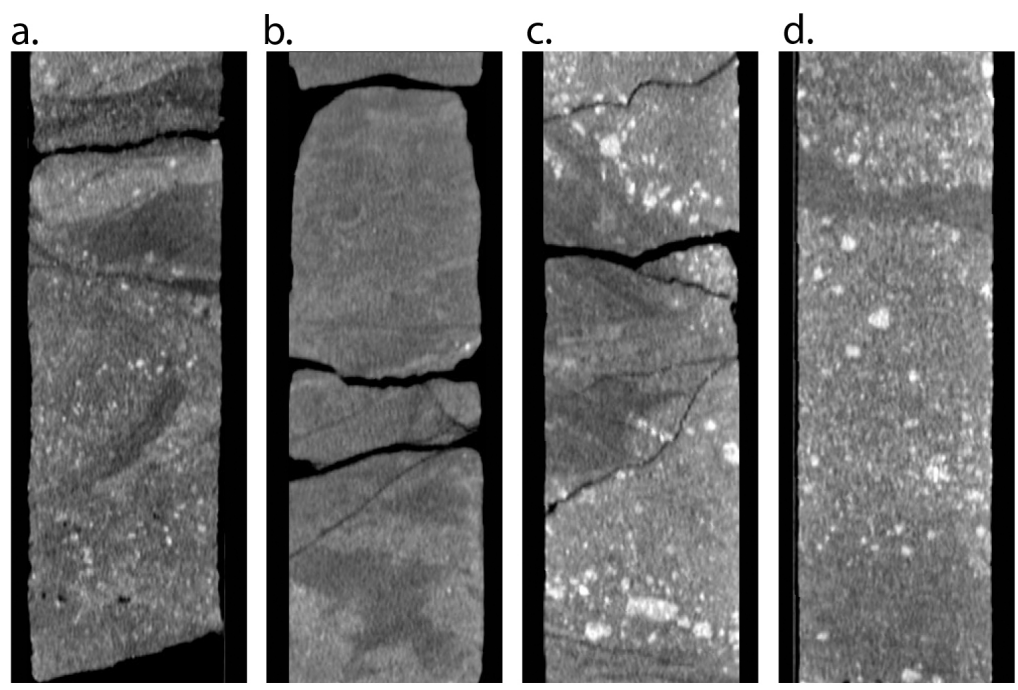

Fig. 3.12 Sandstone (facies 4) sedimentary features. (a) 2A 13.08-13.23 m - highly deformed with extraformational mud clasts, (b) 3A 17.92-18.07 m - soft sediment deformation, (c) 18.18-18.33 $\mathrm{m}$ - deformation by shearing and exhibiting clast alignment, (d) 3A 27.60-27.75 $\mathrm{m}$ weak stratification. Images are CT scans, with shading representing a materials relative density. High density material such as clasts appear in lighter shades. 


\section{Interpretation}

The mud-rich, poorly-sorted and unstratified nature of facies 4 is suggestive of sediment deposition from sandy sediment gravity flows. The lack of sedimentary structures resembles a subaqueous cohesive debris flow, such as a hyperconcentrated flow. Moreover, the occurrence of floating extraformational clasts and rip-ups is characteristic of a debris flow (e.g. Shanmugam, 1996), reflecting the mass transport and rapid deposition of these sediments (Benn \& Evans, 2010). The occurrence of facies 4 in association with facies 2 and 3 is consistent with deposition in a delta front or delta toe lacustrine environments. Relatively lower proportions of Staurosirella spp. and Staurosira spp in this facies indicate flowing, rather than stagnant, water (Griffiths et al., 2017). No direct evidence of glacial conditions can be inferred from facies 4 , although the debris flows could have originated near the grounding zone of a lake-terminating glacier.

\subsubsection{Facies 5 - Cross stratified sandstone}

\section{Description}

Yellow-brown to grey, well-sorted, cross-stratified fine to coarse sandstone. Varieties of ripple cross bedding (Fig. $3.13 \mathrm{~b}$ ) to steep angle cm-scale cross bedding (Fig. $3.13 \mathrm{c}$ ), with $\mathrm{mm}$ to $\mathrm{cm}$-scale stratification (Fig. $3.13 \mathrm{a}-\mathrm{d}$ ). Series of fine to coarse sands and pebble nests separate beds (Fig. 3.13 b-d), with mud drapes on ripples occurring where angle is lowest. Stratification often well-defined, however weak stratification correlates with more physically intermixed units. In general, the lower contact of facies 5 is gradational, with high angle erosional surfaces of the underlying facies is also associated with those units that are physically intermixed. In most cases, facies 5 shows far less deformation than facies 1-4, and is relatively well-preserved. Rare lonestones occur towards the upper section of each unit (Fig. 3.13 c). This facies accounts for $2.85 \%$ of the total facies assemblage. 
a.

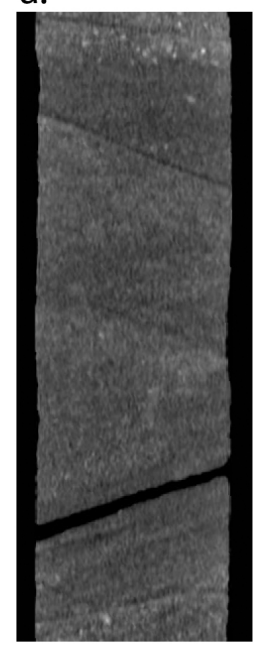

b.

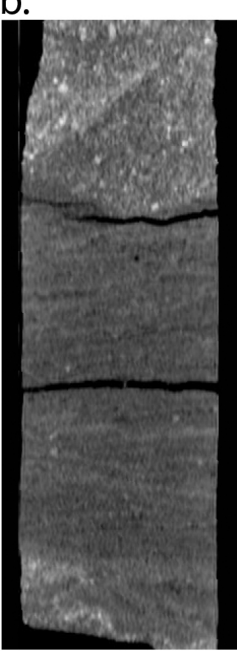

C.

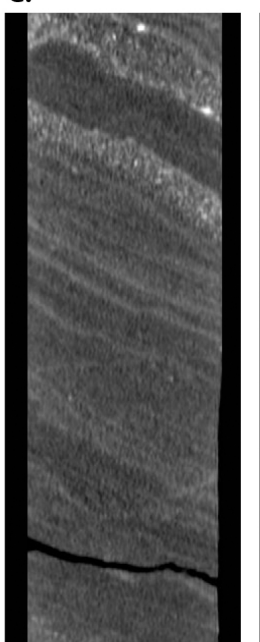

d.

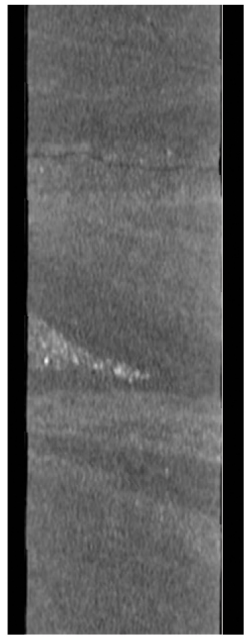

Fig. 3.13 Cross stratified sandstone (facies 5) sedimentary features. (a) 2A 13.26-13.41 $\mathrm{m}-\mathrm{mm}$ scale cross stratification, (b) 2A 13.85-14.00 m - ripple cross stratification, (c) 3A 22.67-22.82 m - high angle cross stratification, (d) 3A 28.62-28.77 m - cm scale cross bedding. Images are CT scans, with shading representing a materials relative density. High density material such as clasts appear in lighter shades.

\section{Interpretation}

A coarsening upwards succession of cross bedded sands is common in prograding deltas (Eyles \& Eyles 1983). Assemblages of laminated, cross stratified, ripple and cross bedded sands are indicative of shoreline distal sedimentation (Thomas et al., 2004). Ripple cross bedding is particularly common in sandy fluvial and glacial-lacustrine environments (Benn \& Evans 2010) while a lack of ice-rafted debris in some sequences suggests accumulation in a prograding delta with water sufficiently shallow to exclude large icebergs (Porter \& Beget). Mud drapes were likely laid down as flows waned and fine suspended sediment settled out of stagnant water left in abandoned channels (e.g. Miall, 1977). Where physical intermixing with underlying facies occurs and facies 5 is directly below a GSE (Fig. 3.13 d), deposition may have occurred as a subglacial fluvial channel. 


\subsubsection{Facies 6 - Breccia}

\section{Description}

Light olive brown clast-rich, poorly sorted breccia with a muddy sand matrix. Clasts are angular to sub-rounded and dominated by intraclasts and clastic intrusions derived from underlying sediments (Fig. $3.14 \mathrm{a}, \mathrm{b}$ ). This facies is rare but occurs in association with massive diamicton (facies 8), which it underlies, in association with the GSE. It is generally deformed displaying physical intermixing. This facies accounts for just $0.45 \%$ of the total facies assemblage.

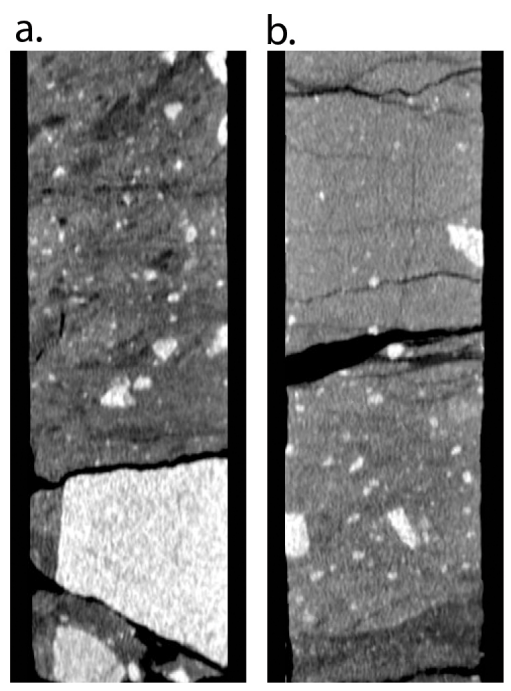

Fig. 3.14 Breccia (facies 6) sedimentary features. (a) 2A 4.83-4.98 m extraformational clasts and clastic intrusion below GSE, (b) 2A 12.95-13.10 m - erosional surface and brecciation in overlying till. Images are CT scans, with shading representing a materials relative density. High density material such as clasts appear in lighter shades.

\section{Interpretation}

Redeposition of previously deposited sediments by mass flows including rip-ups, physical intermixing and shearing, together with close association with facies 8 suggests a glaciotectonite (Atkins et al., 2002) and likely represents the lower deformed part of a traction till resulting from shear imparted by overriding ice on sediments below. Fine grained units can be heavily deformed, however, coarser units such as sands or gravels form relatively undeformed pods or lenses (Benn \& Evans 1998). 
Antarctic Ice Sheet evolution and variability during the mid-Miocene Climate Transition

\subsubsection{Facies 7 - Stratified diamicton}

\section{Description}

Grey clast-rich to clast-poor, sandy or muddy sub-horizontal to high-angle weakly stratified (beds up to $20 \mathrm{~cm}$ thick) diamicton. These are relatively uncommon in the Friis Hills sediments but occur throughout Core 3A (Fig. 3.15 a-d) and upper parts of Core 1A, where they are stratigraphically above massive diamicton. Stratification style is most commonly bedded and cm-scale (Fig. 3.15 a-d) and defined by concentrations of angular to sub-rounded clasts with increased sand matrix, separated by $\mathrm{cm}$-scale fine sandy mudstone beds (Fig. $3.15 \mathrm{~b}$-d). In some cases, clasts are aligned along a-axis parallel to bedding, resembling imbrication. Rare clast rotation and halos were observed. This facies accounts for $4.26 \%$ of the total facies assemblage.
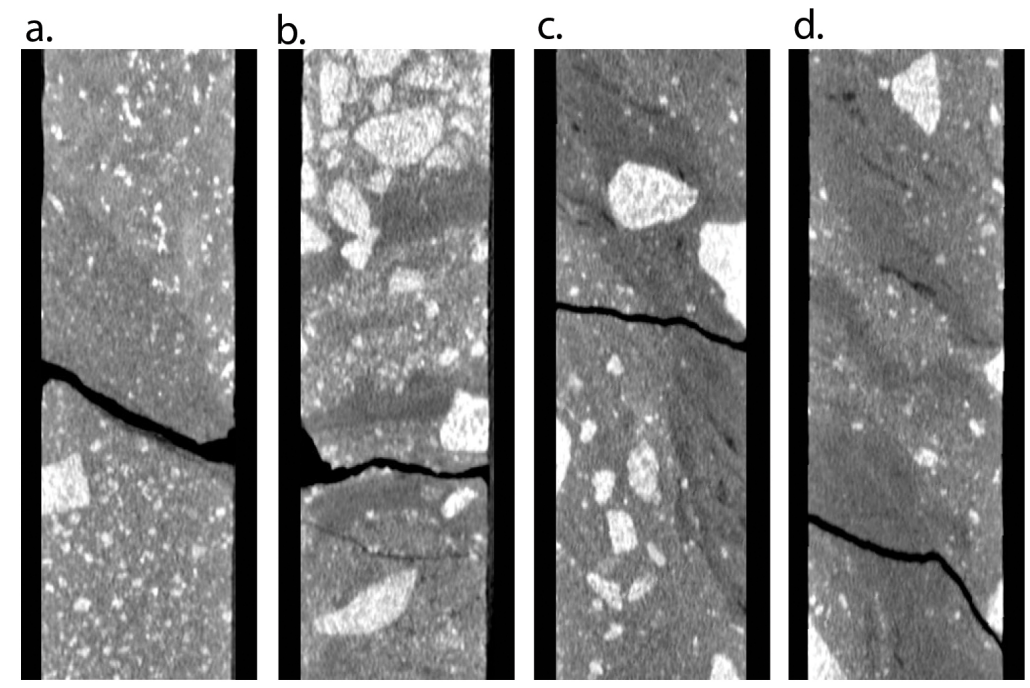

Fig. 3.15 Stratified diamictite (facies 7) sedimentary features. Examples of stratified diamictite display high angle, tilted, slumped beds and clast alignment as the result of subaqueous debris flow deposition. (a) 3A 23.43-23.58 m, (b) 3A 26.10-26.25 m, (c) 3A 43.52-43.67 m, (d) 3A 43.97-44.12 m. Images are CT scans, with shading representing a materials relative density. High density material such as clasts appear in lighter shades.

\section{Interpretation}

Stratified diamictons grade into and out of massive diamicton facies but generally occur above massive diamictons at the transition to glacio-fluvial or glacio-lacustrine proglacial facies (facies 1-5). Stratified diamicts with low clast counts most likely formed as cohesive 
debris flows with sufficient melt water to concentrate clasts, whereas clast alignment is likely related to melt-out processes (Lawson, 1979). The presence of deformation structures indicates subaerial deposition of this facies is most likely, with these structures formed as a result of deposition and collapse on melting ice (Fitzsimons, 1992).

\subsubsection{Facies 8 - Massive diamicton}

\section{Description}

Grey to yellow-brown, massive clast-rich to clast-poor, sandy to intermediate diamicton. These are the most common facies in the Friis Hills cores and vary from 0.2-13.3 $\mathrm{m}$ in thickness. Grainsize distributions of the matrix are typically broad, but generally follow a polymodal distribution (e.g. Fig. 3.7). There is an overall trend of a gradual fining upwards of the matrix through each of the diamicton successions. Where the matrix is sandy, the diamicton locally grades into sandstone by decreasing clast content, whereas where the matrix is muddy, the diamicton locally grades through pebbly mudstone into mudstone via decreasing clast content. Mud content of the matrix material varies locally, from $23 \%$ to 93\%, throughout the core. Diamictons in the upper part of Core $1 \mathrm{~A}$ and Core $2 \mathrm{~A}$ tend to be lighter in colour compared to the lower intervals of Core $2 \mathrm{~A}$ and all of Core 3A. Lewis and Ashworth (2015) also noted this distinct colour change between the Friis II (lower) and Friis II (upper) drifts (Fig. 3.16).

Clasts are randomly oriented and range from angular (Fig. 3.17 a) to subrounded (Fig. $3.17 \mathrm{~s}$ ) and many are striated and faceted. Some display vertical fractures (Fig. 3.17 a,c,f,g,m,s), rotational features (Fig. 3.17 d,l), clast halos (Fig. 3.17 e,l), and fracture filled faults (Fig. $3.17 \mathrm{~m}, \mathrm{~s}$ ). In some intervals the matrix fabric is sheared (Fig. $3.17 \mathrm{r}$ ), faulted (Fig. 3.17 h), and displays necking (Fig. 3.17 j,k,n) and comet structures (Fig. 3.17 1). Porewater escape features (Fig. 3.17 o), ice lenses (Fig. 3.17 q) and layering and foliation features (Fig. $3.17 \mathrm{~h}$ ) are also evident.

These deformation features tend to be concentrated in the lower portions of diamicton units, where the basal contact is often sharp, erosional and loaded (Fig. 3.17 t). Immediately underlying lithologies, commonly facies 1, 2 and 3, display a range of ductile and brittle deformation features (see above). The basal parts of this facies also display extraclast (ripups) of underlying lithologies (Fig. 3.17 p) and clastic sills and dykes (Fig. 3.17 i) often containing pebbly coarse sands are physically intermixed with underlying lithologies. Pods of 
gravel and sand-sized clasts up to $0.5 \mathrm{~cm}$, that are distinct in grainsize from the surrounding diamicton occur intermittently. These features are structureless, but some are deformed by overlying sediment. The upper portions of this facies are typically less deformed, but the texture remains equally homogenised. Ice lenses are present in diamictons both near the surface and at depth $<1 \mathrm{~m}$ and $\sim 43 \mathrm{~m}$. This is the most common facies in the cores, accounting for $69.84 \%$ of the total facies assemblage.

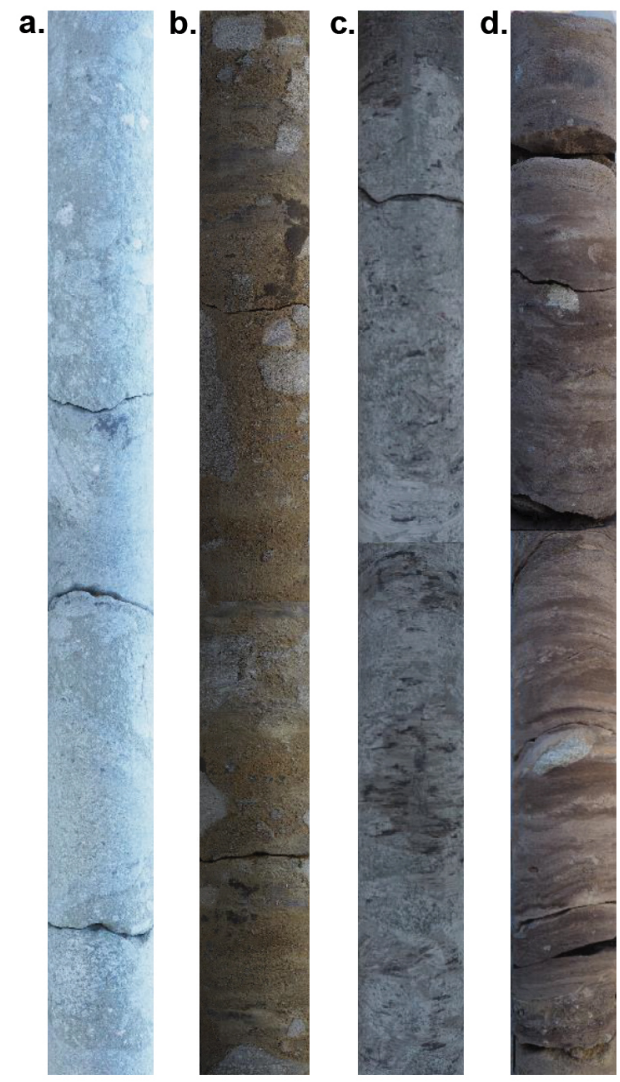

Fig. 3.16 Visible change between Friis II (upper and lower) deposits in cores FHDP-3A and -1A/B: (a) lower section of Friis II (upper) drift diamictite (FHDP-1A 25.26-25.76m), (b) upper section of Friis II (upper) drift diamictite (FHDP-1A 2.15-2.65m), (c) Friis II (lower) drift interstratified mudstone and sandstone (FHDP-3A 32.25-32.75m), (d) Friis II (upper) drift interstratified mudstone and sandstone (FHDP-1B 15.6-16.1m). 

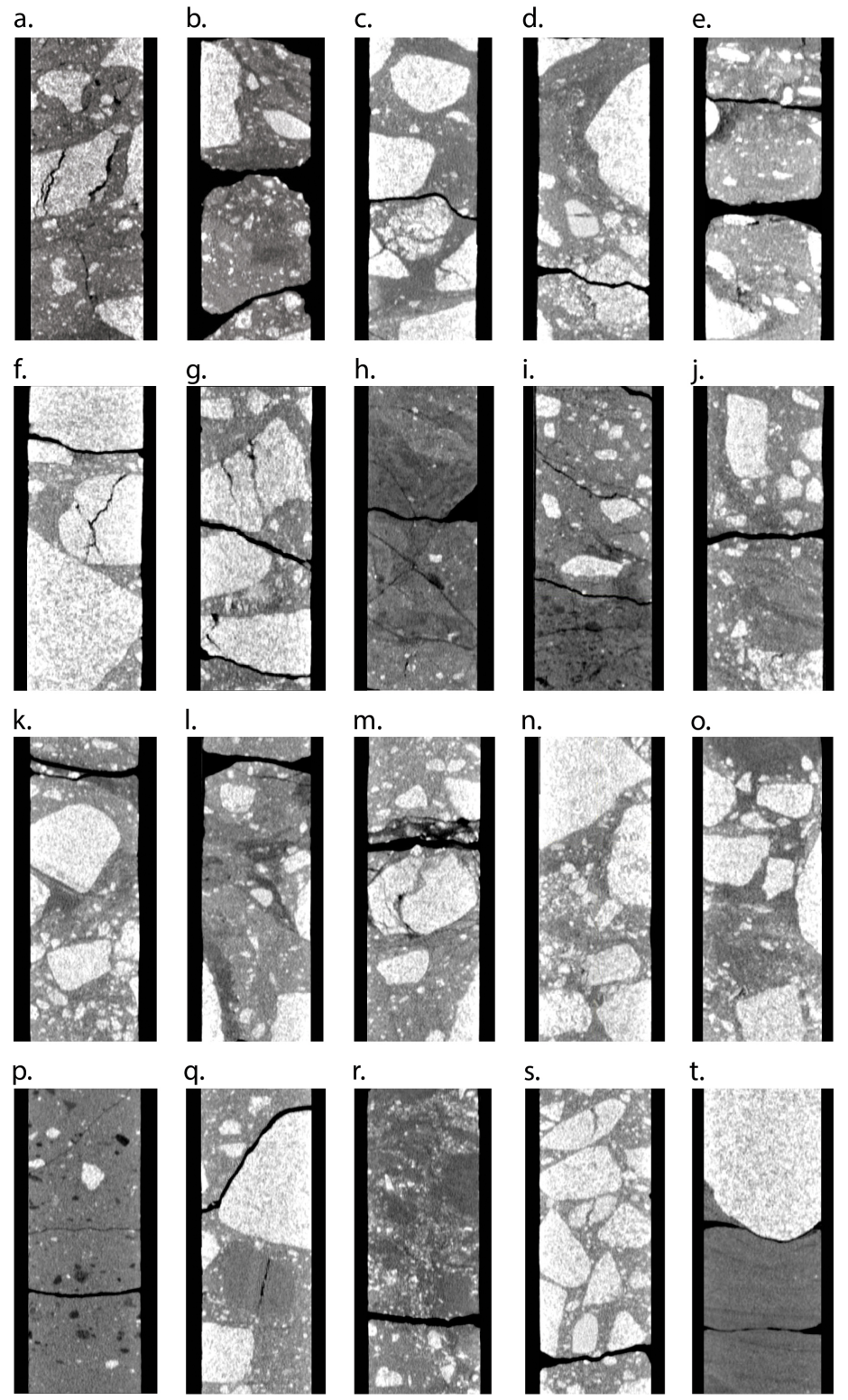

Fig. 3.17 Massive diamictite (facies 8) sedimentary features. (a) 1A 2.42-2.57 m - cracked clast and vertical fracture, (b) 1A 19.37-19.52 m - rotational features, (c) 1A 20.36-20.51 $\mathrm{m}$ - cracked clast and vertical fracture, (d) 1A 20.96-21.11 m - rotational feature, (e) $1 \mathrm{~A}$ 22.94-23.09 m - clast halo, (f) 1A 25.56-25.71 m - cracked clast and vertical fracture, (g) 1A 28.31-28.46 m - cracked clast and vertical fracture, (h) 2A 3.40-3.55 m-layering and foliation, (i) 2a 3.57-3.72 m - extraformational clasts and sill and dyke feature, (j) 3a 19.30-19.45 m - necking, (k) 3A 19.64-19.79 m - rotational feature and necking, (l) 3A 22.23-22.38 m - clast halo and comet structure, (m) 3A 21.60-21.75 m - cracked clast, (n) 3A 26.30-26.45 m - necking, (o) 3A 30.12-30.27 m - porewater escape, (p) 3A 36.60-36.75 $\mathrm{m}$ - extraformational clasts, (q) 3A 38.00-38.15 m - cracked clast and ice lense, (r) 3A 41.87-42.02 $\mathrm{m}$ - shear zone, (s) 3A 47.45-47.60 m - fracture filled fault, (t) 3A 49.22-49.37 $\mathrm{m}$ - sharp glacial surface of erosion. Images are CT scans, with shading representing a materials relative density. High density material such as clasts appear in lighter shades. 
Antarctic Ice Sheet evolution and variability during the mid-Miocene Climate Transition

\section{Interpretation}

Sharp-based, massive, structureless diamictons, which dominate this facies, are interpreted broadly as subglacial traction tills (Evans et al., 2006; Benn and Evans, 2010). At a sequence stratigraphic scale (discussed below) this facies often overlies proglacial fluvial-lacustrine mudstone, sandstone and gravel facies (facies 1-5), that display a range of ductile and brittle deformation features consistent with shearing and compressional loading. Ductile deformation in the lower portions of this facies expressed as physical intermixing of underlying lithologies, clastic intrusions, comet structures and lee-side cavity-fills, folding and crenulation, and matrix realignment are consistent with shearing and loading by sliding, overriding ice. Additionally, faceted and striated clasts with strain caps and evidence of rotation, and bi-modal grainsize distributions in the matrix imply processes of subglacial transport in lodgement tills.

\subsubsection{Facies 9 - Tephra}

\section{Description}

White/grey, deformed, massive to laminated, vitric, sandy mud to silty mud (tephra) up to $20 \mathrm{~cm}$ thick. Laminations occur on $\mathrm{mm}$ to $\mathrm{cm}$-scale, with intercalated lonestones ranging in size from $2 \mathrm{~mm}$ to $5 \mathrm{~cm}$. Facies 9 tephra are both fortuitously-preserved beneath GSEs, but as a consequence are physically intermixed and deformed locally, as pods and intraclasts of volcaniclastic sediment (Fig. 3.18 a,c). Lower contacts of the tephra layers are generally sharp and irregular, whereas the upper contacts tend to be gradational and usually contain an admixture of ash and terrigenous grains disseminated over millimetres to centimetres upsection. The tephras white colour means that they are easily distinguished from the enclosing terrigenous terrestrial glacial-lacustrine facies (Fig. $3.18 \mathrm{~d}-\mathrm{f}$ ). This facies accounts for $0.56 \%$ of the total facies assemblage. 

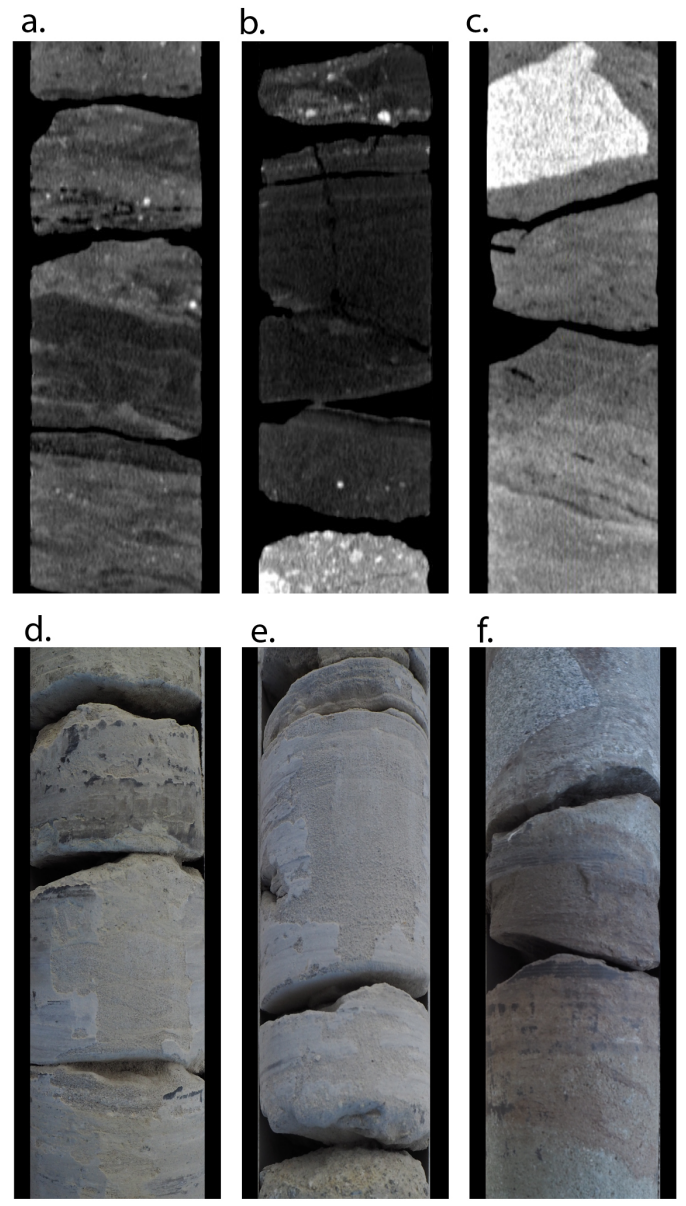

Fig. 3.18 Tephra (facies 9) sedimentary features. Tephra has been redeposited in flow, normally graded, stratified, with decreasing primary ash and extraformational clasts. (a) 2A 5.12-5.27 m, (b) 2A 5.27-5.32 m, (c) 3A 27.10-27.25 m, (d-f) tephra deposits could be visually identified in the cores due to a fine, light grey/white appearance, as is evident in these photos. Images are CT scans, with shading representing a materials relative density. High density material such as clasts appear in lighter shades, while low density material such as tephra is represented by darker shades (black).

\section{Interpretation}

The tephras are interpreted as the products of primary volcanic airfall processes and subsequent remobilisation within fluvio-lacustrine sedimentary environments, when the glacier was retreated. They comprise glassy pumiceous ash of rhyolitic composition in the case of the tephra at $5.3 \mathrm{~m}$ in FHDP-2A, and trachytic composition in the case of the tephra at $27.2 \mathrm{~m}$ in FHDP-3A (Fig. 3.19 a). While rhyolitic in composition, the FHDP-2A tephra appears to contain two distinct glass populations on the basis major element bivariate and 
Le Maitre plots, indicative of a composite origin (Fig. 3.19 a,b). Mixed glass populations may result from a variety of origins including post-emplacement sedimentary reworking of different eruptive deposits, or eruption of a chemically zoned magma chamber, and therefore, provide a minimum age of emplacement. FHDP-3A contains a single tightly clustered glass composition consistent with a single eruptive event. Mount Morning is the likely source of the tephras in FHDP-2A and 3A, with both trachyte and rhyolitic eruptions from the centre documented during the mid-Miocene (Martin et al., 2010).

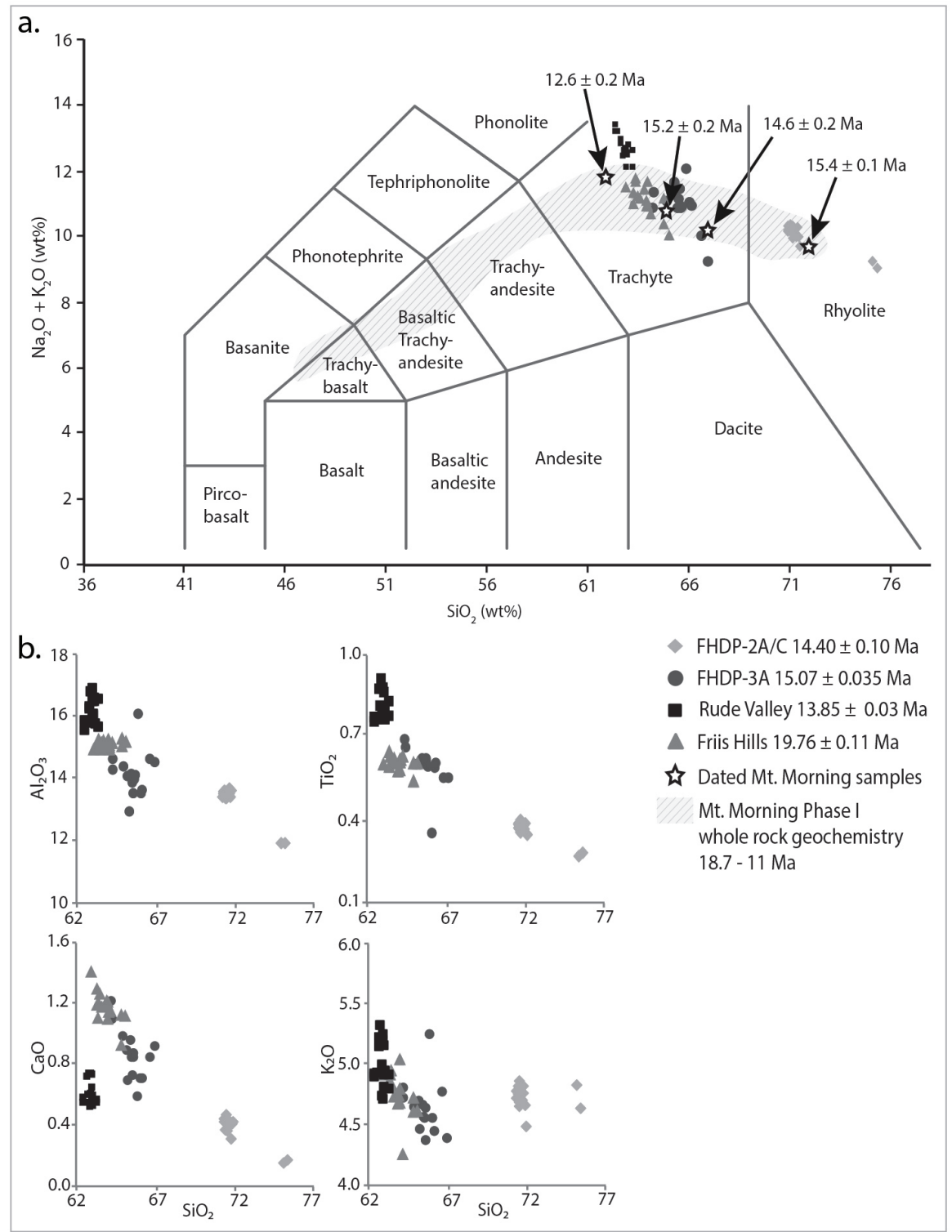

Fig. 3.19 Major element glass chemistry data for the two new silicic tephra Continued on the following page. 
Fig. 3.19 (cont) reported in this chapter (FHDP-2A/C 14.756 $\pm 0.035 \mathrm{Ma}$ and FHDP-3A $15.075 \pm 0.029 \mathrm{Ma})$, the $19.76 \pm 0.11 \mathrm{Ma}$ tephra from Friis I unit reported in Lewis and Ashworth (2015), and a sample collected from Rude Valley dated at 13.85 $\pm 0.03 \mathrm{Ma}$ (Lewis et al., 2007), (a) Total alkali vs. silica Strat(TAS) classification diagram (after Le Maitre et al., 2000) shows that all tephra plot as trachyte with exception of FHDP-2A/C tephra which plots as a rhyolite of similar age and composition to Mt. Morning Phase I eruption from Martin and others (2010), dated by Kyle and Muncy (1989) and Martin and others (2010). (b) Major element bivariate plots differentiate FHDP-2A/C tephra from FHDP-3A tephra.

\subsubsection{Depositional architecture of a glacial-interglacial sedimentary cycle}

An idealised sequence stratigraphic motif (Fig. 3.20) and 3-D conceptual depositional model (Fig. 3.21) for a cycle of glacial advance and erosion, interglacial retreat and subsequent glacial advance was produced. This model is based on the recognition of four repetitive facies successions preserved in many of the fifteen cycles from the FHDP cores and will be discussed in further detail below. 
Antarctic Ice Sheet evolution and variability during the mid-Miocene Climate Transition
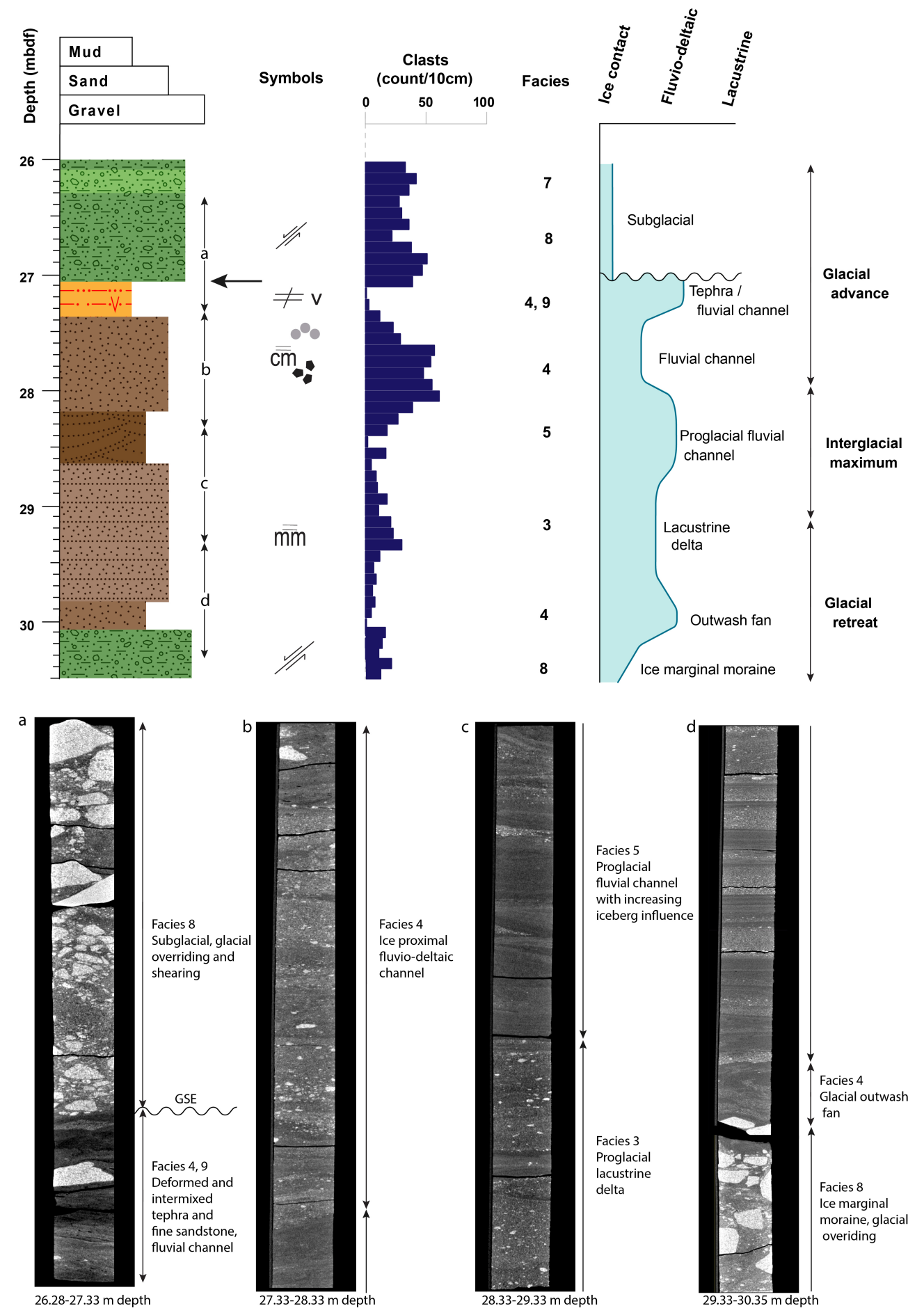

Fig. 3.20 Example of a typical sedimentary cycle from FHDP-3A (26.28-30.35 m; see Fig. 3.7) showing (from the bottom up) a retreat facies succession from glacier terminus proximal diamicton to graded beds (facies 4) deposited in an ice-distal lacustrine environment followed by a glacial advance succession, ice-overriding and erosion. Geologic key is provided in Fig. 3.5 


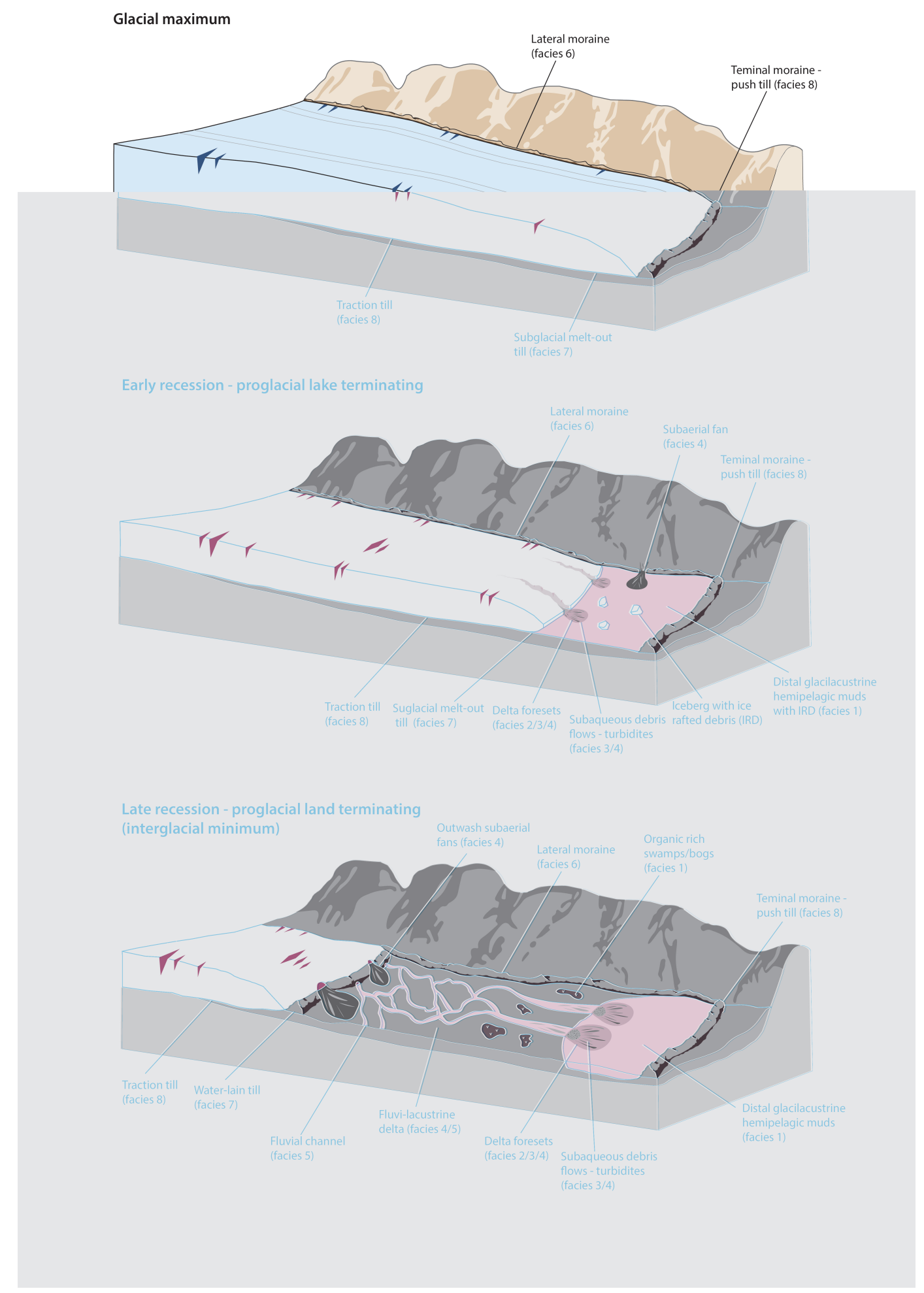

Fig. 3.21 Three-dimensional sedimentary depositional environment model for the Friis Hills central basin during the MMCT, showing facies and depositional environments associated with glacial maximum, early recession and interglacial minimum phases of a glacial-interglacial climate cycle. 
Antarctic Ice Sheet evolution and variability during the mid-Miocene Climate Transition

\section{Subglacial erosion and deposition during ice advance (glacial maximum)}

Sharp erosional surfaces that generally mark the base of each sequence are interpreted as GSEs, which have been observed and described from coastal glacimarine settings where advancing ice grounds in marine environments (Dunbar et al., 2008; McKay et al., 2009). Massive diamicton units, typically between 0.5-5 m thick, overlie deformed or brecciated glaciofluvial or glaciolacustrine lithofacies, and generally reflect ice grounding and overriding in a subaqueous environment. The contact between them is often sharp, highly sheared or contains clastic intrusions. Above the contact, the diamicton is physically intermixed with the underlying facies before grading upward into a massive diamicton, that is interpreted to be the result of homogenisation by subglacial shearing. Subglacial shear and ice loading is also indicated by syndepositional soft sediment deformation structures, intraclasts, and clastic dykes within diamictons, clast halo's and comet structures as well as compressional load features such as vertically-cracked clasts. Additionally, subglacial features are indicated by linear microstructures and a pervasive plasmic fabric, characterised by an oriented clay matrix, within diamictons and deformed sediments beneath diamictons. The basal characteristics of these diamictons are consistent with known examples of subglacial deposition and overriding by grounded ice (Hart \& Boulton, 1991; Hart, 1996; Hiemstra \& van der Meer, 1997; Evans et al., 2006; Benn \& Evans, 2010).

The GSEs and overlying massive diamicton facies are interpreted as till sheets deposited by southeastward advance and grounding of regionally- and locally-sourced alpine glaciers during a cold climate glacial phase. Grounding often occurs in association with small proglacial lakes where limited water depth does not reduce load significantly through flotation. Within some massive diamictons which overly GSEs, sharp local change in colour and/or clast content could signify a change in glacial load, for example a minor retreat followed by glacial readvance within a lodgement till unit (Eyles et al., 1982; Miller, 1989).

In the stratigraphically-younger FHDP-1A core, diamicton units dominate and are up to $12 \mathrm{~m}$ thick, and show an increased frequency of compressional and shearing deformation features. This, together with an observed increase in clast content and granitic clasts indicates the style of glaciation was colder and perhaps more regionally extensive, compared to the stratigraphically-older diamictons in FHDP-1 and -2 cores. Diamictons in these cores are dominated by dolerite and Beacon Sandstone generally contain a higher mud percentage and sedimentary features consistent with high levels of meltwater during glacial advance. 


\section{Proglacial deposition during ice retreat (early recession)}

Massive homogenised diamictons may also occur in both subaerial and subaqueous proglacial environments such as fans and delta's as debris flows deposited under the influence of gravity. In a few cases where this facies lacks deformation features associated with sliding and overriding ice, and it does not occur above a GSE, the interpretation is equivocal, and could represent pro-glacial deposition during retreat (or advance, see below). Stratified diamictons in association with massive diamictons may be deposited near the glacier terminus in terminal and/or lateral moraines, and as cohesive debris flows and rain-out deposits as the glacier terminus recedes.

However, in general, subglacial tills are overlain by broadly fining-upwards facies successions ranging from $0.5-4 \mathrm{~m}$ thick, and including stratified diamictons, poorly-sorted pebbly-sandstones, well-sorted cross-stratified sandstones, normally graded-sandstone beds and interstratified mudstone and sandstone. This recessional succession represents retreat of the glacier terminus up-valley towards the northwest onto surrounding highlands and the development of a small fluvial-lacustrine delta system in the Central Friis Hills basin (Fig. 3.2), where sediment transport and deposition occurred via tractional currents in river channels and subaerial and subaqueous debris flows. As the meltwater supply increased, the lake broadened and deepened, and the sedimentary succession became increasingly more iceand shoreline-distal and was characterised by hemipelagic mudstones and sandy mudstones, with a decreasing influence of IRD.

\section{Interglacial lacustrine deposition (late recession)}

Organic-rich, 0.5-4.5 m thick mudstones and laminated fine sandy-mudstone units with rare ice-berg rafting represent lacustrine deposition in the most ice-distal environments during interglacial warm phases. These intervals occur throughout all the FHDP cores. In many cases these deposits contain Nothofagus wood and root fragments and pollen, moss mats, insect remains and freshwater diatoms, characteristic of low-energy benign (unstratified) relatively shallow lake surrounded by alpine shrub tundra (Lewis \& Ashworth, 2015). Where the organic content is high enough the mudstones are expressed as fissile shales and peats. These organic-rich, facies correspond to fossil-bearing siltstone beds described in pit sections by Lewis and Ashworth (2015) in the Friis II (lower) drift, which additionally contain Nothofagus leaf mats. They observed that the closest locality where modern representatives of the taxa occur today is near tree line in southern-most South America, where MSTs are 
Antarctic Ice Sheet evolution and variability during the mid-Miocene Climate Transition 104 ( 15.1-13.8 Ma), from the Friis Hills, Antarctica

$\sim 6-7^{\circ} \mathrm{C}$ (Ashworth \& Lewis, 2011; 2012). Based on limited paleoecological information, described in section 3.9, it is assumed that each interglacial deposit represents broadly similar environmental and climatic condition during which time the Friis Hills may have been periodically-ice-free, or almost ice-free.

\section{Proglacial deposition during ice advance}

In some sedimentary cycles the interglacial lacustrine facies are overlain by a $0.5-5 \mathrm{~m}$ thick, coarsening-upwards proglacial facies succession that includes at its base subaqueous sediment gravity flow deposits, such as interstratified sandstone laminae and beds and sequences of $5-50 \mathrm{~cm}$ thick graded sandstone beds, deposited as a delta progrades towards and across organic-rich lake beds. These deposits may in turn pass upwards into well-sorted ripple cross-stratified sandstones deposited in river/stream channels and eventually be overlain by glacier terminus-proximal debris flow deposits in the form and massive pebbly sandstones and stratified diamictons. The coarsening-upwards succession represents an increased supply of sediment and deformation as the land terminating ice front advances down-valley towards the lake and the glacier eventually overrides the fluvial-lacustrine environment. An increased occurrence of outsized clasts and IRD upsection in lacustrine and delta-front facies indicates ice-bergs were calving as the glacier entered the lake. Due to subglacial erosion at the glacial maximum, the full progradational facies succession is not always preserved in cycles below the GSE.

\subsection{Paleoecology}

\subsubsection{Pollen}

Eighteen samples from interglacial sedimentary intervals in FHDP-1A/B, -2A and -3A were examined for palynology. Pollen and spore abundance in the 18 samples was generally low ranging from 0 to 146 specimens. Nine samples contained more than 30 pollen grains with an average concentration of 4623 specimens/gram sediment (Appendix F). These samples were all taken from either sedimentary facies 1 (mudstone and fine sandy mudstone) or facies 2 (interstratified mudstone and sandstone). Four samples contained less than 30 specimens/gram sediment were collected from a mix of fine- and coarse-grained sedimentary facies (facies 1, 2, 4 and 5). Four barren samples were from facies 4 (sandstone) and 5 
(cross stratified sandstone). Variations in palynomorph abundance clearly reflect changes in depositional environment with highest numbers preserved in the most ice distal environments.

Common elements in the Friis Hills samples include Nothofagidites fusca type, Podocarpidites spp., Retitriletes spp., and Coptospora spp. This assemblage is like that observed in lower Miocene sediments in the CRP-2A (Askin \& Raine, 2000; Prebble et al., 2006) and DSDP Site 270 (Kulhanek et al., 2019) drill cores and poorly dated sediments from the Meyer Desert Formation of Oliver Bluffs in the central TAM. These assemblages likely reflect tundra mosaic vegetation with low growing Nothofagus and Podocarpaceae scrub occupying warmer sites (Askin \& Raine, 2000; Prebble et al., 2006). This palynomorph assemblage is common to most interglacial intervals through the entire Friis Hills sequence and while there is some variability between interglacial intervals, there is no clear stratigraphic (temporal) pattern or trend. For example, samples L31229 (37.16 m) and L31223 (15.73 m) in FHDP-3A and L31223 (15.73 m) in FHDP-1A all contain high pollen concentrations (grains per gram) and an assemblage with similar composition including relatively abundant Nothofagidites and Podocarpidites. Thirty-three samples from interglacial intervals were also examined for organic microfossils, and report a similar result, with no clear stratigraphic pattern or trend, and relatively abundant Nothofagidites during some interglacial periods recorded in FHDP-1A/1B (see Appendix G). Other observations include tardigrades, insect fragments, and feather barbs.

These data combined suggest that the range of environmental conditions that characterised interglacial episodes in the Friis Hills did not change through the time interval recorded in the Friis Hills sedimentary sequence. Abundant Permian pollen is present in Beacon Sandstone (Askin, 1995) but is not found in the Friis Hills sediments. The absence of reworked Permian pollen, along with rare clusters of Nothofagidites pollen, implies a quite restricted catchment area and limited transport distance, or limited erosion. No indicators of marine deposition were observed.

\subsubsection{Diatoms}

Forty-five genera and 140 species were observed in the Friis Hills drillholes. Most mudstone samples (facies 1 and 2) contained diatom remains, the exception being the lower mudstones in FHDP-1A (>19 $\mathrm{m}$ downhole) and FHDP-3A (7 samples deeper than $45 \mathrm{~m}$ ). Diatoms were also present in some of the sandstones (facies 3 and 4) adjacent to or interstratified with 
Antarctic Ice Sheet evolution and variability during the mid-Miocene Climate Transition 106 ( 15.1-13.8 Ma), from the Friis Hills, Antarctica

mudstones. Only a few samples of diamicton were processed and diatoms were either sparse or absent in these facies.

The diatom flora is like that from the mid-Miocene lake deposits of Mount Boreas (Lewis et al., 2008) with 35 common genera (Appendix E). The Friis Hills flora indicate habitats were available for both shallow water plankton (Staurosirella, Staurosira and chrysophycean flagellates) and for benthic species living on mud, stones, mosses and waterweeds. Overall, the diatom assemblages at Friis Hills and Mt Boreas bear little resemblance to modern Antarctic floras (Kellogg \& Kellogg, 2002; Spaulding et al., 2019) and are more like assemblages that characterise low ionic-strength lakes in the Arctic (Joynt \& Wolfe 2001; Smol et al., 2005).

\subsection{Age model and chronostratigraphic correlation}

An integrated age model was constructed for the Miocene Friis Hills terrestrial glacial succession by developing a paleomagnetic reversal stratigraphy, which was correlated to the Global Polarity Time Scale (GPTS; Gradstein et al., 2012) using numeric ages for two interbedded silicic tephra, and very limited biostratigraphic constraints (Fig. 3.22). 


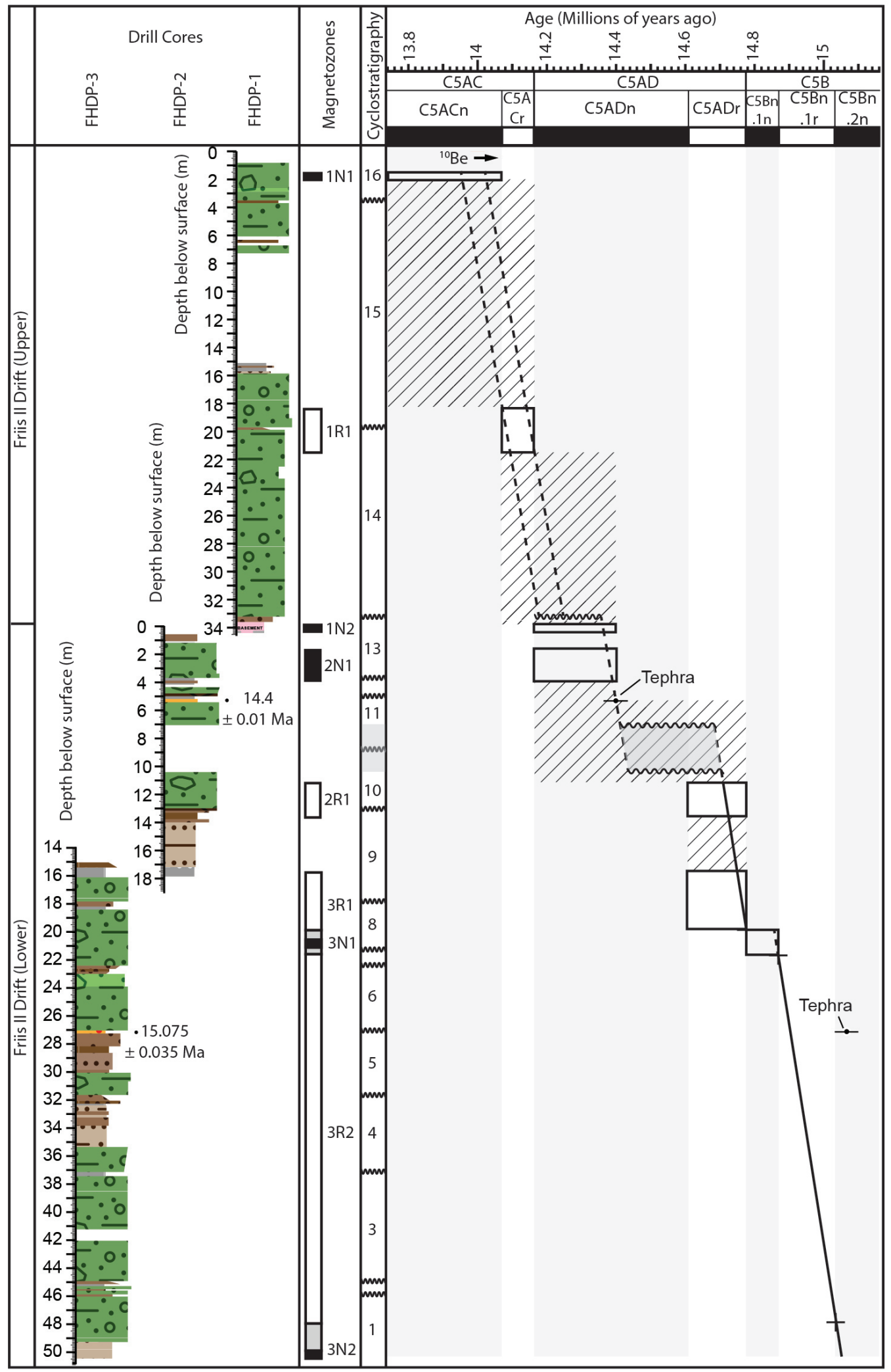

Fig. 3.22 Composite age model for the Friis II succession recovered in drill cores from the Friis Hills central basin. 
Antarctic Ice Sheet evolution and variability during the mid-Miocene Climate Transition 108 ( 15.1-13.8 Ma), from the Friis Hills, Antarctica

\subsubsection{Biostratigraphy}

Unfortunately, biostratigraphic constraints are limited, as terrestrial biostratigraphic datums in Antarctica suffer from endemism, poor age calibration and a lack stratigraphic resolution compared to marine fossil datums generated from nearby marine sedimentary sequences. Notwithstanding this, the pollen assemblage reported above for the interglacial facies is similar to that observed in lower Miocene sediments in the CRP-2A drill core from McMurdo Sound (Askin, 2000; Prebble et al., 2006), the AND-2A core (Warny et al., 2009) and DSDP 270 core from central Ross Sea (Kulhanek et al., 2019). Although this flora is not generally age diagnostic, one observed taxon, Tricoplites spp, indicates the sequence is younger than late Oligocene (Kulhanek et al., 2019). The Friis Hills assemblages also lack key elements of the more diverse Eocene assemblages recovered from the Ross Sea McMurdo Erratics (Askin, 2000), which supports localised provenance contemporary with deposition. Diatoms recovered from the Friis Hills sediments were not age diagnostic, however it is noted that species composition is similar to that reported in well-dated mid-Miocene deposits at Mt. Boreas, with 35 common genera.

\subsubsection{Tephrostratigraphy and tephrochronology}

Radiometric analysis of single crystals from each tephra layer indicate a numeric age of $15.07 \pm 0.035 \mathrm{Ma}$ for the tephra at 27.2 $\mathrm{m}$ in FHDP-3A and 14.4 $\pm 0.01 \mathrm{Ma}$ for the tephra at $5.3 \mathrm{~m}$ in FHDP-2A (Fig. 3.23). These numeric ages indicate a maximum age at the relevant stratigraphic interval as the tephra consist of reworked volcanic material. 
a.
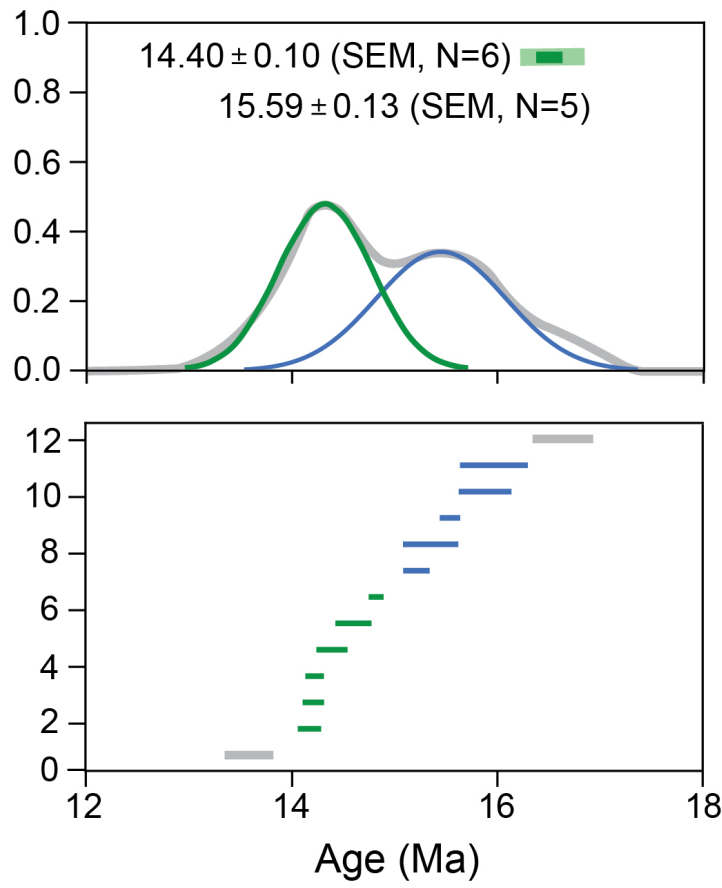

b.
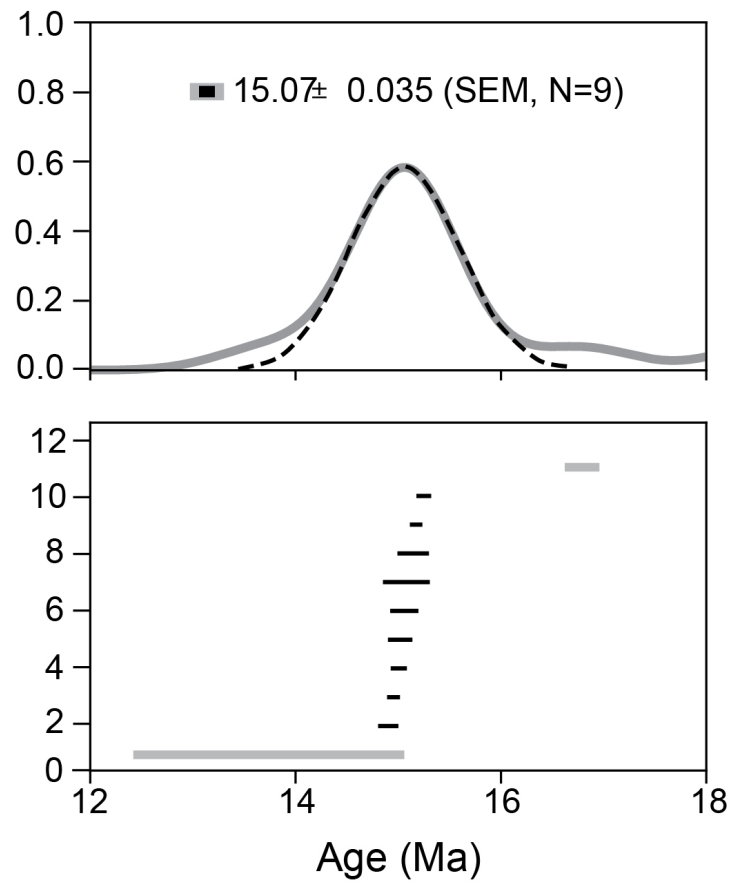

Fig. $3.23{ }^{40} \mathrm{Ar} /{ }^{39} \mathrm{Ar}$ ages for the FHDP-2A/C and -3A tephra.

Major elemental composition of glass shards from the tephra in FHDP-2A/C plot within the rhyolitic field on a Total Alkali Silica classification diagram (Le Maitre et al., 1989). Shards from the tephra in FHDP-3A plot within the trachyte field (Fig. 3.19 a). As already noted, glass chemistry from sample FHDP-2A/C shows a bimodal population, with two shards exhibiting high $\mathrm{SiO}_{2}(\geq 75 \mathrm{wt} \%)$ at comparatively low $\mathrm{CaO}(0.2 \mathrm{wt} \%)$ in comparison to the other shards, which cluster around $72 \mathrm{wt} \% \mathrm{SiO}_{2}$ at $0.4-0.6 \mathrm{wt} \% \mathrm{CaO}$. For sample FHDP-3A, the $\mathrm{SiO}_{2}$ concentration is much lower at 64-68 wt\% with comparatively high, and diverse $\mathrm{CaO}$ values (0.6 - $1.6 \mathrm{wt} \%$ ) (Fig. 3.19 b). On the basis of major elemental analysis, the two tephra layers clearly derive from two distinct eruption events and are not correlatives.

The FHDP-3A tephra has a trachyte composition and it is known that during this time, Mount Morning was erupting trachytic compositions (Martin et al., 2010). Kyle and Muncy (1989) report a quartz trachyte flow at Lake Morning with a K-Ar age of 15.2 $\pm 0.2 \mathrm{Ma}$ that correlates with the FHDP-3A tephra when plotted on a TAS diagram (Fig. 3.19 a). It is therefore likely that Mount Morning is the source of this eruption. The bimodal rhyolitic glass from the FHDP-2A/C core may also have derived from Mount Morning, which has one 
Antarctic Ice Sheet evolution and variability during the mid-Miocene Climate Transition 110 ( 15.1-13.8 Ma), from the Friis Hills, Antarctica

known rhyolitic eruptive dated at 15.4 Ma \pm 0.1 Ma in Pinnacle Valley (Martin et al., 2010), older than the FHDP rhyolitic tephra.

\subsubsection{Paleomagnetism}

Rock magnetic analyses indicate magnetite is the dominant carrier of the Characteristic Remanent Magnetisation (ChRM), with minor contributions of higher-coercivity minerals in Core 2A. Hysteresis data had median coercivity (Hc) values of $10.8 \mathrm{mT}$ for core $3 \mathrm{~A}, 19.2$ $\mathrm{mT}$ for core FHDP-2A and $11.3 \mathrm{mT}$ for core $1 \mathrm{~A}$ (Appendix I, Fig. $1 \mathrm{a}$ ), and IRM analyses (Appendix I, Fig. 1 b) revealed low median coercivity of remanence (Hcr) values of 27.1 $\mathrm{mT}$ for core $3 \mathrm{~A}, 50.7 \mathrm{mT}$ for core $2 \mathrm{~A}$ and $30.7 \mathrm{mT}$ for core $1 \mathrm{~A}$. FORC diagrams analyses (Appendix I, Fig. 1 d) of selected samples from core FHDP-3A (where there is the highest density and number of samples) indicate that low-coercivity minerals (such as magnetite) are dominant, with variable mixtures of single-domain and multi-domain grains (Appendix I, Fig. $1 \mathrm{c} ; 27.78 \mathrm{~m}$ ) or of superparamagnetic and single-domain grains (Appendix I, Fig. $1 \mathrm{~d}$; $43.78 \mathrm{~m})$.

Representative demagnetisation data were plotted on orthogonal component vector plots (Appendix I, Fig. 2) to inform fitting of PCA directions for polarity determinations of the ChRM, which is assumed to be a Detrital Remanent Magnetisation (DRM). Glaciogenic sediments in all three cores contain large clasts of basement rocks, which can have strong magnetisations that can overwhelm the DRM of the sediment matrix, resulting in spurious magnetisations. While every effort was made to avoid large clasts during sampling, some samples still had spurious magnetisations. There are too few samples to allow division of the data into statistically significant categories; however, three broad groups of demagnetisation behaviour are apparent. The first group of samples (Appendix I, Fig. 2 a-d) had easily interpreted normal or reversed polarity magnetisations with a steeply inclined, linear component between 20 and $100 \mathrm{mT}$ that was directed towards the origin and which is interpreted as the ChRM. The signal-to-noise ratio is high, with PCA Maximum Angular Deviation (MAD) values typically between $1^{\circ}$ and $5^{\circ}$.

A low-coercivity normal polarity component was observed in most reversed polarity samples, which varied in strength from very strong to weak. Such steeply inclined vertical overprints are commonly observed in high latitude drill core samples (e.g. Florindo et al., 2005; Wilson et al., 2012). This low-coercivity normal polarity component is interpreted as a Viscous Remanent Magnetisation (VRM) which resulted from rotary drilling of the 
sediment core. The second group of samples displayed magnetisations that do not relate to the geomagnetic field at the time of deposition. Samples (Appendix I, Fig. 2 e) often had linear demagnetisation trajectories that were directed to the origin but the inclination of magnetisation was too shallow and demagnetisation behaviour abnormal (e.g. higher coercivity than other samples). These samples contain strongly magnetised clasts of basement rock which overwhelmed the magnetisation of the surrounding matrix. The remaining samples were not interpretable. They had noisy demagnetisation data or did not display a single clear component. Data were either offset from the origin or centred about the origin.

\subsubsection{Magnetostratigraphy}

The longest continuous magnetostratigraphy is from core FHDP-3A, which contains 33 samples with stable magnetisation on which PCA was conducted. Six samples had magnetisation inclinations which are too shallow and likely caused by the presence of a strongly magnetised clast in the sample (Appendix I, Fig. 3). The remaining samples had demagnetisation data which varied in quality from very good with a low noise level and MAD values below $10^{\circ}$ (20 samples) to higher noise level with a maximum MAD of $17^{\circ}(22.24 \mathrm{~m})$. A down core R-N-R-N pattern of magnetozones is identified with the 3R1-3N1 transition between 20.7 $\mathrm{m}$ and $21.14 \mathrm{~m}$, the $3 \mathrm{~N} 1-3 \mathrm{R} 2$ transition between $21.8 \mathrm{~m}$ and $22.14 \mathrm{~m}$, and the $3 \mathrm{R} 2-3 \mathrm{~N} 2$ transition between $48.9 \mathrm{~m}$ and $50.7 \mathrm{~m}$ depth (Appendix I, Fig. 3).

Core FHDP-2A contains six samples which had stable magnetisation that are attributed to a geomagnetic field origin and one sample which has a shallow magnetisation that is likely controlled by a clast. A further seven samples had very noisy demagnetisation data and were not interpretable. Two samples at $1.75 \mathrm{~m}$ and $3.92 \mathrm{~m}$ have stable magnetisations with relatively low MAD values $\left(4.3^{\circ}\right.$ and $8.4^{\circ}$ respectively). The magnetisation of these samples likely resulted from deposition in a normal polarity field, which are used to define magnetozone 2N1. Between $11.22 \mathrm{~m}$ and $13.68 \mathrm{~m}$ are four well-behaved, reversed polarity samples (magnetozone $2 \mathrm{R} 1$ ), which have MAD values of between $13^{\circ}$ and $3.1^{\circ}$. Although highly discontinuous, due to poor core recovery and unsuitable lithologies for sampling, a down core N-R zonation stratigraphy for FHDP-2A has been tentatively identified.

Core FHDP-1A has only four samples with stable magnetisation that it is suggested are associated with the contemporary geomagnetic field. An isolated normal polarity sample at $1.83 \mathrm{~m}$ displays noisy demagnetisation data and a MAD of $11.8^{\circ}$, defines magneto zone $1 \mathrm{~N} 1$ 
Antarctic Ice Sheet evolution and variability during the mid-Miocene Climate Transition 112 ( 15.1-13.8 Ma), from the Friis Hills, Antarctica

(Appendix I, Fig. 3). Two samples at $20.48 \mathrm{~m}$ and $21.35 \mathrm{~m}$ have reversed polarity inclinations (magnetozone 1R1) of $71.8^{\circ}$ and $62.26^{\circ}$ and corresponding MAD values of $9.3^{\circ}$ and $18.8^{\circ}$.

\subsubsection{Integrated chronostratigraphy}

This age model (Fig. 3.22) is primarily based on correlation of magnetozones to the GPTS (Gradstein et al., 2012) constrained by radiometric ages from the two tephra. Stratigraphic relationships observed in the field (Lewis \& Ashworth, 2015), the basin geomorphology, and seismic refraction profiles are used to guide stratigraphic correlation between drill sites and across the basin (Fig. 3.3). The tephra layer in FHDP-3A provides a maximum age of $15.07 \pm 0.035 \mathrm{Ma}$ for the stratigraphic horizon at $\sim 27.2 \mathrm{~m}$. However, the tephra occurs within an interval of reversed polarity (magnetozone 3R2), which suggests the sanidine crystals have been reworked up section and are consistent with sedimentological evidence of remobilisation in a fluvial environment. Based on these stratigraphic relationships the interval from 50.3 to $21.9 \mathrm{~m}$ is correlated to C5Bn.1r (15.032 to $14.870 \mathrm{Ma}$ ). An average sedimentation rate of $16 \mathrm{~cm} \mathrm{kyr-1}$ is therefore estimated for this well constrained interval (Fig. 3.22). The normal magnetozones 3N2 below $50.3 \mathrm{~m}$ are correlated to C5Bn.2n (15.160 to $15.032 \mathrm{Ma}$ ) and 3N1 between 21.9 and $20.87 \mathrm{~m}$ to C5Bn.1n (14.870 to $14.775 \mathrm{Ma})$ and reversed magnetozone 3R1 above $20.87 \mathrm{~m}$ to the base of C5ADr (14.775 to $14.609 \mathrm{Ma}$ ). It is inferred that $\sim 60$ kyrs of time is missing within a disconformity in magnetozone $3 \mathrm{~N} 1$ based on accumulation rates discussed.

The radioisotopic age of the tephra at $5.3 \mathrm{~m}$ in FHDP-2A exhibits a bimodal distribution indicating the tephra has a mixed age population and includes material from at least two eruptive events (Fig. 3.23). The youngest age (14.4 $\pm 0.01 \mathrm{Ma})$ is used as a maximum constraint for the age model. This requires the age of normal magnetozone $2 \mathrm{~N} 1$ (between 3.92 and $1.75 \mathrm{~m}$ ) is younger than $14.4 \mathrm{Ma}$. Therefore, the interval from 1 to $4 \mathrm{~m}$ most likely correlates to the upper part of C5ADn $(<14.4$ to $>14.163 \mathrm{Ma})$. Poor quality paleomagnetic data between 4 and $7 \mathrm{~m}$ and poor core recovery from 7 to $10 \mathrm{~m}$ preclude location of the magnetic reversal boundary that must occur in this interval. The stratigraphically lower magnetozone 2R1 (13.68-11.22m) is correlated to C5ADr (14.775 to $14.609 \mathrm{Ma})$, inferring that the base of FHDP-2A correlates to $15 \mathrm{~m}$ in FHDP-3A (Fig. 3.22). A line of correlation (LOC) that originates at reversal 3N1/3R1 (C5Bn.1n/ C5ADr) and maintains the slope of the well-constrained lower section in FHDP-3A, passes through reversal 2R1 and supports the inferred correlation between FHDP-3A and lower section of FHDP-2A. The age of the 
section between the top of $2 \mathrm{R} 1$ at $11.2 \mathrm{~m}$ and the tephra at $5.3 \mathrm{~m}$ in FHDP-2A is difficult to precisely constrain. The correlation/age model requires that this part of the sequence is condensed or missing in an unconformity, but this cannot be identified as this section of the core was not recovered. Sediments below this interval must be >14.6 Ma and those above are 14.4 Ma or younger. Assuming the average sedimentation rate was relatively constant, a LOC can be applied to the poorly constrained interval with similar slope to the underlying sequence. It is assumed this LOC must pass through the tephra, constraining the age of the upper $10 \mathrm{~m}$ of FHDP-2A to between 14.44 and 14.36 Ma (Fig. 3.22). This correlation implies that at least 240 kyrs of record is missing somewhere within the interval between 7 and $10.5 \mathrm{~m}$ in FHDP-2A.

Chronostratigraphic constraints in FHDP-1A and B are limited. Magnetostratigraphic data from FHDP-1A are limited to six reliable samples that suggest normal polarity at the base of the core, an interval of reversed polarity in the middle, and a normal interval at the top (Fig. 3.22). These magnetozones cannot be confidently correlated to the GPTS due to an absence of independent biostratigraphic or radioisotopic age control. However, sedimentological and glaciological characteristics of the diamictites in FHDP-1A suggest they are most like diamictites in the Friis Hills II (upper) drift of Lewis and Ashworth (2015). Diamictites in FHDP-2A and -3A are like those in Friis Hills II (lower) drift of Lewis and Ashworth (2015). Based on this evidence, it is suggested that sediments at the base of FHDP-1B sit stratigraphically above the top of FHDP-2A. Based on this inferred stratigraphic relationship magnetozone $1 \mathrm{~N} 2$ is correlated to C5ADn (14.609 to 14.163 Ma). Reversed magnetozone 1R1 is then correlated to $\mathrm{C} 5 \mathrm{ACr}(14.163$ to $14.070 \mathrm{Ma})$ and the normal magnetozone $1 \mathrm{~N} 1$ at the top of FHDP-1B to C5ACn (14.070 to $13.739 \mathrm{Ma})$.

Assuming the sedimentation rate at FHDP-1A was like that at FHDP-3A, a LOC can be applied to FHDP-1A with similar slope. This LOC must pass through reversed magnetozone 1R1 (Fig. 3.22). This interpretation suggests the sedimentary sequence in FHDP-1A is younger than 14.25 Ma and older than 13.95 Ma. This interpretation is consistent with a minimum age assignment for the Friis Hills succession of 14 Ma based on meteoric 10Be analysis (Valletta et al., 2015). However, the maximum age for the Friis Hills sequence suggested in this thesis ( 15.1 Ma) is younger than suggested by Valletta et al., (2015) and indicates sediments in the Central Basin were deposited at the end of the MCO and through the MMCT. Furthermore, the age model indicates the Friis Hills succession is discontinuous with significant disconformities at the base of FHDP-1A and within FHDP-2A indicating 
Antarctic Ice Sheet evolution and variability during the mid-Miocene Climate Transition 114 ( 15.1-13.8 Ma), from the Friis Hills, Antarctica

episodes of erosion (depositional hiatuses) occurred across the Central Basin between 14.7 and 14.2 Ma.

\subsection{Updated composite stratigraphy for the Miocene Friis Hills deposits}

In Fig. 3.3, topographic profiles, previous mapping (Lewis \& Ashworth, 2015), new drill core stratigraphy, and seismic refraction survey data have been interpreted to derive a basin geometry and stratigraphic architecture of the basin fill for central Friis Hills. An updated stratigraphic history by integrating the new FHDP drill core stratigraphy with the stratigraphic framework established by Lewis and Ashworth (2015) is now outlined. Importantly, new chronostratigraphic constraints from the more continuous and complete FHDP drill cores allow for the observations and reconstructions provided by Lewis and Ashworth (2015) to be further refined and expanded.

\subsubsection{Friis I drift}

Exposure of the oldest sediments in the Friis Hills Miocene sequence is limited to the lowermost $5.5 \mathrm{~m}$ of a $34 \mathrm{~m}$ thick succession of drifts that infills a shallow valley, glaciallycut into granitic basement on the far eastern flank of the Friis Hills inselberg. The $5.5 \mathrm{~m}$ succession contains two lodgement (traction) tills deposited by a southwestward flowing, wet-based alpine glacier (Fig. 3.2). The tills are ascribed to the Friis I drift and are separated by an interglacial interval of sandstone, conglomerate and a volcanic ash dated at $19.76 \pm$ 0.11 Ma (Lewis \& Ashworth, 2015). Sediments of early Miocene age were not recovered in the FHDP cores, implying they are likely absent in the Central Basin.

\subsubsection{Friis II (lower) drift}

A 12 m thick, cyclic succession comprising of four sharp-based till sheets, stratigraphicallyseparated by three coarsening-upwards, proglacial, fossiliferous intervals of lacustrine mudstone and fluvial sandstone are ascribed to the lower unit of the Friis II drift (Lewis \& Ashworth, 2015). The drift is well-exposed around the margins of Central Basin, where it overlies glacially-moulded basement and infills a broad south-eastward oriented valley (Fig. 
3.2 c). Outcrops of Friis II (lower) drift in eastern Friis Hills are more sporadic and less complete, but a single glacial-interglacial cycle comprising a distinctive red, organic-rich sandy siltstone overlain by a sharp-based till occurs immediately above the Friis I drift. Where the till directly overlies basement in the far eastern margin, bedrock lineations have the same south-eastward flow direction as Friis II drift in Central Basin. Nothofagus pollen, leaves and macroscopic wood fragments are diagnostic of Friis II interglacial units in the Central Basin (Lewis \& Ashworth, 2015), but are absent in the organic-rich interglacial siltstones in the eastern regions and the cross-cut valley (Fig. 3.2). Although inferred, Lewis and Ashworth (2015) could not establish a definitive chronostratigraphic correlation of Friis II drift deposits across the entire region.

The Friis II (lower) drift is correlated with a $\sim 53 \mathrm{~m}$ thick composite interval recovered in FHDP-3A and -2A spanning $\sim 15.1-14.4$ Ma based on new volcanic ash dating and paleomagnetic stratigraphy, that comprises 13 vertically-stacked glacial-interglacial, sedimentary cycles. This includes 8 and a half cycles in the FHDP-3A drill core, and four and half cycles in the FHDP-2A drill core. While drilling recovered a thicker and more complete interval of cyclic sedimentation equivalent to the Friis II (lower) drift than Lewis and Ashworth (2015), the thickness and stratigraphic architecture of the individual cycles in FHDP cores are remarkably similar, albeit with the following notable differences.

In general, iron-stained, weathered surfaces and boulder pavements at the top of till units prior to lacustrine and/or fluvial facies during glacial retreat were not observed. Rather, the drill cores record a gradational recessional facies succession grading from coarse-grained ice proximal facies into finer-grained fluvial-lacustrine facies. In some cases, the transition is more abrupt, but evidence for development of soils or a weathered surface indicating a period of subaerial exposure at the top of diamictons was not identified. These features may have been more prevalent on the margins of the Central Basin, where Lewis and Ashworth (2015) described many of their sections, whereas these drill cores sampled the central axis of the valley where sedimentation was more continuous and complete.

While moss, pollen, diatoms, insect remains, wood, and root fragments in all interglacial intervals were recovered, intact Nothofagus leaf impressions were not present in the drill cores. However, it is possible to directly correlate the fossiliferous interglacial fluviallacustrine facies between 4 to $5 \mathrm{~m}$ depth in FHDP-2A with leaf beds that are exposed at the same elevation in a topographic low $400 \mathrm{~m}$ to the west of the drill site. These fossiliferous beds occur above the 14.4 Ma tephra layer in the core and provide age constraint for the Nothofagus leaves also reported in Lewis and Ashworth (2015). 
Antarctic Ice Sheet evolution and variability during the mid-Miocene Climate Transition 116 ( 15.1-13.8 Ma), from the Friis Hills, Antarctica

\subsubsection{Friis II (upper) drift}

A stratigraphically younger succession containing up to five glacifluvial-lacustrine cycles with broadly similar characteristics to cycles in Friis II (lower) drift, was assigned to Friis II (upper) drift by Lewis and Ashworth (2015). It was differentiated from the Friis II (lower) based on an increase in granite clasts and Beacon Supergroup quartzite erratics in tills and a decrease in mud content and meltwater features such as fluvial outwash facies. Outcrop studies indicate that Friis II (upper) drift is up to $\sim 12 \mathrm{~m}$ thinner than Friis II (lower) drift in the Central Basin and comprises two till sheets. It is regionally more extensive than Friis II (lower) drift in the Central Basin and extends to the southern margin of the Pearse Valley, however on the eastern margin of Friis Hills it is largely restricted to the cross-cut channel where it is $\sim 22 \mathrm{~m}$ thick.

FHDP-1A cut into Friis II (upper) sediments, covering $\sim 33 \mathrm{~m}$ of the sequence and terminating in doleritic basement. It is inferred that this sequence filled a channel that cut through Friis II (lower) sediments creating a basin wide disconformity 200 kyrs in duration (Figs. 3.3, 3.22). Complete recovery of the Friis II (upper) drift in FHDP-1A core was not achieved due to variations in ice cement with depth and the difficulties coring through dry permafrost. However, three, diamicton-dominated cycles, comprising sharpbased, heavily-deformed massive till units up to $13 \mathrm{~m}$ thick overlain by thin $0.5 \mathrm{~m}$ thick intervals of organic-rich lacustrine/peat bog and fluvial facies were preserved (Fig. 3.5 a). The diamictons lack evidence for subaqueous deposition and exhibit brittle and ductile deformation features associated with glacial loading and shearing. These sedimentological changes are consistent with a transition to a colder climate and thicker more extensive ice cover across the Friis Hills during glacial episodes between $\sim 14.4$ and 13.9 Ma. However, it is noted that while these glacial facies infer an increasingly cold climate, interglacial facies were similar in sedimentological character and fossil content to those recorded in the Friis II (lower) drift unit.

\subsection{Evolution of the Antarctic Ice Sheet in Southern Vic- toria Land through the mid-Miocene}

Data from coastal and offshore drill cores and seismic data indicate a highly dynamic AIS characterised much of the early to mid-Miocene (Barrett, 1987, Barrett et al., 1989, Fielding et al., 2000, Naish et al., 2001, Dunbar et al., 2008, Passchier et al., 2013, Levy et al., 2016). 
Large outlet glaciers have advanced and retreated through the TAM since the Early Oligocene and the AIS has episodically extended well beyond the Victoria Land coast and across the Ross Sea continental shelf since the latest Oligocene (Naish et al., 2001, Levy et al., 2016). Environmental proxies, including pollen and spores, indicate a polar tundra to sub polar oceanic climate persisted throughout this time (Prebble et al., 2006, Warny et al., 2009, Levy et al., 2016). While major expansion of terrestrial ice sheets into marine environments first occurred well before the MMCT, records from the circum-Antarctic suggest extensive sea ice and marine ice sheets became more persistent during and immediately following the MMCT (Crampton et al., 2016, Sangiorgi et al., 2018, Levy et al., 2019). In apparent contrast to the offshore records, glaciological and geomorphic evidence from the Dry Valleys sector suggest small ice caps and alpine glaciers dominated the TAM through the early to mid-Miocene and that large overriding ice sheets only formed after $\sim 14$ Ma when the EAIS is inferred to have become a permanent feature (Sugden et al., 1991, Marchant, 1993, Marchant et al., 1996, Lewis et al., 2006, Lewis et al., 2008).

This thesis now reconciles evidence for a prevailing temperate alpine style glaciation in the TAM and an inferred relatively small EAIS during the mid-Miocene with records of sub-polar to temperate climate and advance and retreat of large outlet glaciers into the marine environment along the Southern Victoria Land coast. A glacial-interglacial history for the Friis Hills region is reconstructed from $\sim 15$ to $\sim 13 \mathrm{Ma}$ (Fig. 3.24) by integrating knowledge from previous mapping in the region (Lewis and Ashworth, 2015), the new FHDP drill cores, coastal drill core and seismic records (Brancolini et al., 1995, Levy et al., 2016), geomorphological studies (Sugden et al., 1995, Lewis et al., 2006), and modern topography from the Reference Elevation Model of Antarctica (REMA) and Bedmachine (Morlighem et al., 2019). Mid-Miocene paleotopography is reconstructed based on the following assumptions: (1) that mountain peaks and highest elevation regions have undergone minimal change since the mid-Miocene (Schaefer et al., 1999) (2) outlet glaciers episodically flowed through the Ferrar and Taylor Valleys through the mid-Miocene as evidenced by large glacial troughs in offshore Miocene sequences (Brancolini et al., 1995), (3) subglacial bed contours upstream of the Pearse and upper Taylor Valleys are similar (Morlighem et al., 2019) and suggest there is no hidden subglacial topographic barrier that may have stopped ice flowing down the Pearse Valley in the past, (4) changes in slope that form platforms at 1300 and $\sim 800$ to $900 \mathrm{~m}$ at the margins of the Pearse Valley and Simmons Basin represent paleovalley floors, and (5) a mountain ridge previously connected the Friis and Kukri Hills and separated the Ferrar and Taylor Valleys (Lewis and Ashworth, 2015). 
Antarctic Ice Sheet evolution and variability during the mid-Miocene Climate Transition

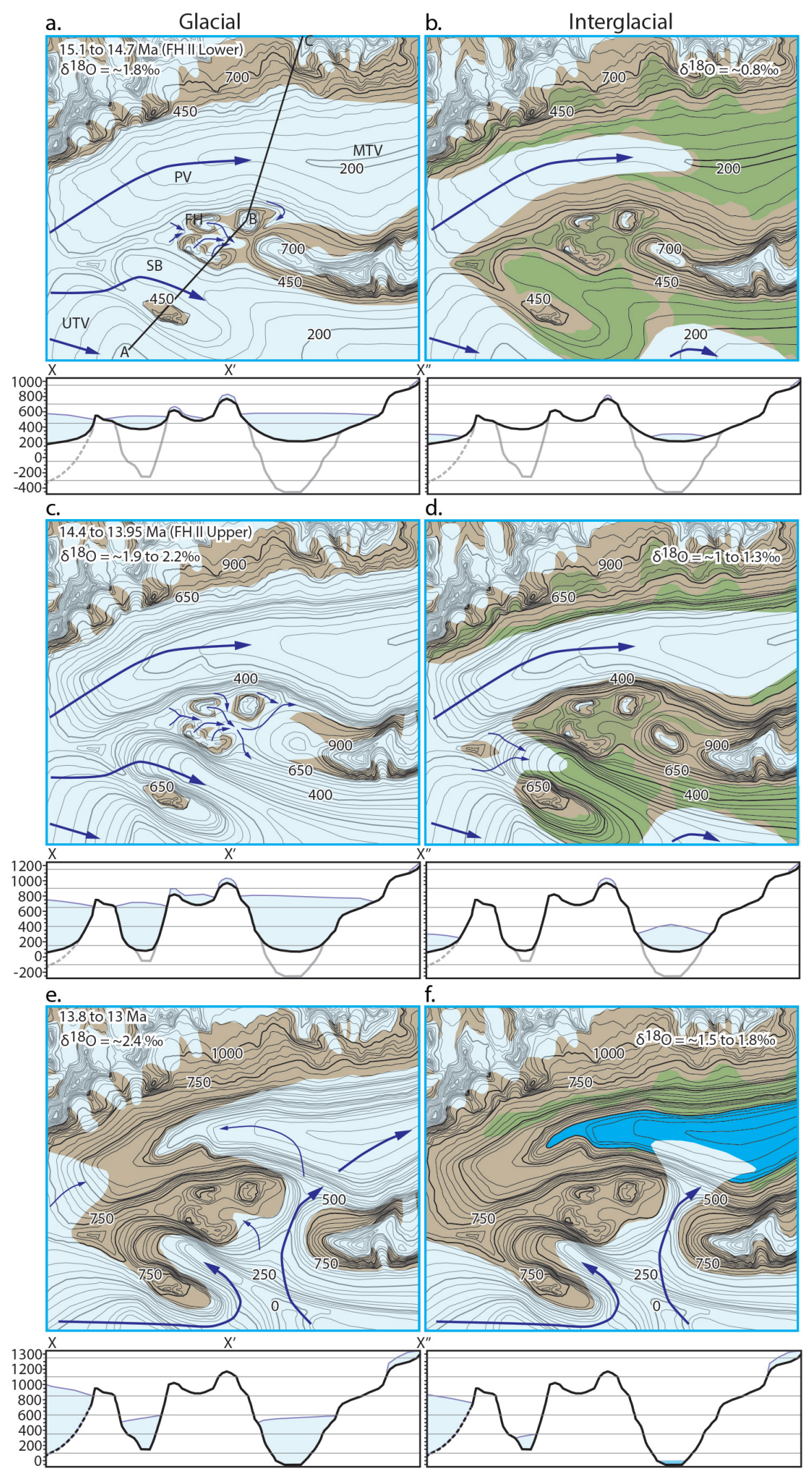

Fig. 3.24 Glacial-interglacial reconstructions for the Frill Hills region. Continued on the following page. 
Fig. 3.24 (cont) UTV = upper Taylor Valley, $\mathrm{SB}=$ Simmons Basin, FH = Friis Hills, PV = Pearse Valley, MTV = Mid Taylor Valley. Reconstructed surface contours for time intervals in Panels A-D are based on geomorphological features in the Pearse Valley and Simmons Basin and ages for similar features in the upper Wright Valley (Lewis et al., 2006). Reconstructed surface contours for time intervals in Panels E-F are based on modern topography produced from the Reference Elevation Model of Antarctica (REMA) (https://www.pgc.umn.edu/data/rema/) but are inferred to have been lower in elevation. Paleoelevations shown in cross section X-X" in panels A-F are reconstructed to accommodate uplift of $300 \mathrm{~m}$ that is inferred to have occurred during the MMCT and was driven by selective linear erosion and tectonics (see text for details). Paleoglacial flow directions are indicated by blue arrows. Green colours indicate inferred distribution of vegetation. The blue region in panel $\mathrm{F}$ indicates an area at or below $0 \mathrm{~m}$ (sea level) that may have been inundated during interglacial marine incursions.

This conceptual model accommodates both localised temperate alpine glaciation along the mountain axes and contemporaneous glacial incision in major trunk valleys during the mid-Miocene, well before the hypothesised widespread EAIS overriding at $\sim 14 \mathrm{Ma}$ (Denton et al., 1984, Sugden et al., 1995). The complex interactions between climate, glaciation, and landscape development likely means different regions across the TAM evolved at different spatial and temporal scales. Regardless, it is suggested the geomorphic and geological evidence in the Friis Hills region provides key insights into the climatic and glacial evolution of Southern Victoria Land and the East Antarctic Ice Sheet in its hinterland.

Deposition of Friis Hills II Lower Drift indicates alpine glaciers advanced and retreated across the central Friis Hills between $\sim 15.1$ and 14.7 Ma. Coastal records through this time interval are missing in unconformities (Levy et al., 2016), which suggests large-thick outlet glaciers at times advanced down the Ferrar and Pearse/Taylor Valleys and beyond the coast during maximum glacial intervals (Fig. 3.24a). It is inferred that the floors of these large valleys were shallower than today and suggest that the U-shaped feature that forms when the platforms on either side of the Pearse Valley are connected represents the valley floor at $\sim 15 \mathrm{Ma}$ (see cross sections beneath Figs. 3.24a, b). This feature occurs at a higher elevation (present day $\sim 1200 \mathrm{~m}$ ) than the labyrinth surface and its geomorphological equivalents (present day $\sim 800 \mathrm{~m}$ ), which is dated between 14 and $12 \mathrm{Ma}$ (Lewis et al., 2006) and supports the inferred age for the Pearse paleovalley. During interglacials ice likely retreated inland from the coast along the shallow and broad paleovalleys to the heads of the Taylor Valley and Simmons Basins (Fig. 3.24b). During this time, the Friis Hills supported an alpine tundra vegetation around a system of small proglacial lakes and bogs linked by 
Antarctic Ice Sheet evolution and variability during the mid-Miocene Climate Transition ( 15.1-13.8 Ma), from the Friis Hills, Antarctica

fluvial channels to retreated glacier termini and may have resembled the valleys and fjords of present-day southwest Greenland.

Glacial-interglacial variations of up to $\sim 1 \%$ (from 1.8 to $0.8 \%$ ) are recorded in deep sea ${ }^{18} \mathrm{O}$ data through most of this time interval ; Figs. 3.24a,b). Magnesium-calcium based temperature reconstructions indicate Antarctic bottom water temperature may have varied by up to $3^{\circ} \mathrm{C}$ through the mid-Miocene (Lear et al., 2010). Therefore, between 60 to $70 \%$ of the total glacial-interglacial variation in the 180 records can be explained by changes in bottom water temperature $\left(\sim 0.66 \%\right.$ if we apply $0.22 \%$ per $1{ }^{\circ} \mathrm{C}$ of temperature change). It then follows that the remaining $0.33 \%$ reflects ice volume changes between 42 and $30 \mathrm{~m}$ (sea level equivalent) if the Pleistocene calibration of $0.08-0.11 \%$ per $10 \mathrm{~m}$ sea level is applied (Fairbanks and Matthews, 1978, Adkins et al., 2002). This range of glacial-interglacial variability through the mid-Miocene is compatible with sea level records (Kominz et al., 2016).

At the onset of the MMCT at $\sim 14.7 \mathrm{Ma}$, the AIS again expanded well beyond the Victoria Land Coast and across the Ross Sea continental shelf during glacial episodes. This episode of ice sheet expansion into marine environments coincides with a drop in atmospheric $\mathrm{CO} 2$ below 400 ppm (Fig. 3.1) and is captured by a shift to more positive glacial values in ${ }^{18} \mathrm{O}$ records (>1.8\%0), by disconformities in coastal drill cores (Levy et al., 2016) and extensive seismic unconformities including Ross Sea Unconformity 4 (De Santis et al., 1999, McKay et al., 2019). It is also reflected by diatom turnover in the Southern Ocean (Crampton et al., 2016) and a significant increase in obliquity sensitivity inferred to indicate marine ice sheet growth (Levy et al., 2019). A cold polar sedimentary motif is also recorded for the first time in the AND-2A drill core (Fielding et al., 2011, Passchier et al., 2011). These changes indicate episodic expansion of glaciers and grounded ice well beyond the Southern Victoria Land coast. The MMCT onset is recorded in the Friis Hills by a $\sim 200$ kyr unconformity within the uppermost $10 \mathrm{~m}$ of the Friis II Drift (lower) sequence. The unconformity coincides with several major glacial excursions in the ${ }^{18} \mathrm{O}$ record including the first time in the Miocene that values $>2 \%$ (Fig. 3.1). It is noted that there is no difference between the facies of preand post-MMCT onset sediments in the Friis Hills, which suggests a return to relatively warm conditions following this initial episode of more extensive glacial advance.

The first evidence of persistent and significant local environmental change in the Friis Hills occurs just after 14.4 Ma and is reflected by the transition from Friis II Drift lower to the Friis II Drift upper sequence that is captured by a $\sim 200$ kyr disconformity and shift in character of glacial facies. The glacial diamictites in the Friis II Drift upper sequence 
imply thicker, more extensive ice flowed across the central Friis Hills. It is inferred that these thicker local glaciers were fed from expanding ice caps and large outlet glaciers flowing from the East Antarctic Ice Sheet into the Simmons Basin-Ferrar Valley and Pearse-middle Taylor valley during glacial advances (Fig. 3.24). This episode of major glacial advance in the Friis Hills coincides with an interval where glacial values in the ${ }^{18} \mathrm{O}$ record exceed 2.2\% (Fig. 3.1) that is inferred to indicate times when extensive but transient marine-based ice sheets grew across the Antarctic continental shelf. An extensive disconformity marks a major sequence boundary at the New Jersey margin and likely reflects one or more sea level low stands through this time interval (Kominz et al., 2016). Glacial erosion is hypothesised to have enhanced during this time and the Pearse and mid-Taylor Valleys were downcut by at least $300 \mathrm{~m}$ forming a new paleovalley floor at an elevation similar to the Labyrinth (cross section below Figs. 3.24c,d). Although glacial advances were extensive, interglacials were still relatively warm, characterised by similar climate and environmental conditions to those that preceded the MMCT. Glaciers likely thinned and retreated up valley during these warm intervals (Fig. 3.24d). Whereas peak glacial values in the deep sea ${ }^{18} \mathrm{O}$ data reached $2.2 \%$ (De Vleeschouwer et al., 2017), maximum glacial-interglacial variability was still $\sim 1 \%$. Because bottom water temperature variability was like that prior to the MMCT onset, it follows that glacial-interglacial changes in ice volume were also similar. However, given the extensive evidence that the Antarctic ice sheet extended well into marine environments, glaciers must not have retreated as far inland during interglacials (Fig. 3.24d).

While chronological control at the top of the Friis Hills sequence is poor, exposure age dating suggests much of the Friis Hills surface has remained relatively unmodified by glacial processes since $\sim 14 \mathrm{Ma}$ (Valletta et al., 2015). Deep ocean ${ }^{18} \mathrm{O}$ data indicate a final period of warm climate and ice sheet retreat occurred between 14 and 13.9 Ma (Fig. 3.1). This episode of relative warmth is potentially reflected by interglacial sediments at the top of FHDP-1A and by fossil assemblages recovered at Mt Boreas in the Olympus Range (Lewis et al., 2008). It is noted that the network of sinuous channels and potholes cut in bedrock in the upper Pearse Valley, while smaller but similar appearance to the Labyrinth, may have formed at this time representing a contemporary phase of glacial outburst flooding during the final stages of the MMCT. Subsequent glacial advance was relatively large and by $13.8 \mathrm{Ma}{ }^{18} \mathrm{O}$ values persistently exceeded $2.2 \%$ (Fig. 3.1). ᄀSea level fell by up to 100 m (John et al., 2011) reaching its lowest level since the Oligocene - Miocene boundary (Miller et al., 2005, Kominz et al., 2008, Miller et al., 2020). Disconformities in the AND-2A record persist through this time and stacked mud-poor diamictites indicative of cold polar environments occur at the base of AND-1B (McKay et al., 2009). Enhanced glacial erosion 
Antarctic Ice Sheet evolution and variability during the mid-Miocene Climate Transition

and downcutting after $\sim 13.9 \mathrm{Ma}$ is inferred to have dissected the 'Labyrinth-equivalent' surface in the Pearse Valley and deepened the trunk valleys a further $\sim 200 \mathrm{~m}$. Erosion and downcutting in regions south of the Friis Hills reduced ice flow through the Pearse Valley and directed more ice down the Upper Taylor and Ferrar. The increase in ice flow to the south of the Friis Hills exploited the ever-decreasing elevation of the divide between Friis and Kukri Hills and flowed into the mid Taylor Valley (Fig. 3.1 c, after Lewis and Ashworth, 2015). Deposition of the Cavendish Drift, a series of granite-rich lateral ablation and debris flow moraines that cross-cut older Friis II Drift (upper) deposits in Friis Hills, likely occurred at this time (after Lewis Ashworth, 2015).

Following the last major step in the MMCT at $13.85 \mathrm{Ma},{ }^{18} \mathrm{O}$ maxima reached $2.4 \%$ o and remained below $1.8 \%$ for $\sim 200$ kyrs, suggesting that both terrestrial and marine portions of the Antarctic ice sheet persisted through several glacial-interglacial cycles (Fig. 3.1). By 13.6 Ma interglacial ${ }^{18} \mathrm{O}$ values decreased and were once again similar to those that characterised 'cold' interglacials and 'warm' glacials through the MMCT (Holbourn et al., 2014, De Vleeschouwer et al., 2017; Fig. 3.1). Sea level rose along the New Jersey margin reaching relative values like those that previously characterised the mid-Miocene. Late Miocene sediments in the AND-2A and -1B drill cores reflect a shift from polar to sub-polar climate by the early late Miocene (McKay et al., 2009, Fielding et al., 2012). Furthermore, marine diatom fossils recovered from Dry Valley Drilling Project core 4A indicate the upper Wright Valley was a fjord in the late Miocene (Brady, 1979). These data suggest the AIS and outlet glaciers in Southern Victoria Land once again retreated inland during interglacial episodes as climate warmed following peak ice sheet expansion at the end of the MMCT (Fig. 3.24f). Notwithstanding this, there is limited evidence that temperate glaciation or tundra vegetation returned to the Friis Hills or persisted at other locations in the high TAM after $\sim 13$ Ma (Marchant, 1993, Lewis et al., 2007, Lewis et al., 2008). Although evidence for water in the Cavendish drift suggests temperatures remained warm enough to cause significant glacial melt (Lewis and Ashworth, 2015).

\subsection{Conclusions}

The $\sim 50 \mathrm{~m}$ thick terrestrial glacial succession recovered from the Friis Hills records 15 cycles of advance and retreat of wet-based glaciers through the mid-Miocene, implying conditions considerably warmer and wetter than those of present-day. Repetitive facies successions preserved in many of these cycles record regular oscillations in depositional environment, 
from subglacial to fluvial-deltaic lacustrine environment, bounded by GSEs. An idealised sequence stratigraphic motif has been used to create conceptual depositional environment models for glacial maximum, early recession, and late recession at the Friis Hills during the mid-Miocene.

An age model was developed using the correlation of magnetozones to the GPTS, constrained by the radiometric ages of the two tephra recovered, which provide a maximum age of the sediment based on sedimentological evidence that suggest remobilisation of tephra in a fluvial environment. These constraints infer an age of between $\sim 15.1$ and 13.8 Ma for the Friis Hills sediments. Unconformities marked by GSEs up to 400 kyrs in duration occur in the FHDP record, primarily in the upper $\sim 15 \mathrm{~m}$ of FHDP-3A (likely to record loss of Friis II (lower)) and between $\sim 7-15 \mathrm{~m}$ of FHDP-1A (likely to record loss of Friis II (upper)). Complete recovery of the cores was not achieved, with an average recovery of $72 \%$, due to variations in ice cement with depth and dry permafrost.

The Friis Hills record clearly shows that vegetation disappeared from the high mountains at the end of the MMCT, but why vegetation disappeared remains unclear. Several causes have been suggested and include climatic cooling (Lewis et al., 2008) and loss of refugia due to glacial overriding during the final phase of the MMCT. While vegetation may have disappeared from the mountains, sedimentological and paleoecological evidence suggests that sub-polar climatic conditions persisted at the coast through much of the late Miocene and early Pliocene ( McKay et al., 2009, Naish et al., 2009, Levy et al., 2012). Furthermore, proxy data from the DVDP-10 and -11 drill cores also indicate higher plants persisted at low elevations in the Taylor Valley through the early Pliocene (Fielding et al., 2012; Ohneiser et al., 2020).

The conceptual model and environmental history outlined in this chapter includes a mechanism that can potentially explain the loss of vegetation at present day high elevations in the TAM. This model includes several episodes of valley downcutting. It is inferred that $\sim 500 \mathrm{~m}$ of sediment was removed from Simmons Basin and upper Taylor and Pearse Valley's between $\sim 14.7 \mathrm{Ma}$ and today, with at least $300 \mathrm{~m}$ of downcutting through the MMCT. These values imply an average erosion rate of $<0.5 \mathrm{~mm} \mathrm{yr}^{-1}$ through the MMCT, which is less than rates observed for modern Patagonian glaciers ( 1 to $>10 \mathrm{~mm} \mathrm{yr}^{-1}$ ) but higher than those observed along the western Antarctic Peninsula (0.01 to $0.1 \mathrm{~mm} \mathrm{yr}^{-1}$; Koppes et al., 2015). Average erosion rate was $<0.015 \mathrm{~mm} \mathrm{yr}^{-1}$ after the MMCT, which is consistent with the lowest modern values in the Antarctic Peninsula. Therefore, the estimated erosion rates presented here fit modern observations for sub-polar and polar environments. 
Antarctic Ice Sheet evolution and variability during the mid-Miocene Climate Transition

Focused removal of sediment from AIS outlet valleys and associated isostatic rebound can account for up to $50 \%$ of peak elevation in the TAM (Stern et al., 2005). Therefore, selective linear erosion and removal of $500 \mathrm{~m}$ of sediment over the past 15 million years may have caused at least several hundred metres of uplift of the Friis Hills and surrounding mountain ridges. TAM uplift rates of up to $100 \mathrm{~m} \mathrm{myrs}^{-1}$ have been inferred on the basis on fission-track thermochronology (Fitzgerald, 1992). Latest Miocene to early Pliocene marine deposits today sit at 165 masl in the Wright Valley (Vucetich and Topping, 1972, Brady, 1979) and require uplift rates greater than $50 \mathrm{~m} \mathrm{myrs}^{-1}$ (e.g. Levy et al., 2012). Other studies suggest $<800 \mathrm{~m}$ of uplift in the region since the MMCT (Wilch et al., 1993). At an average modern elevation of $1325 \mathrm{~m}$, the range of uplift estimates for the region places the Friis Hills somewhere between sea level and $\sim 600$ m elevation in the mid-Miocene during the time the Friis II Drift was deposited.

This thesis suggests that the lowermost elevation estimates are unlikely based in part, on the absence of in-situ or reworked marine fossils in the Friis Hills sediments. It also supports previous arguments that erosion and downcutting that created the Friis Hills inselberg through the MMCT contributed to uplift, regional cooling, and aridification across the mountain peaks (Stern et al., 2005, Lewis and Ashworth, 2015;). A change in elevation of $\sim 800 \mathrm{~m}$ alone due to selective linear erosion, isostatic rebound, and tectonic uplift may have caused a 4.8 to $5.6{ }^{\circ} \mathrm{C}$ decrease in surface temperature across the Friis Hills and surrounding regions (assuming a high latitude moist adiabatic lapse rate of 6 to $7{ }^{\circ} \mathrm{C} \mathrm{km}^{-1}$ ). As marine-based ice sheets and sea-ice advanced across the Ross Sea across the MMCT (e.g. Levy et al., 2016, McKay et al., 2019), a drier adiabatic lapse rate could have resulted in even greater cooling in response to uplift. This uplift-driven cooling across the mountain peaks may have contributed to retreat of vegetation towards the valley floors and coastal regions both during and following the MMCT. 


\section{Chapter 4}

\section{Carbon-dioxide and tectonic controls on Antarctic climate and ice sheet evolution in the mid-Miocene: a model-data integration}

Author contributions are as follows: The project was designed from the outset by H. Chorley and A. Halberstadt (University of Massachusetts Amherst), their supervisors (T. Naish, R. Levy, \& R. DeConto (University of Massachusetts Amherst)) and D. Kowalewski (Worcester State University), who co-ordinated and undertook the fieldwork in the Friis Hills in 2016. Subsequently, during a visit to the University of Massachusetts, Amherst and AGU in December 2018, with the assistance of R. DeConto (Halberstadt's PhD supervisor) and E. Gasson (University of Bristol), a plan for the data-model comparison project was developed. Consequently, the work presented in this chapter is co-produced and will also form part of A. Halberstadt's PhD. The relative contribution of A. Halberstadt and H. Chorley to this chapter is $40 \%$ to $60 \%$. A. Halberstadt carried out the ice sheet and climate model simulations as part of this project and has therefore written the methods associated with these (e.g. model setup). All other work conducted, including the analysis and interpretation of results has been carried out by H. Chorley and A. Halberstadt. T. Naish, R. Levy, R. DeConto, E. Gasson, and D. Kowalewski have provided guidance and advice on refining the main outcomes of the work for publication. 
Carbon-dioxide and tectonic controls on Antarctic climate and ice sheet evolution in the

\subsection{Abstract}

Geologic proxy data and model simulations imply a dynamic Antarctic Ice Sheet (AIS), with major variations in the volume and extent of its marine and terrestrial ice sectors during the mid-Miocene ( $\sim 17-13.8 \mathrm{Ma})$. This time period has direct relevance for understanding ice sheet response to future climate change as atmospheric carbon dioxide $\left(\mathrm{CO}_{2}\right)$ concentrations and global temperatures were similar to those projected in the near future. Previous attempts to simulate AIS response to Miocene warmth have been hindered by a strong hysteresis and therefore, have been unable to successfully replicate conditions implied by geologic records. This study produces an ensemble of model simulations for a recently published mid-Miocene topography and plausible range of $\mathrm{CO}_{2}$ concentrations, Transantarctic Mountain (TAM) uplift scenarios, and glacial-interglacial orbits in order to better understand the evolution and behaviour of the East Antarctic Ice Sheet (EAIS) in the Southern Victoria Land and Wilkes Land sectors and intervening the TAM. Geologic paleoenvironmental proxy data and reconstructions were used to identify the range of model boundary conditions and forcings used in the simulations. Sedimentological and palynological data provided the primary constraint on evaluation of modelled ice extent and temperature variability, respectively, across the Miocene Climatic Optimum (MCO, 17-15 Ma) and mid-Miocene Climate Transition (MMCT, 14.8-13.8 Ma).

Results of this model-data comparison are used to evaluate likely boundary conditions and forcings for the MCO and MMCT. TAM elevations of between 300-500 m lower than present-day are hypothesised, with uplift driving the shift in dominant glacial style from wetto cold-based across the MMCT that is observed in geologic records. $\mathrm{CO}_{2}$ concentrations were elevated during the MCO, with peak warmth most compatible with $780 \mathrm{ppm}$ modelled $\mathrm{CO}_{2}$. Cooler $\mathrm{MCO}$ interglacials were characterised by lower $\mathrm{CO}_{2}$ concentrations of $690 \mathrm{ppm}$ and likely remained at similar concentrations during MCO glacial periods. A transition to lower $\mathrm{CO}_{2}$ concentrations across the MMCT modelled the growth of a continental scale ice sheet during glacials, with a marine-terminating margin and the initiation of marine-based ice as inferred in the geologic record. The onset of marine-based ice advance across the continental shelf is inferred at $\mathrm{CO}_{2}$ concentrations between 280 and 460 ppm, but likely nearer $400 \mathrm{ppm}$, with perennial sea ice only associated with an expanded marine ice sheet. MMCT interglacials remained moderate, most consistent with the 460-690 ppm modelled $\mathrm{CO}_{2}$. These scenarios require $\mathrm{CO}_{2}$ variability on a glacial-interglacial scale, which has previously been suggested to explain variability across the mid-Miocene. The persistence of a significantly-retreated, thick EAIS under even the highest modelled $\mathrm{CO}_{2}$ concentrations 
imply a strong hysteresis effect, which creates stable conditions and limits significant retreat of the terrestrial ice sheet. Finally, the persistence of localised tundra vegetation under low $\mathrm{CO}_{2}$ concentrations and glacial orbits in the model supports the persistence of plants in coastal lowlands beyond the MMCT.

\subsection{Introduction}

Antarctic climate and ice sheet evolution during the mid-Miocene has direct relevance for understanding the response and stability of the ice sheet to rapidly increasing atmospheric $\mathrm{CO}_{2}$ concentrations in the future. The mid-Miocene was significantly warmer than present and is characterised by a dynamic AIS, with major fluctuations in the volume and extent of terrestrial and marine-based ice sheets (Miller et al., 2005; Gasson et al., 2016; Levy et al., 2016; Jovane et al., 2019). Based on deep-sea oxygen isotope $\left(\delta^{18} \mathrm{O}\right)$ records, the MCO (Flower \& Kennett, 1993) was identified as a period of unusual global warmth between $\sim 17$ $15 \mathrm{Ma}$, punctuating a long term cooling trend from the greenhouse climate of the early Eocene to the icehouse climate of the early Miocene, during which the AIS was highly dynamic fluctuating on orbital timescales by between 30\% (Liebrand et al., 2011; Holbourn et al., 2013) and 80\% (Shevenell et al., 2008; Lear et al., 2010; De Boer et al., 2010) of present-day volume. While interglacials remained warm during the ensuing MMCT ( 14.8-13.8 Ma), increasingly larger glacial periods characterise this period, culminating in one of the major cooling and ice expansion steps during the Cenozoic evolution of the AIS. Following the MMCT there was a change in climate state, whereby interglacial values in $\delta{ }^{18} \mathrm{O}$ records were cooler and more enriched and similar in magnitude to glacial values during the MCO (Holbourn et al., 2014), implying a generally larger AIS and colder sea-surface temperatures (SST) at bottom water formation sites

These climatic variations have been attributed to a combination of atmospheric $\mathrm{CO}_{2}$ drawdown, orbitally-driven temperature and precipitation variations, ocean circulation changes, and/or ocean gateway reconfiguration (Flower \& Kennett, 1994; Shevenell et al., 2004; Shevenell et al., 2008; Holbourn et al., 2005; Holbourn et al., 2007; Holbourn et al., 2014; Holbourn et al., 2015; Langebroek et al., 2009; Badger et al., 2013). While the mid-Miocene provides a relevant analogue for modern and future ice sheets as conditions were relatively similar to present (e.g. continental configuration, ocean circulation), considerable uncertainty remains over the climate and tectonic boundary conditions during this time. Geological data 
from a range of different proxies indicate that atmospheric $\mathrm{CO}_{2}$ concentrations could have varied between 280 to $840 \mathrm{ppm}$ during the $\mathrm{MCO}$, with a general decline across the MMCT.

The TAM are a $>3000 \mathrm{~km}$ long mountain chain that divides the West Antarctic Rift System from the East Antarctic craton (Fig. 4.1). The northern and central TAM, at presentday elevations of $>4000 \mathrm{~m}$, have undergone a spatially and temporally complex uplift since the Cretaceous (Stern \& ten Brink, 1989; ten Brink et al., 1997; Fitzgerald, 2002; Lisker, 2002; Paxman et al., 2019a). Glacial erosion and subsequent isostatic uplift have further modified TAM elevations since ice sheet inception at $34 \mathrm{Ma}$, which could be responsible for up to $50 \%$ of TAM uplift (Stern \& Baxter, 2002; Stern et al., 2005). The timing and interplay of thermal, tectonic, and erosional drivers of TAM uplift remain relatively poorly-constrained (Stern et al., 2005; Brenn et al., 2017; Paxman et al., 2019a). Despite uncertainty over the style and timing of uplift, the TAM plays a significant role in the growth and stability of the EAIS, acting to buttress growth and limit ice flow through to the coast, but also as a focus of ice sheet nucleation (DeConto \& Pollard, 2003; Gasson et al., 2016). This study uses a 14 Ma Antarctic topographic reconstruction by Paxman and others (2019b), which places the TAM at elevations relatively similar to modern, with partial valley incision, and applies a range of elevation adjustments to account for these uncertainties. 


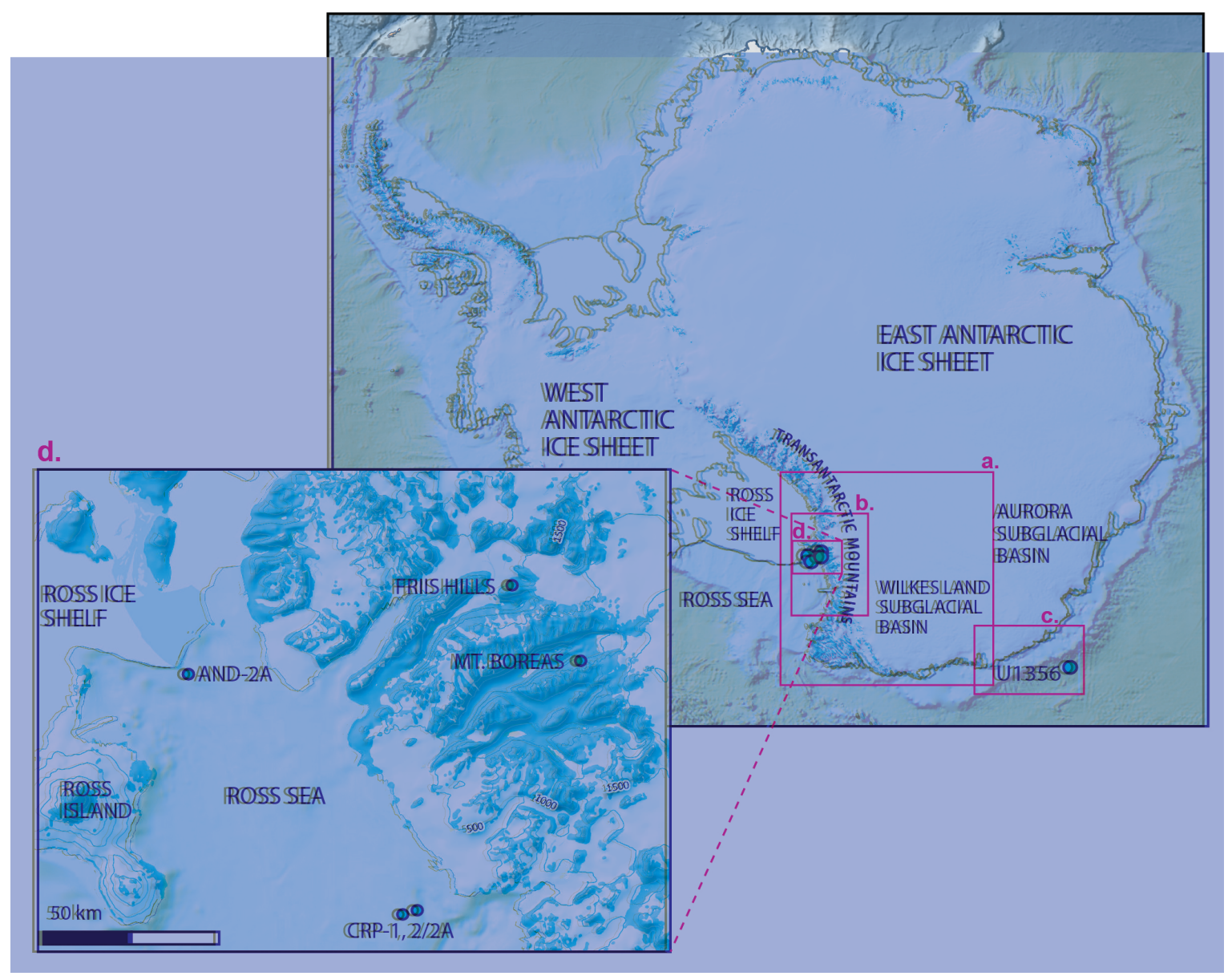

Fig. 4.1 Location of regions mentioned in text, along with paleo records used for model-data comparison (AND-2A: ANDRILL-2A, CRP: Cape Roberts Project, Mt. Boreas, Friis Hills, U1356). (a) The greater Transantarctic Mountain and Wilkes Land Basin region (domain for Figure. 4.10). For each model, a 15-km resolution nested RCM is initiated across smaller domains: (b) Transantarctic Mountains region, to provide context for AND-2A, CRP, and terrestrial records (domain for Figure 4.9), and (c) offshore and coastal Wilkes Land, to provide context for the U1356 drill core. (d) The McMurdo Dry Valleys region (domain for Figure 4.7).

Many of the key geologic datasets spanning the early to mid-Miocene are located along the TAM coast or in the McMurdo Dry Valleys (MDV, Fig. 4.1, e.g. Cape Roberts Project, ANDRILL-2A, Friis Hills, Mt. Boreas), with U1356 off the Wilkes Coast reconstructing Wilkes Land Subglacial Basin (WLB, Fig. 4.1) variability during this time. The climate and ice sheet interpretations and reconstructions derived from these records are highly sensitive to atmospheric $\mathrm{CO}_{2}$ concentrations and TAM elevation. This study therefore explores the range of variable $\mathrm{CO}_{2}$ concentrations and TAM uplift, constrained by geological data, by 
Carbon-dioxide and tectonic controls on Antarctic climate and ice sheet evolution in the 130 mid-Miocene: a model-data integration

modelling an ensemble of boundary conditions and forcings. Antarctic climate and ice sheet configuration is investigated under a range of plausible past $\mathrm{CO}_{2}$ concentrations, TAM uplift scenarios, and astronomical orbits using coupled climate and ice sheet models. This work expands on previous efforts (Gasson et al., 2016) by using a new topographic reconstruction (Paxman et al., 2019b), including a wider range of possible boundary conditions, and constrained by a wider range of geological data.

\subsubsection{Transantarctic Mountain uplift scenarios}

Antarctic bedrock topography is also poorly constrained for the Miocene, despite playing a key role in determining where ice flows and erodes (e.g. Gasson et al., 2016). Moreover, there is considerable uncertainty over uplift rates since the Miocene that limits current understanding of the role of tectonics on the evolution of the EAIS. Despite this, it is thought that rising mountain elevations could have significantly contributed to the change in basal ice thermal character, resulting in the more stable ice sheet that exists in Antarctica today (Marchant et al., 1993; Sugden \& Denton, 2004; Lewis et al., 2006; Lewis et al., 2008; Lewis $\&$ Ashworth, 2015). It was previously thought that the formation of the TAM occurred in three main episodes of uplift during the early Cretaceous, and early Cenozoic (Fitzgerald, 2002), as a result of repeated tectonism and magmatism (Fitzgerald, 2002; Goodge et al., 2004). More recently, a re-evaluation of thermochronology data combined with observations in geologic records and thermal history modelling indicate this uplift was far more complex, varying spatially and in timing along the mountain range (Lisker \& Läufer, 2013; Lisker et al., 2014), with uplift rates expected to be greater near highly erosive glaciers (e.g. Byrd and David Glaciers) due to greater isostatic rebound.

The Dry Valleys are just one block of many within the TAM (Fitzgerald, 1992), with a unique pattern of uplift that may vary from those surrounding it. This is a particularly significant region to focus on, not only due to the availability of paleoenvironmental records, but also due to evidence that indicates the block has uplifted as one unit since the early Tertiary (Fitzgerald et al., 1986). Due to differing uplift rates between mountain blocks and a lack of data for the whole continental margin, it is difficult to reconstruct evolving surface elevations along the entire TAM. TAM uplift has previously been attributed to several mechanisms, including but not limited to, thermal conduction or advection (ten Brink $\&$ Stern, 1992; ten Brink et al., 1993; Stern et al., 2005), isostatic rebound in response to normal faulting (Bott \& Stern, 1992), and erosional based rebound from valley incision (Stern \& 
ten Brink, 1989). Despite the loading enforced by the EAIS and the unknown extent of overriding of the TAM during the Miocene, rebound in response to ice sheet loading has been shown to be minimal, on the scale of 100-200 m (Stern \& ten Brink, 1989). On the other hand, rebound in response to valley incision can account for up to $50 \%$ of mountain elevation in the Central TAM (Stern \& Baxter, 2002; Stern et al., 2005). It is therefore important to constrain the timing of valley incision in the TAM derived from paleoenvironmental records.

While the mechanisms responsible for the formation of the WLB and the TAM remain subject to debate, the most accepted mechanism for the uplift of the TAM is a 'flexural cantilever hinge' model (Fig. 4.2). This model can explain the high elevations of the TAM ( $>4000$ metres above sea level) and a WLB that is up to $1 \mathrm{~km}$ below sea level. The WLB is a flexurally controlled basin that is lowered in elevation, the result of regional compensation for the significant uplift of the TAM (Fig. 4.2, Stern \& ten Brink, 1989). Surface uplift estimates since the mid-Miocene vary from up to $1 \mathrm{~km}$ (Behrendt \& Cooper, 1991; Fitzgerald, 1992; Wilch et al., 1993; Kerr \& Huybrechts, 1999) to uplift of the TAM to present-day elevations occurring prior to the Miocene (Clapperton \& Sugden, 1990; Wilson, 1995; Sugden et al., 1999). Higher estimates of uplift place many TAM paleoenvironmental records considerably closer to sea level, influencing the interpretation of both ice flow dynamics and, given an adiabatic lapse rate of $0.5^{\circ} \mathrm{C} / 100 \mathrm{~m}$ (Lewis \& Ashworth, 2015), the reconstructed mean annual temperatures (MAT) under a range of atmospheric $\mathrm{CO}_{2}$ concentrations. By investigating changing surface elevations of the TAM, the surface temperature change during the mid-Miocene that are due to changes in atmospheric $\mathrm{CO}_{2}$ concentrations can begin to be distinguished from those that can be attributed to increasing elevation of the TAM. 


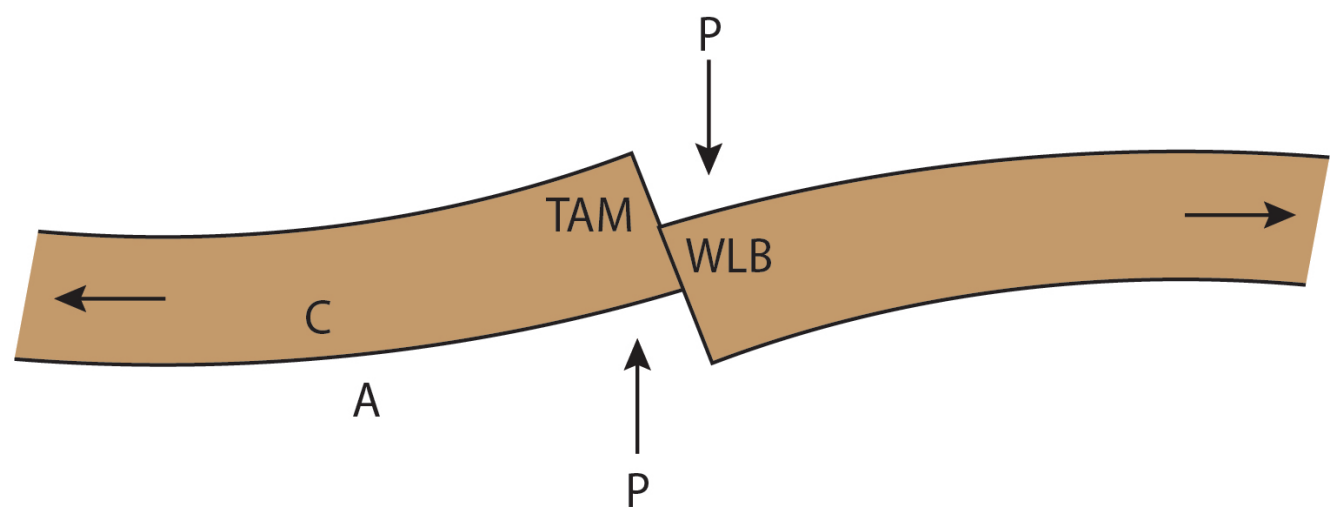

Fig. 4.2 Cantilever style hinged deflection shows how TAM elevations continued to rise while elevations of the WLB were lowered, with the WLB explained as a flexurally controlled basin produced as a form of regional compensation for TAM uplift. $\mathrm{C}$ is the elastic plate, which is buoyantly supported by a displaced, fluid substratum, A. Each limb of the plate acts as an independent, cantilevered beam and the load ' $\mathrm{P}$ ' acting equally but in opposite directions on each side of the inclined fault arises from buoyancy forces. As the lithosphere is buoyantly supported by the asthenosphere, the limb of the footwall of unloaded and will flex upward. The hanging wall now has extra mass and will flex downward in response. Figure adapted from Stern and ten Brink (1989).

The most recent topographic reconstruction of Miocene surface elevation by Paxman and others (2019b) uses a back-stripping method to estimate and restore glacially eroded material to the topography, adjusting elevation for flexural isostatic responses in response to increased loading. The continual evolution of topography from $34 \mathrm{Ma}$ to present is calculated using a history of sediment deposition from drill core records from the Wilkes Land Margin and western Ross Sea. The Paxman and others (2019b) topographic reconstruction places the course-scale Friis Hills grid in the simulation at an average $+92 \mathrm{~m}$ higher than present-day elevations. However, due to the high degree of topographic variability within a grid (10 $\mathrm{km}^{2}$ ) and the steep sided glacial valleys disecting mountains, this is likely to considerably overestimate the elevation of the Friis Hills during the mid-Miocene.

\subsubsection{Atmospheric carbon-dioxide concentrations}

Reliable reconstructions of pre-Quaternary atmospheric $\mathrm{CO}_{2}$ concentrations are temporallysparse limiting a clear understanding between greenhouse gas forcing and climate variability established from geological records (Greenop et al., 2014; Sosdian et al., 2018). Through the early to mid-Miocene, proxy $\mathrm{CO}_{2}$ reconstructions derive from paleosols (Cerling, 1992; Ekart et al., 1999; Retallack, 2009), phytoplankton biomarker carbon isotopic composition 
(Badger et al., 2013; Zhang et al., 2013; Super et al., 2018), boron isotopic composition of fossil foraminiferal calcite (Foster et al., 2012; Greenop et al., 2014), B/Ca composition of fossil foraminiferal calcite (Badger et al., 2013), fossil leaf stomata (Royer et al., 2001; Kürschner et al., 2008; Beerling et al., 2009). These various proxy methods have strengths and weaknesses (summarised in Masson-Delmotte et al., 2013) and together produce a wide range of estimates, with values that range from 300 to $840 \mathrm{ppm}$ through the mid-Miocene. Despite this, there is general agreement that atmospheric $\mathrm{CO}_{2}$ concentrations were higher than pre-industrial levels during the $\mathrm{MCO}$, with a decline in $\mathrm{CO}_{2}$ across the MMCT.

Elevated $\mathrm{CO}_{2}$ during the $\mathrm{MCO}$ and interglacial periods interchange with low $\mathrm{CO}_{2}$ coinciding with major glaciations (Kürschner et al., 2008). $\mathrm{CO}_{2}$ could have fluctuated on glacial-interglacial timescales during the mid-Miocene (Greenop et al., 2014), which would help explain a highly dynamic EAIS during this time as indicated in $\delta{ }^{18} \mathrm{O}$ records (e.g. Holbourn et al., 2014), although the mechanism of such geologically short high-amplitude $\mathrm{CO}_{2}$ variations is difficult to identify. These variations in $\mathrm{CO}_{2}$ concentrations have been attributed to dynamic changes to the carbon cycle, including changes in volcanic emissions, silicate weathering, the organic carbon sub-cycle, and the ocean carbon reservoir (Derry \& France-Lanord, 1996; Raymo \& Ruddiman, 1992; Foster et al., 2012). Greenop and others (2014) propose that the sensitivity of the AIS to $\mathrm{CO}_{2}$ variability was divided during the Miocene, with a higher elevation terrestrial reservoir of ice that remained stable at relatively high $\mathrm{CO}_{2}$ concentrations (e.g. the EAIS plateau) and another lower-elevation marine-based reservoir (e.g. the WLB) that remained dynamic even at the lower end of reconstructed $\mathrm{CO}_{2}$ concentrations.

Previous attempts to simulate AIS dynamics during relative warmth of the Miocene have been hindered by a strong hysteresis, which required surface temperatures to warm by $15-20^{\circ} \mathrm{C}$ for retreat to occur from a fully glaciated state, and $\mathrm{CO}_{2}$ concentrations at the high end of proxy reconstructions (DeConto \& Pollard, 2003; DeConto et al., 2008; Gasson et al., 2016). Langebroek and others (2009) found variations in orbital forcing when combined with declining levels of atmospheric $\mathrm{CO}_{2}$ allowed for a hysteresis more closely aligned with $\mathrm{CO}_{2}$ reconstructions for the Miocene, with deglaciation of the EAIS at $\sim 725 \mathrm{ppm}$. 


\subsection{Methods}

\subsubsection{Mid-Miocene paleo-records and model-data comparison}

Antarctic Miocene temperature reconstructions are sparse and often difficult to chronologically constrain or correlate. Those that do exist, however, provide data against which climate model output can be evaluated. Paleoenvironmental data from terrestrial and marine records across the TAM and WLB were compiled (Fig. 4.1, Table 4.1-4.3). These paleoenvironmental data were divided into sedimentological and palynological evidence and further divided into glacial and interglacial periods to provide a means against which to test both the cold and warm orbit simulations.

Sedimentological data provides a record of ice-extent, basal conditions, and flow directions that can be compared with model output. The palynological data provides pollen assemblages that can be directly compared with the modelled BIOME4 output and mean summer temperatures (MST) at each of the sites at the time of deposition. Where pollen data is recorded in marine records, model grid cells from the adjacent coast were selected for model-data comparison on the basis that pollen grains showed little evidence of transport prior to deposition (Warny, personal communication).

Geologic records imply a tundra dominated TAM and WLB during the mid-Miocene, which are divided into five classifications in the BIOME4 model (Table. 4.4). In the case of mid-Miocene vegetation, it is assumed that model output in the range of erect-dwarf shrub tundra to graminoid and forb tundra best fit pollen assemblages, with shrubs reaching up to 50 $\mathrm{cm}$ in height (Warny et al., 2009). In the case of the U1356 record, palynological assemblages imply a more diverse environment in the WLB than across the TAM. The presence of localised coastal forests (Sangiorgi et al., 2018) is inferred as taiga/montane (boreal) forest in the BIOME4 output. The presence of tundra vegetation also constrains minimum annual temperatures, with a minimum temperature threshold of $-22^{\circ} \mathrm{C}$ for vegetation survival (Sakai et al., 1981; Francis \& Hill, 1996; Hill et al., 1996). 
Table 4.1 Sedimentological and palynological proxy data for interpreting ice extent and temperature during interglacial periods of the early Miocene and Miocene Climatic Optimum (MCO).

\begin{tabular}{|c|c|c|c|c|c|c|}
\hline Period & Site & Lat,Long & $\begin{array}{l}\text { Age } \\
\text { (Ma) }\end{array}$ & $\begin{array}{l}\text { Temp } \\
\left({ }^{\circ} \mathrm{C}\right)\end{array}$ & Palynological & Sedimentological \\
\hline \multirow[t]{3}{*}{$\begin{array}{l}\text { Pre- } \\
\text { MCO } \\
\text { (early } \\
\text { Miocene) }\end{array}$} & $\begin{array}{l}\text { ANDRILL- } \\
2 \mathrm{~A}\end{array}$ & $\begin{array}{l}-77.45 \\
165.16\end{array}$ & $21-17$ & - & - & $\begin{array}{l}\text { More widespread glaciation, lodgement tills, clasts } \\
\text { and lack of erratics suggests deposition predates } \\
\text { downcutting of surrounding valleys, brief ice-free } \\
\text { periods, deformation from ice readvance, local topo- } \\
\text { graphic low, ice was alpine, no continental ice sheet } \\
\text { flowed over Friis Hills at this time, ice flow to SW. }\end{array}$ \\
\hline & $\begin{array}{l}\text { Cape } \\
\text { Roberts } \\
\text { Project CRP- } \\
1 \text { and CRP } \\
2 / 2 \mathrm{~A}\end{array}$ & $\begin{array}{l}-77.01 \\
163.76\end{array}$ & $19-17$ & $7-10$ & MST; pollen (Raine, 1998) & $\begin{array}{l}\text { Tidewater glaciation (analogous to EM III) (Fielding } \\
\text { et al., 2000; Naish et al., 2001); tundra vegetation } \\
\text { (Raine, 1998; Raine et al., 2006) }\end{array}$ \\
\hline & Friis Hills & $\begin{array}{l}-77.45 \\
161.30\end{array}$ & 19.76 & - & - & Ice-free (Lewis \& Ashworth, 2015) \\
\hline \multirow[t]{3}{*}{$M C O$} & $\begin{array}{l}\text { ANDRILL- } \\
2 \mathrm{~A}\end{array}$ & $\begin{array}{l}-77.45 \\
165.16\end{array}$ & $\begin{array}{l}17- \\
14.8\end{array}$ & $\sim 10$ & MST; pollen (Warny et al., 2009) & $\begin{array}{l}\text { Peak warmth indicated by EM IV minimum ice with } \\
\text { open ocean and receded ice caps; also EM III cold } \\
\text { temperate conditions with tidewater glaciation; tun- } \\
\text { dra vegetation (Levy et al., 2016) }\end{array}$ \\
\hline & U1356 & $\begin{array}{l}-63.18 \\
135.59\end{array}$ & $\begin{array}{l}17- \\
14.8\end{array}$ & $>10$ & $\begin{array}{l}\text { MST (Sangiorgi et al., 2018); } \\
\text { MAT } 5.8-13^{\circ} \mathrm{C} \text { and } 10-12^{\circ} \mathrm{C} \pm \\
5^{\circ} \mathrm{C} \text { (Sangiorgi et al., 2018), } \\
\text { MAT 6-8 } \pm 4^{\circ} \mathrm{C} \text { (Paashchier et } \\
\text { al., 2013) }\end{array}$ & $\begin{array}{l}\text { Extensive terrestrial ice-free regions, tundra vegeta- } \\
\text { tion with boreal forests in sheltered coastal lowlands; } \\
\text { absence of sea ice (Sangiorgi et al., 2018) }\end{array}$ \\
\hline & Friis Hills & $\begin{array}{l}-77.45 \\
161.30\end{array}$ & $\begin{array}{l}15.1- \\
14.8\end{array}$ & $6-7$ & $\begin{array}{l}\text { MST; pollen, insect remains } \\
\text { (Lewis et al., 2015) }\end{array}$ & $\begin{array}{l}\text { Ice-free but site located near ice margin (Chapter 3); } \\
\text { tundra vegetation (Lewis et al., 2015) }\end{array}$ \\
\hline
\end{tabular}


Table 4.2 Sedimentological and palynological proxy data for interpreting ice extent and temperature during interglacial periods of the mid-Miocene Climate Transition (MMCT).

\begin{tabular}{|c|c|c|c|c|c|c|}
\hline Period & Site & Lat,Long & $\begin{array}{l}\text { Age } \\
\text { (Ma) }\end{array}$ & $\begin{array}{l}\text { Temp } \\
\left({ }^{\circ} \mathbf{C}\right)\end{array}$ & Palynological & Sedimentological \\
\hline \multirow[t]{4}{*}{$M M C T$} & $\begin{array}{l}\text { ANDRILL- } \\
2 \mathrm{~A}\end{array}$ & $\begin{array}{l}-77.45 \\
165.16\end{array}$ & $\sim 14.5$ & - & - & $\begin{array}{l}\text { Cold temperate conditions (EM III) with tidewater } \\
\text { glaciation; sea ice evidence (Levy et al., 2016) }\end{array}$ \\
\hline & U1356 & $\begin{array}{l}-63.18 \\
135.59\end{array}$ & $\begin{array}{l}14.8- \\
14.2\end{array}$ & $>10$ & 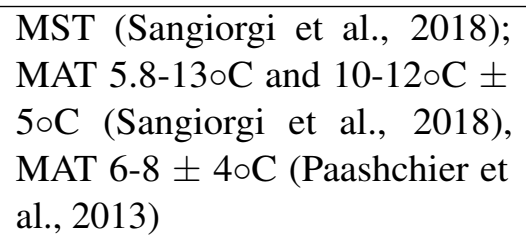 & $\begin{array}{l}\text { Greater continental ice cover compared to MCO but } \\
\text { a receded ice configuration compared to modern; } \\
\text { tundra vegetation; sea ice indicators (Sangiorgi et } \\
\text { al., 2018) }\end{array}$ \\
\hline & Friis Hills & $\begin{array}{l}-77.45 \\
161.30\end{array}$ & $\begin{array}{l}\sim 14.8- \\
14\end{array}$ & $6-7$ & $\begin{array}{l}\text { MST; pollen, insect remains } \\
\text { (Lewis \& Ashworth, 2015) }\end{array}$ & $\begin{array}{l}\text { Ice-free but site located near ice margin (Chapter 3); } \\
\text { tundra vegetation (Lewis et al., 2015) }\end{array}$ \\
\hline & Mt. Boreas & $\begin{array}{l}-77.48 \\
161.11\end{array}$ & $\begin{array}{l}14.07 \\
\pm \\
0.05\end{array}$ & $\sim 5$ & $\begin{array}{l}\text { MST; pollen, insect remains } \\
\text { (Lewis et al., 2008) }\end{array}$ & Ice free; moss tundra (Lewis et al., 2008) \\
\hline
\end{tabular}


Table 4.3 Sedimentological proxy data for interpreting ice extent during glacial periods of the early to mid-Miocene.

\begin{tabular}{|c|c|c|c|c|}
\hline Period & Site & Lat,Long & $\begin{array}{l}\text { Age } \\
\text { (Ma) }\end{array}$ & Sedimentological \\
\hline \multirow[t]{3}{*}{$\begin{array}{l}\text { Pre- } \\
\text { MCO } \\
\text { (early } \\
\text { Miocene) }\end{array}$} & ANDRILL-2A & $\begin{array}{l}-77.45 \\
165.16\end{array}$ & $21-17$ & $\begin{array}{l}\text { EM II cold polar conditions, with ice grounded at coast and calving into } \\
\text { Ross Sea or possibly forming an ice shelf; also EM I maximum ice with } \\
\text { marine ice advance over drill site, final pre-MCO ice sheet advance at } \\
\text { 17.8 Ma (Fielding et al., 2011; Levy et al., 2016) }\end{array}$ \\
\hline & $\begin{array}{l}\text { Cape Roberts } \\
\text { Project CRP-1 and } \\
\text { 2/2A }\end{array}$ & $\begin{array}{l}-77.01 \\
163.76\end{array}$ & $19-17$ & $\begin{array}{l}\text { Ice-proximal glacimarine to marine ice advance, analogous to EM II - } \\
\text { EM I (Fielding et al., 2000; Naish et al., 2001) }\end{array}$ \\
\hline & Friis Hills & $\begin{array}{l}-77.45 \\
161.30\end{array}$ & 19.76 & $\begin{array}{l}\text { Advance of wet-based alpine temperate glaciers (Lewis \& Ashworth } \\
\text { 2015) }\end{array}$ \\
\hline \multirow[t]{3}{*}{$M C O$} & ANDRILL-2A & $\begin{array}{l}-77.45 \\
165.16\end{array}$ & $17-14.8$ & $\begin{array}{l}\text { EM II cold polar conditions with ice grounded at coast, sea ice indicators } \\
\text { (Levy et al., 2016) }\end{array}$ \\
\hline & U1356 & $\begin{array}{l}-63.18 \\
135.59\end{array}$ & $17-14.8$ & Absence of sea ice or marine-terminating ice (Sangiorgi et al., 2018) \\
\hline & Friis Hills & $\begin{array}{l}-77.45 \\
161.30\end{array}$ & $15.1-14.8$ & Ice covered (Chapter 3) \\
\hline \multirow[t]{4}{*}{$M M C T$} & ANDRILL-2A & $\begin{array}{l}-77.45 \\
165.16\end{array}$ & 14.6 & $\begin{array}{l}\text { EM I maximum ice sheet advance, with grounded ice over drill site; } \\
\text { EM II cold polar conditions (Levy et al., 2016); correlates with major } \\
\text { unconformities that extend across the continental shelf (De Santis et al., } \\
\text { 1999) }\end{array}$ \\
\hline & U1356 & $\begin{array}{l}-63.18 \\
135.59\end{array}$ & $14.8-14.2$ & $\begin{array}{l}\text { Marine terminating ice (Passchier et al., 2013; Pierce et al., 2017; San- } \\
\text { giorgi et al., 2018) }\end{array}$ \\
\hline & Friis Hills & $\begin{array}{l}-77.45 \\
161.30\end{array}$ & $\sim 14.8-14$ & Ice covered (Chapter 3) \\
\hline & Mt. Boreas & $\begin{array}{l}-77.48, \\
161.11\end{array}$ & $\begin{array}{l}14.07 \\
\pm 0.05\end{array}$ & Ice covered (Lewis et al., 2008) \\
\hline
\end{tabular}


Carbon-dioxide and tectonic controls on Antarctic climate and ice sheet evolution in the 138 mid-Miocene: a model-data integration

Table 4.4 BIOME4 circumpolar tundra biome classification from Kaplan and others (2003).

\begin{tabular}{|c|c|c|}
\hline Biome & Definition & Typical Taxa \\
\hline $\begin{array}{l}\text { Low- and high- } \\
\text { shrub tundra }\end{array}$ & $\begin{array}{l}\text { continuous shrubland, } 50 \mathrm{~cm} \text { to } \\
2 \mathrm{~m} \text { tall, deciduous or evergreen, } \\
\text { sometimes with tussock-forming } \\
\text { graminoids and true mosses, bog } \\
\text { mosses and lichens }\end{array}$ & $\begin{array}{l}\text { Alnus, Betula, Salix, Pinus pumila } \\
\text { (in eastern Siberia), Eriophorum, } \\
\text { Sphagnum }\end{array}$ \\
\hline $\begin{array}{l}\text { Erect dwarf-shrub } \\
\text { tundra }\end{array}$ & $\begin{array}{l}\text { continuous shrubland } 2-50 \mathrm{~cm} \\
\text { tall, deciduous or evergreen, with } \\
\text { graminoids, true mosses en lichens }\end{array}$ & $\begin{array}{l}\text { Betula, Cassiope, Empetrum, Salix, } \\
\text { Vaccinium, Gramineae, Cyperaceae }\end{array}$ \\
\hline $\begin{array}{l}\text { Prostrate dwarf- } \\
\text { shrub tundra }\end{array}$ & $\begin{array}{l}\text { discontinuous shrubland of prostrate } \\
\text { deciduous shrubs, } 0-2 \mathrm{~cm} \text { tall }\end{array}$ & $\begin{array}{l}\text { Salix, Dryas, Pedicularis, Aster- } \\
\text { aceae, Caryophyllaceae, Gramineae, } \\
\text { true mosses }\end{array}$ \\
\hline $\begin{array}{l}\text { Cushion forb, } \\
\text { lichen and moss } \\
\text { tundra }\end{array}$ & $\begin{array}{l}\text { discontinuous cover of rosette plants } \\
\text { or cushion forbs with lichens and } \\
\text { mosses }\end{array}$ & $\begin{array}{l}\text { Papaver, Draba, Saxifragaceae, } \\
\text { Caryophyllaceae, lichens, true } \\
\text { mosses }\end{array}$ \\
\hline $\begin{array}{l}\text { Graminoid and } \\
\text { forb tundra }\end{array}$ & $\begin{array}{l}\text { predominantly herbaceous vege- } \\
\text { tation, dominated by forbs and } \\
\text { graminoids, with true mosses and } \\
\text { lichens }\end{array}$ & $\begin{array}{l}\text { Artemisia, Kobresia, Brassicaceae, } \\
\text { Asteraceae, Caryophyllaceae, } \\
\text { Gramineae, true mosses }\end{array}$ \\
\hline
\end{tabular}

\subsubsection{Model setup}

Mid-Miocene ice sheet stability is investigated under a variety of different boundary conditions, by constructing a model ensemble with varying atmospheric $\mathrm{CO}_{2}$ and TAM uplift scenarios. Each modelled ice sheet was equilibrated with its imposed boundary conditions under a 'warm' or 'cold' austral orbit, reflecting maximum interglacial and glacial conditions. These astronomical orbits are independent of the prescribed atmospheric $\mathrm{CO}_{2}$ concentrations, with a glacial climate represented by an austral astronomical configuration and ocean heat flux that is favourable for conditions that allow for Antarctic glaciation (Fig. 4.3). Boundary conditions were purposefully chosen to be extreme; they span the upper and lower limits of reconstructed $\mathrm{CO}_{2}$ and TAM uplift scenarios, so that the resulting model ensemble encompasses all plausible boundary conditions for the Friis Hills region during the mid-Miocene (Fig. 4.3). 


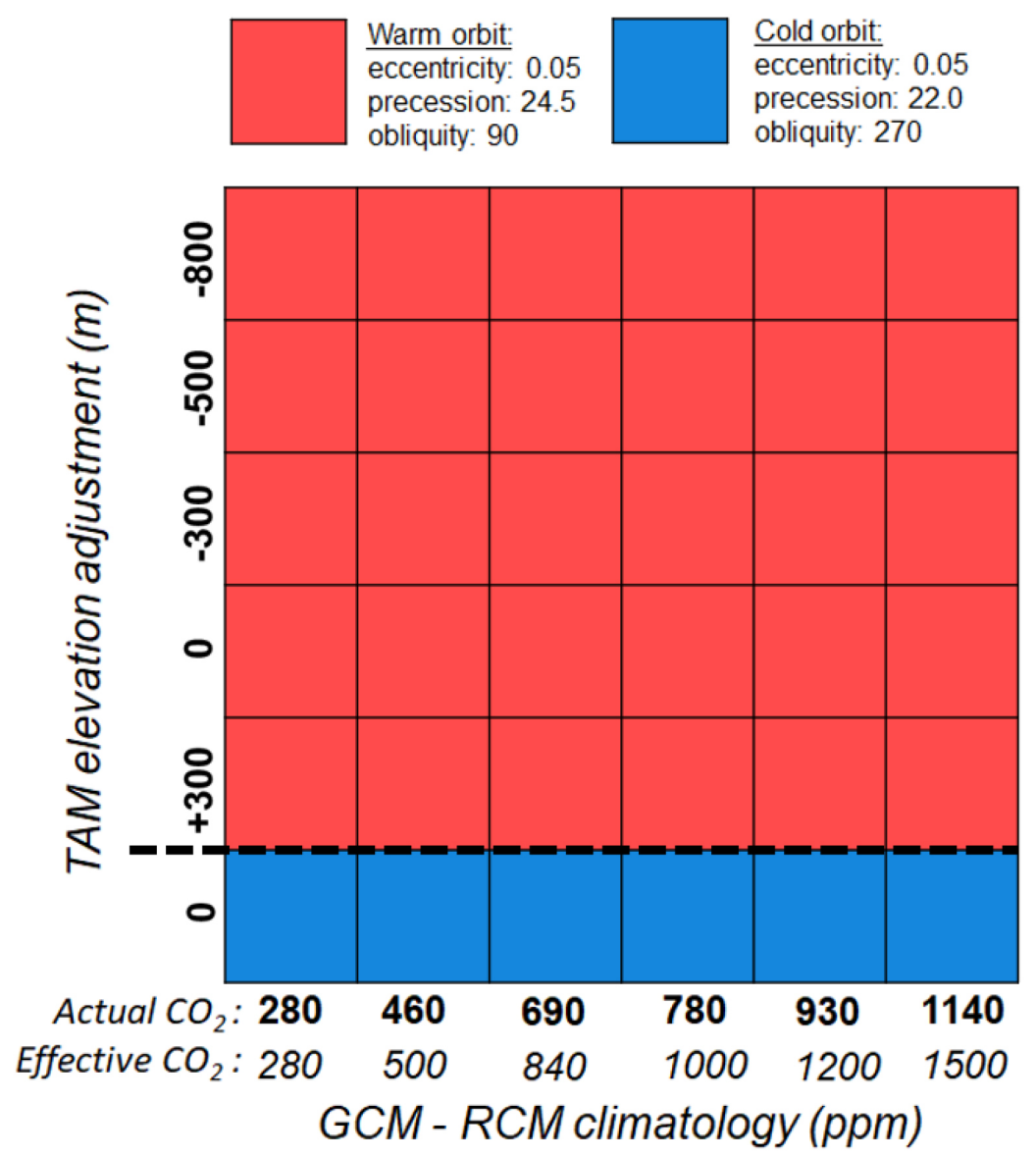

Fig. 4.3 Model ensemble design with varying $\mathrm{CO}_{2}$, topography (TAM elevation), and cold/warm astronomical orbits representative of glacial-interglacial conditions. Default topography is provided by Paxman and others (2019b).

For each combination of boundary conditions, a global climate model (GCM), regional climate model (RCM), and an ice sheet model (ISM), was asynchronously coupled following the approach of Gasson and others (2016). The RCM downscaled the GCM output, providing an Antarctic-wide climatology input to the ISM. The ISM calculated ice sheet change resulting from the input climatology, producing an updated topography for the GCM-RCM, which then re-calculated a new climatology to the ISM. This asynchronous coupling proceeded until there was negligible ice sheet topographic change (i.e., the climate forcing was in equilibrium with the ice sheet, Fig. 4.4). 
Carbon-dioxide and tectonic controls on Antarctic climate and ice sheet evolution in the

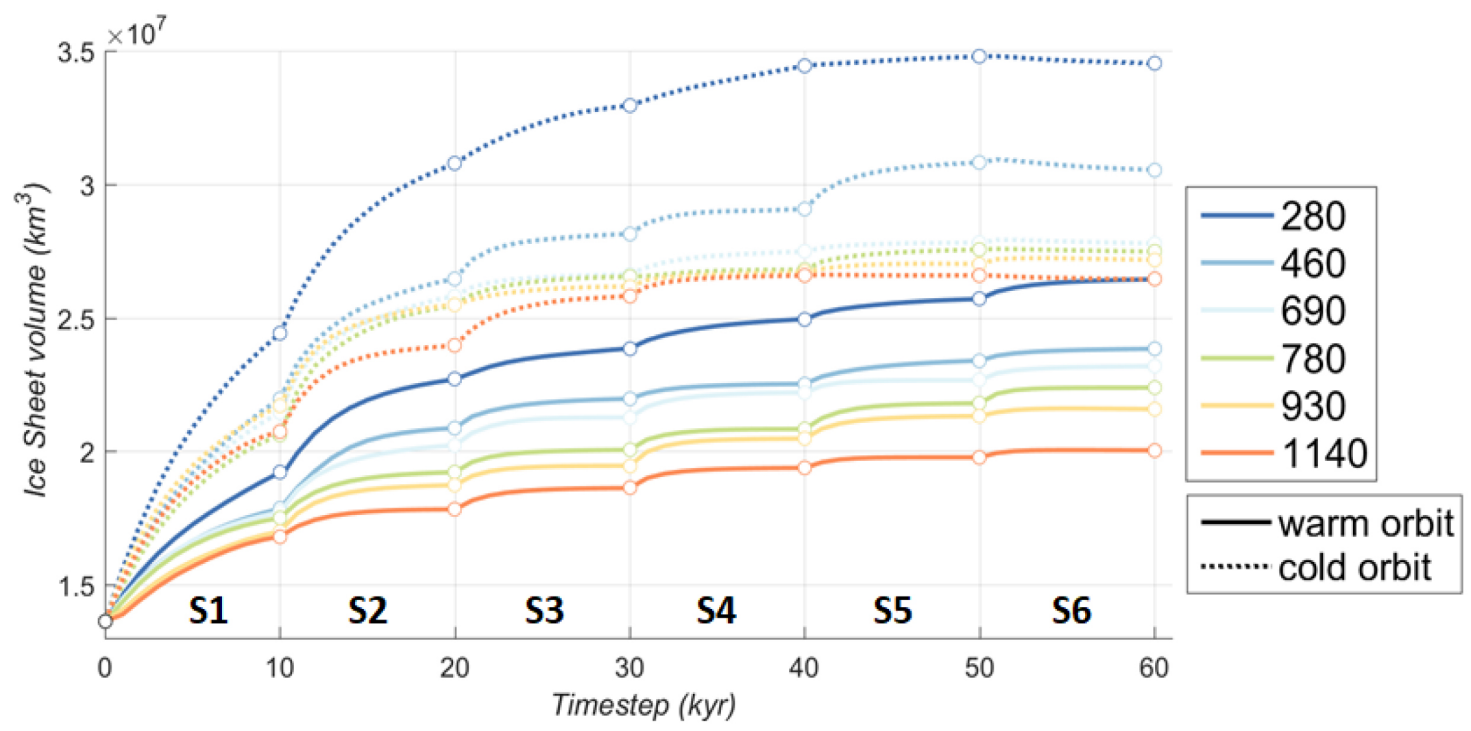

Fig. 4.4 Asynchronous coupling of GCM/RCM/ISM proceeds until equilibrium is reached. The climate provided to the ISM is updated at every coupling step (represented by a white circle). Here the evolution of model members for a range of atmospheric $\mathrm{CO}_{2}$ forcing with default topography under cold and warm orbits is shown. Initial conditions are provided by Gasson et al., (2016) for a warm Miocene climate.

A 50-model-year spin-up using the GENESIS version 3.0 GCM (Thompson \& Pollard, 1997) was run for each prescribed climatology. The atmospheric model was coupled to multi-layer surface models of vegetation, snow, soil, ice, and sea ice on a $2^{\circ} \times 2^{\circ}$ surface grid, and an interactive vegetation module (BIOME4; Kaplan et al., 2003). The GCM also included a mixed-layer slab ocean with dynamical sea ice and diffusive horizontal heat transport. Ocean heat flux was increased in the Southern Ocean following the approach of DeConto and others (2012) and Gasson and others (2016) to maintain ice-free conditions during warm periods with no West Antarctic Ice Sheet (WAIS), in accordance with geologic records (e.g., Naish et al., 2009). To best represent the maximum possible glacial-interglacial variability, this additional ocean heat flux was applied to the warm orbit runs only. At each coupling step, the GCM was run for 10 model years and produced boundary conditions (6-hour meteorological saves) that were subsequently used for downscaling with the RCM (RegCM3; Pal et al., 2007). 10 model years of RCM output (at $60 \mathrm{~km}$ resolution) were averaged to produce the climatology forcing that was input to the ISM.

The ISM is a hybrid shallow ice/shallow shelf approximation model (PSU-ISM; Pollard \& DeConto, 2012), with a grounding-line parameterisation based on Schoof (2007) and an ice shelf hydrofracture mechanism (DeConto et al., 2015). Initial conditions for the first 
coupling step were provided by Gasson and others (2016) for a warm Miocene world (840 $\mathrm{ppm}$ ); all model members regrew ice from this minimal configuration, so the resulting ice sheet configurations represent regrowth after a retreated period. The ISM was run at a $10-\mathrm{km}$ grid resolution. Subsurface ocean temperatures are required to calculate basal melt rates; modern high-resolution ocean subsurface temperatures (Levitus et al., 2012) were supplied to the ISM, uniformly scaled by a warming factor (cf. DeConto et al., 2016; Gasson et al., 2016). For each prescribed climatology, the ocean scaling factor was based on the Southern Hemisphere sea surface temperature (SST) anomaly between the experimental GCM and a modern GCM, following the approach of Golledge and others (2015). This 'control' GCM was run with $280 \mathrm{ppm}$, a modern orbital configuration, and no additional Southern Ocean heat flux, and produced similar global SSTs to the modern ocean dataset (Levitus et al., 2012). Ocean temperatures do not significantly impact the dynamics of a terrestrial ice sheet within the ice sheet model, so for warm-orbit runs with Southern Hemisphere SST anomaly greater than $2^{\circ} \mathrm{C}$, an ocean scaling factor of $+2^{\circ} \mathrm{C}$ following Gasson and others (2016) was imposed. The climate forcing to the ISM, provided by RCM model output, included a uniform correction of $+2^{\circ} \mathrm{C}$ applied to RCM temperatures due to a cold bias in control simulations compared with modern temperatures. The ISM input climatology was updated every $10 \mathrm{kyr}$ until additional coupling steps did not drive significant ice volume change (Fig. 4.4).

TAM climatology was explored in further detail for each ensemble member, nesting the final RCMs over TAM and WLB (Fig. 4.1 b,c) to investigate smaller-scale patterns at a higher resolution $(15 \mathrm{~km})$ not feasible for the entire continent. These nested domains were determined based on the locations of paleo-records (Fig. 4.1), to investigate regional modelled temperatures and ice configuration at a higher resolution for model-data comparison.

\subsubsection{Model boundary conditions}

Atmospheric $\mathrm{CO}_{2}$ concentrations throughout the mid-Miocene are still largely unconstrained. A variety of different datasets and paleoenvironment reconstructions suggest that Miocene $\mathrm{CO}_{2}$ ranged from preindustrial levels (280 ppm) to possibly 840 ppm (Pagani et al., 1995; Pearson \& Palmer, 2000; Kürschner et al., 2008; Retallack, 2009; Foster et al., 2012; Zhang et al., 2013; Greenop et al., 2014; Sosdian et al., 2018). The model strategy of using 'effective' $\mathrm{CO}_{2}$ (the level of $\mathrm{CO}_{2}$ that drives all extra radiative forcing while holding $\mathrm{N}_{2} \mathrm{O}$ and $\mathrm{CH}_{4}$ at their preindustrial levels) was employed to improve climate model representation 
of warm worlds, following Huber and Caballero (2011) and DeConto and others (2012). To encompass all possible warm worlds throughout the Miocene, the model ensemble spans $280 \mathrm{ppm}$ to $1500 \mathrm{ppm}$ effective $\mathrm{CO}_{2}$. When converted from effective $\mathrm{CO}_{2}$, the highest- $\mathrm{CO}_{2}$ model end-member (1140 ppm) is still higher than any of the proxy reconstructions for the Miocene. These high- $\mathrm{CO}_{2}$ runs were included in the model ensemble to ensure that the model was capturing all possible warm Miocene climates. The climate models used in this study (GENESIS, downscaled with RegCM3) have relatively weak climate sensitivity $\left(2-3{ }^{\circ} \mathrm{C}\right.$ warming per $\mathrm{CO}_{2}$ doubling; Kothavala et al., 1999; Otto-Bliesner et al., 2006; Kiehl et al., 2006). Thus, if climate sensitivity in the Miocene was higher than the climate model is able to reproduce, high $\mathrm{CO}_{2}$ worlds in the Miocene may still be accurately represented with the $1140 \mathrm{ppm}$ model reconstructions.

Global mid-Miocene paleotopography was provided from Herold and others (2008), onto which the median 14 Ma Antarctic topography of Paxman and others (2019b) was overlain. Topography was then modified according to the chosen TAM uplift scenario (Fig. 4.5). TAM elevations were hinged following the ten Brink and Stern (1989) flexural cantilever model for TAM uplift (Fig. 4.2). To reverse the hypothesised flexural cantilever-style uplift, the central and northern TAM were treated as a plate hinged along the lowest point in Wilkes Basin, with a free edge at the modern coastline, and the free end was lowered by $300 \mathrm{~m}, 500$ $\mathrm{m}$ and $800 \mathrm{~m}$. This large range aims to encompass the possible uplift histories previously discussed. A higher TAM elevation was also investigated by raising the free end by $300 \mathrm{~m}$ to represent an extreme scenario of isostatic uplift caused by early erosion of TAM glacial valleys, or possibly reflecting a more dynamic uplift process. 


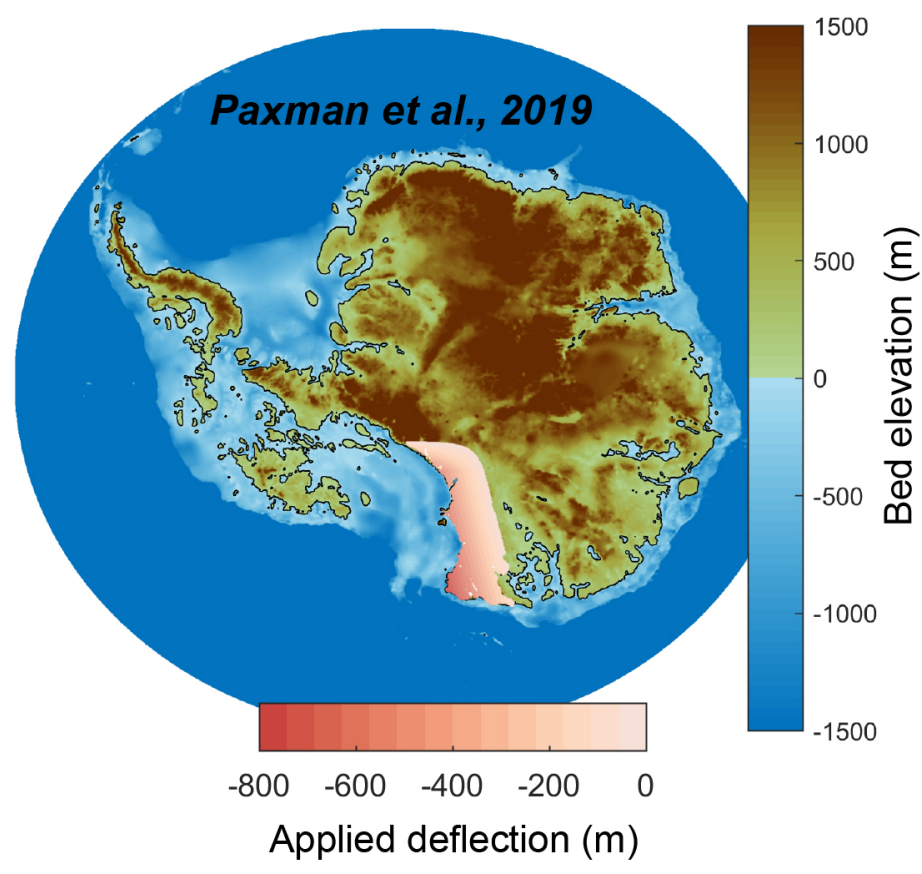

Fig. 4.5 Paxman and others (2019b) mid-Miocene (14 Ma) topography, overlain with varying TAM elevations to recreate various stages of TAM uplift by applying a corresponding cantilever-style hinged deflection (Fig. 4.2, Stern \& ten Brink, 1989). This figure shows the $-800 \mathrm{~m}$ end member, hinging the TAM by $-800 \mathrm{~m}$ at the free end to represent an early stage of TAM uplift.

\subsection{Results}

\subsubsection{Continent scale ice sheet reconstructions}

The model ensemble spans a wide range of possible $\mathrm{CO}_{2}$ concentrations, TAM uplift scenarios and cold/warm astronomical orbits representative of glacial-interglacial periods. The largest ice sheet was produced by the lowest $\mathrm{CO}_{2}$ concentration $(280 \mathrm{ppm}$ ) under a cold astronomical orbit representative of a glacial period. These conditions produce a larger than modern ice sheet $(135 \%)$ with a marine ice sheet expanded out onto the continental shelf and extensive perennial sea ice. At $280 \mathrm{ppm}$ modelled $\mathrm{CO}_{2}$ under a warm orbit representative of interglacial periods, winter sea ice is prevalent but does not persist year-round. In the modelled $280 \mathrm{ppm}$ $\mathrm{CO}_{2}$ under glacial conditions, there is significant marine ice growth around the continent (Fig. 4.6 a) that is consistent with geological observations of expanded marine ice sheets into 
Carbon-dioxide and tectonic controls on Antarctic climate and ice sheet evolution in the 144 mid-Miocene: a model-data integration

the Ross Sea during the Miocene (Anderson \& Bartek, 1992; Brancolini et al., 1995; De Santis et al., 1999; Naish et al., 2001; Chow \& Bart, 2003; Levy et al., 2016).

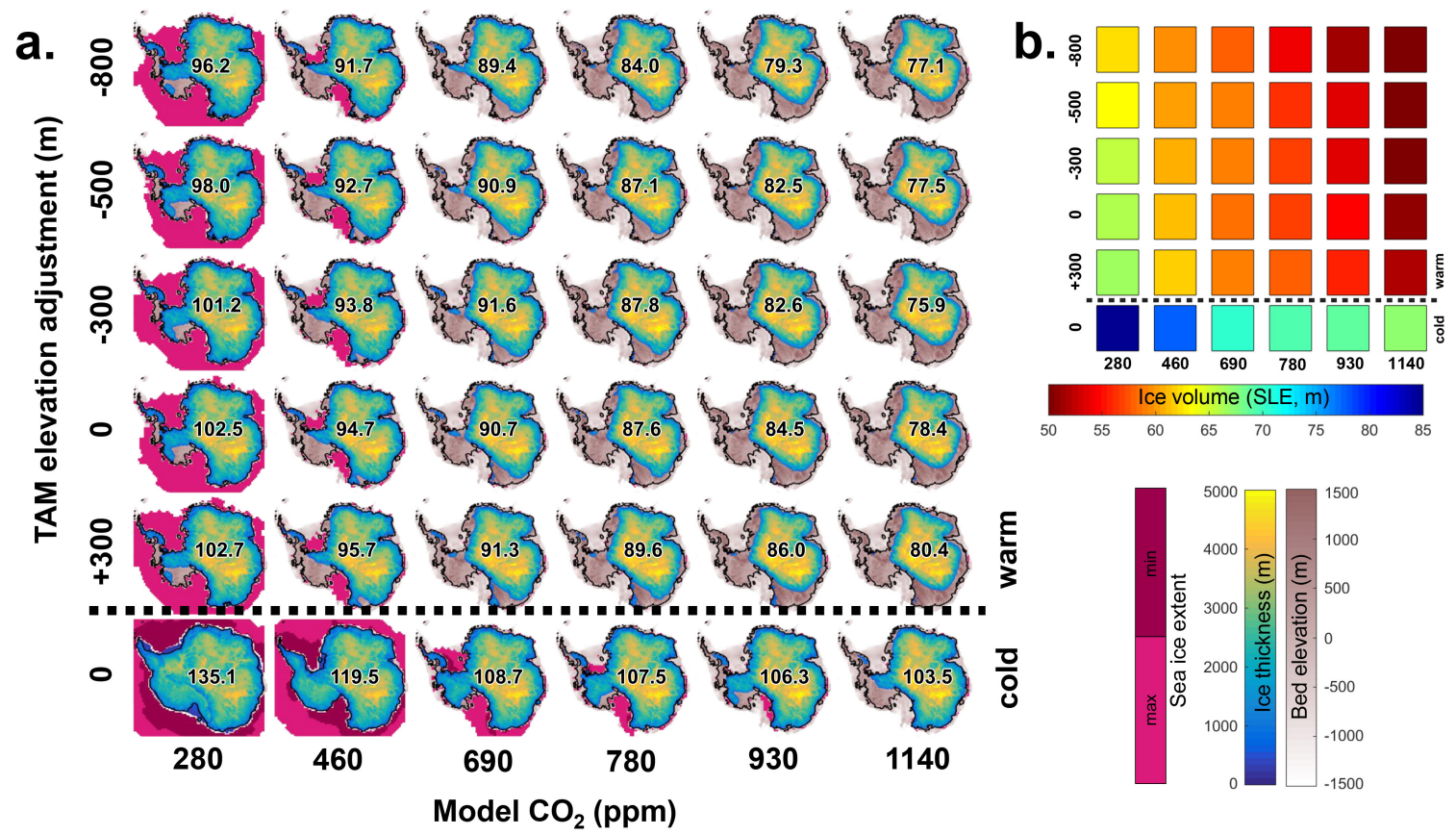

Fig. 4.6 Model ensemble results: (a) Equilibrated ice sheet configurations under varying astronomical orbits ('cold' and 'warm'), topography, and $\mathrm{CO}_{2}$ boundary conditions with \% ice sheet relative to modern. Initial model topography is provided by Paxman and others (2019b) with an additional TAM elevation adjustment (discussed in text). Sea ice extent is shown for the months where sea ice is at a maximum and minimum. (b) Ice sheet volume for each set of boundary conditions, with same axes as the main figure.

Small scale marine ice advance is also observed around the fringes of the continent under 460 ppm glacial conditions. During 460 ppm glacial periods, regional marine ice advance coincides with widespread winter sea ice that persists regionally throughout the summer. During modelled glacial periods under higher $\mathrm{CO}_{2}$ concentrations, the EAIS reaches the coast, but warm ocean temperatures no longer support further ice sheet advance into the marine realm. The smallest ice sheet was produced by the warmest model member, at 1140 ppm $\mathrm{CO}_{2}$ under interglacial conditions. A significant EAIS is stable under the most extreme boundary conditions, with an ice sheet $\sim 75 \%$ still persisting in this model member. This ice sheet is the smallest in area, with margins that have receded far from the coastline, but grows the thickest over the EAIS plateau due to increased precipitation in warmer worlds.

Ice sheet volume is the result of an interplay of $\mathrm{CO}_{2}$ concentration and TAM elevation (Fig. 4.6 b). Unsurprisingly, elevated $\mathrm{CO}_{2}$ concentrations decrease ice volume and exerts a 
much greater influence than TAM elevation. Despite this, TAM elevation does impact the resulting ice sheet volume, with lower TAM elevations associated with lower ice volumes throughout the model ensemble, with a $6.5 \%$ difference relative to the modern ice sheet between the highest and lowest modelled TAM elevations at $280 \mathrm{ppm} \mathrm{CO}_{2}$. This process highlights the importance of TAM elevation in acting as a buttress to EAIS flow through the TAM, with higher elevations supporting a thicker ice sheet. $\mathrm{CO}_{2}$ exerts the greatest influence over ice in the WLB, with retreat starting at $460 \mathrm{ppm}$ under interglacial conditions, and significant retreat at $690 \mathrm{ppm}$ or higher $\mathrm{CO}_{2}$, suggesting the WLB is particularly vulnerable to warming. The Aurora Subglacial Basin has a greater deglaciation threshold than the WLB, with retreat from the coast under interglacial conditions only occurring at $\geq 780 \mathrm{ppm} \mathrm{CO}_{2}$ and significant deglaciation at $1140 \mathrm{ppm} \mathrm{CO}_{2}$.

\subsubsection{Transantarctic Mountain ice sheet dynamics}

Basal temperature of the ice sheet can be used to infer if the ice is frozen to the bed (indicative of cold-based glaciation) or not frozen to the bed (indicative of the warm-based glaciation style most characteristic of the mid-Miocene). In the model ensemble, $\mathrm{CO}_{2}$ has the greatest influence on the distribution of ice that is not frozen at the bed, while TAM elevation has the greatest influence on the extent of ice that is frozen to the bed (Fig. 4.7), with the ice becoming increasingly frozen at higher TAM elevations. This could be due to increasing geothermal heat flux acting on the base of the ice sheet at lower elevations, thereby influencing basal conditions and the style of glaciation that dominates. It could also be inferred that rising TAM elevations across the mid-Miocene drove the shift in basal thermal character across the MMCT (Marchant et al., 1993; Sugden \& Denton, 2004; Lewis et al., 2006; Lewis et al., 2008; Lewis \& Ashworth, 2015). 
Carbon-dioxide and tectonic controls on Antarctic climate and ice sheet evolution in the mid-Miocene: a model-data integration
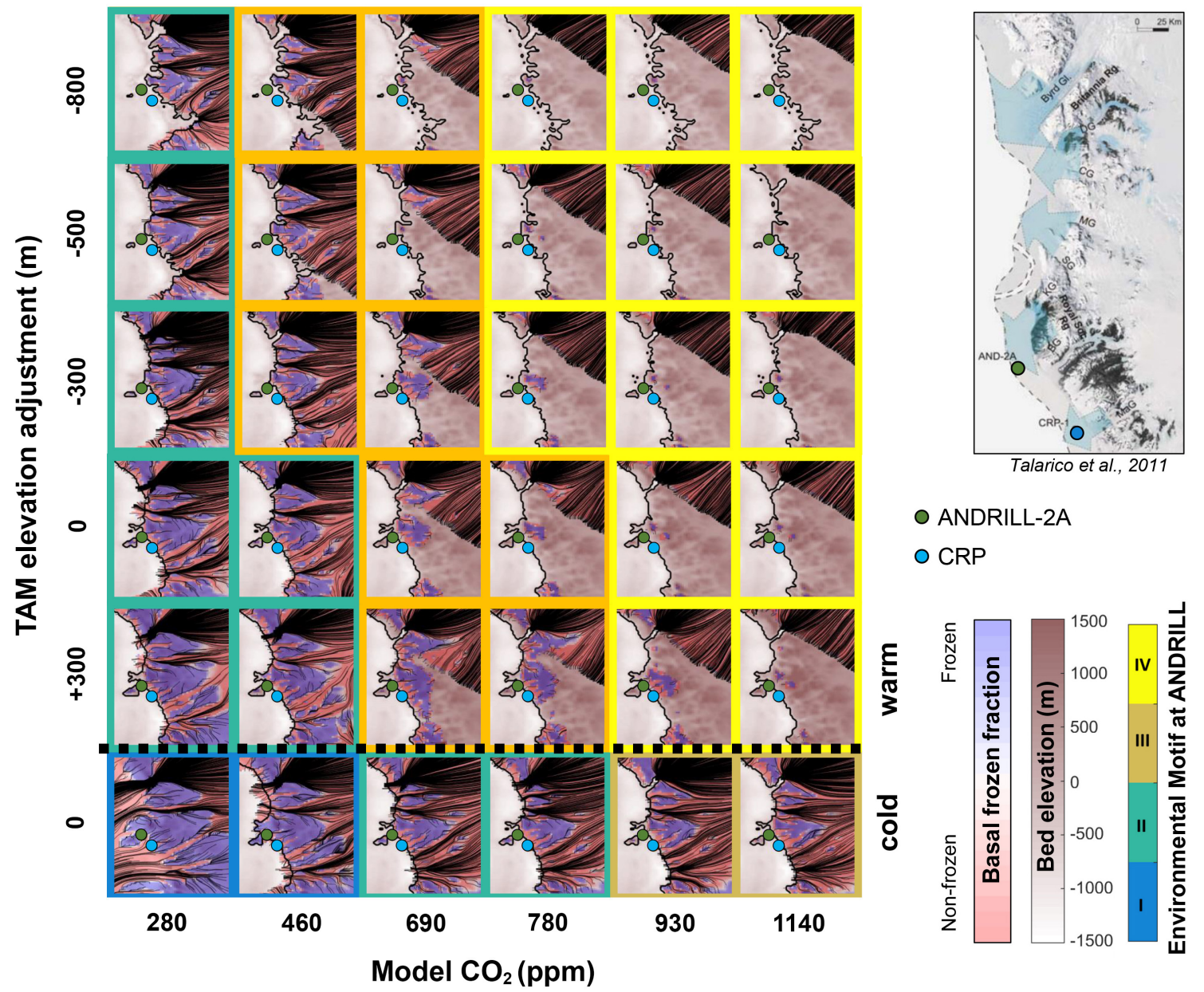

Fig. 4.7 Ice sheet configuration and flowlines across the TAM region, with ANDRILL and CRP drill sites indicated, as well as the environmental motif interpreted for each model member. Grounded ice is coloured according to the modelled basal frozen fraction. Reconstructed interglacial paleo-flowlines from Talarico and others (2011) are shown for comparison. Domain for model results is shown in Figure $4.1 \mathrm{~d}$.

Modelled flowlines under all interglacial boundary conditions match reconstructed paleoice sheet flowlines inferred from mineral provenance data at the AND-2A site (Talarico et al., 2011). It is noted that Byrd Glacier actively drains the EAIS and potentially sources clasts to the site under all modelled boundary conditions. Conversely, Mulock Glacier is closer to the drill site and is active only when a full EAIS is connected to the TAM (Fig. 4.7). The model resolution is too coarse to resolve the changes in flow direction over the Friis Hills as implied by Lewis and Ashworth (2015), however, it is noted that under all boundary conditions that develop ice over or near the Friis Hills, flow is localised rather than directly from the EAIS, even during periods of EAIS overriding (Fig. 4.8). This corroborates geologic data (Lewis \& 
Ashworth, 2015, Chapter 3) and model results suggest this flow pattern is due to the flow of ice from the frozen section of the ice cap or ice sheet into the unfrozen section exerting a greater influence over flow patterns at higher elevations, while EAIS flow is directed through outlet valleys.
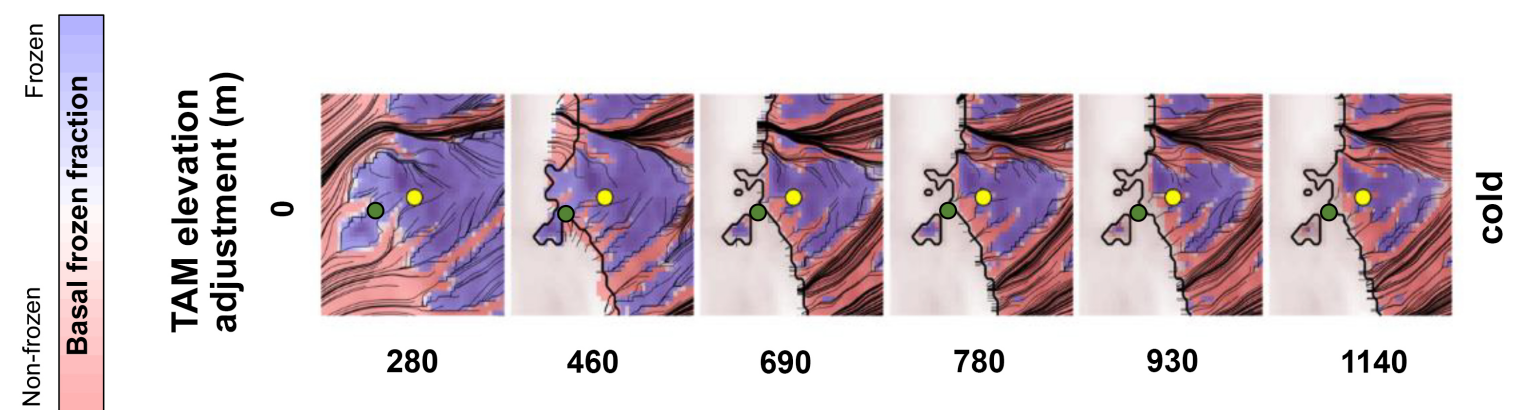

280

460

690

780

930

1140

- ANDRILL-2A

Model $\mathrm{CO}_{2}(\mathrm{ppm})$

o Friis Hills

Fig. 4.8 Ice sheet configuration and flowlines across the McMurdo Dry Valleys during glacial periods, with the Friis Hills drill site indicated. Grounded ice is coloured according to the modelled basal frozen fraction. Domain for model results is shown in Figure $4.1 \mathrm{~d}$.

\subsubsection{Mid-Miocene climate}

All boundary conditions under interglacial conditions support some degree of precipitation (Fig. 4.9), with rainfall only occurring at $\mathrm{CO}_{2}$ concentrations $\geq 690 \mathrm{ppm}$, and between 280 to $460 \mathrm{ppm} \mathrm{CO}_{2}$ precipitation occurring as snowfall. The only glacial ensemble member to support rainfall is at $1140 \mathrm{ppm} \mathrm{CO}_{2}$. Over large ice-free areas (e.g. WLB), prevailing winds flow onshore in the summer and shift to flow offshore/along shore in the winter. Precipitation increases as TAM elevations are lowered, with an elevated TAM (with or without an ice cap) blocking summer onshore winds form the Ross Sea from reaching the inner TAM, therefore decreasing summer precipitation. Most rainfall occurs in the austral summer, when prevailing winds flow onshore. In the austral winter, the dominant surface wind is northward alongshore, although winter offshore flow occurs in higher $\mathrm{CO}_{2}$ worlds with mostly deglaciated TAM and WLB regions. Winter precipitation is dominated by snowfall, with significant winter rainfall occurring only in the highest $\mathrm{CO}_{2}$ worlds $(1140 \mathrm{ppm}$, although extremely low TAM elevations can facilitate rainfall under 930 ppm, Fig. 4.9). 
Carbon-dioxide and tectonic controls on Antarctic climate and ice sheet evolution in the

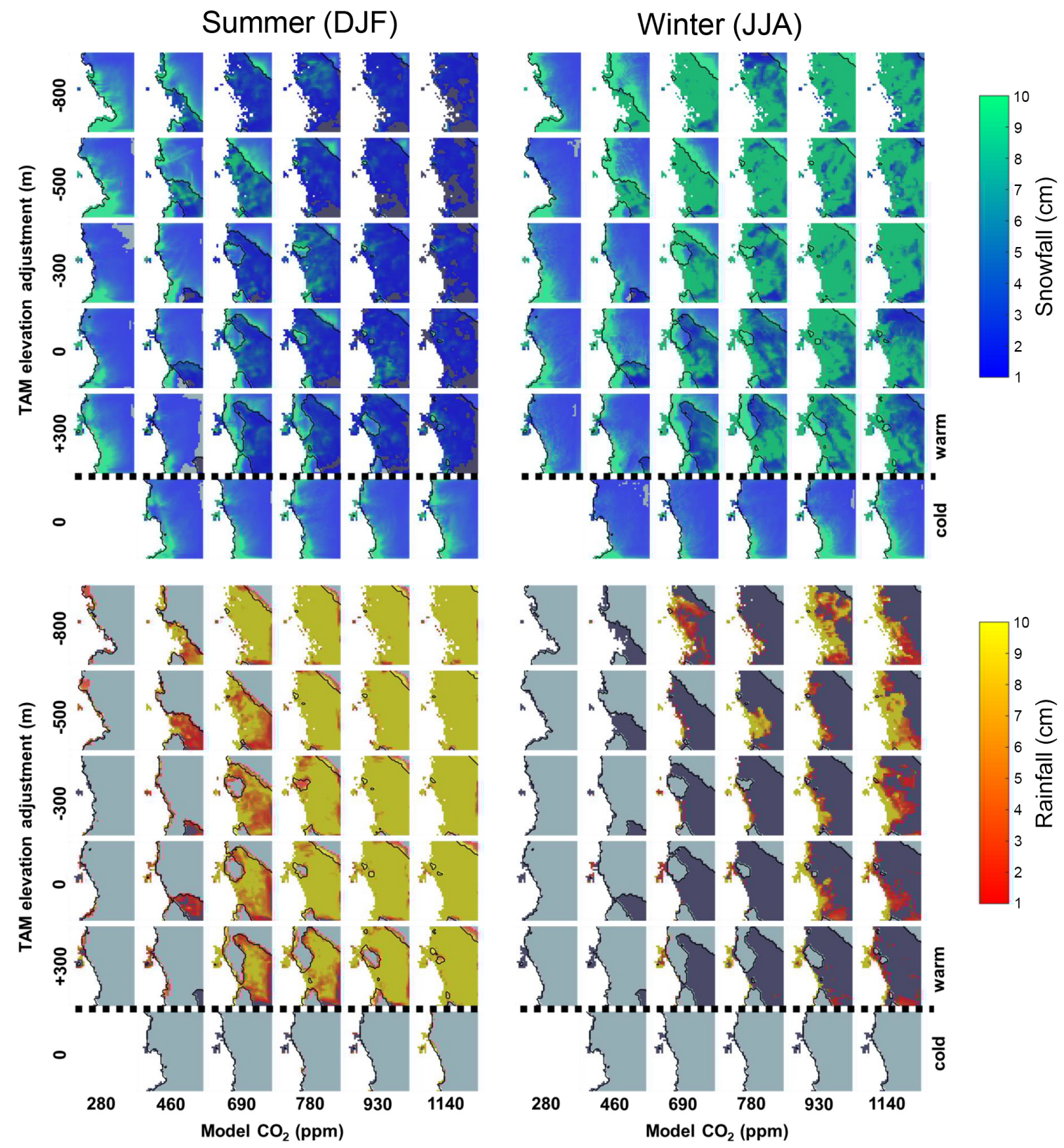

Fig. 4.9 Summer and winter precipitation shown as both snowfall and rainfall across the TAM region for 460 and $690 \mathrm{ppm}$ model members under cold and warm orbits and all modelled TAM elevations. Domain for model results is shown in Figure $4.1 \mathrm{~b}$.

\subsubsection{Constraining model results with geologic data}

Geologic records of mid-Miocene paleoenvironment can be used to constrain plausible $\mathrm{CO}_{2}$ and TAM uplift boundary conditions through comparison with model results. Existing 
terrestrial and marine datasets from the mid-Miocene were compiled for both glacial and interglacial periods (Table 4.1-4.3). In the MDVs, local terrestrial temperatures and paleoenvironments have been reconstructed from sedimentological data and fossil assemblages including pollen, beetles, diatoms, and mosses (Lewis et al., 2008; Lewis \& Ashworth, 2015). Marine records do not record site specific temperature snapshots, but instead provide records of regional ice dynamics and coastal land and SSTs at the time of deposition. Pollen samples indicate little erosion or transport prior to deposition (Warny, personal communication), and are therefore considered to represent environmental conditions at the time of deposition. On this basis, coastal cells within the model ensemble that most likely represent the temperatures indicated in marine records were selected for comparison. The terrestrial records from the MDVs (Friis Hills, Mount Boreas) are complemented with marine records adjacent to the TAM (AND-2A, CRP-1 and 2/2A) and offshore WLB (U1356). At each site, the geologic reconstructions of paleoenvironment are compared with climate and ice sheet model outputs to identify a range of past $\mathrm{CO}_{2}$ concentrations and TAM uplift scenarios that are most consistent with the geologic record.

An interactive vegetation model was used to reproduce the unique biomes that develop under each set of boundary conditions within the model ensemble (Fig. 4.10). Tundra and boreal forests are the most prevalent vegetation types, with interspersed desert and shrubland, and forest vegetation at the coastline in the warmest interglacial worlds. There is a distinct shift in vegetation across the model ensemble; with increasing $\mathrm{CO}_{2}$ concentrations, the dominant biome transitions from tundra to boreal forest. Model ensembles with lower TAM elevations are warmer, and therefore cause this biome shift at lower $\mathrm{CO}_{2}$ concentrations. It is noted that even during glacial periods and low $\mathrm{CO}_{2}$ concentrations, with ice sheet volume of $136 \%$ modern, isolated patches of tundra survive along the coast and at the edge of the ice sheet, suggesting the boundary conditions investigated are unable to simulate the complete removal of vegetation in this region. 


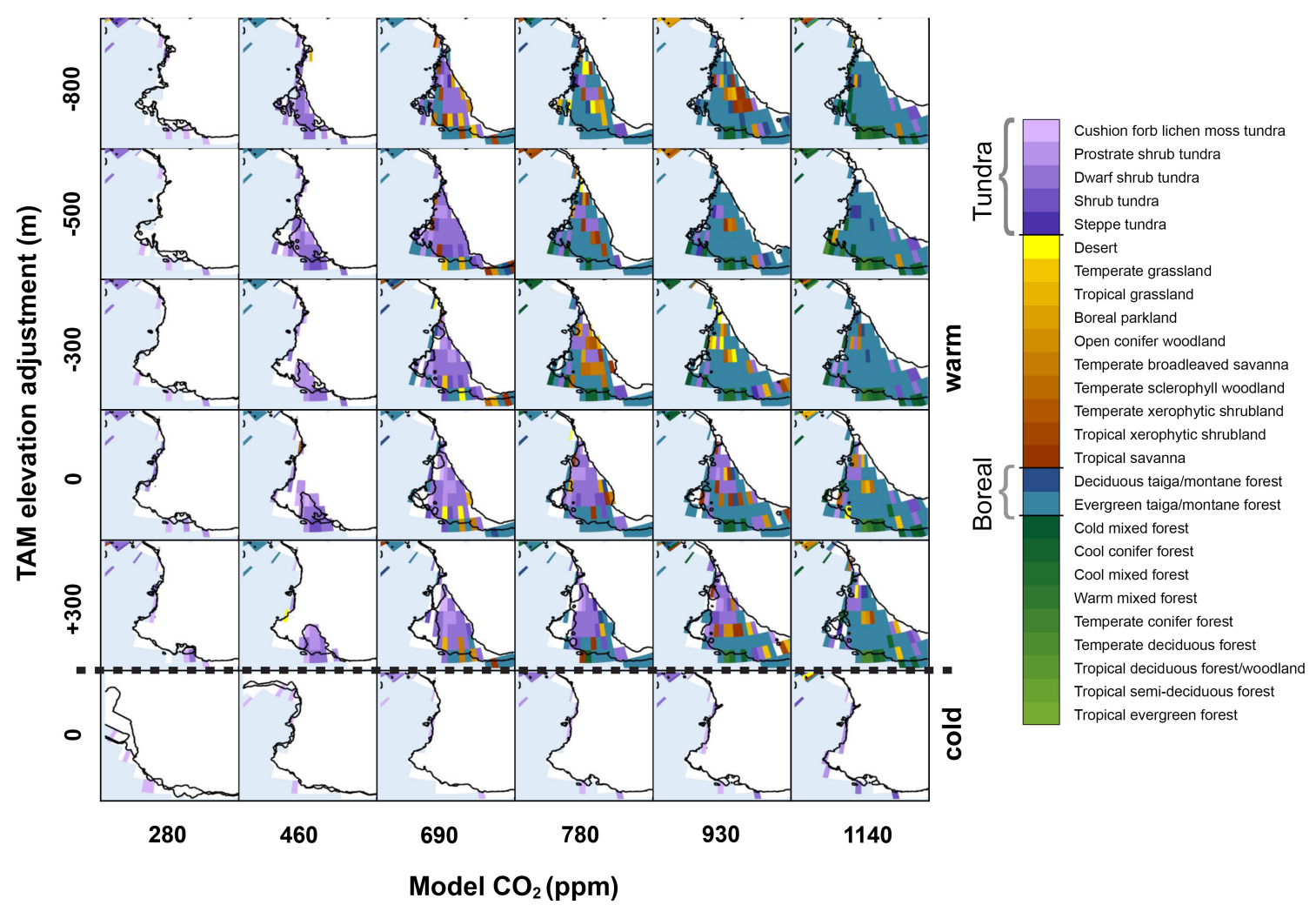

Fig. 4.10 Vegetation over the TAM and WLB region modelled using the BIOME4 interactive vegetation module (GCM resolution is $2^{\circ} \times 2^{\circ}$; black line shows $10 \mathrm{~km}$ resolution ISM grounding line). The colour bar groups together biome outputs by vegetation type (Kaplan et al., 2003). Domain for model results is shown in Figure 4.1 a.

Model boundary conditions are constrained using reconstructed paleo-temperature estimates at each location (Table 4.1-4.3) and a minimum temperature threshold for vegetation survival (Fig. 4.11). While this study used a $-22^{\circ} \mathrm{C}$ threshold (Sakai et al., 1981; Francis \& Hill, 1996; Hill et al., 1996), this is a conservative estimate, and other studies have suggested tundra survival at $-60^{\circ} \mathrm{C}$ (Billings \& Mooney, 1968; Chapin, 1987). Ice-free interglacial conditions at the Friis Hills and Mt.Boreas sites remain above the $-22^{\circ} \mathrm{C}$ threshold (Fig. $4.11 \mathrm{a}, \mathrm{b})$ and therefore, this is unable to offer further constraint. Model results imply that interglacial minimum temperatures remained above $-22^{\circ} \mathrm{C}$ at $>280 \mathrm{ppm} \mathrm{CO}_{2}$ at the AND-2A coast (Fig. $4.11 \mathrm{c}$ ) and $>460 \mathrm{ppm} \mathrm{CO}_{2}$ at the CRP coast (although this threshold is crossed at $>280$ ppm $\mathrm{CO}_{2}$ when TAM elevations are $-800 \mathrm{~m}$, Fig. $4.11 \mathrm{~d}$ ). Under interglacial conditions, the WLB remained above $-22^{\circ} \mathrm{C}$ under all modelled $\mathrm{CO}_{2}$ concentrations (Fig. $4.11 \mathrm{e}$ ). 


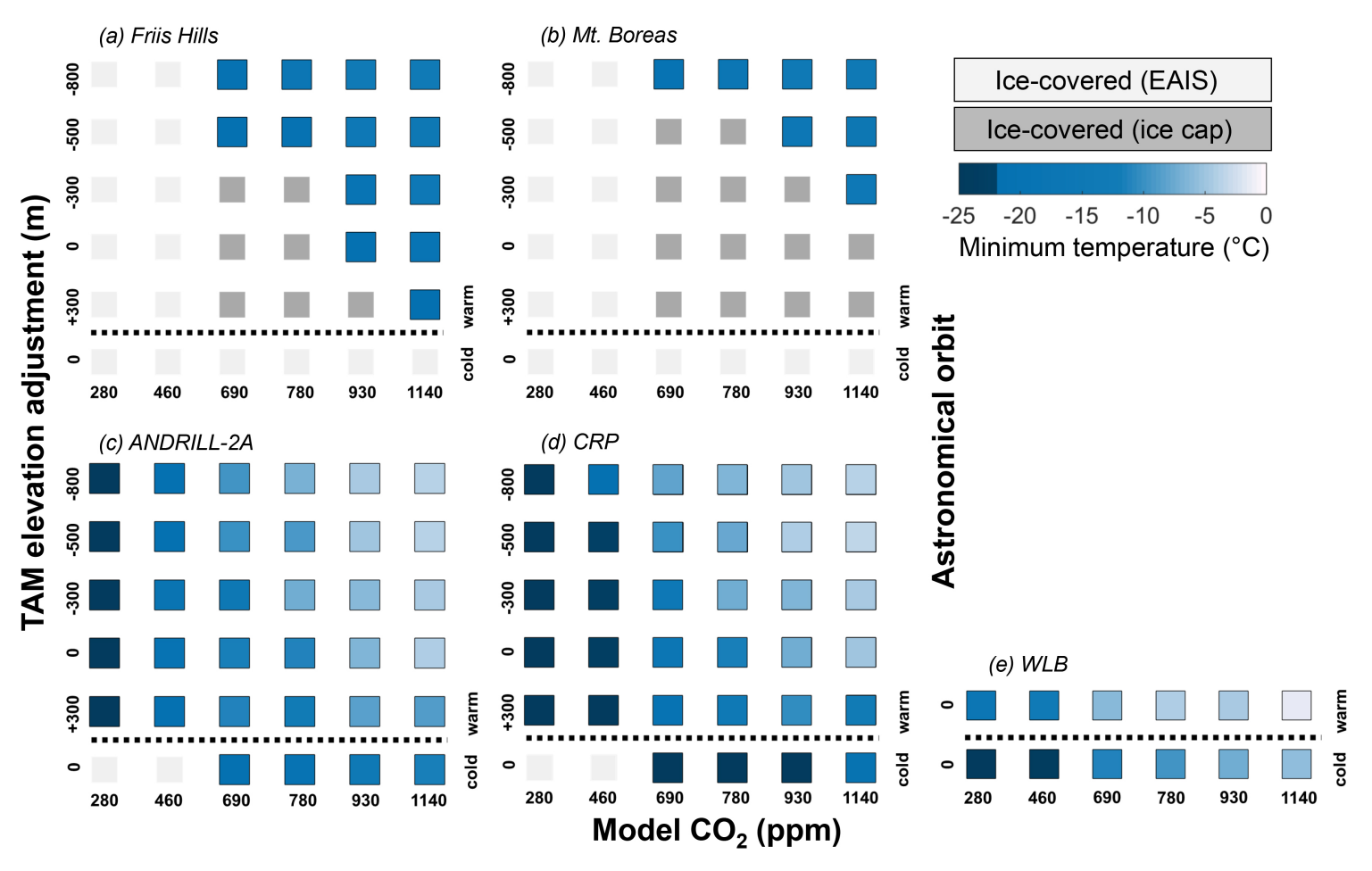

Fig. 4.11 Minimum temperatures for paleodata locations shown in Fig. 4.1. At each location (or, for the marine drill cores, a range of nearby coastal locations), minimum monthly temperature climate model output is plotted under each set of boundary conditions. A $-22^{\circ} \mathrm{C}$ minimum temperature threshold for vegetation survival is used (Sakai et al., 1981; Francis and Hill 1996; Hill et al., 1996). (a,b) Terrestrial temperatures are compiled from the corresponding model grid cell. (c-e) Marine temperatures reflect an average temperature across all proximal coastal grid cells near the drill core site. (e) Only the original reconstructed topography is shown because the TAM hinging region does not extend across the WLB.

\subsubsection{Terrestrial records}

At the Friis Hills, reconstructed interglacial MSTs of $6-7^{\circ} \mathrm{C}$ (Lewis \& Ashworth, 2015) requires $\geq 930 \mathrm{ppm}$ modelled $\mathrm{CO}_{2}$, with TAM elevation adjustment between -300 and -500 $\mathrm{m}$ (Fig. $4.12 \mathrm{a}$ ). Mt Boreas requires $690 \mathrm{ppm} \mathrm{CO}_{2}$ and significantly lower TAM elevations (-800 $\mathrm{m}$ adjustment) to reconstruct interglacial MSTs of $\sim 5^{\circ} \mathrm{C}$ (Fig. $4.12 \mathrm{~b}$; Lewis et al., 2008). Many model members grow ice over Mt. Boreas under boundary conditions that produce ice-free conditions and cooler temperatures at the nearby Friis Hills. Due to the topographic and climatic complexity of the MDVs, it is likely that a higher model resolution would reveal that these same boundary conditions produce ice-free conditions (and relatively 
Carbon-dioxide and tectonic controls on Antarctic climate and ice sheet evolution in the 152 mid-Miocene: a model-data integration

lower MSTs) at Mt. Boreas. Tundra paleoenvironment has been inferred at both locations (Table 4.1, 4.2), ruling out model members with high $\mathrm{CO}_{2}$ ( $\geq 930$ ppm, Fig. 4.10).
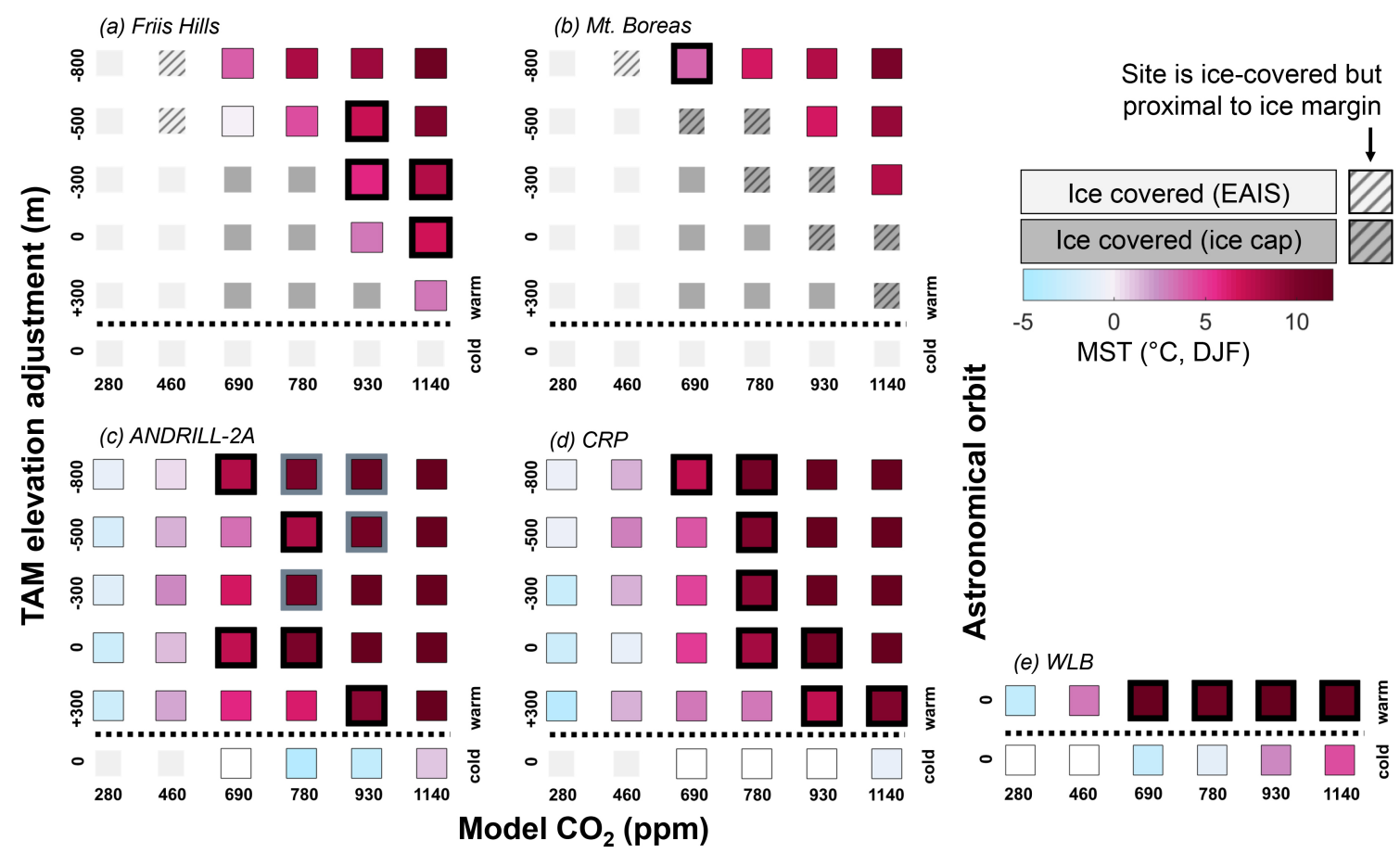

Fig. 4.12 Model-data temperature comparisons for paleodata locations shown in Fig. 4.1. At each location (or, for the marine drill cores, a range of nearby coastal locations), MST climate model output is shown under each set of boundary conditions. Grey boxes indicate that the location is ice-covered, either by the EAIS (light grey) or an ice cap (dark grey). Black outlines denote the various combinations of boundary conditions that fall within the range of reconstructed MSTs at each location (Table 4.1, 4.2). (a-b) Terrestrial temperatures are compiled from the corresponding model grid cell. Stippling indicates that the site is icecovered but located $<10 \mathrm{~km}$ from the ice margin. (c-e) Marine temperatures reflect an average MST across all proximal coastal grid cells near the drill core site, representing the source of terrestrial pollen to the drill core. At ANDRILL-2A, black outlines denote temperatures $7-10^{\circ} \mathrm{C}$, and grey outlines denote temperatures $10-11^{\circ} \mathrm{C}$ (interglacial temperatures and peak warmth, respectively; Warny et al., 2009). (e) At WLB, only the original reconstructed topography is shown because the TAM hinging region does not extend across the WLB.

It is noted that TAM elevation plays a significant role in determining the distance of MDV records to the coast. Under 1140 ppm $\mathrm{CO}_{2}$ and -800 m TAM elevation, the Friis Hills site is within $10 \mathrm{~km}$ ( 1 model grid cell) of the coast, with this distance increasing as TAM elevations rise. Under the $+300 \mathrm{~m}$ model ensembles, the Friis Hills is $\sim 70 \mathrm{~km}$ from the coast. This could have significant implications for the interpretation of data at these sites, including 
precipitation, temperatures, and vegetation assemblage and highlights the importance of a better understanding of TAM uplift history in the MDVs during the mid-Miocene.

Both Friis Hills and Mt. Boreas are covered by an expanded EAIS under all glacial conditions and under interglacials with 280-460 ppm modelled $\mathrm{CO}_{2}$ (Fig. $4.12 \mathrm{a}, \mathrm{b}$ ). An ice cap covers the MDVs under many of the remaining boundary conditions. Ice-free interglacials for both locations require a modelled $\mathrm{CO}_{2}$ concentration of $690 \mathrm{ppm}$ with low TAM elevations, and higher $\mathrm{CO}_{2}$ concentrations at higher TAM elevations. It is noted that under some boundary conditions, these locations are modelled as ice covered but are adjacent to ice free grid cells (Fig. 4.12 a,b). The Friis Hills and Mt. Boreas were ice-covered during glacials, but ice-free or located close to the ice margin during interglacials (Lewis et al., 2008; Lewis \& Ashworth, 2015), implying that small scale glacial fluctuations potentially below the resolution of the nested climate model $(15 \mathrm{~km})$ or the ice sheet model $(10 \mathrm{~km})$.

\subsubsection{Marine records}

The AND-2A and Cape Roberts Project (CRP) drill cores reveal wide-ranging conditions, from marine ice advance to open ocean with coastal tundra vegetation and receded ice caps. Each model member is matched with one of the four environmental motifs described by Levy and others (2016) to characterise the glaciological setting captured by both the AND-2A and CRP records (Table 4.5, Fig. 4.13). This analysis reveals significant local variability between the two locations under the same boundary conditions during the early Miocene when these cores overlap (Fig. 4.13 c). Grounded ice advances over the drill sites in both 280 and 460 ppm glacial worlds (Figs. 4.6 a, 4.13) correspond to the 'maximum ice' environmental motif (EM I). The $280 \mathrm{ppm}$ glacial model is the only ensemble member with large-scale marine ice advance, while the $460 \mathrm{ppm}$ glacial model is characterised by small-scale localised advance of marine ice sourced from the TAM (Fig. 4.7). The 'cold polar' motif (EM II) matches higher- $\mathrm{CO}_{2}$ glacial worlds and 280 and 460 ppm interglacial worlds (Fig. $4.13 \mathrm{c}$ ); grounded ice at the coast is supported by a full EAIS overriding the TAM, rather than localised TAM ice caps (Fig. 4.7). A full EAIS flowing through the TAM can produce the 'cold temperate' motif (EM III, characterised by tidewater glaciation) in the 460 ppm interglacials; this motif also occurs in warmer worlds, 690 and 780 ppm interglacials, where tidewater glaciers are sourced from an ice cap extending towards the coast (Fig. 4.7). The warmest 'minimum ice' motif (EM IV; only identified in AND-2A) occurs under elevated $\mathrm{CO}_{2}$ (780 ppm or higher- $\mathrm{CO}_{2}$ interglacials). 
Carbon-dioxide and tectonic controls on Antarctic climate and ice sheet evolution in the 154 mid-Miocene: a model-data integration

Table 4.5 ANDRILL-2A environmental facies and model representation.

\begin{tabular}{|l|l|l|l|l|}
\hline & $\begin{array}{l}\text { Levy and others } \\
\mathbf{( 2 0 1 6 )} \text { environ- } \\
\text { mental motif }\end{array}$ & $\begin{array}{l}\text { Sedimentologic } \\
\text { evidence }\end{array}$ & $\begin{array}{l}\text { Environmental } \\
\text { interpretation }\end{array}$ & Model representation \\
\hline 1 & Maximum ice & $\begin{array}{l}\text { Glacial erosional } \\
\text { surface }\end{array}$ & $\begin{array}{l}\text { Grounded ice cover- } \\
\text { ing drill site; full } \\
\text { EAIS }\end{array}$ & $\begin{array}{l}\text { Grounded ice covering } \\
\text { drill site }\end{array}$ \\
\hline 2 & Cold polar & $\begin{array}{l}\text { Proximal glacial } \\
\text { marine sediments }\end{array}$ & $\begin{array}{l}\text { Ice grounded at TAM } \\
\text { coast; ice shelf is } \\
\text { present TAM ice } \\
\text { caps }\end{array}$ & $\begin{array}{l}\text { Ice grounded within one } \\
\text { model grid cell (10 km) of } \\
\text { coast, with or without the } \\
\text { presence of an ice shelf }\end{array}$ \\
\hline 3 & Cold temperate & $\begin{array}{l}\text { Some iceberg- } \\
\text { rafted debris }\end{array}$ & $\begin{array}{l}\text { Outlet glaciers with } \\
\text { icebergs calving into } \\
\text { the ocean }\end{array}$ & $\begin{array}{l}\text { Grounded ice reaches the } \\
\text { coast in some locations but } \\
\text { not everywhere }\end{array}$ \\
\hline 4 & Minimum ice & Abundant diatoms & $\begin{array}{l}\text { Open ocean; ice } \\
\text { grounded on land } \\
\text { only }\end{array}$ & $\begin{array}{l}\text { No grounded ice occurs } \\
\text { within one model grid cell } \\
\text { (10 km) of coast }\end{array}$ \\
\hline
\end{tabular}

(a)

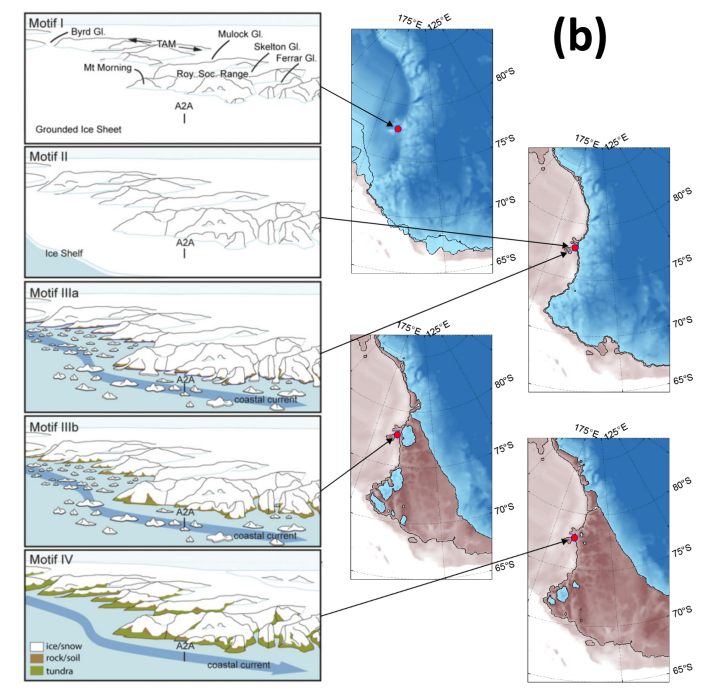

(c)

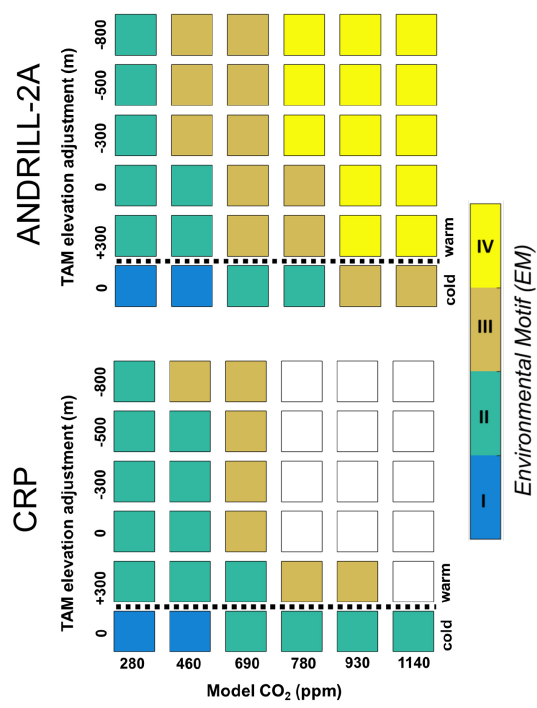

CRP

AND-2A

Fig. 4.13 ANDRILL-2A and Cape Roberts model-data comparison (a) Schematic of environmental motifs identified at the ANDRILL site (Levy et al., 2016), with (b) the corresponding model representation for each motif based on Table 4.5 where EM I is 'maximum ice' (grounded ice); EM II is 'cold polar' (coastal ice); EM III is 'cold temperate' (tidewater glaciation); and EM IV is 'minimum ice'; Levy et al., 2016). (c) a motif for each ensemble model member across both ANDRILL and CRP drill cores is identified, (d) drill core recovery is represented with environmental motifs through time, where dashed lines represent glacial erosional surfaces. EM IV is not identified at CRP. 
Coastal temperatures adjacent to the AND-2A and CRP sites are relatively similar under all boundary conditions. Glacial periods are generally characterised by summer temperatures below freezing and cooler interglacial temperatures at lower $\mathrm{CO}_{2}$ concentrations and lower TAM elevations. Palynological analysis of the AND-2A core suggest mean summer temperatures of $<10^{\circ} \mathrm{C}$, with peak warmth of the $\mathrm{MCO}$ reaching or exceeding $10^{\circ} \mathrm{C}$ (Warny et al., 2009). These temperature ranges $\left(7-10^{\circ} \mathrm{C}\right.$ and $\left.10-11^{\circ} \mathrm{C}\right)$ imply interglacial $\mathrm{CO}_{2}$ concentrations of 690, 780, and $930 \mathrm{ppm}$ at all TAM elevations in the model (Fig. $4.12 \mathrm{c}$ ). Interglacial temperatures of $7-10^{\circ} \mathrm{C}$ at CRP for the early Miocene (Raine, 1998) is mostly consistent with $780 \mathrm{ppm}$, however, lower $\mathrm{CO}_{2}$ concentrations are possible with a significantly lowered TAM (Fig. 4.12 d). Minimum temperature thresholds eliminate $280+\mathrm{ppm}$ and some $460 \mathrm{ppm} \mathrm{CO}_{2}$ concentrations for reconstructed interglacial periods (Fig. $4.11 \mathrm{c}, \mathrm{d}$ ).

The U1356 marine record off the coast of Wilkes Land recovered a detailed record of EAIS dynamics and paleoenvironment throughout the Miocene. Extensive ice-free conditions are reconstructed during peak Miocene warmth, characterised by soil formation on extensive ice-free coastal lowlands, and episodic growth of marine-terminating ice (Sangiorgi et al., 2018). This dynamic glaciation is recorded in the model ensemble, with an ice-covered WLB during all modelled glacials and pervasive ice-free conditions during interglacials under $\mathrm{CO}_{2}$ concentrations $\geq 460 \mathrm{ppm}$. Pollen assemblages suggest MATs of $5.8-13^{\circ} \mathrm{C}$ (MATs of $10-12^{\circ} \mathrm{C} \pm 5^{\circ} \mathrm{C}$ are also reconstructed from branched tetraether lipids), and MSTs $>10^{\circ} \mathrm{C}$ during MCO interglacials (Sangiorgi et al., 2018), consistent with $\mathrm{CO}_{2}$ concentrations of $\geq 690 \mathrm{ppm}$ in the model ensemble (Figs. $4.12 \mathrm{e} ; 4.14$ ). A third proxy for paleotemperatures, based on inorganic chemical weathering, reconstructs MATs of $6-8^{\circ} \mathrm{C} \pm 4^{\circ} \mathrm{C}$ (Passchier et al., 2013); this lower range matches only the 780 ppm interglacial world (Fig. 4.14). 


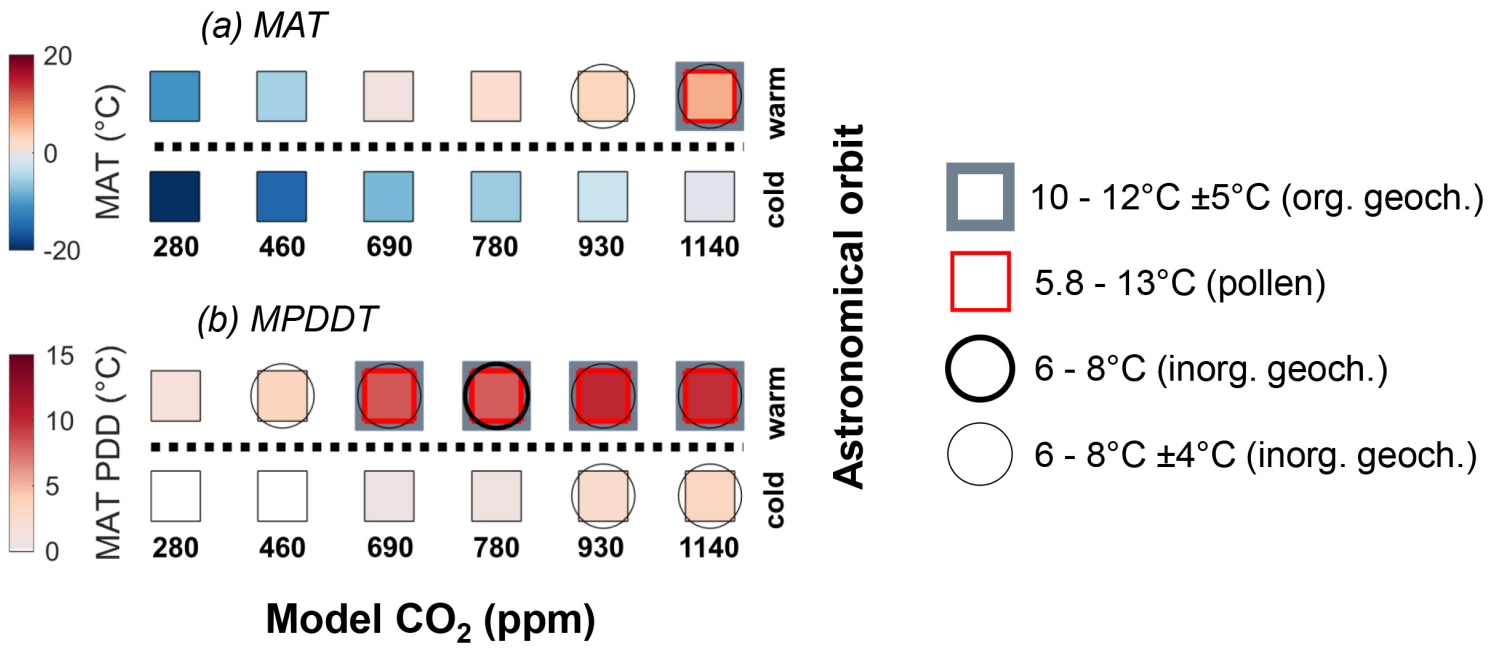

Fig. 4.14 Modelled mean annual temperatures for the Wilkes Land U1356 drill core. The reconstructed temperature ranges that are based on organic geochemistry (calibrations of branched tetraether lipids; $10-12^{\circ} \mathrm{C} \pm 5^{\circ} \mathrm{C}$; Sangiorgi et al., 2018) could either reflect (a) mean annual air temperatures (MAT), or (b) only the mean temperature of the positive-degreeday growing period (MPDDT). A pollen-based MAT reconstruction $\left(5.8-13^{\circ} \mathrm{C}\right)$ is also shown for comparison, along with a MAT reconstruction based on inorganic geochemistry $(6$ $-8^{\circ} \mathrm{C} \pm 4^{\circ} \mathrm{C}$; Passchier et al., 2013).

Terrestrial palynomorphs indicate woody tundra vegetation with boreal forests in sheltered coastal areas, which is reproduced by modelled interglacials with $780 \mathrm{ppm} \mathrm{CO}_{2}$ or greater (Fig. 4.10). A lack of sea ice throughout the $\mathrm{MCO}$ corresponds to modelled $\mathrm{CO}_{2}$ concentrations $\geq 780 \mathrm{ppm}$, while increased sea ice post-MCO suggests that $\mathrm{CO}_{2}$ then remained below 780 ppm (Fig. 4.6 a). After the MCO, cooler marine and terrestrial temperatures and episodic ice-rafted debris also suggest ice expansion punctuated by episodes of ice sheet retreat with a reduced margin compared to the present-day (Pierce et al., 2017; Sangiorgi et al., 2018). These conditions correspond to $460 \mathrm{ppm} \mathrm{CO}_{2}$ during interglacials in the model ensemble (Fig. 4.6 a).

\subsection{Discussion}

\subsubsection{Implications for Antarctic Ice Sheet dynamics}

The design of this model ensemble explores the interplay between climate, tectonic forcings, and ice sheet evolution. $\mathrm{CO}_{2}$ exerts a greater influence on ice volume than TAM elevation, 
however, elevation does impact the resulting ice sheet (Fig. 4.6). At lower $\mathrm{CO}_{2}$ concentrations with a full EAIS (e.g. 280 ppm), higher TAM elevations provide less vertical accommodation, but buttress EAIS growth, promoting a thicker ice sheet and greater ice volumes. At higher $\mathrm{CO}_{2}$ (warmer temperatures), where the TAM is mostly deglaciated, higher TAM elevations remain cooler, supporting the growth of larger ice caps and greater ice volumes. It can therefore be suggested that the uplift of the TAM through time has contributed to greater ice volumes. This is inconsistent with previous findings that inferred TAM elevation had only a local effect on ice sheet dynamics (Kerr \& Huybrecht, 1999).

The climatic threshold for large-scale marine ice growth is a key uncertainty in reconstructing past AIS dynamics and future response to climatic warming. This threshold is exceeded at $280 \mathrm{ppm}$ under glacial conditions in this model (Fig. 4.6 a). A hypothesised marine ice threshold of 280 ppm for Northern Hemisphere marine ice growth (DeConto et al., 2008), along with a lack of evidence for Northern Hemisphere glaciation during the Miocene, also support $\mathrm{CO}_{2}$ concentrations $>280 \mathrm{ppm}$. The growth of marine ice along the fringes of the continent at $460 \mathrm{ppm} \mathrm{CO}_{2}$ suggests that the threshold for large-scale marine ice growth in the model is therefore between 280 and $460 \mathrm{ppm}$, which generally agrees with $\mathrm{CO}_{2}$ proxy data (e.g. Foster et al., 2012; Zhang et al., 2013).

Periods of marine ice expansion in the AND-2A drill core record generally occurred during periods of eccentricity minima, coupled with $\mathrm{CO}_{2}$ concentrations below $400 \mathrm{ppm}$ (Levy et al., 2016). A decline in $\mathrm{CO}_{2}$ concentrations to 265 ppm (Greenop et al., 2019) is thought to have played a significant role in the first large-scale marine ice expansion observed in geologic records at the Oligocene-Miocene boundary, 23 Ma (Barrett et al., 1991; Naish et al., 2001a; Dunbar et al., 2008; Kulhanek et al., 2019), implying that lower $\mathrm{CO}_{2}$ concentrations than those reported in this study are required to initiate marine ice advance. It should be noted that the $\mathrm{CO}_{2}$ concentrations referred to here are restricted to those used as boundary conditions for these model simulations, and do not reflect actual values for the onset of glaciation or deglaciation of the terrestrial and marine sectors of the AIS. Thresholds for the onset of Antarctic glaciation are highly dependent on the type of climate or ice sheet model used (Gasson et al., 2014) and therefore will likely differ considerably between models.

A persistent and thick EAIS is modelled under even the most extreme boundary conditions (high $\mathrm{CO}_{2}$, low TAM elevations, Fig. 4.6 a), despite partial EAIS collapse expected under more moderate $\mathrm{CO}_{2}$ concentrations (Pekar \& DeConto, 2006; DeConto \& Pollard, 2016; Wilson et al., 2018; Blackburn et al., 2020). Increased precipitation in these warmer worlds 
Carbon-dioxide and tectonic controls on Antarctic climate and ice sheet evolution in the 158 mid-Miocene: a model-data integration

supports a thick EAIS interior despite a significantly reduced total area. Under elevated $\mathrm{CO}_{2}$ concentrations, the EAIS grows thicker and larger than the initial conditions (Methods), so the persistence of the ice sheet in these warmer worlds is not dependent on a surface elevation - mass balance feedback. This result is inconsistent with $\mathrm{CO}_{2}$-sea level composite curves (Foster \& Rohling, 2013) that demonstrate EAIS insensitivity to $\mathrm{CO}_{2}$ between 400-600 ppm due to the loss of marine-based ice at $400 \mathrm{ppm}$, while the terrestrial AIS begins to lose mass at 600 ppm (Foster \& Rohling, 2013).

There is evidence to suggest that large subglacial basins in the EAIS have contributed to high sea levels during past warm periods (Young et al., 2011; Cook et al., 2013; Dutton et al., 2015; DeConto \& Pollard, 2016; Grant et al., 2019) and are vulnerable to collapse in the future under rising $\mathrm{CO}_{2}$ concentrations (DeConto \& Pollard, 2016). With modelled $\mathrm{CO}_{2}$ concentrations of $\geq 460 \mathrm{ppm}$, the WLB is deglaciated during interglacials. Under 460 ppm modelled $\mathrm{CO}_{2}$, the shape of the WLB ice embayment varies with TAM elevation while at higher $\mathrm{CO}_{2}$ concentrations, the receded eastern margin remains consistent across all topographies, with only the TAM ice cap on the western side is influenced by TAM elevation (Fig. 4.6 a). Under all $\mathrm{CO}_{2}$ concentrations, ice regrows over the WLB during glacial periods. These reconstructions of large glacial/interglacial fluctuation of grounded ice across the WLB are consistent with other studies suggesting deglaciation of the WLB during warm periods (Cook et al., 2013; Patterson et al., 2014; Pollard et al., 2015; Cook et al., 2017; Pierce et al., 2017; Bertram et al., 2018; Sangiorgi et al., 2018; Wilson et al., 2018). An exposed WLB under interglacial conditions (Fig. 4.6) and flow lines (Figs. 4.7, 4.8) support the theory that TAM ice flow was frequently routed westward during warm periods, explaining the sedimentation patterns off the Wilkes Land margin and a lack of eroded sediments in the Ross Sea (Paxman et al., 2019a,b).

\subsubsection{Implications for Antarctic climate and feedbacks}

The importance of moisture supply in the evolution of the AIS has long been acknowledged, with EAIS growth during past warm periods linked to ocean transfer of heat and moisture from low latitudes (Prentice \& Matthews, 1991; Schnitker, 1980; Shevenell et al., 2008), a process that is highlighted in the present-day moisture limited MDVs (Dagel, 1985; Judd, 1986; Denton et al., 1989; Hall et al., 2000; Higgins et al., 2000; Sugden \& Denton, 2004; Swanger et al., 2017). Moisture transport to the ice sheet and terrestrial regions is limited by ice shelves and sea ice that act to block moisture transport onshore. Marine ice cover can also 
alter surface ocean circulation and impact ocean dynamics such as stratification, overturning circulation, and poleward heat transfer (Shevenell et al., 2008; McKay et al., 2012). Warmer climates (under higher $\mathrm{CO}_{2}$ in this model) promote greater moisture transport to the ice sheet interior. This increased moisture transport is not only the result of a lack of ice in the marine realm, but through increased moisture capacity of the air at warmer temperatures, and the warming ocean surface around the continent, which is more conducive to greater moisture uptake.

The stability of the EAIS plateau under high $\mathrm{CO}_{2}$ boundary conditions (Fig. 4.6) is likely due to increased precipitation in the model under a warmer climate. Large ice sheets concentrate precipitation at the margins due to an orographic effect that restrict moisture transport and creates desert-like conditions at the interior (similar to present-day). Despite a reduced area and margins that are significantly receded, the greater moisture capacity of warmer air allows more moisture to reach the EAIS interior, meaning thicker ice sheets are observed in the model under warmer boundary conditions. Precipitation in the TAM and WLB is also influenced by orographic effects, with the elevation of the TAM acting as a barrier to moisture transport from the Ross Sea. Model results show that higher TAM elevations limit onshore moisture transport, restricting inland precipitation as both snow and rainfall (Fig. 4.9). It should be noted, however, that despite this process, total ice volume remains too large in terms of ice volume inferred from proxy records, which infer an AIS of as little as 30\% volume relative to present-day extent (Holbourn et al., 2013; Liebrand et al., 2017). This implies the ice sheet model used in this study is still suffering from issues with hysteresis at high $\mathrm{CO}_{2}$ concentrations that hinders deglaciation.

All precipitation falling as snowfall would still support the growth of vegetation in the region, should temperatures during summer reach enough to create meltwater. Furthermore, the survival of plants in cold environments may be enhanced by snow blanketing, which can insulate the plants from extreme winter temperatures (Raine, 1998). Nothofagus beardmorensis in the Sirius Group (similar dwarf species to those found in the MDVs) likely grew in MSTs of $\sim 5^{\circ} \mathrm{C}$, however, winter temperatures could have been as low as $-22^{\circ} \mathrm{C}$ and MATs $-12^{\circ} \mathrm{C}$ (Francis and Hill, 1996). Uncertainties arise in the use of this interpretation, as inferences of species that are found in the geologic record are based on the plant response to climates similar to present-day. At higher atmospheric $\mathrm{CO}_{2}$ levels, such as those that characterise the mid-Miocene, woody plants could have existed at temperatures lower than those that limit their present-day distribution (Creber \& Chaloner, 1985). If temperatures from mid-Miocene pollen assemblages have been over-estimated given these constraints, this 
Carbon-dioxide and tectonic controls on Antarctic climate and ice sheet evolution in the 160 mid-Miocene: a model-data integration

could broaden the range of boundary conditions under which environmental conditions at a site can be reconstructed.

Marine ice expansion and widespread perennial sea ice has been linked to changes in ocean circulation and cryosphere development (Flower \& Kennett, 1994; Shevenell et al., 2004; Shevenell et al., 2008; Levy et al., 2019). Expanded marine ice is only reconstructed under the coldest boundary conditions ( $280 \mathrm{ppm}$ under glacial conditions). It is also noted that this expanded ice configuration is the only ensemble member characterised by perennial sea ice along the entire continent. This maximum ice scenario restricts moisture transport to the ice sheet, resulting in the lowest ice thickness across the EAIS plateau (Fig. 4.6 a).

\subsubsection{Terrestrial records}

Temperatures and ice configurations in the MDVs are highly sensitive to TAM uplift and reconstructed temperatures at Friis Hills and Mt. Boreas are only reproduced by the model under extreme boundary conditions. The Friis Hills requires modelled $\mathrm{CO}_{2} \geq 930 \mathrm{ppm}$ while Mt. Boreas requires a TAM elevation adjustment of $-800 \mathrm{~m}$ and modelled $\mathrm{CO}_{2} 690 \mathrm{ppm}$ (Fig. 4.12 a,b). Given the relatively coarse model resolution and complex topography of the MDVs, it is likely that a much wider range of boundary conditions can produce ice-free conditions at these sites but is not represented in this model approach. A resolution of 15 $\mathrm{km}$ is too coarse to fully capture the highly variable microclimates of the MDVs (Doran et al., 2002) and small ice cap fluctuations across the complex and variable TAM topography. Nearby ice caps can isolate the adjacent ice-free areas year-round, and therefore could have a significant impact on local temperatures shown in the model. It is therefore hypothesised that MSTs of $\sim 5^{\circ} \mathrm{C}$ can be achieved at Mt. Boreas under a wider range of boundary conditions than shown in Fig. $4.12 \mathrm{~b}$ but the necessary model resolution masks these subtle variations in ice cover. A generous interpretation of these model results would suggest that satisfactory model boundary conditions to match ice-free paleoenvironments would entail modelled $\mathrm{CO}_{2}$ concentrations of $\geq 690 \mathrm{ppm}$ (or $460 \mathrm{ppm}$ at lower TAM elevations).

A shift in glaciation style at the Friis Hills across the MMCT could represent the growth of the TAM ice cap as glacial conditions became increasing colder (Chapter 3). As this ice cap expanded, the Friis Hills could have shifted from the wet-based to cold-based realm of the ice cap, resulting in thicker glacial sequences and more shearing and fracturing of underlying sediment. This growth in the TAM ice cap occurs in the model with decreasing $\mathrm{CO}_{2}$ concentrations and increasing TAM elevations (Fig. 4.8). 
In addition to the Friis Hills and Mt. Boreas records, the Sirius Group deposits at Beardmore Glacier also suggest mid-Miocene conditions similar to that in the MDVs (Sugden et al., 1993; Webb et al., 1994; Hambrey et al., 2003; Francis et al., 2007; Rees-Owen et al., 2018), however age control has been problematic with these deposits. A thick EAIS covers the Southern TAM under all modelled boundary conditions, with this region one of the least sensitive coastal areas to elevated $\mathrm{CO}_{2}$ concentrations in the model (Fig. 4.6 a). The Beardmore Glacier, associated with the Sirius Group, is located on the edge of the TAM hinging region used in this model (Fig. 4.5), and as a different tectonic block of the TAM (Kerr \& Huybrechts, 1999), may have experienced a different uplift history and subsequent ice sheet evolution than the region focused on in this study. For these reasons, this site is not analysed any further.

\subsubsection{Marine records}

Marine records can provide detailed information on past ice dynamics at a particular region through time. These ice sheet model reconstructions provide spatial context for the environmental motifs identified at the AND-2A site and subsequently interpreted from the CRP record (Table 4.5). While located in the same region (Fig. 4.1), model results show large spatial differences occur in ice extent at each of the drill sites. Conditions at CRP are often ice-proximal under the same boundary conditions that suggest a retreated ice configuration at the AND-2A site (Fig. $4.13 \mathrm{c}$ ). This trend likely results from the different glacial catchments that influence each of these drill sites; a TAM outlet glacier, the McKay drains into the Ross Sea near the CRP site, whereas smaller outlet glaciers such as the Ferrar drain into the Ross Sea near the AND-2A site. When the EAIS was receded and the WLB was deglaciated, the TAM ice cap may have predominantly drained through the McKay, implying cooler, or more ice proximal conditions at CRP. This highlights the importance of considering multiple records when interpreting ice sheet variability through time.

The distribution of coastal temperatures at AND-2A and CRP are similar, although the coastline at CRP is more glacially-dominated and temperatures are therefore slightly cooler. Model results match paleodata reconstructions at 690-930 ppm $\mathrm{CO}_{2}$ with moderate TAM uplift scenarios, while peak warmth temperatures (summer temperatures $\geq 10^{\circ} \mathrm{C}$ ) require $\mathrm{CO}_{2}$ of 780-930 ppm under interglacial conditions (Fig. $4.12 \mathrm{c}, \mathrm{d}$ ). At the AND-2A site, there is not a clear delineation in boundary conditions to produce summer temperatures of below or above $10^{\circ} \mathrm{C}$. The lack of a clear temperature gradient (Fig. $4.12 \mathrm{c}$ ) may reflect the variability 
Carbon-dioxide and tectonic controls on Antarctic climate and ice sheet evolution in the mid-Miocene: a model-data integration

in coastal temperatures; proximal coastal grid cells are averaged to produce a representative summer temperature for each model member.

Boundary conditions that satisfy the Levy and others (2016) maximum ice motif (EM I), with grounded ice over the drill site, are characterised by an expanded EAIS, supporting the interpretation of EM I as reflecting a full EAIS flowing through TAM outlet glaciers. Grounded ice in this region does not require the presence of the WAIS in the model. For the second environmental motif (EM II), interpreted as ice grounded at the coastline and possibly forming an ice shelf, Levy and others (2016) suggest that this 'cold polar' motif is associated with expanding ice caps. Model results show that this motif is only produced by EAIS overriding, rather than a TAM ice cap (Fig. 4.7). The 'cold temperate' motif (EM III), indicating tidewater glaciation at the coast is achieved by both a full EAIS and a TAM ice cap in the model. EM III boundary conditions where the EAIS overrides the TAM have lower $\mathrm{CO}_{2}$ concentrations and higher TAM elevations; while lower $\mathrm{CO}_{2}$ supports the growth of a large EAIS, high TAM elevations prevent ice from fully reaching the coast (described as EM II). At higher $\mathrm{CO}_{2}$ concentrations, EM III (tidewater glaciation) is reconstructed with a TAM ice cap expanded towards the coast.

This observation of diverging glacial environments within EM III is consistent with the Levy and others (2016) subdivision of the EM III motif into a cooler EM IIIa and warmer EM IIIb. Model results allow for a further interpretation of this subdivision, suggesting that EM IIIa occurs at lower $\mathrm{CO}_{2}$, with a full EAIS overriding the TAM, and EM IIIb is characterised by higher $\mathrm{CO}_{2}$ concentrations, a deglaciated WLB, and a TAM ice cap (Fig. 4.7). The warmest reconstruction at ANDRILL, the 'minimum ice' motif (EM IV), is interpreted as a significantly retreated ice sheet and coastal tundra (Levy et al., 2016). This occurs under elevated modelled $\mathrm{CO}_{2}$ concentrations ( $\geq 780$ ppm; Fig. 4.13), however widespread tundra is only produced at the lower bound of these $\mathrm{CO}_{2}$ concentrations (780-930 ppm).

Geological reconstructions of paleo-flowlines sourcing the ANDRILL site based on mineral provenance provide additional validation data of model results. Modelled flowlines generally match those reconstructed by Talarico and others (2011) for interglacial conditions (Fig. 4.7). Under glacial conditions, the only model member with extensive marine ice (280 ppm) shows that flow from the TAM extended out into the western Ross Sea. Model results were unable to replicate the flow reversal reconstructed by Talarico and others (2011) for glacial periods. Modelled ice flowlines (Fig. 4.7) indicate that Byrd Glacier was a significant EAIS outlet under all boundary conditions and could have sourced sediment to the ANDRILL site throughout the Miocene. This is consistent with Levy and others (2016), who 
observed coarse iceberg-rafted sediment delivered to the drill site from large outlet glaciers even during warm environments (e.g. EM IIIb). While an actively flowing Byrd Glacier is reconstructed under all boundary conditions, significant ice flow through the more proximal Mulock Glacier indicates that a full EAIS is connected to the TAM (Fig. 4.7). Model results therefore imply that sediments that can be linked to Mulock Glacier can be interpreted as representative of EAIS overriding the TAM at the time of deposition.

Off the coast of Wilkes Land, the U1356 drill core records extensive ice-free conditions during the $\mathrm{MCO}$, consistent with modelled $\mathrm{CO}_{2}$ concentrations of $460 \mathrm{ppm}$ and greater under interglacial conditions (Fig. 4.6 a). $\mathrm{CO}_{2}$ concentrations of $690 \mathrm{ppm}$ or greater are required to reconstruct MCO MSTs inferred by this record (Fig. $4.12 \mathrm{e}$ ). Branched tetraether lipids from U1356 were calibrated to reconstruct coastal MATs (De Jonge et al., 2014; Sangiorgi et al., 2018), although it is suggested that these temperatures may only reflect positive degree days above freezing (Sangiorgi et al., 2018). Model results support this latter interpretation, showing that both MSTs and positive degree day MATs are consistent with the same boundary conditions $\left(\mathrm{CO}_{2}\right.$ concentrations $\geq 690 \mathrm{ppm}$ under interglacial conditions, Fig 4.14). The U1356 record suggests the WLB was characterised by warmer conditions than the TAM region during the MCO, with high pollen percentages of conifers and woody taxa (Sangiorgi et al., 2018). Model results also support this interpretation, modelled temperatures over the TAM are consistently cooler than the WLB, which is accentuated at higher TAM elevations. This temperature difference derives from topographical differences between the elevated TAM and the lower, more coastal WLB, as well as a latitudinal difference between the two regions.

The lack of evidence for marine or sea ice offshore the Wilkes coast throughout the MCO requires $\mathrm{CO}_{2}$ concentrations of $\geq 780 \mathrm{ppm}$ under glacial conditions in the model, whereby the model reproduces a thin ice-free zone at the coast. This is likely due to warm ocean temperatures, which could have minimised marine-terminating glaciation and explain the lack of ice-rafted debris in the $\mathrm{U} 1356$ record. These warm ocean temperatures during high $\mathrm{CO}_{2}$ glacial periods would also have prevented sea ice formation. During MMCT glacial periods, episodic marine ice advance and sea ice are reported at the site (Sangiorgi et al., 2018). Under glacial conditions, the model reproduces ice expanded over the WLB to the coast with perennial sea ice at $\mathrm{CO}_{2}$ concentrations of $<690 \mathrm{ppm}$ (Fig. 4.6 a). At $280 \mathrm{ppm}$, with marine ice expanding around the continent, grounded ice does not grow across the Wilkes continental shelf, but instead shows large-scale marine-terminating glaciers, capable of producing the ice-rafted debris pulses that reached site U1356 (Pierce et al., 2017; Sangiorgi et al., 2018). 
Carbon-dioxide and tectonic controls on Antarctic climate and ice sheet evolution in the 164 mid-Miocene: a model-data integration

This is consistent with the conclusions of Pierce and others (2017), who use provenance data from ice-rafted debris at site U1356 to conclude that the MMCT ice sheet expanded over the WLB but remained inland of its present location.

\subsubsection{Characterising the mid-Miocene}

Finally, the ice sheet and climate model results, combined with available paleodata from the TAM and WLB regions (Table 4.1-4.3) are used to highlight possible boundary condition changes across the major climatic events of the mid-Miocene: the MCO $(\sim 17-15 \mathrm{Ma})$ and the MMCT ( 14.8-13.8 Ma). This in turn allows for the evolution of atmospheric $\mathrm{CO}_{2}$, TAM uplift, and ice sheet dynamics to be reconstructed for glacial-interglacial cycles during this time.

\section{Early Miocene}

The early Miocene (pre-MCO, Table 4.1-4.3) was characterised by warm interglacials with tundra vegetation and episodes of marine ice advance into the Ross Sea (Fig. $4.13 \mathrm{~d}$ ). This advance of marine ice over the AND-2A and CRP drill sites requires $\mathrm{CO}_{2}$ to periodically drop below $460 \mathrm{ppm}$. Glacials characterised by the 'cold polar' motif, with a lack of grounded ice at the drill sites, require $\mathrm{CO}_{2}$ concentrations $\geq 460$ ppm (Fig. $4.13 \mathrm{c}$ ). All boundary conditions have ice-covered MDVs during glacial periods, which is consistent with the alpine glaciation recorded at the Friis Hills during the early Miocene (Lewis and Ashworth, 2015). The AND-2A record also records intervals of 'minimum ice', implying at times $\mathrm{CO}_{2}$ contractions exceeded $690 \mathrm{ppm}$, although these warm intervals are absent in the CRP record (Fig. 4.13 c,d). Interglacials characterised by the 'cold temperate' motif and tidewater glaciation imply $\mathrm{CO}_{2}$ concentrations of $460-930 \mathrm{ppm}$, a figure that is also consistent with an ice-free Friis Hills during interglacial periods (Fig. 4.12 a, Lewis \& Ashworth, 2015).

\section{Miocene Climatic Optimum}

The MCO ( 17-15 Ma) was a period of unusual warmth during a long-term global cooling trend and one of the warmest intervals since the onset of Antarctic glaciation. Peak MCO warmth was characterised by summer temperatures of $>10^{\circ} \mathrm{C}$ and extensive tundra vegetation at the TAM coast (Warny et al., 2009) and minimum ice (EM IV; Levy et al., 2016), which requires $\mathrm{CO}_{2}>690 \mathrm{ppm}$ in the model (Fig. $4.13 \mathrm{c}$ ). Cold temperate (EM 
III) tidewater glaciation interglacial conditions in the AND-2A record can be reconstructed under a significantly broader range of $\mathrm{CO}_{2}$ in the model, with $>280$ and $<930$ ppm $\mathrm{CO}_{2}$ required depending on TAM elevation. To reconstruct temperatures during cold temperature interglacials requires $\mathrm{CO}_{2}>690$ and $<1140$ ppm to reconstruct peak warmth temperatures (Fig. 4.12). Ice free conditions at the Friis Hills during the late MCO support the inference of high $\mathrm{CO}_{2}$ concentrations, with modelled $\mathrm{CO}_{2} \geq 930 \mathrm{ppm}$ required to reconstruct these conditions (Fig. $4.12 \mathrm{a}$ ).

The WLB was characterised by extensive ice-free conditions (Sangiorgi et al., 2018), which is consistent under all modelled interglacial boundary conditions $\geq 460 \mathrm{ppm}$ (Fig. 4.6). While TAM records suggest tundra vegetation was dominant during the MCO, the WLB record reconstructs a greater diversity of woody taxa than MDV records, with localised boreal forests in sheltered coastal lowlands (Sangiorgi et al., 2018). To satisfy both these conditions in the model requires $690-780 \mathrm{ppm} \mathrm{CO}_{2}$ under interglacial conditions, however, $780 \mathrm{ppm} \mathrm{CO} 2$ at $-800 \mathrm{~m}$ TAM elevation reproduces more widespread boreal forests across the TAM and MDVs (Fig. 4.10), implying more moderate TAM elevations of -500 to $-300 \mathrm{~m}$.

Given the constraints discussed, it is hypothesised that MCO 'peak warmth' interglacials are best represented by modelled $\mathrm{CO}_{2}$ concentrations of $780 \mathrm{ppm}$ and moderate TAM elevations $(-500$ to $-300 \mathrm{~m})$ in the model. This allows for the model to reconstruct peak warmth temperatures, a fully receded TAM ice cap and EAIS (EM IV), and tundra growth across the TAM and WLB coast, with localised boreal forests at the WLB coast. Cooler MCO glacials were likely characterised by lower $\mathrm{CO}_{2}$ concentrations, with the $690 \mathrm{ppm} \mathrm{CO}_{2}$ modelled world producing the reconstructed temperatures and cold temperate (EM III) conditions at the AND-2A site (Fig. $4.13 \mathrm{c}$ ). While both of these $\mathrm{CO}_{2}$ concentrations are too low to reconstruct conditions at the Friis Hills, given the uncertainties with temperature reconstruction (see Methods) and the model resolution issues previously discussed, boundary conditions that closely replicate conditions in offshore records, at more realistic $\mathrm{CO}_{2}$ concentrations, are more seriously considered.

The AND-2A drill core records grounded ice at the TAM coast during MCO glacials (EM II, cold polar), which requires $\mathrm{CO}_{2}$ of $460-930 \mathrm{ppm}$ in the model under glacial conditions. U1356 lacks evidence for marine terminating ice or sea ice at the WLB coast during MCO glacials. Localised ice-free regions along the WLB coast under 690 ppm $\mathrm{CO}_{2}$ could explain the lack of evidence for marine terminating ice at this site. To reconstruct a lack of sea ice off the WLB coast also requires high $\mathrm{CO}_{2}$ concentrations during glacials ( $>690 \mathrm{ppm}$ ). Under these boundary conditions, winter sea ice is absent offshore WLB but is present in the Ross 
Carbon-dioxide and tectonic controls on Antarctic climate and ice sheet evolution in the 166 mid-Miocene: a model-data integration

Sea and covers the AND-2A site (Fig. 4.6 a). To reconcile the WLB and Ross Sea records, it is hypothesised that MCO glacial $\mathrm{CO}_{2}$ concentrations were $\geq 690 \mathrm{ppm}$ in the model.

\section{Mid-Miocene Climate Transition}

The MMCT ( 14.8-13.8 Ma) was a large-scale climate transition characterised by global cooling, declining $\mathrm{CO}_{2}$ and progressive glacial expansion (Flower \& Kennett, 1993; Shevenell et al., 2004; Holbourn et al., 2014). Interglacials remained similar to more moderate MCO interglacials, with tundra vegetation and ice-proximal to ice-free conditions characterising the MDVs and TAM coast. Tidewater glaciation at the AND-2A site during MMCT interglacials requires $\mathrm{CO}_{2}$ of 280-930 ppm (Fig. $4.13 \mathrm{c}$,d), providing little constraint. At U1356, the MMCT was characterised by more ice cover across the WLB relative to the $\mathrm{MCO}$, but warm water incursion led to smaller ice configurations than present-day, with tundra growth on ice-free areas (Sangiorgi et al., 2018). This is most compatible with 460 ppm $\mathrm{CO}_{2}$ interglacial in model results, under which the ice sheet model produces an interglacial ice configuration in the WLB that matches bedrock erosion patterns suggested by MMCT ice-rafted debris provenance (Pierce et al., 2017). High $\mathrm{CO}_{2}$ concentrations are required to reconstruct MSTs at Friis Hills and Mt. Boreas (Fig. 4.12), however, once again, there are a number of uncertainties when interpreting these records and therefore modelled $\mathrm{CO}_{2} \geq 460 \mathrm{ppm}$ is considered as reasonable. From these model-data comparisons, it is reasonable to suggest that $\mathrm{CO}_{2}$ concentrations during MMCT interglacials were 460-690 ppm.

Glacials intensified across the MMCT, with marine ice expansion at 14.6 Ma (Levy et al., 2016), ice overriding of the MDVs (Lewis et al., 2007; Lewis et al., 2008; Lewis \& Ashworth, 2015), and ice expansion across the WLB (Sangiorgi et al., 2018). The modelled $280 \mathrm{ppm}$ $\mathrm{CO}_{2}$ glacial reconstructs these conditions, however as previously discussed, model results imply this marine-ice advance during likely occurred between 280 and 460 ppm. Similar to geologic data from the AND-2A (Levy et al., 2016) and U1356 (Sangiorgi et al., 2018) records, model results also show that widespread perennial sea ice accompanied marine ice advance across the MMCT. While marine ice advanced over the Ross Sea, glacial conditions in the model produce marine terminating glaciers across the WLB coast (Fig. 4.6), likely responsible for the ice-rafted debris in the U1356 record (Pierce et al., 2017; Sangiorgi et al., 2018). The growth of large-scale marine-based ice at $14.6 \mathrm{Ma}$ is produced by a drop in $\mathrm{CO}_{2}$ to below $460 \mathrm{ppm}$. It is likely that the increasing strength of these glacials across the MMCT was the result of a complex interplay of climate forcings and the significant changes 
in ocean circulation reconstructed at $\sim 14$ Ma (Flower \& Kennett, 1994; Shevenell et al., 2004; Shevenell et al., 2008; Hamon et al., 2013).

\section{Elevation of the Transantarctic Mountains}

Lower TAM elevations during the mid-Miocene allow for temperature reconstructions from the AND-2A, CRP, Friis Hills, and Mt. Boreas records to occur at lower $\mathrm{CO}_{2}$ concentrations that are more in line with proxy $\mathrm{CO}_{2}$ reconstructions. On the other hand, TAM elevations must also remain high enough during this time to maintain coastal and MDV tundra vegetation. A TAM uplift scenario of $-800 \mathrm{~m}$ supports the growth of boreal forests and shrub/grassland (at $\geq 690 \mathrm{ppm} \mathrm{CO}_{2}$ ) along the TAM coast and MDVs, biomes that are not implied from current geologic data. From model data, it is therefore suggested that TAM elevation during the mid-Miocene was -500 to $-300 \mathrm{~m}$ lower than present-day. This allows for the balance between the reconstructed biomes (TAM tundra, WLB tundra with sheltered coastal forests), warm summer temperatures, and the minimum-ice environment recorded in ANDRILL motifs. It is likely that TAM uplift was continual during this time, however from current geologic data, the rate at which this occurred is impossible to predict.

Previous work has suggested that TAM uplift was minimal since the Pliocene (Wilch et al., 1993) and possibly even reached present-day elevation at the end of the MMCT (Marchant et al., 1993; Sugden et al., 1999). It is hypothesised that this final stage of TAM uplift was driven by isostatic rebound due to valley erosion from ice sheet overriding throughout $\mathrm{MCO}$ glacials and successively intensifying across the MMCT (Chapter 3). This interpretation is consistent with Paxman and others (2019a), who reconstructed 600-900 m of uplift due to TAM valley incision and resulting isostatic adjustment since glacial inception at $34 \mathrm{Ma}$, but only minimal erosion and flexural uplift after $14 \mathrm{Ma}$. It is also noted that TAM elevations play a significant role in the amount of ice that is 'frozen to the bed' across the TAM (Fig. 4.7), with lower elevations supporting more warm-based ice, which could also have contributed to high levels of valley erosion. If the final stages of TAM uplift were driven by this valley incision and isostatic rebound, then the gradual shift in dominant glacial style across the TAM from wet to cold based across the MMCT (Behrendt \& Cooper, 1991; Denton et al., 1993; Sugden et al., 1995) could have been driven by TAM uplift to nearer present-day elevations during this time. 
Carbon-dioxide and tectonic controls on Antarctic climate and ice sheet evolution in the 168 mid-Miocene: a model-data integration

\section{Post-MMCT}

Under all boundary conditions, vegetation is still present in localised regions of the TAM and WLB (Fig. 4.10). Geologic records clearly show the extinction of vegetation from high elevations at the end of the MMCT (Lewis et al., 2008; Lewis \& Ashworth, 2015), Rising TAM elevations coupled with decreasing $\mathrm{CO}_{2}$, which from model results is hypothesised to have occurred towards the MMCT, also supports the extinction of vegetation from the high elevations of the MMCT. A decline in $\mathrm{CO}_{2}$ across the MMCT is also likely to have decreased the minimum temperature threshold at which tundra vegetation could survive (Creber \& Chaloner, 1985), aiding in its extinction from high elevations as temperatures post-MMCT declined. The presence of localised tundra vegetation in model results suggest that despite extinction at high elevations, vegetation could have persisted in coastal lowlands beyond the MMCT. This is corroborated by geologic data from the DVDP-10 and -11 cores, which indicate plants persisted at lower elevations in Taylor Valley until the early Pliocene (Ohneiser et al., 2020; Fielding et al., 2012).

\subsection{Conclusions}

The aim of this study was to reconstruct an ensemble of possible mid-Miocene ice sheet configurations under a range of $\mathrm{CO}_{2}$ concentrations, TAM elevations, and glacial-interglacial astronomical orbits. Records of Miocene paleo-temperature in the Antarctic are sparse and often difficult to chronologically constrain or correlate, however, those that do exist provide data to compare with climate and ice sheet model output. Paleoenvironmental data was compiled from terrestrial and marine records across the TAM and WLB. These paleoenvironmental conditions were then divided into glacial and interglacial periods to provide a means against which to test both cold (glacial) and warm (interglacial) orbit simulations.

The largest ice sheet is reconstructed at the lowest $\mathrm{CO}_{2}(280 \mathrm{ppm})$ and a cold orbit representative of a glacial period. These boundary conditions simulate large-scale marine ice advance, such that marine ice is extended out onto the continental shelf, with an ice configuration significantly larger than modern (135\%). The smallest ice sheet reconstructed is under $1140 \mathrm{ppm} \mathrm{CO}_{2}$ and a warm orbit representative of an interglacial period. Despite these extreme boundary conditions and a significantly reduced area, the ice sheet is stable at $\sim 75 \%$ modern volume, driven by increased precipitation in warmer worlds. 
$\mathrm{CO}_{2}$ exerts a greater influence on ice sheet volume than TAM elevation, although it is evident that TAM elevation impacts the resulting EAIS evolution. Under cooler climates, higher TAM elevations restrict the vertical growth of an already thick EAIS, however, also serve to buttress EAIS growth and restrict flow to the coast, leading to greater EAIS volumes. Under warmer climates, higher TAM elevations remain cooler, allowing for the development of a larger TAM ice cap, so ice volume is also greater. With $\mathrm{CO}_{2} \geq 460 \mathrm{ppm}$, the WLB remains deglaciated during interglacials, but under all $\mathrm{CO}_{2}$ concentrations, glacial reconstructions grow an ice sheet back over the region (Fig. 4.6). These large glacial-interglacial fluctuations in ice volume and a dynamic WLB is consistent with other studies that suggest deglaciation of the WLB during warm periods (Cook et al., 2013; Patterson et al., 2014; Pollard et al., 2015; Cook et al., 2017; Pierce et al., 2017; Bertram et al., 2018; Sangiorgi et al., 2018; Wilson et al., 2018; Grant et al., 2019).

Model results suggest the advance of marine ice into the Ross Sea at below $460 \mathrm{ppm}$. Under modelled glacial conditions, $280 \mathrm{ppm}$ allows for the growth of a large marine-based ice sheet around the continent, however, it is noted that $280 \mathrm{ppm}$ is the hypothesised threshold for the onset of large-scale Northern Hemisphere glaciation (DeConto et al., 2008; Willeit et al., 2015), which is considered to have been initiated at $2.7 \mathrm{Ma}$ (Shackleton et al., 1995; Maslin et al., 1996; Jansen et al., 2000; Flesche Kleiven et al., 2002; Mudelsee and Raymo, 2005) and it is likely that a marine-based ice threshold exists between 280 and 460 ppm. Assessment of proxy $\mathrm{CO}_{2}$ records and Antarctic margin geological data suggests that this threshold is 400 ppm (Naish et al., 2009; Pollard / DeConto, 2009; Foster / Rohling 2013; Levy et al., 2016; Levy et al., 2019), consistent with the model results presented here. Year round, large-scale sea ice expansion occurs at $280 \mathrm{ppm}$ under glacial conditions and in association with an expanded marine ice sheet. Despite the lack of marine ice growth, sea ice is also significant at $460 \mathrm{ppm}$. During interglacials, winter sea ice is prevalent at $280 \mathrm{ppm}$, and present in localised regions at $460 \mathrm{ppm}$. This implies a shift of $\mathrm{CO}_{2}$ to $\leq 460 \mathrm{ppm}$ to initiate sea ice growth around the continent under both glacial and interglacial conditions. Higher resolution $\mathrm{CO}_{2}$ concentrations between $280 \mathrm{ppm}$ and $460 \mathrm{ppm}$ would allow for further assessment of the marine ice and sea ice threshold.

TAM uplift is interpreted as ongoing throughout the mid-Miocene, with TAM elevations hypothesised as -500 to $-300 \mathrm{~m}$ lower to allow for reconstructed tundra biomes, warm interglacial summer temperatures, and ice configurations reconstructed at the AND-2A site. Lower TAM elevations corroborate conclusions made in Chapter 3, whereby sediment removal since the mid-Miocene could have accounted for up to $1000 \mathrm{~m}$ of uplift. The final 
stages of TAM uplift towards the end of the MMCT could have contributed to the shift in basal thermal character reported across the TAM at this time (Marchant et al., 1993; Sugden \& Denton, 2004; Lewis et al., 2006; Lewis et al., 2008; Lewis \& Ashworth, 2015). Since this model is unable to reconcile the Friis Hills and Mt. Boreas records under realistic boundary conditions, a higher spatial resolution model through the TAM would allow for a better understanding of the influence of varying TAM elevations and $\mathrm{CO}_{2}$ concentrations at these sites.

Based on the model boundary conditions that produce paleoenvironments most consistent with the sparse geologic record across the MMCT, glacial and interglacial periods across the MCO and MMCT have been characterised (Fig. 4.15). MCO peak warmth is most consistent with the modelled interglacial at $780 \mathrm{ppm} \mathrm{CO}_{2}$, while cooler interglacials were characterised by lower $\mathrm{CO}_{2}$ of $690 \mathrm{ppm}$. To reconcile the Ross Sea and WLB offshore records, $\mathrm{CO}_{2}$ remained elevated during MCO glacials, at $690 \mathrm{ppm}$. Declining $\mathrm{CO}_{2}$ across the MMCT reached the threshold for marine ice growth (less than $460 \mathrm{ppm}$ ), with marine ice advancing into the Ross Sea at 14.6 Ma (Levy et al., 2016), and marine terminating glacial systems at the WLB coast. MMCT interglacials remained moderate, most consistent with the 460-690 ppm $\mathrm{CO}_{2}$ modelled interglacials. 


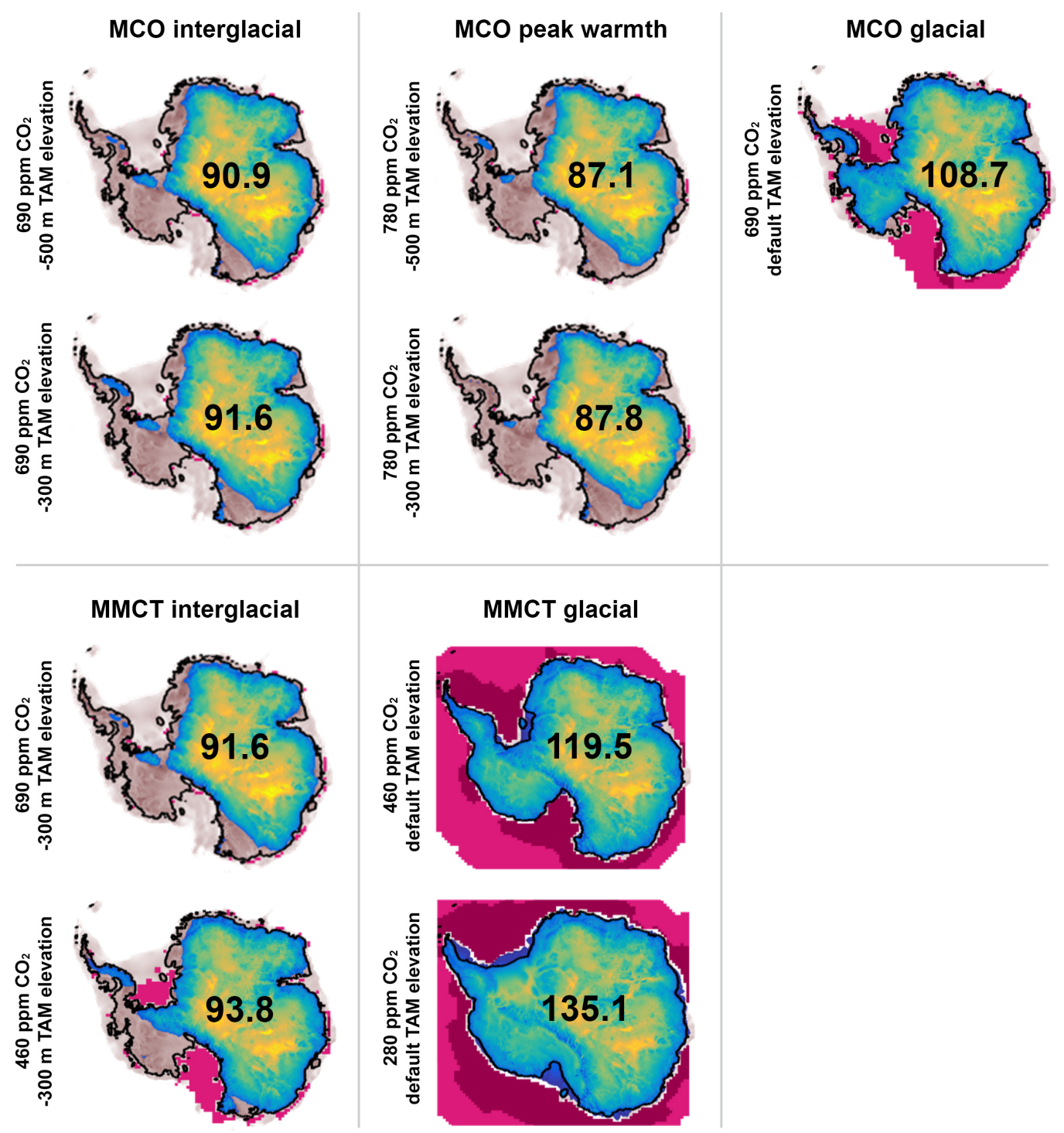

Fig. 4.15 Hypothesised ice sheet configurations for the MCO and MMCT, with peak warmth, interglacial and glacial scenarios. Percentage ice sheet volume relative to present-day is also reported.

These scenarios require $\mathrm{CO}_{2}$ variability on a glacial-interglacial scale, which has previously been suggested to explain variability across the mid-Miocene (Greenop et al., 2014). Mechanisms that could cause this large amplitude $\mathrm{CO}_{2}$ variability are complex, but likely encompass changes in volcanic emissions, silicate weathering and the organic carbon subcycle (Raymo \& Ruddiman, 1992; Derry \& France-Lanord, 1996; Foster et al., 2012). Levy and others (2019) also explore the role of obliquity sensitivity in the development of larger and more expansive glacial periods across the MMCT. 



\section{Chapter 5}

\section{Glacial-interglacial variability and evolution of the Antarctic Ice Sheet across the mid-Miocene: reconciling terrestrial, marine, and far-field records}

Author contributions: Model results are provided by ice sheet and climate model simulations performed by A. Halberstadt in conjunction with results presented in Chapter 4.

\subsection{Introduction}

Proxy ice volume records from the oxygen isotopic composition of deep ocean sediments (Zachos et al., 2001, Coxall et al., 2005), numerical modelling of past ice sheets (DeConto \& Pollard, 2003, Wilson et al., 2013) and direct geological evidence from Antarctic margin marine drill cores (Barrett, 1989, Hambrey et al., 1991, Galeotti et al., 2016) imply development of a continental scale ice sheet by the early Oligocene. The mid-Miocene is characterised by a dynamic AIS with major variations in both volume and extent of terrestrial and marine ice sheets (Fig. 5.1, Miller et al., 2005, Gasson et al., 2016, Levy et al., 2016). This interval was punctuated by an episode of unusual warmth within the Miocene Climatic Optimum (MCO, 17-15 Ma, Flower \& Kennett, 1993) and terminated with major cooling and ice expansion across the mid-Miocene Climate Transition (MMCT, 14.8-13.8 Ma, Flower and Kennett, 1993). 
Glacial-interglacial variability and evolution of the Antarctic Ice Sheet across the mid-Miocene: reconciling terrestrial, marine, and far-field records

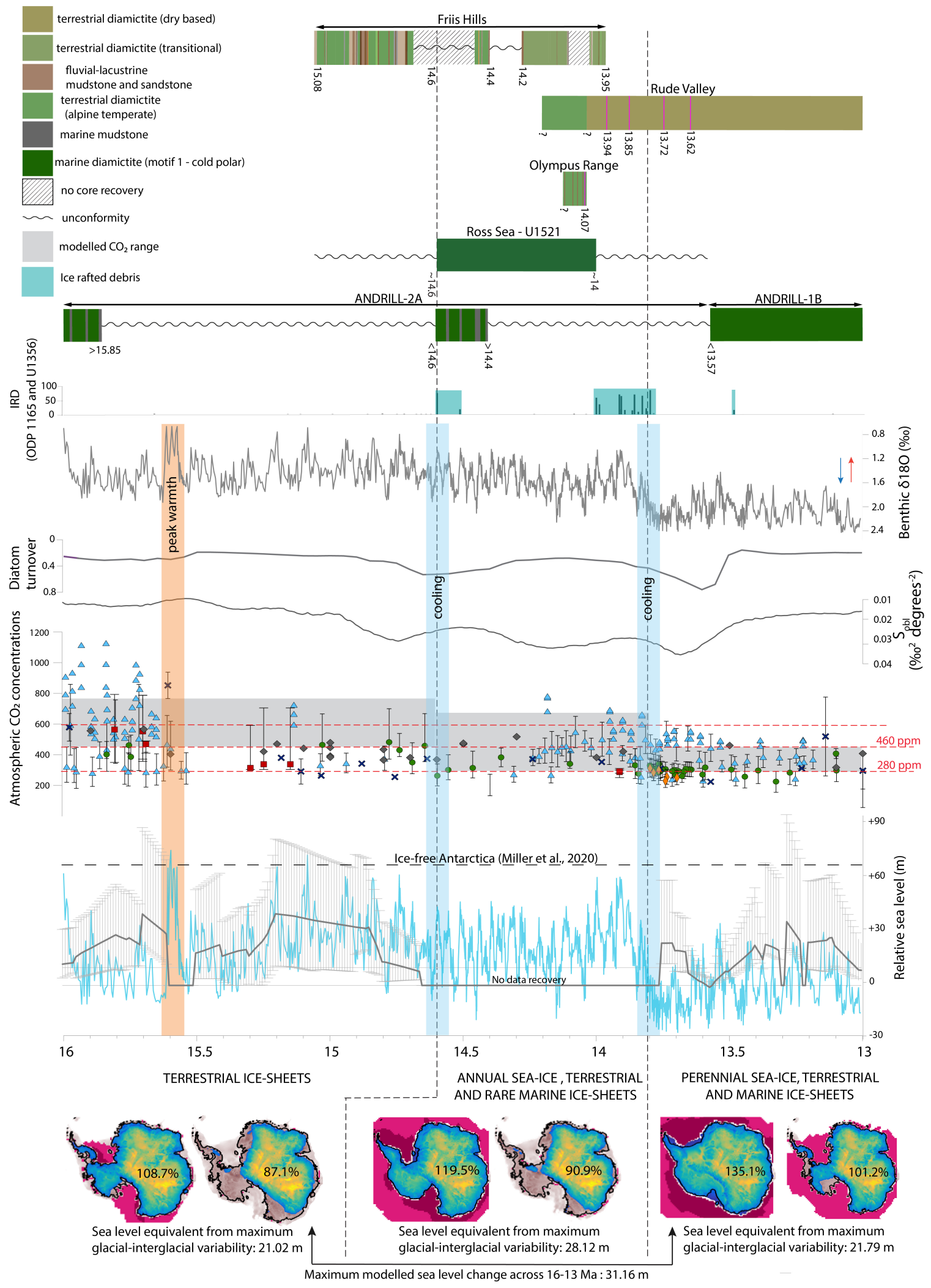

Fig. 5.1 Summary of glacial-interglacial variability across the mid-Miocene (16-13 Ma). Continued on the following page. 
Fig. 5.1 (cont) Terrestrial (Friis Hills: Chapter 3, Rude Valley: Lewis et al., 2006, Olympus Range: Lewis et al., 2008), marine (U1521: McKay et al., 2019, ANDRILL-2A: Levy et al., 2016, ANDRILL-1B: McKay et al., 2009) and ice rafted debris (ODP 1165: Pierce et al., 2017, U1356: Sangiorgi et al., 2018) records correlated to the benthic $\delta^{18} \mathrm{O}$ record (De Vleeschouwer et al., 2017), diatom turnover rates in the Southern Ocean (Crampton et al., 2016), obliquity sensitivity (Levy et al., 2019), and atmospheric $\mathrm{CO}_{2}$ concentrations from boron (blue triangle: Foster et al., 2012, Greenop et al., 2014, Raitzsch et al., 2020, Sosdian et al., 2018 ( $\delta 11 \mathrm{Bsw}-\mathrm{L} 02, \delta 11 \mathrm{Bsw}-\mathrm{RH} 13$, and $\delta 11 \mathrm{Bsw}-\mathrm{G} 17$ reconstructions using 'Pälike' and 'fluid inclusions' scenarios at 66\% confidence intervals)), boron/calcium (orange diamonds: Badger et al., 2013), phytoplankton (green circles: Badger et al., 2013, Zhang et al., 2013, Stoll et al., 2019, Super et al., 2018), stomata (red squares: Royer et al., 2001 and Kurschner et al., 2008, updated by Beerling et al., 2009), paleosols (blue crosses: Ekart et al., 1999, Retallack 2009, Shunchuan et al., 2018), and phytane (grey diamonds: Witkowski et al., 2018). Relative sea level records from Miller et al., (2020) (blue line) and Kominz et al., (2016) (grey line and associated errors). Average change in relative sea level from 16-13 Ma using data from Miller et al., (2020). Model data from study reported in Chapter 4.

Sea level data from back stripping of sedimentary sequences along the eastern margin of the USA indicate maximum relative sea level changes between $\sim 35$ and $\sim 50 \mathrm{~m}$ through the early to mid-Miocene (Fig. 5.1, Kominz et al., 2016). Coupled ice sheet and regional climate modelling experiments for the Miocene (Gasson et al., 2016) produce maximum glacial-interglacial ice volume changes ranging between 29.5 and $43.8 \mathrm{~m}$ of sea level. Importantly, modelling results indicate a relatively large terrestrial ice sheet, equivalent to $34.5 \mathrm{~m}$ of sea level, persisted through even the warmest interglacial episodes (Gasson et al., 2016). These results suggest that the AIS expanded to its modern volume during most glacial intervals throughout the early to mid-Miocene and occasionally expanded beyond its present extent, for example at $\sim 17.8$ and $\sim 14.6$ Ma which mark Ross Sea-wide unconformities (Fig. 5.1, DeSantis et al., 1999, Levy et al., 2016, McKay et al., 2019).

While global climate during the early to mid-Miocene was relatively warm, high resolution $\delta^{18} \mathrm{O}$ records through this time period are punctuated by large magnitude transient perturbations up to $1.5 \%$, which indicate major variations in ice volume and/or bottom water temperature. A gradual increase in glacial values in $\delta^{18} \mathrm{O}$ records (Holbourn et al., 2005, Shevenell et al., 2008, Lear et al., 2010, Holbourn et al., 2014) indicates a period of global cooling, known as the MMCT, began at $\sim 14.6 \mathrm{Ma}$ and ended in a major $\sim 0.5 \%$ shift at $\sim 13.8 \mathrm{Ma}$. The $\delta^{18} \mathrm{O}$ record, however, is not only influenced by ice volume, but also by deep ocean temperatures, and the contribution of each of these to total variability remains unclear (e.g. Billups and Schrag 2002, Shevenell et al., 2008, Langebroek et al., 2010, Liebrand et al., 2011, Holbourn et al., 2013, Bijl et al., 2018). Mg/Ca ratios, taken from the same 

mid-Miocene: reconciling terrestrial, marine, and far-field records

foraminiferal calcite as the $\delta^{18} \mathrm{O}$ measurements allow ocean temperature and ice volume and ice volume to be deconvolved, therefore allowing bottom water temperature estimates in benthic records.

Comparison of $\delta^{18} \mathrm{O}$ and $\mathrm{Mg} / \mathrm{Ca}$ ratios in previous studies indicates that Antarctic ice growth can account for $\sim 0.85 \%$, coupled with a $2-3^{\circ} \mathrm{C}$ cooling in the deep ocean across the MMCT (e.g. Lear et al., 2000, Billups and Schrag, 2003). Glacial-interglacial variations in the $\delta^{18} \mathrm{O}$ record through the MCO were $\sim 0.5 \%$, however reached up to $\sim 1 \%$ during peak warmth. Large excursions in the $\delta^{18} \mathrm{O}$ records during the MCO can be explained by low volume fluctuations in ice-sheet extent and large (up to $3^{\circ} \mathrm{C}$ ) variations in deep ocean temperatures derived from $\mathrm{Mg} / \mathrm{Ca}$ paleothermometry (Lear et al., 2015). Ocean bottom water temperature varied less during the MMCT relative to the MCO (Lear et al., 2015), which suggests glacial-interglacial ice volume changes were significantly greater during this interval. The $\delta^{18} \mathrm{O}$ record and New Jersey sea-level record, however, implies almost complete AIS retreat during the MCO (e.g. Miller et al., 2020), but is in contrast with geologic evidence from the Ross Sea (Levy et al., 2016), other ice sheet modelling studies (Gasson et al., 2016), and model data comparison presented in this study (Chapter 4).

Proxy records corroborate climate models, providing an estimate of glaciation thresholds similar to those in proxy reconstructions, with Antarctic glaciation triggered when atmospheric $\mathrm{CO}_{2}$ levels drop below 750 ppm and Northern Hemisphere glaciation at $<280$ ppm (DeConto et al., 2008, Galeoti et al., 2016). When compared to oxygen and carbon isotope records, proxy $\mathrm{CO}_{2}$ reconstructions appear to fluctuate on eccentricity-paced, glacial-interglacial timescales during the mid-Miocene, 16.9-13.5 Ma (Greenop et al., 2014, Raitzsch et al., 2020), with periods of low $\mathrm{CO}_{2}$ in proxy records coinciding with the major glaciations of the early to mid-Miocene and elevated $\mathrm{CO}_{2}$ during the $\mathrm{MCO}$ and interglacial periods (Kurschner et al., 2008). It has been proposed that a driver of this eccentricity-paced variability is the increase in monsoon intensity at high eccentricity, leading to increased weathering and river fluxes in the tropics, with the increased rates of carbonate and organic carbon burial and sequestration, decreasing atmospheric $\mathrm{CO}_{2}$ concentrations (Raitzsch et al., 2020). Furthermore, $\delta^{18} \mathrm{O}$ records for the MCO peak warm events $(\sim 16.4$ and $\sim 15.6$ Ma) implies shorter-term fluctuations in productivity and organic carbon burial contributed towards heightened glacial-interglacial variability at this time (Holbourn et al., 2014).

The uptake of $\mathrm{CO}_{2}$ by the oceans plays an important role in regulating on orbital timescales (e.g. Broekcer \& Peng 1982, Falkowski et al., 2000, Luthi et al., 2008). Atmospheric $\mathrm{CO}_{2}$ is higher during interglacials due to the increased exchange of $\mathrm{CO}_{2}$ between 
the atmosphere and ocean, however there are a number of hypotheses for how this process occurs. Large increases in $\mathrm{CO}_{2}$ concentrations during interglacial periods, on the scale of a 100 ppm increase in a few thousand years (Luthi et al., 2008), can be attributed to $\mathrm{CO}_{2}$ degassing from the ocean in response to warming (e.g. Stephens \& Keeling, 2000, MartinezGarcia et al., 2009, Menviel et al., 2018). Other mechanisms for glacial-interglacial $\mathrm{CO}_{2}$ variability include increased ocean-atmosphere exchange of $\mathrm{CO}_{2}$ (e.g. Volk \& Hoffert, 1985, Stephens and Keeling, 2000, Menviel et al., 2018), higher marine biosphere productivity (Martinez-Garcia et al., 2009) and/or thawing permafrost and other terrestrial carbon cycle feedbacks (DeConto et al., 2012).

Up to $100 \mathrm{ppm} \mathrm{CO}_{2}$ variability on a glacial-interglacial timescale can easily be accounted for by rates of ocean-atmosphere exchange during warmer and cooler global climates. It is likely necessary for a combination of these mechanisms to be acting simultaneously for fluctuations of $\geq 200$ ppm glacial-interglacial inferred by Greenop et al., (2014) and in this study. A 200-300 ppm general decline in $\mathrm{CO}_{2}$ over the MCO and MMCT is inferred from geologic records (e.g. Foster et al., 2012, Zhang et al., 2013), which has previously been attributed to several mechanisms, including: (1) early to mid-Miocene uplift of the southern Patagonian Andes by $>1 \mathrm{~km}$ culminated at $~ 14$ Ma (Blisniuk et al., 2005) (e.g. Urey 1952, Walker et al., 1981, Raymo and Ruddiman 1992), (2) negative feedback associated with the relative warmth and high sea-level during the MCO is the enhanced organic carbon burial on drowned continental shelves (Sosdian et al., 2020), and (3) Columbia River Basalt eruptions, and the high volumes of $\mathrm{CO}_{2}$ and $\mathrm{SO}_{2}$ they emitted (Foster et al., 2012, Sosdian et al., 2020). The thermal isolation of Antarctica and the development of the Antarctic circumpolar current (ACC) played a key role in the onset of a continental-scale AIS (e.g. Kennett, 1977, Zachos et al., 2001, Barker and Thomas, 2004, Huber and Nof, 2006, Sijp et al., 2009). The development of a full ACC across the MMCT could also have attributed to the general cooling trend and the onset of a stable East Antarctic Ice Sheet (EAIS) post-13.8 Ma (Dalziel et al., 2013). A stronger ACC would have further thermally isolated the continent, supporting AIS growth, while increased upwelling would have led to increased ocean-atmosphere exchange and $\mathrm{CO}_{2}$ drawdown.

The chronologically constrained record at the Friis Hills presented in this thesis is correlated in this chapter with terrestrial (Rude Valley, Olympus Range), marine (AND-2A, U1521, U1356) and far field $\left(\delta^{18} \mathrm{O}\right)$ records to better understand ice-sheet evolution through the mid-Miocene. A model-data comparison conducted as part of this research implied a lower Transantarctic Mountain (TAM) elevation during the mid-Miocene, between -300 

mid-Miocene: reconciling terrestrial, marine, and far-field records

to $-500 \mathrm{~m}$ below present-day elevations (Chapter 4). It is also inferred from summary of the literature above that glacial-interglacial variability in both ice-sheet extent and $\mathrm{CO}_{2}$ concentrations increased across the MMCT. The drivers of climatic changes and ice-sheet variability across the mid-Miocene inferred from terrestrial (Marchant et al., 1993, Sugden and Denton, 2004, Lewis et al., 2006, Lewis et al., 2008, Lewis and Ashworth 2015), marine (McKay et al., 2009, Levy et al., 2016, Pierce et al., 2017, Sangiorgi et al., 2018, McKay et al., 2019) and far-field oxygen isotope (e.g. Holbourn et al., 2014, De Vleeschouwer et al., 2017) and sea level (e.g. Miller et al., 2020) are now discussed.

\subsection{Reconciling mid-Miocene terrestrial, marine, and far field records}

\subsubsection{Evolution of the Antarctic Ice Sheet through the mid-Miocene: evidence from coastal and offshore marine records}

The CIROS-1, MSSTS-1, Cape Roberts Project, and ANDRILL drill cores are located along the Southern Victoria Land coast (Fig. 5.2) and contain sedimentary cycles that record advance and retreat of glaciers through trunk valleys in the TAMs throughout the Oligocene and Miocene (Barrett, 1987, Barrett, 1989, Naish et al., 2001, Dunbar et al., 2008, Passchier et al., 2013, Levy et al., 2016, Fielding, 2017). Furthermore, several seismic profiles in McMurdo Sound that intersect the CIROS-1 and MSSTS- 1 drill cores contain U-shaped valley features within early Miocene strata (Brancolini et al., 1995). These data suggest glaciers have advanced and retreated through the MacKay, Ferrar, and Taylor Valleys since the Oligocene. The first major expansion of the AIS well beyond the TAM and across the Ross Sea continental shelf, occurred during the latest Oligocene to earliest Miocene (Naish et al., 2001, Roberts et al., 2003, Dunbar et al., 2008, Kulhanek et al., 2019). Seismic reflection data from McMurdo Sound and the Ross Sea Embayment (Bartek et al., 1991, Bartek et al., 1996, De Santis et al., 1999, Sorlien et al., 2007) indicate multiple episodes of major ice sheet advance and retreat across the continental shelf through the late Oligocene and MMCT. 


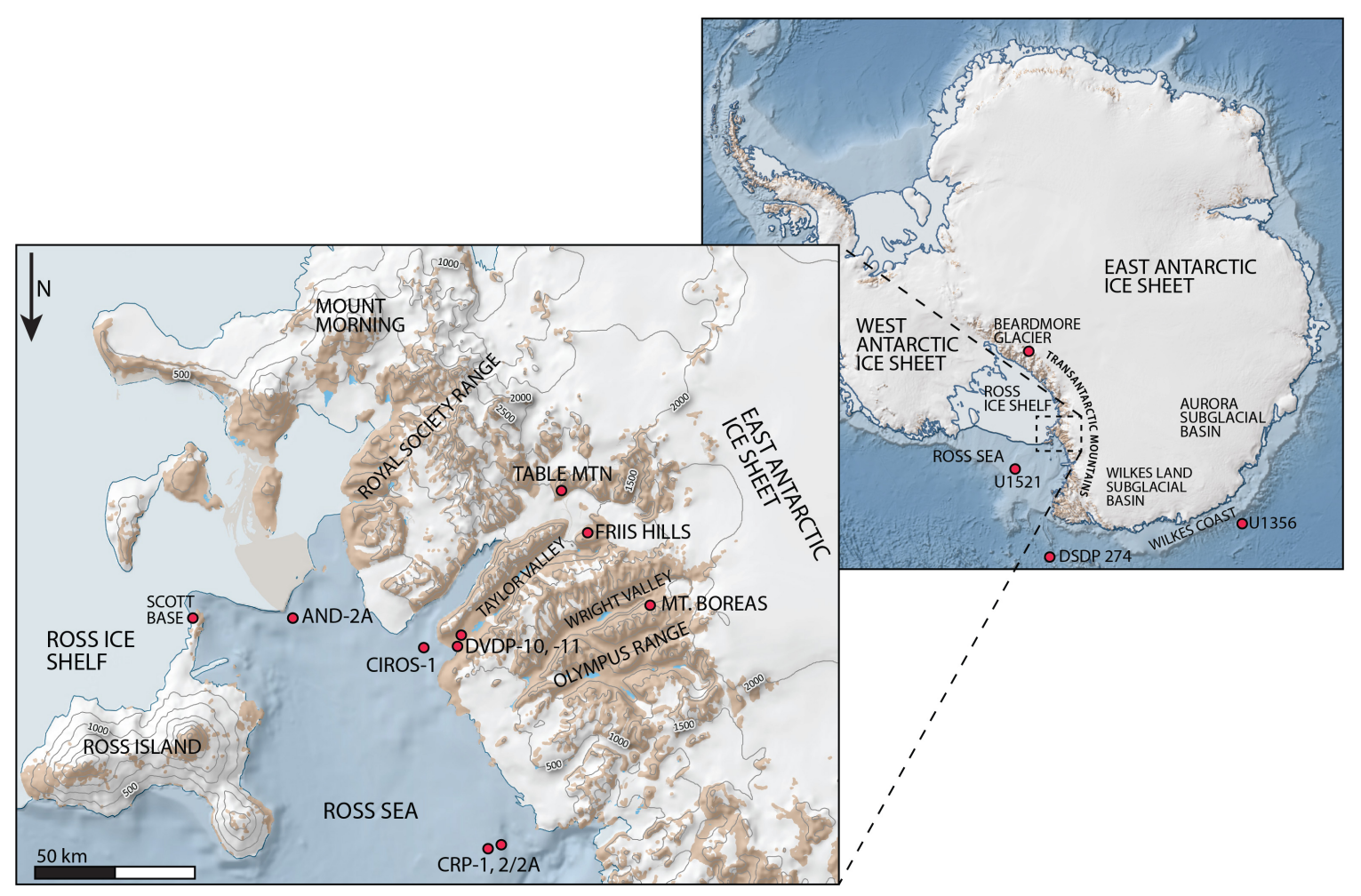

Fig. 5.2 Location map for early to mid-Miocene marine and terrestrial records and other locations discussed in the text. Base map from Quantarctica GIS package.

Sedimentological facies and environmental proxies that bound these disconformities in these records indicate cold polar climatic conditions occurred during these distinct intervals of major ice sheet expansion (Fig. 5.3). A new drill core record from IODP Site U1521 in the Ross Sea indicates that grounded ice advanced to the mid- to outer continental shelf at 14.6-14.0 Ma (McKay et al., 2019), corroborating a shift from marine terminating ice during the MCO to full marine expansion at $14.6 \mathrm{Ma}$ and during subsequent glacial periods of the MMCT. While glaciers did not advance beyond the coastline throughout much of the early to mid-Miocene, ice continued to calve at the Victoria Land Coast during glacial episodes including those during the MCO (Fielding et al., 2011, Passchier et al., 2011, Levy et al., 2016). Environmental proxies, including pollen and spores, indicate a polar tundra to sub polar oceanic climate persisted throughout this time interval (Prebble et al., 2006, Warny et al., 2009, Levy et al., 2016). Recorded changes in diatom and foraminifera assemblages in the AND-2A core indicate the first evidence for sea ice at $\sim 16 \mathrm{Ma}$, however it is likely this wasn't a persistent feature until post-15 Ma (Patterson and Isman 2012, Levy et al., 2016, Sangiorgi et al., 2018). 

mid-Miocene: reconciling terrestrial, marine, and far-field records

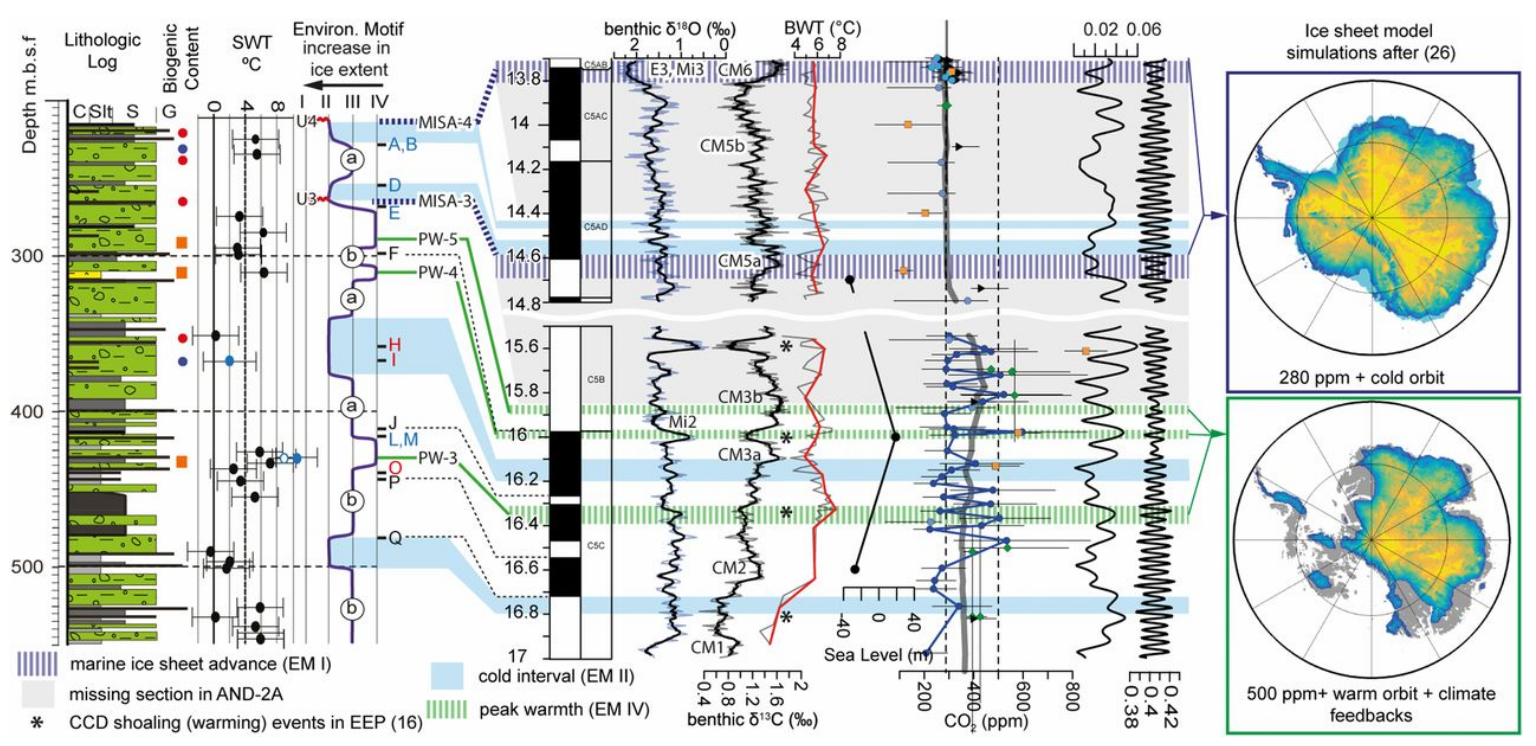

Fig. 5.3 Mid-Miocene ice-sheet variability from the ANDRILL-2A record correlated to the geomagnetic polarity timescale, $\delta^{18} \mathrm{O}$ and $\delta^{13} \mathrm{C}$ Holbourn et al., 2014, Holbourn et al., 2015), bottom water temperatures (BWT; Shevenell et al., 2008), sea level estimates (John et al., 2011), and atmospheric $\mathrm{CO}_{2}$ concentrations from boron isotopes (blue circles; Foster et al., 2012, Badger et al., 2013, Greenop et al., 2014), alkenones (black triangles; Zhang et al., 2001, Badger et al., 2013), stomata (green diamonds; Kurschner et al., 2008), and paleosols (orange squares; Cerling, 1992, Ekart et al., 1999, Retallack, 2009). Environmental motifs reported by Levy and others (2016) highlighted in the record and time missing in unconformities. Orbital eccentricity and obliquity forcing from Laskar and others (2011) and ice-sheet simulations from Gasson and others (2016). Figure from Levy and others (2016).

Evidence from Prydz Bay (ODP Site 1165) and U1356, off the Wilkes Coast record more mild conditions than those reported in the Ross Sea (Pierce et al., 2017, Sangiorgi et al., 2018). High concentrations of ice-rafted debris (IRD) through the MMCT suggest the onset of heavily erosive glacial activity in the Wilkes Land Subglacial Basin (WLB), Aurora Subglacial Basin, and the Lambert Graben, however, ${ }^{40} \mathrm{Ar} /{ }^{39} \mathrm{Ar}$ provenance signals indicate the ice-sheet margin remained inland of present-day configuration (Pierce et al., 2017). A series of IRD pulses suggest advance and retreat of the EAIS margin in these basins superimposed on the general cooling and ice growth trend of the MMCT. The change in provenance of finer-grained sediments in the record implies full advance and retreat of the EAIS over the WLB, with an open WLB during interglacial periods (Pierce et al., 2017). A distinct increase in IRD at 14.6 Ma and between 14.1-13.8 Ma mark the transition into and out of the MMCT as the EAIS expanded across these 3 basins and terminated at a similar extent to present-day (Pierce et al., 2017). 
Relatively rapid species turnover (speciation and extinction) in diatom flora around the continental margin likely reflect large scale environmental perturbations across the Antarctic continental shelves and the Southern Ocean (Crampton et al., 2016). While Southern Ocean phytoplankton communities survive variability of glacial-interglacial timescales, they are sensitive to larger-scale changes in climate due to longer-term changes in both $\mathrm{CO}_{2}$ concentrations and orbital forcing (Crampton et al., 2016). The sensitivity of diatom flora to ice advance can be attributed to high latitude cooling and associated changes in atmospheric circulation. The subsequent changes in the ocean structure and dynamics at the margin inhibit the upwelling of warm deep water onto the continental shelf, promoting perennial sea ice and the expansion of winter sea ice across the Southern Ocean (Crampton et al., 2016). Associated positive feedbacks on global climate caused by extensive sea ice growth further supports large-scale marine-ice advance across the continental shelf (Crampton et al., 2016, Levy et al., 2019). Diatom turnover pulses occurred at 14.65-14.45 Ma and 13.75-13.55 Ma during the mid-Miocene (Crampton et al., 2016), both at times of global cooling as inferred by the $\delta^{18} \mathrm{O}$ record (Holbourn et al., 2014) and an increase in marine-ice extent in drill core records (Levy et al., 2016, Pierce et al., 2017, McKay et al., 2019).

\subsubsection{Evolution of the Antarctic Ice Sheet in Southern Victoria Land through the mid-Miocene: evidence from terrestrial records}

In apparent contrast to the offshore records, glaciological and geomorphic evidence from other trunk valleys and intervening transverse ranges through the Dry Valleys sector imply a different history of glaciation. Smaller ice caps and alpine glaciers dominated the TAM during interglacial periods through the early to mid-Miocene and large overriding ice sheets only formed after $\sim 14$ Ma when the EAIS is inferred to have become a more stable and larger feature. Evidence for this terrestrial history comes from well-dated Miocene tills and drift sheets, similar to those in Friis Hills that crop out in the Olympus Range (Lewis et al., 2007, Lewis et al., 2008), Asgaard Range (Sugden et al., 1991, Marchant et al., 1993, Marchant et al., 1996) and upper Wright Valley (Fig. 5.2, Lewis et al., 2006), summarised in Figure 5.1. Some of these interglacial deposits are associated with pollen assemblages from an alpine tundra vegetation that, along with fossil diatom flora and invertebrate fauna, suggest mean summer temperatures (MST) of $5-7^{\circ} \mathrm{C}$ during interglacial episodes (Lewis and Ashworth 2015). Pollen and fossil assemblages in deposits at Mt. Boreas in the Olympus Range indicate a relatively cooler climate at the limits of plant growth, with MSTs of $\sim 5^{\circ} \mathrm{C}$ at 14.07 Ma (Lewis et al., 2008). 

mid-Miocene: reconciling terrestrial, marine, and far-field records

Argon radioisotopic dating of tephras within till sequences in the Circe-Rude Valley (Olympus Range) date a transition from temperate wet-based glaciation to colder climate, drybased tills at $\sim 13.8 \mathrm{Ma}$ (Lewis et al., 2007). This is consistent with ages from other tephra from the region that date the widespread development of glacially-moulded and striated surfaces around the same time (Marchant et al., 1996). Together, these geomorphological studies suggest extensive north-eastward flowing EAIS overriding at $\sim 13.8 \mathrm{Ma}$, downcutting valleys, and stripping out or overtopping older wet-based tills. In the upper Wright Valley, a $50 \mathrm{~km}$ long network of glacially-scoured features known as the Labyrinth emerges from under the margin of EAIS (Lewis et al., 2006). Dates on tephra indicate the Labyrinth formed between 14.4 and 12.4 Ma when large subglacial outburst floods occurred beneath an expanded and thickened EAIS (Lewis et al., 2006).

Geomorphological studies suggest valley downcutting rates increased and ice generally thickened in the major outlet glaciers towards the end of and post-MMCT, as evidenced by the elevation of lateral moraines such as the Cavendish drifts at the Friis Hills (Lewis and Ashworth, 2015). Contemporaneous rock uplift in the intervening ranges enhanced by isostatic rebound in response to valley incision (Stern et al., 2005, Paxman et al., 2019a), isolated the Friis Hills inselberg, and many of the areas of the Dry Valleys. This isolation, coupled with the presence of a large inland EAIS that creates near-persistent katabatic winds and blocks moist easterlies from travelling far inland over the Dry Valleys, has kept this region ice-free from $\sim 12 \mathrm{Ma}$. The result is a hyper-arid desert landscape, characterised by the presence of sand-wedge polygons and ventifact pavements and some of the lowest denudation rates on Earth (Sugden et al., 1995, Marchant et al., 1996, Prentice et al., 1998).

\subsubsection{Reconciliation of marine and terrestrial records in Southern Vic- toria Land}

Early Miocene sediments from the Friis Hills (Friis I drift), are restricted to the small glacial valley in the eastern Friis Hills and indicate a temperate glacier advanced and retreated towards the southwest $\sim 19.76 \mathrm{Ma}$ (Lewis and Ashworth, 2015). A major disconformity in AND-2A at $19.8 \mathrm{Ma}$ is overlain by a series of glacial and interglacial units that include thick diamictites with box fractures that indicate glacial over-riding (Levy et al., 2016). These units coincide with a significant sea level lowstand (Kominz et al., 2016) and together indicate the EAIS expanded beyond the TAM during this time interval. This implies that ice flowed south down the main trunk valleys (Pearse, Taylor, and Simmons Basin) either side of the Friis 
Hills during glacial episodes since this time and sediments in the Friis I drift were deposited by advance and retreat of a relatively small lobe of ice that entered the eastern Friis Hills as southwest flowing ice from a Pearse/Taylor valley outlet glacier.

Another major expansion of glaciers through the TAM and across the Ross Sea occurred at $17.8 \mathrm{Ma}$, with the advance and retreat of glaciers at the coast throughout the MCO (Levy et al., 2016). Records for most of this time have not been recovered from the Friis Hills, but may reflect the absence of a large TAM ice cap in Southern Victoria Land or the presence of glaciers that bypassed the Friis Hills during the MCO. The deposition of Friis II (lower) indicates alpine glaciers advanced and retreated across the Friis Hills between $\sim 15.2$ and 14.4 Ma (see Chapter 3). Coastal records such as AND-2A are missing in unconformities during this time, which suggests large glaciers advanced down the Ferrar and Taylor Valleys beyond the coast during glacial periods, although the floors of these valleys were likely shallower than present-day during this time. During interglacials, ice retreated inland from the coast, as implied by the AND-2A record. The Friis Hills record implies an ice proximal environment during interglacials recorded during the later stages of the MCO, suggesting while large outlet glaciers were marine-terminating or retreated inland, small local alpine glaciers remained present over the Dry Valleys. During these interglacial periods, the Friis Hills supported a tundra vegetation similar to that reported in AND-2A Warny et al., 2009), with small proglacial lakes and fluvial channels that may have resembled present-day southwest Greenland (Chapter 3). During MCO glacials, grounded ice extended to the AND-2A site (Levy et al., 2016), however there is no evidence for large-scale marine-based ice advance during the MCO.

Following the relative warmth of the MCO, the AIS re-expanded across the continental shelf during glacial periods, with marine ice expansion across the AND-2A and U1521 site recorded at 14.6 Ma (Fielding et al., 2011, Passchier et al., 2011, Levy et al., 2016, McKay et al., 2019). This period of ice sheet expansion is captured by a shift to more positive glacial values in $\delta^{18} \mathrm{O}$ records ( $>2 \%$ ), by diatom turnover in the Southern Ocean (Crampton et al., 2016), and by disconformities in coastal drill cores and extensive seismic unconformities, including Ross Sea Unconformity 4 (De Santis et al., 1999). The MMCT is recorded at the Friis Hills by a $\sim 400$ kyr unconformity between Friis Hills II lower and upper sequences and a 200 kyr snapshot of environmental conditions preserved in the Friis II (upper) drift sediments. These diamictites imply thicker, more extensive ice flowed over the Friis Hills during glacial advances (as discussed in Chapter 3), with enhanced glacial erosion during this time further downcutting the Pearse and Taylor Valleys and forming a new valley floor at 

mid-Miocene: reconciling terrestrial, marine, and far-field records

a similar elevation to the Labyrinth. While glacial advances were becoming more extensive, interglacials remained warm, characterised by similar climate and environmental conditions that characterised the MCO.

The last major step of the MMCT records a final major warming episode between 14 and 13.9 Ma, during which $\delta^{18} \mathrm{O}$ values increased to $\sim 1 \%$ and global sea level rise to values similar to those recorded during high stands through the mid-Miocene (Fig. 5.1; Kominz et al., 2016). By $13.8 \mathrm{Ma}, \delta^{18} \mathrm{O}$ values had increased to $2.3 \%$ (Fig. 5.1), implying another major cooling event and extensive advance of marine-ice sheets across the Ross Sea. Late Miocene sediments in the AND-2A and -1B drill cores imply a shift from polar to sub-polar climate occurred during this time (McKay et al., 2009, Levy et al., 2016). This suggests the AIS and outlet glaciers in Southern Victoria Land once again retreated inland during interglacial episodes as climate warmed following the MMCT. Notwithstanding this, there is no evidence that temperate glaciation or tundra vegetation returned to the Friis Hills or persisted at other locations in the high TAM after $\sim 13 \mathrm{Ma}$ (Marchant et al., 1993, Lewis et al., 2007, Lewis et al., 2008, Chapter 3).

\subsubsection{Reconciliation of Friis Hills glacial-interglacial cycles and far- field records for the mid-Miocene}

The evolution of the Friis Hills terrestrial glacial sedimentary cycles and their relationship to marine records, long-term climate and glacial trends, and shorter-term orbitally-paced global ice volume and climate change is summarised in Fig. 5.1. Fifteen glaciofluvial glaciolacustrine cycles, each bounded by glacial surfaces of erosion (GSE) occur in the FHDP cores and record the regular advance and retreat of a relatively local alpine glacial system connected to the EAIS during the mid-Miocene (Fig. 5.4). Three types of unconformity have been identified in the FHDP record: (1) unconformities where secondary processes (dry permafrost) have limited core recovery (e.g. 0-15 m FHDP-3A), (2) unconformities where major erosion due to glacial advance has resulted in time missing that is longer than a Milankovitch cycle (e.g. base of Cycle 7), and (3) those where a full facies cycle is recovered and the glacial advance erodes only part of the underlying sequence (e.g. diamictites rich in extraformational clasts from immediately underlying lithologies; Fig. 3.17 p). 


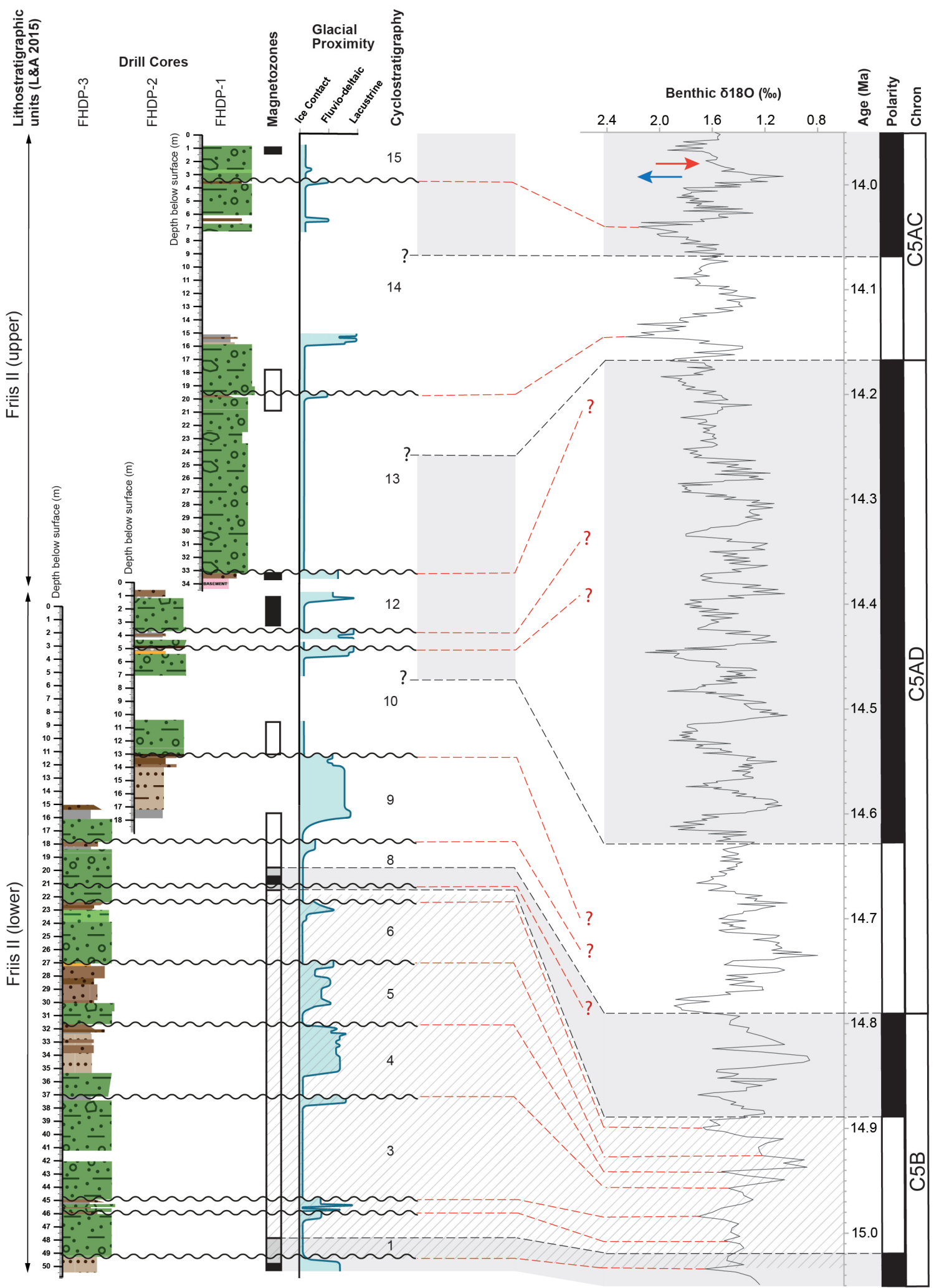

Fig. 5.4 Correlation of FHDP drill cores to the $\delta^{18} \mathrm{O}$ record. Continued on the following page. 
Glacial-interglacial variability and evolution of the Antarctic Ice Sheet across the mid-Miocene: reconciling terrestrial, marine, and far-field records

Fig. 5.4 (cont) Facies in drill cores FHDP-1A, -2A, and -3A, associated drifts (Lewis \& Ashworth, 2015) and magnetozones (see Chapter 3) are plotted against depth. Glacial proximity and glacial surfaces of erosion identified in drill cores are used to identify glacial extent relative to the drill site and cycle duration is constrained using chronostratigraphy reported in Chapter 3 (Fig. 3.22). 7.5 of these well-constrained cycles in FHDP-3A have then been matched to $\sim 160 \mathrm{ka}$ of the $\delta^{18} \mathrm{O}$ record (De Vleeschouwer et al., 2017).

While 15 cycles were identified within the cores, only 7.5 cycles, identified between 50.3-21.9 $\mathrm{m}$ in core FHDP-3A, are well enough constrained by the age model to be correlated with relative precision to the $\delta^{18} \mathrm{O}$ record in order to assess for orbital pacing (Fig. 5.4). These 7.5 cycles span $15.032-14.870 \mathrm{Ma}, \sim 160 \mathrm{ka}$, constrained by paleomagnetic reversals and tephra chronology, implying glacial-interglacial cycles at the Friis Hills during this time interval were paced by 20 ka orbital precession.

Precession plays a direct role on the intensity and duration of Antarctic insolation and therefore ice volume variability, especially on terrestrial sectors of the AIS. During past warm periods with higher $\mathrm{CO}_{2}$, when the AIS is terrestrially terminating, it is thought that precession was therefore the dominant driver of AIS variability (e.g. Levy et al., 2019). It can therefore be inferred that the cyclicity recorded in the Friis Hills drill cores provides evidence of orbital forcing of local variations of a small alpine system, but when considered together with far-field evidence of the frequency of global sea-level change (e.g. Holbourn et al., 2007) supports eccentricity-modulated precession of the wider terrestrial EAIS. The correlation made in Fig. 5.4 between Friis Hills sedimentary cycles and orbital cycles in the $\delta^{18} \mathrm{O}$ record is relatively well-constrained for FHDP-3A, however, while orbital cyclicity is implied there is no unique solution above this depth for FHDP-2A and -1A cores.

Precession was the dominant control on AIS variability during the pre-MMCT phase of deposition at the Friis Hills, in the Friis II (lower) drift. Unconformities and missing sections preclude correlation of the FHDP cores with AND-2A (Fig. 5.1). Therefore, it is difficult to infer whether marine and terrestrial parts of the AIS were responding to different orbital forcing frequencies during the mid-Miocene. While numerical ice sheet models may be able to test this in the future, analysis of oxygen isotope record (e.g. Levy et al., 2019) implies a shift to obliquity dominance and sensitivity through the MMCT as the AIS expands into the marine realm (Fig. 5.1). 


\subsection{The role of carbon dioxide on mid-Miocene climate variability}

The oxygen isotope record and Friis Hills geological data discussed in Chapter 3 imply that the amplitude of glacial-interglacial variability increased across the MMCT, with interglacials remaining warm enough to support extensive tundra vegetation in the TAM and WLB, while ice became more extensive in the Friis Hills and marine-based ice extended into the Ross Sea during glacials. Reconstructions of atmospheric $\mathrm{CO}_{2}$ concentrations across the mid-Miocene suggest a general decline in $\mathrm{CO}_{2}$ during the transition from the MCO into the MMCT (Fig. 5.1, e.g. Foster et al., 2012, Zhang et al., 2013), which may explain this overall intensification of glacials during this climatic shift. This is consistent with model results (Chapter 4), which reconstruct increasing amplitude of ice volume and sea-level change on orbital timescales for progressively lower $\mathrm{CO}_{2}$ values (Table 5.1, Fig. 5.1). The difference in simulated AIS volume, expressed as sea level equivalent (SLE) ice volume between cold and warm orbital configurations for declining $\mathrm{CO}_{2}$ concentrations is summarised Table 5.1. An increase in the average amplitude of glacial-interglacial change at lower $\mathrm{CO}_{2}$ concentrations is consistent with the $\delta^{18} \mathrm{O}$ and $\mathrm{CO}_{2}$ records, whereby $\mathrm{CO}_{2}$ decreased across the MMCT, while glacialinterglacial variability observed in the $\delta^{18} \mathrm{O}$ increased (Fig. 5.1, Holbourn et al., 2014, De Vleeschouwer et al., 2017).

Table 5.1 Modelled glacial-interglacial AIS variability for different atmospheric $\mathrm{CO}_{2}$ concentrations, using a default topography (TAM elevation is kept constant).

\begin{tabular}{|c|c|c|c|c|c|c|c|}
\hline \multicolumn{2}{|l|}{ Modelled $\mathrm{CO}_{2}(\mathrm{ppm})$} & 280 & 460 & 690 & 780 & 930 & 1140 \\
\hline \multicolumn{2}{|c|}{$\begin{array}{l}\Delta \text { SLE ice volume between orbits } \\
\text { (m) }\end{array}$} & 21.1 & 17.0 & 11.7 & 12.9 & 14.2 & 16.2 \\
\hline \multirow{2}{*}{$\Delta$ SLE ice volume (m) } & Warm orbit & 66.37 & 61.30 & 58.77 & 56.74 & 54.72 & 50.66 \\
\hline & Cold orbit & 87.40 & 77.26 & 70.42 & 69.66 & 68.90 & 66.88 \\
\hline
\end{tabular}

The amplitude of glacial-interglacial sea level variability inferred from some other $\delta^{18} \mathrm{O}$ records (e.g. Miller et al., 2020) exceeds the amplitude of maximum modelled SLE ice volume variability, and may suggest that glacial-interglacial changes in $\mathrm{CO}_{2}$ are occurring during the mid-Miocene, which is consistent with some geological proxy reconstructions of $\mathrm{CO}_{2}$ (e.g. Greenop et al., 2014). While origin of glacial-interglacial $\mathrm{CO}_{2}$ fluctuations greater than $100 \mathrm{ppm}$ is more difficult to explain, they could be the result of increased ocean- 

mid-Miocene: reconciling terrestrial, marine, and far-field records

atmosphere exchange of $\mathrm{CO}_{2}$ (e.g. Stephens and Keeling, 2000, Menviel et al., 2018), higher marine biosphere productivity (Martinez-Garcia et al., 2009) and/or thawing permafrost and other terrestrial carbon cycle feedbacks (DeConto et al., 2012).

The model-data comparison carried out in Chapter 4 required modelled $\mathrm{CO}_{2}$ to vary on a glacial-interglacial timescale during both the MCO and MMCT to best fit the glacialinterglacial variability inferred in geologic records. In order to better compare the glacialinterglacial variability in the model with far field records, the SLE ice volume for a range of average high $\mathrm{CO}_{2}$ periods during the Miocene was calculated (Fig. 5.1). The modelled range of $\mathrm{CO}_{2}$ inferred for each period defined during the mid-Miocene (MCO, MMCT, and postMMCT) is shown in Figure 5.1 and Table 5.2. It should be noted that these scenarios represent the more extreme glacial and interglacial cycles during each of these periods and therefore the average $\mathrm{CO}_{2}$ concentrations inferred from the model are likely more representative of conditions. Since $\mathrm{CO}_{2}$ proxy reconstructions are so sparse for the mid-Miocene, it may also be best to report average modelled $\mathrm{CO}_{2}$, as proxy records are likely to better represent the average range of $\mathrm{CO}_{2}$ than glacial-interglacial variability. 
Table 5.2 Model-data comparison of carbon dioxide and sea level equivalent ice volume estimates for the mid-Miocene. Glacial-interglacial modelled $\mathrm{CO}_{2}$ range for the Miocene Climatic Optimum, mid-Miocene Climate Transition and post mid-Miocene Climate Transition, showing average modelled $\mathrm{CO}_{2}$, and using the extreme glacial and interglacial $\mathrm{CO}_{2}$ end members inferred by the model the maximum ice volume change expressed as sea level equivalent (SLE) ice volume within each period, and maximum sea level decline across the mid-Miocene (17-13.8 Ma). Esimates of glacial interglacial variability from proxy data (Kominz et al., 2016, Miller et al., 2020) and the glacial interglacial $\delta^{18} \mathrm{O}$ values used to calibrate sea level estimates to bottom water temperature (BWT). BWT contribution to the $\delta^{18} \mathrm{O}$ record calculated at $0.22 \%$ per ${ }^{\circ} \mathrm{C}$ of temperature change. BWT calibrated ice volume variability calculated using a Pleistocene calibration of $0.08-0.11 \%$ per $10 \mathrm{~m}$ sea level change (Fairbanks \& Matthews 1978, Adkins et al., 2002).

\begin{tabular}{|c|c|c|c|}
\hline & $\begin{array}{l}\text { Miocene Climatic } \\
\text { Optimum (17-15 Ma) }\end{array}$ & $\begin{array}{l}\text { mid-Miocene Climate } \\
\text { Transition (14.4-13.8 Ma) }\end{array}$ & $\begin{array}{l}\text { Post mid-Miocene } \\
\text { Climate Transition } \\
(<13.8 \mathrm{Ma})\end{array}$ \\
\hline $\begin{array}{l}\text { Modelled } \mathrm{CO}_{2} \text { range - } \\
\text { glacial }\end{array}$ & $460-690 \mathrm{ppm}$ & $280-460 \mathrm{ppm}$ & $280 \mathrm{ppm}$ \\
\hline $\begin{array}{l}\text { Modelled } \mathrm{CO}_{2} \text { range - } \\
\text { interglacial }\end{array}$ & $690-780$ ppm & $260-690 \mathrm{ppm}$ & 280-460 ppm \\
\hline Average & $620 \mathrm{ppm}$ & $485 \mathrm{ppm}$ & $370 \mathrm{ppm}$ \\
\hline $\begin{array}{l}\text { Maximum glacial } \\
\text { interglacial } \Delta \text { SLE ice } \\
\text { volume variability }\end{array}$ & $21.02 \mathrm{~m}$ & $28.12 \mathrm{~m}$ & $21.79 \mathrm{~m}$ \\
\hline $\begin{array}{l}\text { Maximum glacial } \\
\text { interglacial } \Delta \text { SLE ice } \\
\text { volume variability } \\
\text { (Miller et al., 2020) }\end{array}$ & $>66 \mathrm{~m}$ & $50 \mathrm{~m}$ & $20-30 \mathrm{~m}$ \\
\hline $\begin{array}{l}\text { Maximum glacial } \\
\text { interglacial } \triangle \text { SLE ice } \\
\text { volume variability } \\
\text { (Kominz et al., 2016) }\end{array}$ & up to $50 \mathrm{~m}$ & up to $50 \mathrm{~m}$ & up to $50 \mathrm{~m}$ \\
\hline $\begin{array}{l}\text { Glacial } \delta^{18} \mathrm{O} \text { values } \\
\text { (De Vleeschouwer et } \\
\text { al., 2017) }\end{array}$ & $1.8 \%$ & $2.1 \%$ & $2.4 \%$ \\
\hline $\begin{array}{l}\text { Interglacial } \delta^{18} \mathrm{O} \text { values } \\
\text { (De Vleeschouwer et } \\
\text { al., 2017) }\end{array}$ & $0.8 \%$ & $1.1 \%$ & $1.8 \%$ \\
\hline $\begin{array}{l}\text { BWT variability } \\
\text { (Lear et al., 2010) }\end{array}$ & $3^{\circ} \mathrm{C}$ & $3^{\circ} \mathrm{C}$ & $1^{\circ} \mathrm{C}$ \\
\hline $\begin{array}{l}\text { BWT contribution to } \\
\delta^{18} \mathrm{O} \text { record }\end{array}$ & $0.66 \%$ & $0.66 \%$ & $0.22 \%$ \\
\hline $\begin{array}{l}\text { BWT calibrated SLE } \\
\text { ice volume variability }\end{array}$ & $30-42 \mathrm{~m}$ & $30-42 \mathrm{~m}$ & $35-48 \mathrm{~m}$ \\
\hline
\end{tabular}



mid-Miocene: reconciling terrestrial, marine, and far-field records

Recently published sea level estimates imply almost full retreat of the AIS during MCO peak warmth (Table 5.2; Miller et al., 2020). Other sea level variability estimates for the mid-Miocene, independent of $\delta^{18} \mathrm{O}$, infer a more moderate AIS contribution of up to $50 \mathrm{~m}$ amplitude across glacial-interglacial cycles (Table 5.2; Kominz et al., 2016). An ice free Antarctica during the MCO is not consistent with any proximal geological evidence (e.g. Lewis \& Ashworth 2015, Levy et al., 2016, Chapter 3). The smallest ice-sheet modelled in this study is $77.1 \%$ of modern ice volume and the largest sea level change between modelled glacial-interglacial orbits is $21.1 \mathrm{~m}$ at $280 \mathrm{ppm} \mathrm{CO}_{2}$ (Table 5.1). When SLE is also reported in line with minimum and maximum $\mathrm{CO}_{2}$ concentrations spanning several glacial-interglacial cycles across the mid-Miocene, these figures become closer to previous modelling studies and more moderate geological estimates of sea level variability (e.g. Miller et al., 2005, John et al., 2011, Kominz et al., 2016) and previous modelling estimates (30-36 m; Gasson et al., 2016), with $28.12 \mathrm{~m}$ glacial-interglacial variability during the MMCT (Fig. 5.1, Table 5.2).

Using the same method discussed in section 3.12 of this thesis, bottom water temperature (BWT) calibrated sea level estimates also reduces the degree of ice volume variability to between 30-42 $\mathrm{m}$ for the MCO and MMCT and 35-48 m post-MMCT. While the Miller and others (2020) sea level record reports less variability post-MMCT, higher BWT calibrated estimates for this period are due to lower BWT temperatures recorded by Lear and others (2010). The smaller modelled ice sheet variability shown in Table 5.2 could be due to modelled precipitation changes over the interior EAIS, the use of a shallower paleotopography (Paxman et al., 2019b) or the evolution of continental shelf bathymetry across the MMCT, which is not investigated as part of the simulations. The longer duration of the model simulations relative to those used in Gasson et al., (2016) may also have supported a greater precipitation feedback. The use of a transient model simulations rather than those that have reached equilibrium could reduce AIS variability, requiring a greater contribution to $\delta^{18} \mathrm{O}$ fluctuations by deep-sea temperature change (Stap et al., 2019). Furthermore, the application of a Pleistocene calibration may not be applicable to the Miocene, with further research into the relationship between $\delta^{18} \mathrm{O}$ and sea level variability required for the Miocene.

Periods of peak warmth during the MCO ( 16.4 and $\sim 15.6 \mathrm{Ma})$ were characterised by relatively higher $\mathrm{CO}_{2}$ concentrations in geological reconstructions (e.g. Retallack 2009, Sosdian et al., 2018) and a significantly reduced AIS (e.g. Warny et al., 2009, Passchier et al., 2011, Levy et al., 2016), modelled in Chapter 4 as 780 ppm. A strong precessional signal at $\sim 15.6 \mathrm{Ma}$ supports a considerable role for insolation in triggering peak warm events during the MCO (Holbourn et al., 2014) especially under a warm climate state driven by elevated 
$\mathrm{CO}_{2}$, however this does not explain variability between "peak warm" and "mild" interglacials during the MCO. It is likely that milder MCO interglacials were characterised by lower $\mathrm{CO}_{2}$ concentrations, represented by model scenarios at $690 \mathrm{ppm}$. Overall, $\mathrm{CO}_{2}$ was likely highly variable through the MCO, inferred from model results in this study, but also corroborated by proxy records (Fig. 5.1).

Maximum modelled sea level variability across the $\mathrm{MCO}$ with 460-780 $\mathrm{ppm} \mathrm{CO}_{2}$ variability is $21.02 \mathrm{~m}$, significantly lower than estimates of sea level variability during this time (Table 5.2). It should be noted, however, that the modelled $21.02 \mathrm{~m}$ could represent sea level variability across a single glacial-interglacial cycle, while the sea level record may apply to a range of cycles, which may further explain this disparity. Climate and ice-sheet models have, in the past, had issues with a strong hysteresis and relative insensitivity to $\mathrm{CO}_{2}$ concentrations that limits ice-mass loss under elevated $\mathrm{CO}_{2}$ concentrations (Pollard and DeConto 2005, Langebroek et al., 2009, Pollard et al., 2015, Gasson et al., 2016). While the model is consistent with average glacial-interglacial ice volume changes, it is harder to reconcile the peak interglacials, implying the ice-sheet model used in these simulations is still subject to some of these hysteresis issues. There is considerable uncertainty in $\mathrm{CO}_{2}$ proxy reconstructions, with large associated errors both spatially and temporally (Fig. 5.1). When coupled with the uncertainty in sea level and ice-sheet model reconstructions, uncertainty is too high to evaluate and constrain individual glacial-interglacial cycles with respect to $\mathrm{CO}_{2}$ and orbital forcing.

Modelled glacial-interglacial variability was heightened during the MMCT relative to the MCO, with glacial-interglacial sea level equivalent ice volume variability of $28.12 \mathrm{~m}$ for the MMCT and $21.02 \mathrm{~m}$ for the MCO (Table 5.2). While this enhanced variability is not evident in the proxy sea level records, enhanced glacial-interglacial variability during the MMCT is evident in the full glacial-interglacial advance and retreat of the WLB through the MMCT (Pierce et al., 2017, Sangiorgi et al., 2018) and the increasingly cold glacials recorded in diamictites at the Friis Hills while interglacials remained warm (Chapter 3). It has been inferred that this was driven by increased glacial-interglacial variability as the climate cooled due to falling $\mathrm{CO}_{2}$ concentrations (Table 5.1). This observation in the model could be a similar process to that reported in Foster and Rohling (2013), where they show an AIS insensitivity window between $\sim 400-600 \mathrm{ppm}$, whereby $400 \mathrm{ppm}$ is the threshold for significant loss of marine-based ice, but the terrestrial-based AIS responds at $600 \mathrm{ppm}$. When modelled $\mathrm{CO}_{2}$ concentrations drop below $460 \mathrm{ppm}$, the AIS can begin to advance across the continental shelf and becomes more sensitive to smaller changes in $\mathrm{CO}_{2}$. 

mid-Miocene: reconciling terrestrial, marine, and far-field records

Across the MMCT, lower amplitude glacial-interglacial cycles were characterised by tundra vegetation across the TAM and WLB, consistent with the $460 \mathrm{ppm}$ modelled scenario. At the final stages of the MMCT, higher amplitude cycles were characterised by warmer interglacials, inferred from boundary conditions required to simulate ice-free conditions at Mt. Boreas, and were likely characterised by slightly higher $\mathrm{CO}_{2}$ concentrations of 460-690 ppm. This shift between lower and higher amplitude cycles across the MMCT is also observed in the $\delta^{18} \mathrm{O}$ record, with relatively warmer interglacial conditions inferred by higher $\delta^{18} \mathrm{O}$ values towards the end of the MMCT (Fig. 5.1).

Ocean-atmosphere exchange of $\mathrm{CO}_{2}$ can reasonably explain up to $100 \mathrm{ppm}$ variability on a glacial-interglacial scale (e.g. Stephens \& Keeling, 2000, Luthi et al., 2008, MartinezGarcia et al., 2009, Menviel et al., 2018), and therefore other sources and sinks are required to explain the larger variability implied here, indicating significant input from the terrestrial biosphere. It should be noted that the total $320 \mathrm{ppm}$ difference between the modelled glacialinterglacial cycles across the MCO, with glacial interglacial values of 460 and 780 ppm (Table 5.2), represents the maximum and minimum $\mathrm{CO}_{2}$ during each period. It is therefore likely individual glacial-interglacial cycle would have experienced considerably less variability, with these smaller variations superimposed on the general warmth of the MCO. Eccentricity (100 kyr) paced variability in $\mathrm{CO}_{2}$ of $200 \mathrm{ppm}$ across the $\mathrm{MCO}$ is already acknowledged (Greenop et al., 2014), placing the degree of variability reported here within range.

A $135 \mathrm{ppm}$ decline in average $\mathrm{CO}_{2}$ used in the model simulations between the $\mathrm{MCO}$ and MMCT is lower than the 200-300 ppm decline suggested in proxy records (e.g. Foster et al., 2012, Zhang et al., 2013), however, this considers the average change between the MMCT and MCO. As is discussed in Chapter 3, glacial periods experienced the most variability between the MCO and MMCT, while interglacials have been characterised as relatively similar and warm enough to continue supporting tundra vegetation across the Dry Valleys. If modelled $\mathrm{CO}_{2}$ variability between glacial periods of the $\mathrm{MCO}$ and MMCT is therefore considered (see Table 5.2), then a decline in $\mathrm{CO}_{2}$ of 180-230 ppm between the MCO and MMCT can be inferred from the model, more in line with geologic data.

\subsubsection{The role of carbon dioxide on stepwise climate cooling and thresh- olds in the Antarctic Ice Sheet during the mid-Miocene}

To better correlate model data with near-field marine and terrestrial records and the far-field sea level and $\delta^{18} \mathrm{O}$ estimates, it is suggested that $\mathrm{CO}_{2}$ concentrations varied on a glacial- 
interglacial scale during the mid-Miocene, as is also inferred in other studies (e.g. Greenop et al., 2014). It is hypothesised that two boundaries in average long-term atmospheric $\mathrm{CO}_{2}$ were crossed during the mid-Miocene: the first at $\sim 14.6 \mathrm{Ma}$ and second at $\sim 13.8 \mathrm{Ma}$ (Figure 5.1). It should be noted that this discussion uses $\mathrm{CO}_{2}$ concentrations defined by those run in the model simulations presented in Chapter 4, and do not represent actual thresholds or boundaries in the climate system. Rather they should instead be taken as representative of a stepped approach to the general cooling observed over the mid-Miocene, which is consistent with $\mathrm{CO}_{2}$ thresholds implied in geological studies (e.g. Galeoti et al., 2016, Levy et al., 2016, Levy et al., 2019). To better constrain $\mathrm{CO}_{2}$ concentrations at which these shifts occur, higher resolution model simulations for $\mathrm{CO}_{2}$ concentrations between 280 and 460 ppm integrated with existing geological reconstructions should be used.

Boundary 1 is defined as $\sim 460 \mathrm{ppm}$. $\mathrm{CO}_{2}$ concentrations remained relatively high during the MCO, reaching up to $780 \mathrm{ppm}$ at peak warmth $(\sim 15.6 \mathrm{Ma})$. Model results infer that $\mathrm{CO}_{2}$ varied by up to $320 \mathrm{ppm}$ across this $2 \mathrm{Myr}$ interval, with drivers of this change discussed in the text above. It is hypothesised that a drop in $\mathrm{CO}_{2}$ to below $460 \mathrm{ppm}$, along with feedbacks previously discussed, triggered the onset of the MMCT. Glacial-interglacial variability during the MMCT was heightened, an observation inferred in modelled scenarios $\leq 460 \mathrm{ppm}$ (see Chapter 4), in near-field records from the Friis Hills (as glacial periods intensified, see Chapter 3 ) and far-field records such as the $\delta^{18} \mathrm{O}$ curve (Holbourn et al., 2014, De Vleeschouwer et al., 2017). During this time, interglacials remained relatively warm, with similar characteristics to milder interglacials of the MCO, however colder glacial periods (charactertised by modelled $\mathrm{CO}_{2}$ of $280-460 \mathrm{ppm}$ ) were characterised by large scale marine-ice advance onto the continental shelf. It is hypothesised that the cause of increased glacial-interglacial variability at lower $\mathrm{CO}_{2}$ is the sensitivity of marine-based ice sheets to $\mathrm{CO}_{2}$ concentrations below $460 \mathrm{ppm}$. A shift in $\mathrm{CO}_{2}$ concentrations below this first boundary triggered numerous feedbacks, discussed below, that allowed for the advance of ice into the marine realm. Post-MMCT, interglacials never get warmer than MCO and MMCT glacials after the first threshold (460 ppm) is crossed to colder climate and dominance of marine-based ice sheets.

Model simulations require a large ice-sheet reaching the coast before sea ice develops (DeConto et al., 2007), and this is corroborated by the model results presented in Chapter 4 whereby sea ice only develops in modelled scenarios where the EAIS overrides the TAM and reaches the coast (Fig. 4.6). The growth of a more significant terrestrial AIS as $\mathrm{CO}_{2}$ declined supported the development of annual sea ice around the continent during glacial 

mid-Miocene: reconciling terrestrial, marine, and far-field records

periods, evidenced in geologic records (Levy et al., 2016, Pierce et al., 2017, Sangiorgi et al., 2018) and during cooler interglacial periods in the model. This transition also coincides with a shift from high to low eccentricity fluctuations, with an increase in obliquity-paced variability, driven by this onset of marine-ice advance onto the continental shelf (Holbourn et al., 2007, Levy et al., 2019).

Boundary 2 is defined as $280 \mathrm{ppm}$. The development of a perennial sea ice field around the continent post-13.8 Ma decreases ocean-atmosphere exchange of $\mathrm{CO}_{2}$, acting as positive feedback to further reduce atmospheric $\mathrm{CO}_{2}$ concentrations. A permanent sea ice field increases albedo around the continent and limits the influence of warm circumpolar deep water upwelling near marine-based ice margins, further supporting large-scale ice advance across the continental shelf. A change to a colder climate state limited the role of precession driven local insolation but enhanced the ice-sheets sensitivity obliquity-paced ocean variability, with the previously dynamic terrestrial AIS therefore less subject to variability (Levy et al., 2019).

At lower $\mathrm{CO}_{2}$, the westerlies that circle Antarctica are less contracted around the continent, and therefore have less influence over the ACC, making overall flow weaker (Toggweiler and Russell, 2008). A weaker ACC would further limit the upwelling of warm deep-waters onto the continental shelf, which would support greater expansion of marine-based ice. As Southern Hemisphere westerlies are modulated by obliquity, and play such a large role in ACC strength and the upwelling of warm deep-water on the continental shelf, this creates a marine ice-sheet that is particularly sensitive to obliquity variability (Naish et al., 2009, Timmermann et al., 2014, Levy et al., 2019).

\subsection{Conclusions}

The Friis Hills drill cores provide direct records of orbital scale ice-sheet advance and retreat across the TAM, while corresponding marine records provide direct evidence for how the marine sector of the AIS was also responding to this forcing. It has been suggested that the terrestrial AIS is sensitive to local insolation controlled by precession (e.g. Levy et al., 2019) during past warm periods. The Friis Hills provides a direct record of a terrestrial AIS responding to precession during the absence of marine-based ice under warm climate state of the MCO. A lack of age control in the upper FHDP record makes it difficult to constrain the response of the terrestrial AIS to orbital forcing when climate cooled and the ice sheet expanded to the coast and advanced across the continental shelf at $14.6 \mathrm{Ma}$. A shift to lower $\mathrm{CO}_{2}$ concentrations in the model increases glacial-interglacial variability, potentially due 
to the sensitivity of marine-based ice at $\sim 400$ ppm (Naish et al., 2009, Foster and Rohling, 2013, Levy et al., 2019). Comparison between the $\mathrm{CO}_{2}$ variability on glacial-interglacial time scale, which is inferred in both the geologic record (Greenop et al., 2014) and the model-data comparison, this thesis begins to reconcile modelled SLE ice volume with the geologic record. While the SLE ice stored within the AIS under warmer climates from the model is too high compared with proxy geologic data (Miller et al., 2005, John et al., 2011, Holbourn et al., 2014, Miller et al., 2020), SLE ice volume change between modelled glacial-interglacial orbits and variable $\mathrm{CO}_{2}$ concentrations provides a considerably better fit to the data.

Based on the model results discussed, it is observed that two $\mathrm{CO}_{2}$ boundaries were crossed during the mid-Miocene that potentially explains climate and ice sheet transitions observed in the geologic record and proxy data at $\sim 14.6$ and 13.8 Ma. At 14.6 Ma, a shift to $\mathrm{CO}_{2}$ concentrations below $460 \mathrm{ppm}$, coupled with other feedbacks in the climate system, supported the growth of annual sea ice and advance of small-scale marine-based ice into the Ross Sea. At 13.8 Ma, a further decline in $\mathrm{CO}_{2}$ concentrations to below $280 \mathrm{ppm}$, supported perennial sea ice expansion which limited the influence on warm, deep-water upwelling and resulted in large-scale marine-based ice advance, stabilising the previously highly dynamic AIS. While these concentrations are based solely on those represented in the model, they approximate and corroborate threshold responses to $\mathrm{CO}_{2}$ proposed across the mid-Miocene in a previous study Gasson et al., 2016, Levy et al., 2019). The general decline of 200-300 ppm across the MMCT observed in proxy records (e.g. Foster et al., 2012, Badger et al., 2013, Zhang et al., 2013) is consistent with these reconstructions and observations.

Records in the TAM (e.g. Rude Valley) and the lack of deposition recorded across the Dry Valleys implies conditions remained cool enough to support the extinction of vegetation at higher elevations of the TAM. As is discussed in Chapter 4, this apparent disparity between terrestrial records with marine and far-field records could be attributed to TAM uplift across the MMCT. The shift of TAM elevations to those similar to present-day towards the end of the mid-Miocene and the lack of moisture availability as marine-based ice and sea ice grew across the Ross Sea created conditions unfavourable for an alpine glacier system in the Dry Valleys.

Proxy records of $\mathrm{CO}_{2}$ during the mid-Miocene are too sparse to capture the real variability on an individual glacial-interglacial timescale, and in part, individual records contradict each other as well as the general climatic pattern inferred in the $\delta^{18} \mathrm{O}$ record. For example, boron isotopes (Foster et al., 2012, Greenop et al., 2014, Raitzsch et al., 2020) imply a similar 
Glacial-interglacial variability and evolution of the Antarctic Ice Sheet across the mid-Miocene: reconciling terrestrial, marine, and far-field records

range of $\mathrm{CO}_{2}$ concentrations for both the $\mathrm{MCO}$ and MMCT. It should be noted, however, that this record of $\mathrm{CO}_{2}$ variability during the MMCT, closely matches the estimated range of $\mathrm{CO}_{2}$ variability inferred from the model used in this study (Fig. 5.1, 280-690 ppm). On this basis, it could be implied that boron isotopes underestimate $\mathrm{CO}_{2}$ concentrations during the $\mathrm{MCO}$. This disparity between $\mathrm{CO}_{2}$ proxy records amplifies uncertainty regarding $\mathrm{CO}_{2}$ concentrations during the mid-Miocene.

This model-data comparison of glacial-interglacial variability provides some constraints on the debate of $\mathrm{CO}_{2}$ variability across the mid-Miocene. While it is clear that climate and ice-sheet models are still yet to fully represent mid-Miocene climates, with the possible scenarios for this disparity having been discussed, it is also noted that there is considerable uncertainty in $\mathrm{CO}_{2}$ proxy reconstructions and the volume of AIS variability inferred from the $\delta^{18} \mathrm{O}$ record. 


\section{Chapter 6}

\section{Conclusions and future work}

The mid-Miocene provides an important example relevant to understanding future Antarctic Ice Sheet (AIS) response to warming, as not only were $\mathrm{CO}_{2}$ concentrations similar to those projected for the near-future, but geologic records imply a highly dynamic AIS, with cyclic advance into the marine realm and retreat to its terrestrial margin. Understanding of this timeperiod, has in the past, been hindered by a lack of continuous terrestrial records to complement marine drill-cores (e.g. AND-2A), sparse proxy data (e.g. $\mathrm{CO}_{2}$ proxy reconstructions), and discrepancies between model and proxy data. This thesis addresses these issues with analysis of a new terrestrial geological record from the Friis Hills in the Transantarctic Mountains (TAM), a climate-ice sheet model compared to the data constraints to better understand the drivers of the dynamic mid-Miocene AIS, and the reconciliation of marine, terrestrial, and far field records. Key conclusions are summarised below.

\section{Chapter 3}

- The composite stratigraphy for 3 drill core records spanning a $\sim 50 \mathrm{~m}$ thick sequence of permafrost sediments from the Friis Hills Drilling Project (FHDP-1A, -2A, and $-3 \mathrm{~A}$ ) was presented. Nine facies were identified in the drill cores, ranging from a mudstone and fine-sandy mudstone indicating deposition in glacially-influenced fluvial and lacustrine environments, to a massive diamictite, indicating phases of ice proximal and subglacial deposition. Environmental interpretation, based on the sedimentary and paleoecological characteristics of the facies was used to construct an index of glacial proximity, which inferred a total of 15 cycles of advance and retreat of a temperate 
alpine glacier system. Each cycle is bounded by a glacial surface of erosion produced during ice advance.

- An idealised stratigraphic motif identified four cyclically-repeating depositional environments characterised the Friis Hills during the mid-Miocene, indicative of a considerably warmer and wetter climate than present-day: (1) subglacial erosion and deposition during ice advance (glacial maximum), (2) proglacial deposition during ice retreat (early recession), (3) interglacial lacustrine deposition during maximum ice retreat (late recession), and (4) proglacial deposition during ice advance.

- An integrated age model based on magnetostratigraphy and new ${ }^{40} \mathrm{Ar} /{ }^{39} \mathrm{Ar}$ ages on two silicic tephra constrains deposition of this sedimentary succession between $\sim 15.1-13.8$ $\mathrm{Ma}$, with some unconformities of up to $400 \mathrm{kyr}$ duration. This research provided new age constraints and a more continuous and complete stratigraphic framework, augmenting the previous work by Lewis \& Ashworth (2015), showing the the cycles corresponded in duration to Milankovitch climate frequencies. Interpretation of diamictite facies upsection inferred that those deposited after 14.4 Ma represented progressively colder and more widespread glaciation across the mid-Miocene Climate Transition (MMCT), while palynological and sedimentological analyses suggested interglacials remained similar to those that characterised the late-MCO. This corroborates the increasing glacial-interglacial variability across the MMCT inferred by the $\delta$ ${ }^{18} \mathrm{O}$ record (Holbourn et al., 2014).

\section{Chapter 4}

- $\mathrm{CO}_{2}$ and tectonic controls on climate and ice sheet evolution during the mid-Miocene were evaluated. To do this, a series of climate and ice sheet model simulations were run for a range of plausible $\mathrm{CO}_{2}$ concentrations, TAM uplift scenarios, and glacial-interglacial orbital configurations. Sedimentological and paleoecological data from the TAM (including the Friis Hills Drilling Project (FHDP) cores reported in Chapter 3) Ross Sea, and Wilkes coast provided the primary constraint on ice extent and temperature variability across the mid-Miocene. The division of these paleoenvironmental conditions into glacial and interglacial periods provided a means against which to test both cold (glacial) and warm (interglacial) orbit simulations.

- The simulations inferred a likely TAM elevation of between 300-500 m below presentday, with rising TAM elevations, in combination with declining atmospheric $\mathrm{CO}_{2}$, 
across the mid-Miocene likely contributing to the shift in basal glacial thermal character reported at the end of the MMCT (Marchant et al., 1993; Sugden \& Denton 2004; Lewis et al., 2006; Lewis et al., 2008). As expected, the model ensemble implied that $\mathrm{CO}_{2}$ exerts a greater influence on ice sheet volume than TAM elevation, although it is evident that TAM elevation impacts East Antarctic Ice Sheet (EAIS) evolution. Higher TAM elevations supported the growth of a larger TAM ice cap under warmer simulations, and under cooler simulations acted to buttress ice sheet growth, both of which supported greater total ice volumes. It could therefore be inferred that rising TAM elevations across the mid-Miocene led to the thicker, more stable EAIS that characterises present-day Antarctica.

- It was found that modelled $\mathrm{CO}_{2}$ concentrations of $780 \mathrm{ppm}$ best represent peak $\mathrm{MCO}$ warmth, in line with higher estimates of $\mathrm{CO}_{2}$ for this time-period (e.g. Retallack 2009). Ice advance into the Ross Sea under 460 ppm modelled $\mathrm{CO}_{2}$ and the development of a full marine-based ice sheet at $280 \mathrm{ppm}$ suggested a marine-ice threshold of between 280 and $460 \mathrm{ppm}$ in the model. While model results support previous suggestions that vegetation went extinct at higher elevations of the TAM at the end of the MMCT (e.g. Lewis et al., 2008), they also support the persistence of vegetation in localised refugia in coastal regions post-MMCT, as is inferred from Dry Valley Drilling Project, DVDP-10 and -11 drill core records (Fielding et al., 2012; Ohneiser et al., 2020).

- This model ensemble explored the role both $\mathrm{CO}_{2}$ and TAM elevation played in AIS and climate evolution across the mid-Miocene, with ice-extent and temperatures inferred by the geologic data consistent with model simulations under reasonable $\mathrm{CO}_{2}$ concentrations and TAM elevations. However, there were clear model-data discrepancies; the model was insensitive to high $\mathrm{CO}_{2}$ values, leaving a large ice sheet on East Antarctica, which is not supported by Paleogene geological reconstructions, and the contribution of modelled EAIS volume to glacial-interglacial sea-level variability during the mid-Miocene, underestimated some far-field global sea-level reconstructions (e.g. Miller et al., 2020). This may to some degree be due to unresolved hysteresis issues with the ice sheet model (e.g. DeConto et al., 2003).

\section{Chapter 5}

- This chapter attempted to reconcile the terrestrial, marine, and far-field geological records discussed throughout this thesis to assess glacial-interglacial variability and 
evolution of the AIS across the mid-Miocene. While 15 cycles were identified within the FHDP record, only 7.5 of these were well enough constrained by the age model reported in Chapter 3 to be correlated with relative accuracy to orbital-scale cycles in the $\delta{ }^{18} \mathrm{O}$ record. The 7.5 cycles spanned $\sim 160 \mathrm{ka}$ of the late-MCO and inferred a terrestrial AIS responding to local insolation controlled by precession during the absence of marine-based ice. The Friis Hills cores provide the first direct evidence of orbital-scale AIS variability during the MCO-MMCT, corroborating interpretations of terrestrial AIS response during warmer climates (Levy et al., 2019).

- While the FHDP record provided evidence for orbital scale advance and retreat, it is hypothesised that the long-term, general climate trend observed across the midMiocene was driven by declining mean $\mathrm{CO}_{2}$ concentrations. Marine, terrestrial, and far-field records support a two-step climatic shift across the mid-Miocene, at 14.6 and 13.8 Ma, corroborated by the model-data comparison performed in Chapter 4 . In this thesis, this stepwise shift in climatic cooling across the mid-Miocene was attributed to declining $\mathrm{CO}_{2}$, with two boundaries, approximating thresholds in ice sheet behaviour, crossed during this time.

- An increase in glacial-interglacial variability across the MMCT, inferred by both the $\delta$ ${ }^{18} \mathrm{O}$ record and analysis of the FHDP record, was also observed in the model at $\mathrm{CO}_{2}$ concentrations $\leq 460 \mathrm{ppm}$, under the same boundary conditions that support the onset of marine-based ice sheets in the Ross Sea. It was therefore inferred that the heightened sensitivity of marine-based ice at $\mathrm{CO}_{2}$ concentrations of $\sim 400 \mathrm{ppm}$, as first postulated by Foster \& Rohling (2013) and confirmed by Patterson and others (2014) and Levy and others $(2016 ; 2019)$, was the driver of enhanced glacial-interglacial variability across the MMCT.

- Evidence from the Ross Sea and the Wilkes coast support the absence of marine-based ice during the MCO, however an increase in IRD at 14.6 Ma corroborates AIS advance observed in the Ross Sea. A shift to $\mathrm{CO}_{2}$ concentrations below $460 \mathrm{ppm}$ in the model supported the growth of annual sea ice and further advance of small-scale marine-based ice into the Ross Sea. At $13.8 \mathrm{Ma}$, a further decline in $\mathrm{CO}_{2}$ to concentrations to below $280 \mathrm{ppm}$ enabled the development of perennial sea ice, which limited the influence on warm, deep-water upwelling and resulted in large-scale marine-based ice advance, which stabilised the previously highly dynamic terrestrial AIS. This stepwise pattern of mid-Miocene cooling is consistent with the 200-300 ppm general decline in $\mathrm{CO}_{2}$ observed in proxy records. 


\section{Future work}

Analysis and interpretation conducted as part of this research, however, has raised questions or highlighted areas for further research that were outside the scope of this thesis.

- The model-data comparison presented in Chapter 4 inferred a shift from a TAM ice cap over Southern Victoria Land to a predominantly EAIS influence as modelled $\mathrm{CO}_{2}$ concentrations decline. Provenance studies on the FHDP cores will provide an interesting dataset against which to test model simulations and boundary conditions.

- Higher resolution ice sheet models over the Dry Valleys sector of the TAM, with $1 \mathrm{~km}$ resolution, will offer further insight into ice sheet evolution over the Friis Hills during the mid-Miocene and test the hypotheses reported both in this thesis and by Lewis and Ashworth (2015).

- A marine ice threshold between 280-460 ppm in the model is inferred. Model simulations at higher resolution between 280-460 ppm will also help to further constrain this observation.

- Cold orbit model simulations were only run at default topography (0 m elevation change), to fully assess thresholds for marine-ice advance, these cold orbit simulations should also be run at the hypothesised TAM elevations of -300 to $-500 \mathrm{~m}$.

- The ice sheet model used is still subject to some hysteresis issues, with insensitivity to higher $\mathrm{CO}_{2}$ concentrations that needs to be addressed. There is still, however, considerable uncertainty in $\mathrm{CO}_{2}$ proxy reconstructions both spatially and temporally. While boron isotopes, for example, seem to provide estimates within the range inferred by model results for the MMCT, they appear to underestimate $\mathrm{CO}_{2}$ during the MCO.

- There is also considerable uncertainty regarding the contribution of AIS volume to the $\delta^{18} \mathrm{O}$ record, with relative sea level curves implying almost complete loss of the AIS during the MCO (Miller et al., 2020), a finding that is in contrast to observations from the Antarctic continental margin and terrestrial records. It is apparent that model-data reconciliation across the mid-Miocene requires further development of the ice sheet models used to resolve hysteresis issues and the constraining of proxy data.

- Model simulations are implying higher average $\mathrm{CO}_{2}$ concentrations for the $\mathrm{MCO}$ than is inferred by $\mathrm{CO}_{2}$ proxy reconstructions. The fact that model results and far-field 
proxy data appear to be better reconciled for the MMCT than the MCO infers that, while model hysteresis may contribute in part to this, that another climate forcing was responsible for relative warmth during this time period. This requires further investigation, and the representation of this within the climate and ice sheet models used may begin to reconcile this disparity. 


\section{Bibliography}

Adkins, J., McIntyre, K., \& Schrag, D. (2002). The salinity, temperature, and $\delta^{18} \mathrm{O}$ of the glacial deep ocean. Science, 298(5599), 1769-1773.

Anderson, J., \& Bartek, L. (1992). Cenozoic Glacial History of the Ross Sea Revealed by Intermediate Resolution Seismic Reflection Data Combined with Drill Site Information. In J. Kennett \& D. Warkne (Eds.), The Antarctic Paleoenvironment: A Perspective on Global Change, Part One (pp. 231-264).

Andrews, J., Smith, L., Preston, R., Cooper, T., \& Jennings, A. (1997). Spatial and temporal patterns of iceberg rafting (IRD) along the East Greenland margin, ca. $68 \mathrm{~N}$, over the last 14 cal ka. Journal of Quaternary Science, 12(1), 1-13.

Askin, R. (1995). Permian Palynomorphs from Southern Victoria Land, Antarctica. Antarctic Journal of the United States, 30, 47-48.

Askin, R. (2000). Spores and Pollen from the McMurdo Sound Erratics, Antarctica. Paleobiology and Paleoenvironments of Eocene Rocks: McMurdo Sound, East Antarctica, 76, 161-181.

Askin, R., \& Raine, J. (2000). Oligocene and Early Miocene Terrestrial Palynology of the Cape Roberts Drillhole CRP-2/2A, Victoria Land Basin, Antarctica. Terra Antartica, 7(4), 493-501.

Atkins, C., Barrett, P., \& Hicock, S. (2002). Cold Glaciers Erode and Deposit: Evidence from Allan Hills, Antarctica. Geology, 30(7), 659-662.

Badger, M., Lear, C., Pancost, R., Foster, G., Bailey, T., Leng, M., \& Abels, H. (2013). CO 2 Drawdown Following the Middle Miocene Expansion of the Antarctic Ice Sheet. Paleoceanography, 28(1), 42-53.

Barker, P. (2001). Scotia Sea Regional Tectonic Evolution: Implications for Mantle Flow and Palaeocirculation. Earth-Science Reviews, 55(1), 1-39.

Barker, P., \& Burrell, J. (1977). The Opening of Drake Passage. Marine Geology, 25(1), $15-34$.

Barker, P., \& Thomas, E. (2004). Origin, Signature and Palaeoclimatic Influence of the Antarctic Circumpolar Current. Earth-Science Reviews, 66(1), 143-162.

Barrett, P. (1987). Oligocene Sequence Cored at CIROS-1, Western McMurdo Sound. New Zealand Antarctic Record, 7(3), 1-7.

Barrett, P. (1989). Antarctic Cenozoic History from the CIROS-1 Drill Hole, McMurdo Sound. Science Information Publishing Center. 
Barrett, P. (2008). A History of Antarctic Cenozoic Glaciation - View from the Margin. Developments in Earth and Environmental Sciences, 8, 33-83.

Barrett, P. (2013). Resolving Views on Antarctic Neogene Glacial History - the Sirius Debate. Earth and Environmental Science Transactions of the Royal Society of Edinburgh, 104, 31-53.

Barrett, P., Hambrey, M., Christoffersen, P., Glasser, N., \& Hubbart, B. (2007). Cenozoic Climate and Sea Level History from Glacimarine Strata Off the Victoria Land Coast, Cape Roberts Project, Antarctica. Glacial Sedimentary Processes and Products (pp. 259-287). International Association of Sedimentologists.

Bart, P., \& De Santis, L. (2012). Glacial Intensification During the Neogene: A Review of Seismic Stratigraphic Evidence from the Ross Sea, Antarctica, Continental Shelf. Oceanography, 25(3), 166-183.

Bartek, L., Henrys, S., Anderson, J., \& Barrett, P. (1996). Seismic Stratigraphy of McMurdo Sound, Antarctica: Implications for Glacially Influenced Early Cenozoic Eustatic Change? Marine Geology, 130(1-2), 79-98.

Bartek, L., Vail, P., Anderson, J., Emmet, P., \& Wu, S. (1991). Effect of Cenozoic Ice Sheet Fluctuations in Antarctica on the Stratigraphic Signature of the Neogene. Journal of Geophysical Research, 96, 6753-6778.

Beerling, D., Fox, A., \& Anderson, C. (2009). Quantitative Uncertainty Analyses of Ancient Atmospheric $\mathrm{CO}_{2}$ Estimates from Fossil Leaves. American Journal of Science, 309(9), 775-787.

Behrendt, J., \& Cooper, A. (1991). Evidence of Rapid Cenozoic Uplift of the Shoulder Escarpment of the Cenozoic West Antarctic Rift System and a Speculation on Possible Climate Forcing. Geology, 19(4), 315-319.

Benn, D., \& Evans, D. (1998). Glaciers and Glaciation (1st ed.). Arnold.

Benn, D., \& Evans, D. (2010). Glaciers and Glaciation (2nd ed.). Hodder Education.

Bennett, M., Huddart, D., \& McCormick, T. (2000). The Glaciolacustrine Landform-Sediment Assemblage at Heinabergsjökull, Iceland. Geografiska Annaler: Series A, Physical Geography, 82(1), 1-16.

Berner, R., \& Kothavala, Z. (2001). Geocarb Iii: A Revised Model of Atmospheric $\mathrm{CO}_{2}$ over Phanerozoic Time. American Journal of Science, 301(2), 182-204.

Berthier, E., Le Bris, R., Mabileau, L., Testut, L., \& Remy, F. (2009). Ice wastage on the Kerguelen Islands (49S, 69E) between 1963 and 2006. Journal of Geophysical Research, American Geophysical Union, 114, 3005.

Bertram, R., Wilson, D., van de Flierdt, T., McKay, R., Patterson, M., Jimenez-Espejo, F., Escutia, C., Duke, G., Taylor-Silva, B., \& Riesselman, C. (2018). Pliocene Deglacial Event Timelines and the Biogeochemical Response Offshore Wilkes Subglacial Basin, East Antarctica. Earth and Planetary Science Letters, 494, 109-116.

Bijl, P., Bendle, J., Bohaty, S., Pross, J., Schouten, S., Tauxe, L., Stickley, C., McKay, R., Rohl, U., Olney, M., Sluijs, A., Escutia, C., Brinkhuis, H., \& Scientists, E. 3. (2013). Eocene cooling linked to early flow across the Tasmanian Gateway. Proceedings of the National Academy of Sciences of the United States of America, 110(24), 96459650 . 
Billings, W., \& Mooney, H. (1968). The Ecology of Arctic and Alpine Plants. Biological Reviews, 43(4), 481-529.

Billups, K., \& Schrag, D. (2002). Paleotemperatures and Ice Volume of the Past $27 \mathrm{Myr}$ Revisited with Paired Mg/Ca and 18O/16O Measurements on Benthic Foraminifera. Paleoceanography, 17(1), 3-11.

Blatter, \& Hutter. (1991). Polythermal conditions in arctic glaciers. Journal of Glaciology, 37(126), 261-269.

Blisniuk, P., Stern, L., Chamberlain, C., Idleman, B., \& Zeitler, P. (2005). Climatic and Ecologic Changes During Miocene Surface Uplift in the Southern Patagonian Andes. Earth and Planetary Science Letters, 230(1), 125-142.

Bliss, A., Cuffey, K., \& Kavanaugh, J. (2011). Sublimation and Surface Energy Budget of Taylor Glacier, Antarctica. Journal of Glaciology, 57(204), 684-696.

Blott, S., \& Pye, K. (2001). GRADISTAT: a grain size distribution and statistics package for the analysis of unconsolidated sediments. Earth Surface Processes and Landforms, 26(11), 1237-1248.

Böhme, M. (2003). The Miocene Climatic Optimum: Evidence from Ectothermic Vertebrates of Central Europe. Palaeogeography, Palaeoclimatology, Palaeoecology, 195(3), 389-401.

Bott, M., \& Stern, T. (1992). Finite Element Analysis of Transantarctic Mountain Uplift and Coeval Subsidence in the Ross Embayment. Tectonophysics, 201(3), 341-356.

Boulton, G. (1972). Modern Arctic Glaciers as Depositional Models for Former Ice Sheets. Journal of the Geological Society, 128(4), 361-393.

Brady, H. (1979). A diatom report on DVDP cores 3, 4a, 12, 14, 15 and other related surface sections. Memoirs of National Institute of Polar Research, Special Issue, 13, 150-163.

Brancolini, G., Cooper, A., \& Coren, F. (1995). Seismic Facies and Glacial History in the Western Ross Sea (Antarctica). In A. Cooper, P. Barker, \& G. Brancolini (Eds.), Geology and Seismic Stratigraphy of the Antarctic Margin (pp. 209-233).

Brenn, G., Hansen, S., \& Park, Y. (2017). Variable Thermal Loading and Flexural Uplift Along the Transantarctic Mountains, Antarctica. Geology, 45(5), 463-466.

Broecker, W., \& Peng, T. (1982). Tracers in the Sea. Eldigio Press.

Browning, J., Miller, K., \& Pak, D. (1996). Global Implications of Lower to Middle Eocene Sequence Boundaries on the New Jersey Coastal Plain: The Icehouse Cometh. Geology, 24(7), 639-642.

Cerling, T. (1992). Use of Carbon Isotopes in Paleosols as an Indicator of the $p \mathrm{CO}_{2}$ of the Paleoatmosphere. Global Biogeochemical Cycles, 6(3), 307-314.

Chapin, F. (1987). Environmental Controls over Growth of Tundra Plants. Ecological Bulletins, (38), 69-76.

Chorley, H., Levy, R., Naish, T., Lewis, A., Cox, S., Hemming, S., Ohneiser, C., Gorman., A., Harper, M., Hopkins, J., Prebble, J., Verret, M., Dickinson, W., Florindo, F., Golledge, N., Halberstadt, A., Kowalewski, D., McKay, R., Myers, S., .. Pyne, R. (in review). Antarctic Ice Sheet evolution and variability during the mid-Miocene Climate Transition ( 15.1-13.8 Ma), from the Friis Hills, Antarctica. Geological Society of America Bulletin. 
Chow, J., \& Bart, P. (2003). West Antarctic Ice Sheet Grounding Events on the Ross Sea Outer Continental Shelf During the Middle Miocene. Palaeogeography, Palaeoclimatology, Palaeoecology, 198(1), 169-186.

Clapperton, C., \& Sugden, D. (1990). Late Cenozoic Glacial History of the Ross Embayment, Antarctica. Quaternary Science Reviews, 9(2), 253-272.

Cook, C., Hemming, S., van de Flierdt, T., Pierce Davis, E., Williams, T., Galindo, A., Jiménez-Espejo, F., \& Escutia, C. (2017). Glacial Erosion of East Antarctica in the Pliocene: A Comparative Study of Multiple Marine Sediment Provenance Tracers. Chemical Geology, 466, 199-218.

Cook, C., van de Flierdt, T., Williams, T., Hemming, S., Iwai, M., Kobayashi, M., JimenezEspejo, F., Escutia, C., González, J., Khim, B., McKay, R., Passchier, S., Bohaty, S., Riesselman, C., Tauxe, L., Sugisaki, S., Galindo, A., Patterson, M., Sangiorgi, F., ... Yamane, M. (2013). Dynamic Behaviour of the East Antarctic Ice Sheet During Pliocene Warmth. Nature Geoscience, 6(9), 765-769.

Cooke, P., Nelson, C., Crundwell, M., Field, B., Elkington, S., \& Stone, H. (2004). Textural Variations in Neogene Pelagic Carbonate Ooze at DSDP Site 593, Southern Tasman Sea, and Their Paleoceanographic Implications. New Zealand Journal of Geology and Geophysics, 47(4), 787-807.

Cox, S., Hemming, S., \& Tootell, D. (2020, in review). The Isotopx Ngx and the Atona Faraday Amplifiers. Geochronology Discussions.

Coxall, H., Wilson, P., Pälike, H., Lear, C., \& Backman, J. (2005). Rapid Stepwise Onset of Antarctic Glaciation and Deeper Calcite Compensation in the Pacific Ocean. Nature, 433, 53-7.

Crampton, J., Cody, R., Levy, R., Harwood, D., McKay, R., \& Naish, T. (2016). Southern Ocean Phytoplankton Turnover in Response to Stepwise Antarctic Cooling over the Past 15 Million Years. Proceedings of the National Academy of Sciences, 113(25), 6868-6873.

Creber, G., \& Chaloner, W. (1985). Three Growth in the Mesozoic and Early Tertiary and the Reconstruction of Palaeoclimates. Palaeogeography, Palaeoclimatology, Palaeoecology, 52(1), 35-59.

Cuffey, K., Conway, H., Gades, A., Hallet, B., Lorrain, R., Severinghaus, J., Steig, E., Vaughn, B., \& White, J. (2000). Entrainment at cold glacier beds. Geology, 38(4), 351-354.

Dagel, M. (1985). Stratigraphy and Chronology of Stage 6 and 2 Glacial Deposits, Marshall Valley, Antarctica (Thesis).

Dalrymple, G., Lanphere, M., \& Kraker, G. (1981). Irradiation of Samples for ${ }^{40} \mathrm{Ar} /{ }^{39} \mathrm{Ar}$ Dating Using the Geological Survey Triga Reactor.

Dalziel, I., Lawver, L., Pearce, J., Barker, P., Hastie, A., Barfod, D., Schenke, H., \& Davis, M. (2013). A Potential Barrier to Deep Antarctic Circumpolar Flow until the Late Miocene? Geology, 41(9), 947-950.

De Boer, B., Van de Wal, R., Bintanja, R., Lourens, L., \& Tuenter, E. (2010). Cenozoic Global Ice-Volume and Temperature Simulations with 1-D Ice-Sheet Models Forced by Benthic $\delta{ }^{18} \mathrm{O}$ Records. Annals of Glaciology, 51(55), 23-33. 
De Jonge, C., Hopmans, E., Zell, C., Kim, J., Schouten, S., \& Sinninghe Damsté, J. (2014). Occurrence and Abundance of 6-Methyl Branched Glycerol Dialkyl Glycerol Tetraethers in Soils: Implications for Palaeoclimate Reconstruction. Geochimica et Cosmochimica Acta, 141, 97-112.

De Santis, L., Prato, S., Brancolini, G., Lovo, M., \& Torelli, L. (1999). The Eastern Ross Sea Continental Shelf During the Cenozoic: Implications for the West Antarctic Ice Sheet Development. Global and Planetary Change, 23(1-4), 173-196.

De Vleeschouwer, D., Vahlenkamp, M., Crucifix, M., \& Pälike, H. (2017). Alternating Southern and Northern Hemisphere Climate Response to Astronomical Forcing During the Past 35 M.Y. Geology, 45(4), 375-378.

DeConto, R., \& Pollard, D. (2003). Rapid Cenozoic Glaciation of Antarctica Induced by Declining Atmospheric $\mathrm{CO}_{2}$. Nature, 421(6920), 245-249.

DeConto, R., \& Pollard, D. (2016). Contribution of Antarctica to Past and Future Sea-Level Rise. Nature, 531(7596), 591-597.

DeConto, R., Pollard, D., Wilson, P., Pälike, H., Lear, C., \& Pagani, M. (2008). Thresholds for Cenozoic Bipolar Glaciation. Nature, 455(7213), 652-656.

Denton, G., Bockheim, J., Wilson, S., \& Stuiver, M. (1989). Late Wisconsin and Early Holocene Glacial History, Inner Ross Embayment, Antarctica. Quaternary Research, 31(2), 151-182.

Denton, G., Prentice, M., Kellogg, D., \& Kellogg, T. (1984). Late Tertiary History of the Antarctic Ice Sheet: Evidence from the Dry Valleys. Geology, 12(5), 263-267.

Denton, G., \& Sugden, D. (2005). Meltwater Features That Suggest Miocene Ice-Sheet Overriding of the Transantarctic Mountains in Victoria Land, Antarctica. Geografiska Annaler: Series A, Physical Geography, 87(1), 67-85.

Denton, G., Sugden, D., Marchant, D., Hall, B., \& Wilch, T. (1993). East Antarctic Ice Sheet Sensitivity to Pliocene Climatic Change from a Dry Valleys Perspective. Geografiska Annaler: Series A, Physical Geography, 75(4), 155-204.

Derry, L., \& France-Lanord, C. (1996). Neogene Himalayan Weathering History and River ${ }^{87} \mathrm{Sr} /{ }^{86} \mathrm{Sr}$ : Impact on the Marine Sr Record. Earth and Planetary Science Letters, 142(1), 59-74.

Di Roberto, A., Carlo, P., Rocchi, S., \& Panter, K. (2012). Early Miocene Volcanic Activity and Paleoenvironment Conditions Recorded in Tephra Layers of the AND-2A Core (Southern McMurdo Sound, Antarctica). Geosphere, 8(6), 1342-1355.

Di Vincenzo, G., Bracciali, L., Del Carlo, P., Panter, K., \& Rocchi, S. (2010). ${ }^{40}$ AR/ ${ }^{39}$ AR DATING OF VOLCANOGENIC PRODUCTS FROM THE AND-2A CORE (ANDRILL SOUTHERN MCMURDO SOUND PROJECT, ANTARCTICA): CORRELATIONS WITH THE EREBUS VOLCANIC PROVINCE AND IMPLICATIONS FOR THE AGE MODEL OF THE CORE. Bulletin of Volcanology, 72(4), 487-505.

Dickinson, W., Schiller, M., Ditchburn, B., Graham, I., \& Zondervan, A. (2012). Meteoric Be10 from Sirius Group Suggests High Elevation McMurdo Dry Valleys Permanently Frozen since 6 Ma. Earth and Planetary Science Letters, 355-356, 13-19. 
Doran, P., McKay, C., Clow, G., Dana, L., Fountain, A., Nylen, T., \& Lyons, W. (2002). Valley Floor Climate Observations from the McMurdo Dry Valleys, Antarctica, 1986-2000. Journal of Geophysical Research: Atmospheres, 107(24).

Dunbar, G., Naish, T., Barrett, P., Fielding, C., \& Powell, R. (2008). Constraining the Amplitude of Late Oligocene Bathymetric Changes in Western Ross Sea During Orbitally-Induced Oscillations in the East Antarctic Ice Sheet: (1) Implications for Glacimarine Sequence Stratigraphic Models. Palaeogeography, Palaeoclimatology, Palaeoecology, 260(1), 50-65.

Dutton, A., Carlson, A., Long, A., Milne, G., Clark, P., DeConto, R., Horton, B., Rahmstorf, S., \& Raymo, M. (2015). Sea-Level Rise Due to Polar Ice-Sheet Mass Loss During Past Warm Periods. Science, 349(6244).

Ehrmann, W., \& Mackensen, A. (1992). Sedimentological Evidence for the Formation of an East Antarctic Ice Sheet in Eocene/Oligocene Time. Palaeogeography, Palaeoclimatology, Palaeoecology, 93(1), 85-112.

Ekart, D., Cerling, T., Montanez, I., \& Tabor, N. (1999). A 400 Million Year Carbon Isotope Record of Pedogenic Carbonate: Implications for Paleoatmospheric Carbon Dioxide. American Journal of Science, 805-827.

Elston, D., \& Bressler, S. (1981). The lithologic logs of dvdp cores 10 and 11, eastern taylor valley. In L. Mcginnis (Ed.), Dry valley drilling project.

Evans, D., Phillips, E., Hiemstra, J., \& Auton, C. (2006). Subglacial Till: Formation, Sedimentary Characteristics and Classification. Earth-Science Reviews, 78(1-2), 115176.

Eyles, N., Sladen, J., \& Gilro, S. (1982). A Depositional Model for Stratigraphic Complexes and Facies Superimposition in Lodgement Tills. Boreas, 11(4), 317-333.

Fairbanks, R., \& Matthews, R. (1978). The marine oxygen isotopic record in Pleistocene coral Barbados, West Indies. Quaternary Research, 10, 181-196.

Falkowski, P., Scholes, R., Boyle, E., Canadell, J., Canfield, D., Elser, J., Gruber, N., Hibbard, K., Högberg, P., Linder, S., Mackenzie, F., Moore III, B., Pedersen, T., Rosenthal, Y., Seitzinger, S., Smetacek, V., \& Steffen, W. (2000). The Global Carbon Cycle: A Test of Our Knowledge of Earth as a System. Science, 290(5490), 291-296.

Feakins, S., Warny, S., \& J, L. (2012). Hydrologic cycling over Antarctica during the middle Miocene warming. Nature, 5, 557-560.

Fielding, C. (1984). Upper Delta Plain Lacustrine and Fluviolacustrine Facies from the Westphalian of the Durham Coalfield, NE England. Sedimentology, 31(4), 547-567.

Fielding, C. (2017). Stratigraphic Architecture of the Cenozoic Succession in the McMurdo Sound Region, Antarctica: An Archive of Polar Palaeoenvironmental Change in a Failed Rift Setting. Sedimentology, 65(1), 1-61.

Fielding, C., Browne, G., Field, B., Florindo, F., Harwood, D., Krissek, L., Levy, R., Panter, K., Passchier, S., \& Pekar, S. (2011). Sequence Stratigraphy of the Andrill and-2a Drillcore, Antarctica: A Long-Term, Ice-Proximal Record of Early to Mid-Miocene Climate, Sea-Level and Glacial Dynamism. Palaeogeography, Palaeoclimatology, Palaeoecology, 305(1-4), 337-351. 
Fielding, C., Harwood, D., Winter, D., \& Francis, J. (2012). Neogene Stratigraphy of Taylor Valley, Transantarctic Mountains, Antarctica: Evidence for Climate Dynamism and a Vegetated Early Pliocene Coastline of McMurdo Sound. Global and Planetary Change, 96-97, 97-104.

Fitzgerald, P. (1992). The Transantarctic Mountains of Southern Victoria Land: The Application of Apatite Fission Track Analysis to a Rift Shoulder Uplift. Tectonics, 11(3), 634-662.

Fitzgerald, P. (2002). Tectonics and Landscape Evolution of the Antarctic Plate since the Breakup of Gondwana, with an Emphasis on the West Antarctic Rift System and the Transantarctic Mountains. Royal Society of New Zealand Bulletin, 35, 453-469.

Fitzgerald, P., Sandiford, M., Barrett, P., \& Gleadow, A. (1986). Asymmetric Extension Associated with Uplift and Subsidence in the Transantarctic Mountains and Ross Embayment. Earth and Planetary Science Letters, 81(1), 67-78.

Fitzsimons, S. (1992). Sedimentology and Depositional Model for Glaciolacustrine Deposits in an Ice-Dammed Tributary Valley, Western Tasmania, Australia. Sedimentology, 39(3), 393-410.

Flesche Kleiven, H., Jansen, E., Fronval, T., \& Smith, T. (2002). Intensification of Northern Hemisphere Glaciations in the Circum Atlantic Region (3.5-2.4 Ma) - Ice-Rafted Detritus Evidence. Palaeogeography, Palaeoclimatology, Palaeoecology, 184(3), 213-223.

Florindo, F., Bohaty, S., Erwin, P., Richter, C., Roberts, A., Whalen, P., \& Whitehead, J. (2003). Magnetobiostratigraphic Chronology and Palaeoenvironmental History of Cenozoic Sequences from ODP Sites 1165 and 1166, Prydz Bay, Antarctica. Palaeogeography, Palaeoclimatology, Palaeoecology, 198(1), 69-100.

Florindo, F., Wilson, G., Roberts, A., Sagnotti, L., \& Verosub, K. (2005). Magnetostratigraphic Chronology of a Late Eocene to Early Miocene Glacimarine Succession from the Victoria Land Basin, Ross Sea, Antarctica. Global and Planetary Change, 45(1-3), 207-236.

Flower, B., \& Kennett, J. (1993). Middle Miocene Ocean-Climate Transition: High-Resolution Oxygen and Carbon Isotopic Records from Deep Sea Drilling Project Site 588a, Southwest Pacific. Paleoceanography, 8(6), 811-843.

Flower, B., \& Kennett, J. (1994). The Middle Miocene Climatic Transition: East Antarctic Ice Sheet Development, Deep Ocean Circulation and Global Carbon Cycling. Palaeogeography, Palaeoclimatology, Palaeoecology, 108(3), 537-555.

Foster, G., Lear, C., \& Rae, J. (2012). The Evolution of $p \mathrm{CO}_{2}$, Ice Volume and Climate During the Middle Miocene. Earth and Planetary Science Letters, 341, 243-254.

Foster, G., \& Rohling, E. (2013). Relationship between Sea Level and Climate Forcing by $\mathrm{CO}_{2}$ on Geological Timescales. Proceedings of the National Academy of Sciences, 110(4), 1209-1214.

Fountain, A., Lyons, W., Burkins, M., Dana, G., Doran, P., Lewis, K., McKnight, D., Moorhead, D., Parsons, A., \& Priscu, J. (1999). Physical Controls on the Taylor Valley Ecosystem, Antarctica. Bioscience, 49(12), 961-971. 
Francis, J., Haywood, A., Ashworth, A., \& Valdes, P. (2007). Tundra environments in the Neogene Sirius Group, Antarctica: evidence from the geological record and coupled atmosphere-vegetation models. Journal of the Geological Society, London, 164, 1-6.

Francis, J., \& Hill, R. (1996). Fossil Plants from the Pliocene Sirius Group, Transantarctic Mountains: Evidence for Climate from Growth Rings and Fossil Leaves. PALAIOS, 11(4), 389-396.

Frenot, Y., Van Vliet-Lanoe, B., \& Gloaguen, J. (1995). Particle Translocation and Initial Soil Development on a Glacier Foreland, Kerguelen Islands, Subantarctic. Arctic, Antarctic, and Alpine Research, 27(2), 107-115.

Fretwell, P., Pritchard, H., Vaughan, D., Bamber, J., Barrand, N., Bell, R., Bianchi, C., Bingham, R., Blankenship, D., \& Casassa, G. (2013). Bedmap2: Improved Ice Bed, Surface and Thickness Datasets for Antarctica. The Cryosphere, 7(1), 375-393.

Galeotti, S., DeConto, R., Naish, T., Stocchi, P., Fabio, F., Pagani, M., Barrett, P., Bohaty, S., Lanci, L., Pollard, D., Sandroni, S., Talarico, F., \& Zachos, J. (2016). Antarctic Ice Sheet Variability across the Eocene-Oligocene Boundary Climate Transition. Science, 352.

Galeotti, S., DeConto, R., Naish, T., Stocchi, P., Florindo, F., Pagani, M., Barrett, P., Bohaty, S., Lanci, L., Pollard, D., Sandroni, S., Talarico, F., \& Zachos, J. (2016). Antarctic Ice Sheet Variability across the Eocene-Oligocene Boundary Climate Transition. Science, 352(6281), 76-80.

Gasson, E., DeConto, R., Pollard, D., \& Levy, R. (2016). Dynamic Antarctic Ice Sheet During the Early to Mid-Miocene. Proceedings of the National Academy of Sciences, 113(13), 3459-3464.

Geirsdottir, A., Hardardottir, J., \& Andrews, J. (2000). Late-Holocene terrestrial glacial history of Miki and I.C. Jacobsen Fjords, East Greenland. The Holocene, 10(1), 123-134.

Goff, J., Jennings, I., \& Dickinson, W. (2002). Depositional Environment of Sirius Group Sediments, Table Mountain, Dry Valleys Area, Antarctica. Geografiska Annalar, 84, $11-24$.

Gohl, K., Wellner, J., Klaus, A., Bauersachs, T., Bohaty, S., Courtillat, M., Cowan, E., Esteves, M., De Lira Mota, M., Fegyveresi, J., Frederichs, T., Gao, L., Halberstadt, A., Hillenbrand, C., Horikawa, K., Iwai, M., Kim, J., King, T., Klages, J., \& Yamane, M. (2019). Expedition 379 Preliminary Report Amundsen Sea West Antarctic Ice Sheet History.

Goldner, A., Herold, N., \& Huber, M. (2014). The Challenge of Simulating the Warmth of the Mid-Miocene Climatic Optimum in Cesm1. Climate of the Past.

Golledge, N., Levy, R., McKay, R., \& Naish, T. (2017). East Antarctic Ice Sheet Most Vulnerable to Weddell Sea Warming. Geophysical Research Letters, 44(5), 23432351.

Golledge, N., Marsh, O., Rack, W., Braaten, D., \& Selwyn Jones, R. (2014). Basal conditions of two Transantarctic Mountains outlet glaciers from observation-constrained diagnostic modelling. Journal of Glaciology, 60(223), 855-866. 
Goodge, J., Williams, I., \& Myrow, P. (2004). Provenance of Neoproterozoic and Lower Paleozoic Siliciclastic Rocks of the Central Ross Orogen, Antarctica: Detrital Record of Rift-, Passive- and Active-Margin Sedimentation. Geological Society of America Bulletin, 116.

Gradstein, F., Ogg, J., Schmitz, M., \& Ogg, G. (2012). The Geologic Time Scale. Elsevier.

Grant, G., Naish, T., Dunbar, G., Stocchi, P., Kominz, M., Kamp, P., Tapia, C., McKay, R., Levy, R., \& Patterson, M. (2019). The Amplitude and Origin of Sea-Level Variability During the Pliocene Epoch. Nature, 574(7777), 237-241.

Greenop, R., Foster, G., Wilson, P., \& Lear, C. (2014). Middle Miocene Climate Instability Associated with High Amplitude $\mathrm{CO}_{2}$ Variability. Paleoceanography, 29.

Greenop, R., Sosdian, S., Henehan, M., Wilson, P., Lear, C., \& Foster, G. (2019). Orbital Forcing, Ice Volume, and $\mathrm{CO}_{2}$ across the Oligocene-Miocene Transition. Paleoceanography and Paleoclimatology, 34(3), 316-328.

Gulick, S., Shevenell, A., Montelli, A., Fernandez, R., Smith, C., Warny, S., Bohaty, S., Sjunneskog, C., Leventer, A., Frederick, B., \& Blankenship, D. (2017). Initiation and Long-Term Instability of the East Antarctic Ice Sheet. Nature, 552(7684), 225-229.

Hall, B., Denton, G., \& Hendy, C. (2000). Evidence from Taylor Valley for a Grounded Ice Sheet in the Ross Sea, Antarctica. Geografiska Annaler: Series A, Physical Geography, 82(2-3), 275-303.

Hambrey, M. (1994). Glacial Environments. UBC Press.

Hambrey, M., Ehrmann, W., \& Larsen, B. (1991). Cenozoic Glacial Record of the Prydz Bay Continental Shelf, East Antarctica (Vol. 119).

Hambrey, M., \& Fitzsimons, S. (2010). Development of Sediment-Landform Associations at Cold Glacier Margins, Dry Valleys, Antarctica. Sedimentology, 57(3), 857-882.

Hambrey, M., \& Glasser, N. (1978). Glacial sediments: Processes, environments and facies. Sedimentology (pp. 513-531). Encyclopedia of Earth Science, Springer.

Hambrey, M., \& Glasser, N. (2012). Discriminating Glacier Thermal and Dynamic Regimes in the Sedimentary Record. Sedimentary Geology, 251-252, 1-33.

Hambrey, M., Glasser, N., McKelvey, B., Sugden, D., \& Fink, D. (2007). Cenozoic Landscape Evolution of an East Antarctic Oasis (Radok Lake Area, Northern Prince Charles Mountains), and Its Implications for the Glacial and Climatic History of Antarctica. Quaternary Science Reviews, 26, 598-626.

Hambrey, M., Krissek, L., Powell, R., Barrett, P., Camerlenghi, A., Claps, M., Ehrmann, W., Fielding, C., \& Howe, J. (1997). Cape Roberts Project Core Logging Manual: Coring for Antarctic Tectonic and Climatic History. Antarctic Research Centre, Victoria University of Wellington.

Hambrey, M., Webb, P., D, H., \& Krissek, L. (2003). Neogene Glacial Record from the Sirius Group of the Shackleton Glacier Area, Central Transantarctic Mountains, Antarctica. Geological Society of America Bulletin, 115, 994-1015.

Hamon, N., Sepulchre, P., Lefebvre, V., \& Ramstein, G. (2013). The Role of Eastern Tethys Seaway Closure in the Middle Miocene Climatic Transition (Ca. 14 Ma). Climate of the Past, 9(6), 2687-2702. 
Harrison, R., \& Feinberg, J. (2008). Forcinel: An Improved Algorithm for Calculating FirstOrder Reversal Curve Distributions Using Locally Weighted Regression Smoothing. Geochemistry Geophysics Geosystems, 9.

Hart, J. (1996). Proglacial Glaciotectonic Deformation Associated with Glaciolacustrine Sedimentation, Lake Pukaki, New Zealand. Journal of Quaternary Science, 11(2), 149-160.

Hart, J., \& Boulton, G. (1991). The Interrelation of Glaciotectonic and Glaciodepositional Processes within the Glacial Environment. Quaternary Science Reviews, 10(4), 335350.

Hauptvogel, D., \& Passchier, S. (2012). Early-Middle Miocene (17-14 Ma) Antarctic Ice Dynamics Reconstructed from the Heavy Mineral Provenance in the AND-2A Drill Core, Ross Sea, Antarctica. Global and Planetary Change, 82, 38-50.

Hayes, D., Frakes, L., Barrett, P., Burns, D., Chen, P., Ford, A., Kaneps, A., Kemp, E., McCollum, D., Piper, D., Wall, R., \& Webb, P. (1975). Site 274 - Initial Reports of the Deep Sea Drilling Project (Vol. 28).

Hays, J., Imbrie, J., \& Shackleton, N. (1976). Variations in the Earth's Orbit: Pacemaker of the Ice Ages. Science, 194(4270), 1121-1132.

Henrot, A., François, L., Favre, E., Butzin, M., Ouberdous, M., \& Munhoven, G. (2010). Effects of $\mathrm{CO}_{2}$, Continental Distribution, Topography and Vegetation Changes on the Climate at the Middle Miocene: A Model Study. Climate of the Past, 6(5), 675-694.

Herold, N., Huber, M., \& Müller, D. (2011). Modeling the Miocene Climatic Optimum. Part I: Land and Atmosphere. Journal of Climate, 24, 6353-6372.

Herold, N., Huber, M., Müller, D., \& Seton, M. (2012). Modeling the Miocene Climatic Optimum: Ocean Circulation. Paleoceanography, 27, 1209.

Herold, N., Seton, M., Müller, D., You, Y., \& Huber, M. (2008). Middle Miocene Tectonic Boundary Conditions for Use in Climate Models. Geochemistry Geophysics Geosystems, 9.

Herschel, J. (1832). I. The Conclusion of Sir J. Herschel's Paper on the Orbits of Binary Stars. Monthly Notices of the Royal Astronomical Society, 2(9), 51-54.

Hiemstra, J., \& van der Meer, J. (1997). Pore-Water Controlled Grain Fracturing as an Indicator for Subglacial Shearing in Tills. Journal of Glaciology, 43, 446-454.

Higgins, S., Denton, G., \& Hendy, C. (2000). Glacial Geomorphology of Bonney Drift, Taylor Valley, Antarctica. Geografiska Annaler: Series A, Physical Geography, 82(2-3), 365389.

Hill, R., Harwood, D., \& Webb, P. (1996). Nothofagus Beardmorensis (Nothofagaceae), a New Species Based on Leaves from the Pliocene Sirius Group, Transantarctic Mountains, Antarctica. Review of Palaeobotany and Palynology, 94(1), 11-24.

Hobbs, K., \& Parrish, J. (2016). Miocene Global Change Recorded in Columbia River Basalt Hosted Paleosols. Geological Society of America Bulletin, 128, 1543-1554.

Holbourn, A., Kuhnt, W., Clemens, S., Prell, W., \& Andersen, N. (2013). Middle to Late Miocene Stepwise Climate Cooling: Evidence from a High-Resolution Deep Water Isotope Curve Spanning 8 Million Years. Paleoceanography, 28. 
Holbourn, A., Kuhnt, W., Kochhann, K., Andersen, N., \& Meier, S. (2015). Global Perturbation of the Carbon Cycle at the Onset of the Miocene Climate Optimum. Geology, 43, G36317.1.

Holbourn, A., Kuhnt, W., Lyle, M., Levay, L., Romero, O., \& Andersen, N. (2014). Middle Miocene Climate Cooling Linked to Intensification of Eastern Equatorial Pacific Upwelling. Geology, 42, 19-22.

Holbourn, A., Kuhnt, W., Schulz, M., \& Erlenkeuser, H. (2005). Impacts of Orbital Forcing and Atmospheric $\mathrm{CO}_{2}$ on Miocene Ice-Sheet Expansion. Nature, 438, 483-7.

Holbourn, A., Kuhnt, W., Schulz, M., Flores, J., \& Andersen, N. (2007). Orbitally-Paced Climate Evolution During the Middle Miocene "Monterey" Carbon-Isotope Excursion. Earth and Planetary Science Letters, 261(3), 534-550.

Holdsworth, G., \& Bull, C. (1970). The flow law of cold ice: investigations on Meserve Glacier, Antarctica. Antarctic Glaciological Exploration (ISAGE), 86, 204-216.

Horton, B., \& Schmitt, J. (1996). Sedimentology of a Lacustrine Fan-Delta System, Miocene Horse Camp Formation, Nevada, USA. Sedimentology, 43(1), 133-155.

Huber, M., \& Nof, D. (2006). The Ocean Circulation in the Southern Hemisphere and Its Climatic Impacts in the Eocene. Palaeogeography, Palaeoclimatology, Palaeoecology, 231(1), 9-28.

Huybers, P. (2010). Early Pleistocene Glacial Cycles and the Integrated Summer Insolation Forcing. Science, 313(5786), 508-511.

Huybers, P., \& Aharonson, O. (2010). Orbital Tuning, Eccentricity, and the Frequency Modulation of Climatic Precession. Paleoceanography, 25(4).

Imbrie, J., Hays, J., Martinson, D., McIntyre, A., Mix, A., Morley, J., Pisias, N., Prell, W., $\&$ Shackleton, N. (1984). The orbital theory of Pleistocene climate: support from a revised chronology of the marine $\delta^{18} \mathrm{O}$ record. Milankovitch and Climate (pp. 269305). D. Reidel Publishing Company.

Jansen, E., Fronval, T., Rack, F., \& Channell, J. E. T. (2000). Pliocene-Pleistocene Ice Rafting History and Cyclicity in the Nordic Seas During the Last 3.5 Myr. Paleoceanography, 15(6), 709-721.

Ji, S., Nie, J., Lechler, A., Huntington, K., Heitmann, E., \& Breecker, D. (2018). A Symmetrical $\mathrm{CO}_{2}$ Peak and Asymmetrical Climate Change During the Middle Miocene. Earth and Planetary Science Letters, 499, 134-144.

John, C., Karner, G., Browning, E., Leckie, M., Mateo, Z., Carson, B., \& Lowery, C. (2011). Timing and Magnitude of Miocene Eustasy Derived from the Mixed SiliciclasticCarbonate Stratigraphic Record of the Northeastern Australian Margin. Earth and Planetary Science Letters, 304.

Jovane, L., Fabio, F., Acton, G., Ohneiser, C., Sagnotti, L., Strada, E., Verosub, K., Wilson, G., Iacoviello, F., Levy, R., \& Passchier, S. (2019). Miocene Glacial Dynamics Recorded by Variations in Magnetic Properties in the ANDRILL-2A Drill Core. Journal of Geophysical Research: Solid Earth, 124.

Joynt, E., \& Wolfe, A. (2001). Paleoenvironmental Inference Models from Sediment Diatom Assemblages in Baffin Island Lakes (Nunavut, Canada) and Reconstruction of Sum- 
mer Water Temperature. Canadian Journal of Fisheries and Aquatic Sciences, 58, 1222-1243.

Judd, F. (1986). The Chronology of the Ross Sea Ii Glaciation, an Antarctic Glaciation of Illinoian Age (Thesis).

Kaplan, J., Bigelow, N., Prentice, I., Harrison, S., Bartlein, P., Christensen, T., Cramer, W., Matveyeva, N., McGuire, A., Murray, D., Razzhivin, V., Smith, B., Walker, D., Anderson, P., Andreev, A., Brubaker, L., Edwards, M., \& Lozhkin, A. (2003). Climate Change and Arctic Ecosystems: 2. Modeling, Paleodata-Model Comparisons, and Future Projections. Journal of Geophysical Research: Atmospheres, 108(19).

Kasbohm, J., \& Schoene, B. (2018). Rapid eruption of the Columbia River flood basalt and correlation with the mid-Miocene climate optimum. Science Advances, 4(9).

Kellogg, T., \& Kellogg, D. (2002). Non Marine Diatoms from Antarctic and Subantarctic Regions. Distributions and Updated Taxonomy. Ganter Verlag.

Kennett, J. (1977). Cenozoic Evolution of Antarctic Glaciation, the Circum-Antarctic Ocean, and Their Impact on Global Paleoceanography. Journal of Geophysical Research, 82(27), 3843-3860.

Kennett, J., \& Exon, N. (2004). Paleoceanographic evolution of the tasmanian seaway and its climatic implications. In N. Exon, J. Kennett, \& M. Malone (Eds.), Geophysical monograph series (pp. 345-367). https://doi.org/10.1029/151GM19

Kennett, J., \& Shackleton, N. (1976). Oxygen Isotopic Evidence for the Development of the Psychrosphere 38 Myr Ago. Nature, 260(5551), 513-515.

Kerr, A., \& Huybrechts, P. (1999). The Response of the East Antarctic Ice-Sheet to the Evolving Tectonic Configuration of the Transantarctic Mountains. Global and Planetary Change, 23(1), 213-229.

Kerr, A., \& Sugden, D. (1994). The Sensitivity of the South Chilean Snowline to Climatic Change. Climatic Change, 28, 255-272.

Kim, S., De Santis, L., Hong, J., Cottlerle, D., Petronio, L., Colizza, E., Kim, Y., Kang, S., Kim, H., Kim, S., Wardell, N., Geletti, R., Bergamasco, A., McKay, R., Jin, Y., \& Kang, S. (2018). Seismic stratigraphy of the Central Basin in northwestern Ross Sea slope and rise, Antarctica: Clues to the late Cenozoic ice-sheet dynamics and bottomcurrent activity. Marine Geology, 395, 363-379.

Kirschvink, J. (1980). The Least-Squares Line and Plane and the Analysis of Palaeomagnetic Data. Geophysical Journal International, 62(3), 699-718.

Kominz, M., Browning, J., Miller, K., Sugarman, P., Mizintseva, S., \& Scotese, C. (2008). Late Cretaceous to Miocene Sea-Level Estimates from the New Jersey and Delaware Coastal Plain Coreholes: An Error Analysis. Basin Research, 20, 211-226.

Kominz, M., Miller, K., Browning, J., Katz, M., \& Mountain, G. (2016). Miocene Relative Sea Level on the New Jersey Shallow Continental Shelf and Coastal Plain Derived from One-Dimensional Backstripping: A Case for Both Eustasy and Epeirogeny. Geosphere, 12(5), 1437-1456.

Krapp, M., \& Jungclaus, J. (2011). The Middle Miocene Climate as Modelled in an Atmosphere-Ocean-Biosphere Model. Climate of the Past, 7(4), 1169-1188. 
Kuiper, K., Deino, A., Hilgen, F., Krijgsman, W., Renne, P., \& Wijbrans, J. (2008). Synchronizing Rock Clocks of Earth History. Science, 320, 500-4.

Kulhanek, D., Levy, R., Clowes, C., Prebble, J., Rodelli, D., Jovane, L., Morgans, H., Kraus, C., Zwingmann, H., Griffith, E., Scher, H., McKay, R., \& Naish, T. (2019). Revised Chronostratigraphy of DSDP Site 270 and Late Oligocene to Early Miocene Paleoecology of the Ross Sea Sector of Antarctica. Global and Planetary Change, 178.

Kürschner, W., Kvaček, Z., \& Dilcher, D. (2008). The Impact of Miocene Atmospheric Carbon Dioxide Fluctuations on Climate and the Evolution of Terrestrial Ecosystems. Proceedings of the National Academy of Sciences, 105(2), 449-453.

Kyle, P. (1990). A. McMurdo Volcanic Group Western Ross Embayment. In T. J. Lemasurier W.E. (Ed.), Volcanoes of the Antarctic Plate and Southern Oceans (pp. 18-145). Antarctic Research Series.

Langebroek, P., Paul, A., \& Schulz, M. (2009). Antarctic Ice-Sheet Response to Atmospheric $\mathrm{CO}_{2}$ and Insolation in the Middle Miocene. Climate of The Past, 5, 633-646.

Laskar, J., Fienga, A., Gastineau, M., \& Manche, H. (2011). La2010: A New Orbital Solution for the Long-Term Motion of the Earth. Astronomy and Astrophysics, 532, 89.

Lawson, D. (1979). A Comparison of the Pebble Orientations in Ice and Deposits of the Matanuska Glacier, Alaska. Journal of Geology, 87, 629-645.

Le Maitre, R., Bateman, P., Dudek, A., Keller, J., Lameyre, J., Le Bas, M., Sabine, P., Schmid, R., Sorensen, H., Streckeisen, A., Woolley, A., \& Zanettin, B. (1989). A Classification of Igneous Rocks and a Glossary of Terms (Vol. 1). Blackwell Scientific.

Lear, C., Bailey, T., Pearson, P., Coxall, H., \& Rosenthal, Y. (2008). Cooling and Ice Growth across the Eocene-Oligocene Transition. Geology, 36.

Lear, C., Coxall, H., Foster, G., Lunt, D., Mawbey, E., Rosenthal, Y., Sosdian, S., Thomas, E., \& Wilson, P. (2015). Neogene Ice Volume and Ocean Temperatures: Insights from Infaunal Foraminiferal $\mathrm{Mg} / \mathrm{Ca}$ Paleothermometry. Paleoceanography, 30 .

Lear, C., Elderfield, H., \& Wilson, P. (2000). Cenozoic deep-sea temperatures and global ice volumes from $\mathrm{Mg} / \mathrm{Ca}$ in benthic foraminiferal calcite. Science, 287, 269-272.

Lear, C., Mawbey, E., \& Rosenthal, Y. (2010). Cenozoic Benthic Foraminiferal Mg/Ca and Li/Ca Records: Toward Unlocking Temperatures and Saturation States. Paleoceanography, 25.

Lee, J., Marti, K., Severinghaus, J., Kawamura, K., Yoo, H., Lee, J. B., \& Kim, J. (2006). A Redetermination of the Isotopic Abundances of Atmospheric Ar. Geochimica et Cosmochimica Acta, 70(17), 4507-4512.

Levy, R., Cody, R., Crampton, J., Fielding, C., Golledge, N., Harwood, D., Henrys, S., McKay, R., Naish, T., Ohneiser, C., Wilson, G., Wilson, T., \& Winter, D. (2012). Late Neogene Climate and Glacial History of the Southern Victoria Land Coast from Integrated Drill Core, Seismic and Outcrop Data. Global and Planetary Change, 80-81, 61-84.

Levy, R., Harwood, D., Fabio, F., Sangiorgi, F., Tripati, R., Eynatten, H., Gasson, E., Kuhn, G., Tripati, A., DeConto, R., Fielding, C., Field, B., Golledge, N., McKay, R., Naish, T., Olney, M., Pollard, D., Schouten, S., Talarico, F., \& Zattin, M. (2016). Antarctic 
Ice Sheet Sensitivity to Atmospheric $\mathrm{CO}_{2}$ Variations in the Early to Mid-Miocene. Proceedings of the National Academy of Sciences.

Levy, R., Meyers, S., Naish, T., Golledge, N., McKay, R., Crampton, J., DeConto, R., De Santis, L., Florindo, F., Gasson, E., Harwood, D., Luyendyk, B., Powell, R., Clowes, C., \& Kulhanek, D. (2019). Antarctic Ice-Sheet Sensitivity to Obliquity Forcing Enhanced through Ocean Connections. Nature Geoscience, 12(2), 132-137.

Lewis, A., \& Ashworth, A. (2015). An Early to Middle Miocene Record of Ice-Sheet and Landscape Evolution from the Friis Hills, Antarctica. Geological Society of America Bulletin, 128(5-6), 719-738.

Lewis, A., Marchant, D., Ashworth, A., Hedenäs, L., Hemming, S., Johnson, J., Leng, M., Machlus, M., Newton, A., \& Raine, J. (2008). Mid-Miocene Cooling and the Extinction of Tundra in Continental Antarctica. Proceedings of the National Academy of Sciences, 105(31), 10676-10680.

Lewis, A., Marchant, D., Ashworth, A., Hemming, S., \& Machlus, M. (2007). Major Middle Miocene Global Climate Change: Evidence from East Antarctica and the Transantarctic Mountains. Geological Society of America Bulletin, 119.

Lewis, A., Marchant, D., Kowalewski, D., Baldwin, S., \& Webb, L. (2006). The Age and Origin of the Labyrinth, Western Dry Valleys, Antarctica: Evidence for Extensive Middle Miocene Subglacial Floods and Freshwater Discharge to the Southern Ocean. Geology, 34.

Liebrand, D., Beddow, H., Lourens, L., Pälike, H., Raffi, I., Bohaty, S., Hilgen, F., Saes, M., Wilson, P., van Dijk, A., Hodell, D., Kroon, D., Huck, C., \& Batenburg, S. (2016). Cyclostratigraphy and Eccentricity Tuning of the Early Oligocene through Early Miocene (30.1-17.1 Ma): Cibicides Mundulus Stable Oxygen and Carbon Isotope Records from Walvis Ridge Site 1264. Earth and Planetary Science Letters, 450, 392-405.

Liebrand, D., de Bakker, A., Beddow, H., Wilson, P., Bohaty, S., Ruessink, G., Pälike, H., Batenburg, S., Hilgen, F., Hodell, D., Huck, C., Kroon, D., Raffi, I., Saes, M., van Dijk, A., \& Lourens, L. (2017). Evolution of the Early Antarctic Ice Ages. Proceedings of the National Academy of Sciences, 201615440.

Liebrand, D., Lourens, L., Hodell, D., De Boer, B., Wal, R., \& Paelike, H. (2011). Antarctic Ice Sheet and Oceanographic Response to Eccentricity Forcing During the Early Miocene. Climate of the Past, 7, 869-880.

Lisiecki, L., \& Raymo, M. (2005). A Pliocene-Pleistocene Stack of 57 Globally Distributed Benthic $\delta^{18}$ O Records. Paleoceanography, 20(1).

Lisker, F. (2002). Review of Fission Track Studies in Northern Victoria Land, Antarctica-Passive Margin Evolution Versus Uplift of the Transantarctic Mountains. Tectonophysics, 349(1), 57-73.

Lisker, F., \& Läufer, A. (2013). The Mesozoic Victoria Basin: Vanished Link between Antarctica and Australia. Geology, 41(10), 1043-1046.

Lisker, F., Prenzel, J., Läufer, A., \& Spiegel, C. (2014). Recent Thermochronological Research in Northern Victoria Land, Antarctica. Polarforschung, 84(1), 59-66. 
Lurcock, P., \& Wilson, G. (2012). Puffinplot: A Versatile, User-Friendly Program for Paleomagnetic Analysis. Geochemistry, Geophysics, Geosystems, 13.

Luthi, D., Le Floch, M., Bereiter, B., Blunier, T., Barnola, J., Siegenthaler, U., Raynaud, D., Jouzel, J., Fischer, H., Kawamura, K., \& Stocker, T. (2008). High-resolution carbon dioxide concentration record 650,000-800,000 years before present. Nature, 379-382.

Lüthi, D., Le Floch, M., Bereiter, B., Blunier, T., Barnola, J., Siegenthaler, U., Raynaud, D., Jouzel, J., Fischer, H., Kawamura, K., \& Stocker, T. (2008). High-Resolution Carbon Dioxide Concentration Record 650,000-800,000Years before Present. Nature, 453(7193), 379-382.

Marchant, D., Denton, G., Sugden, D., \& Swisher, C. (1993). Miocene Glacial Stratigraphy and Landscape Evolution of the Western Asgard Range, Antarctica. Geografiska Annaler. Series A, Physical Geography, 75(4), 303-330.

Marchant, D., Denton, G., Swisher, C., \& Potter, N. (1996). Late Cenozoic Antarctic Paleoclimate Reconstructed from Volcanic Ashes in the Dry Valleys Region of Southern Victoria Land. Geological Society of America Bulletin, 108(2), 181-194.

Martin, A., Cooper, A., \& Dunlap, W. (2010). Geochronology of Mount Morning, Antarctica: Two-Phase Evolution of a Long-Lived Trachyte-Basanite-Phonolite Eruptive Center. Bulletin of Volcanology, 72(3), 357-371.

Martínez-Garcia, A., Rosell-Melé, A., Geibert, W., Gersonde, R., Masqué, P., Gaspari, V., \& Barbante, C. (2009). Links between Iron Supply, Marine Productivity, Sea Surface Temperature, and $\mathrm{CO}_{2}$ over the Last 1.1 Ma. Paleoceanography, 24(1).

Maslin, M. A., Haug, G. H., Sarnthein, M., \& Tiedemann, R. (1996). The Progressive Intensification of Northern Hemisphere Glaciation as Seen from the North Pacific. Geologische Rundschau, 85(3), 452-465.

McCabe, A., \& Eyles, N. (1988). Sedimentology of an Ice-Contact Glaciomarine Delta, Carey Valley, Northern Ireland. Sedimentary Geology, 59(1), 1-14.

McCarroll, D., \& Harris, C. (1992). The glacigenic deposits of Western Lleyn, North Wales: Terrestrial or marine? Journal of Quaternary Science, 7(1), 19-29.

McKay, R., Barrett, P., Harper, M., \& Hanah, M. (2008). Atmospheric transport and concentration of diatoms in surficial and glacial sediments of the Allan Hills, Transantarctic Mountains. Palaeogeography, Palaeoclimatology, Palaeoecology, 270(1-2).

McKay, R., Browne, G., Carter, L., Cowan, E., Dunbar, G., Krissek, L., Naish, T., Powell, R., Reed, J., Talarico, F., \& Wilch, T. (2009). The Stratigraphic Signature of the Late Cenozoic Antarctic Ice Sheets in the Ross Embayment. Geological Society of America Bulletin, 121.

McKay, R., Naish, T., Carter, L., Riesselman, C., Dunbar, R., Sjunneskog, C., Winter, D., Sangiorgi, F., Warren, C., Pagani, M., Schouten, S., Willmott, V., Levy, R., DeConto, R., \& Powell, R. (2012). Antarctic and Southern Ocean Influences on Late Pliocene Global Cooling. Proceedings of the National Academy of Sciences, 109(17), 64236428.

McKay, R., Santis, L., Kulhanek, D., Ash, J., Beny, F., Browne, I., Cortese, G., Sousa, I., Dodd, J., Esper, O., Gales, J., Harwood, D., Ishino, S., Keisling, B., Kim, S., Laberg, 
J., Leckie, M., Müller, J., Patterson, M., ... Xiong, Z. (2019). Site U1521. In R. McKay, L. De Santis, D. Kulhanek, Scientists, \& the Expedition 374 (Eds.), Ross Sea West Antarctic Ice Sheet History. Proceedings of the International Ocean Discovery Program, 374.

Mengel, M., \& Levermann, A. (2014). Ice Plug Prevents Irreversible Discharge from East Antarctica. Nature Climate Change, 4(6), 451-455.

Menviel, L., Spence, P., Yu, J., Chamberlain, M., Matear, R., Meissner, K., \& England, M. (2018). Southern Hemisphere Westerlies as a Driver of the Early Deglacial Atmospheric $\mathrm{CO}_{2}$ Rise. Nature Communications, 9(1), 2503.

Menzies, J. (1989). Drumlins-products of controlled or uncontrolled glaciodynamic response? Journal of Glaciology, 8(2), 151-158.

Miall, A. (1977). Lithofacies Types and Vertical Profile Models in Braided River Deposits: A Summary. Dallas Geological Society.

Mienert, J., Andrews, J., \& Milliman, J. (1992). The East Greenland continental margin $(65 \mathrm{~N})$ since the last deglaciation: Changes in seafloor properties and ocean circulation. Marine Geology, 106(3-4), 217-238.

Mildenhall, D. (1989). Antarctic Cenozoic history from the CIROS-1 drillhole (Vol. 425). DSIR Publishing.

Miller, J. (1989). Glacial Advance and Retreat Sequences in a Permo-Carboniferous Section, Central Transantarctic Mountains. Sedimentology, 36(3), 419-430.

Miller, K., Browning, J., Schmelz, W., Kopp, R., Mountain, G., \& Wright, J. (2020). Cenozoic Sea-Level and Cryospheric Evolution from Deep-Sea Geochemical and Continental Margin Records. Science Advances, 6(20).

Miller, K., Kominz, M., Browning, J., Wright, J., Mountain, G., Katz, E., Sugarman, P., Cramer, B., Christie-Blick, N., \& Pekar, S. (2005). The Phanerozoic Record of Global Sea-Level Change. science, 310(5752), 1293-1298.

Miller, S., Fitzgerald, P., \& Baldwin, S. (2010). Cenozoic Range-Front Faulting and Development of the Transantarctic Mountains near Cape Surprise, Antarctica: Thermochronologic and Geomorphologic Constraints. Tectonics, 29.

Min, K., Mundil, R., Renne, P., \& Ludwig, K. (2000). A Test for Systematic Errors in ${ }^{40} \mathrm{Ar} /{ }^{39} \mathrm{Ar}$ Geochronology through Comparison with U/Pb Analysis of a 1.1ga Rhyolite. Geochimica Et Cosmochimica Acta, 64, 73-98.

Moncrieff, A. (1989). Classification of Poorly-Sorted Sedimentary Rocks. Sedimentary Geology, 65(1-2), 191-194.

Morlighem, M., Rignot, E., Binder, T., Blankenship, D., Drews, R., Eagles, G., Eisen, O., Ferraccioli, F., Forsberg, R., Fretwell, P., Goel, V., Greenbaum, J., Gudmundsson, H., Guo, J., Helm, V., Hofstede, C., Howat, I., Humbert, A., Jokat, W., .. Young, D. (2019). Deep Glacial Troughs and Stabilizing Ridges Unveiled beneath the Margins of the Antarctic Ice Sheet. Nature Geoscience, 13(2), 132-137.

Mosbrugger, V., Utescher, T., \& Dilcher, D. (2005). Cenozoic Continental Climatic Evolution of Central Europe. Proceedings of the National Academy of Sciences of the United States of America, 102(42), 14964-14969. 
Mudelsee, M., \& Raymo, M. (2005). Slow Dynamics of the Northern Hemisphere Glaciation. Paleoceanography, 20(4).

Naish, T., Barrett, P., Dunbar, G., Woolfe, K., Dunn, A., Henrys, S., Claps, M., Powell, R., \& Fielding, C. (2001b). Sedimentary Cyclicity in CRP Drillcore, Victoria Land Basin, Antarctica. Terra Antart., 8.

Naish, T., Powell, R., Levy, R., Wilson, G., Scherer, R., Talarico, F., Krissek, L., Niessen, F., Pompilio, M., Wilson, T., Carter, L., DeConto, R., Huybers, P., McKay, R., Pollard, D., Ross, J., Winter, D., Barrett, P., Browne, G., \& Williams, T. (2009). Obliquity-Paced Pliocene West Antarctic Ice Sheet Oscillations. Nature, 458, 322-8.

Naish, T., Powell, R., Levy, R., Henrys, S., Krissek, L., Niessen, F., Pompilio, M., Scherer, R., \& Wilson, G. (2007). Synthesis of the Initial Scientific Results of the MIS Project (AND-1B Core), Victoria Land Basin, Antarctica. Terra Antarctica, 14(3), 317-333.

Naish, T., Wilson, G., Dunbar, G., \& Barrett, P. (2008). Constraining the Amplitude of Late Oligocene Bathymetric Changes in Western Ross Sea During Orbitally-Induced Oscillations in the East Antarctic Ice Sheet: (2) Implications for Global Sea-Level Changes. Palaeogeography, Palaeoclimatology, Palaeoecology, 260(1), 66-76.

Naish, T., Woolfe, K., Barrett, P., Wilson, G., Atkins, C., Bohaty, S., Buecker, C., Claps, M., Davey, F., Dunbar, G., Dunn, A., Fielding, C., Fabio, F., Hannah, M., Harwood, D., Henrys, S., Krissek, L., Lavelle, M., Meer, J., \& Wonik, T. (2001a). Orbitally Induced Oscillations in the East Antarctic Ice Sheet at the Oligocene/Miocene Boundary. Nature, 413, 719-723.

Nemec, W. (1990). Aspects of Sediment Movement on Steep Delta Slopes. Coarse-Grained Deltas (pp. 29-73).

Nemec, W., \& Steele, R. (1984). Alluvial and Coastal Conglomerates and Some Comments on Gravelly Mass-Flow Deposits. (Vol. 10). Canada Society Peroleum Geologists.

Nyland, R., Panter, K., Rocchi, S., Di Vincenzo, G., Del Carlo, P., Tiepolo, M., Field, B., \& Gorsevski, P. (2013). Volcanic Activity and Its Link to Glaciation Cycles: SingleGrain Age and Geochemistry of Early Miocene Volcanic Glass from Andrill AND-2A Core. Journal of Volcanology and Geothermal Research, 250, 106-128.

O’Brien, P., \& Harris, P. (1996). Patterns of Glacial Erosion and Deposition in Prydz Bay and the Past Behaviour of the Lambert Glacier. Papers and Proceedings of the Royal Society of Tasmania, 130.

Oerlemans, J. (2002). On Glacial Inception and Orography. Quaternary International, 95, $5-10$.

Ohneiser, C., Wilson, G., Beltran, C., Dolan, A., Hill, D., \& Prebble, J. (2020). Warm Fjords and Vegetated Landscapes in Early Pliocene East Antarctica. Earth and Planetary Science Letters, 534, 116045.

Orsi, A., \& Wiederwohl, C. (2009). A recount of Ross Sea waters. Deep Sea Research Part II: Topical Studies in Oceanography, 56(13-14), 778-795.

Pälike, H., Norris, R., Herrle, J., Wilson, P., Coxall, H., Lear, C., Shackleton, N., Tripati, A., \& Wade, B. (2006). The Heartbeat of the Oligocene Climate System. Science, 314(5807), 1894-1898. 
Parish, T., \& Bromwich, D. (1987). The Surface Windfield over the Antarctic Ice Sheets. Nature, 328(6125), 51-54.

Passchier, S., Bohaty, S., Jiménez-Espejo, F., Pross, J., Röhl, U., van de Flierdt, T., Escutia, C., \& Brinkhuis, H. (2013). Early Eocene to Middle Miocene Cooling and Aridification of East Antarctica. Geochemistry, Geophysics, Geosystems, 14(5), 1399-1410.

Passchier, S., Browne, G., Field, B., Fielding, C., Krissek, L., Panter, K., Pekar, S., Team, \& Science, A.-S. (2011). Early and Middle Miocene Antarctic Glacial History from the Sedimentary Facies Distribution in the and-2a Drill Hole, Ross Sea, Antarctica. GSA Bulletin, 123(11-12), 2352-2365.

Passchier, S., Falk, C., \& Florindo, F. (2013). Orbitally Paced Shifts in the Particle Size of Antarctic Continental Shelf Sediments in Response to Ice Dynamics During the Miocene Climatic Optimum. Geosphere, 9(1), 54-62.

Patterson, M., \& Ishman, S. (2012). Neogene Benthic Foraminiferal Assemblages and Paleoenvironmental Record for McMurdo Sound, Antarctica. Geosphere, 8(6), 13311341.

Patterson, M., McKay, R., Naish, T., Escutia, C., Jimenez-Espejo, F., Raymo, M., Meyers, S., Tauxe, L., Brinkhuis, H., Klaus, A., Fehr, A., Bendle, J., Bijl, P., Bohaty, S., Carr, S., Dunbar, R., Flores, J., Gonzalez, J., Hayden, T., ... Scientists, I. E. 3. (2014). Orbital Forcing of the East Antarctic Ice Sheet During the Pliocene and Early Pleistocene. Nature Geoscience, 7(11), 841-847.

Pattyn, F. (2010). Antarctic subglacial conditions inferred from a hybrid ice sheet/ice stream model. Earth and Planetary Science Letters, 295, 451-461.

Paxman, G., Jamieson, S., Ferraccioli, F., Bentley, M., Ross, N., Watts, A., Leitchenkov, G., Armadillo, E., \& Young, D. (2019a). The Role of Lithospheric Flexure in the Landscape Evolution of the Wilkes Subglacial Basin and Transantarctic Mountains, East Antarctica. Journal of Geophysical Research: Earth Surface, 124(3), 812-829.

Paxman, G., Jamieson, S., Hochmuth, K., Gohl, K., Bentley, M., Leitchenkov, G., \& Ferraccioli, F. (2019b). Reconstructions of Antarctic Topography since the Eocene-Oligocene Boundary. Palaeogeography, Palaeoclimatology, Palaeoecology, 535, 109346.

Pearson, P. (2012). Oxygen Isotopes in Foraminifera: Overview and Historical Review. The Paleontological Society Papers, 18, 1-38.

Pearson, P., \& Palmer, M. (2000). Atmospheric carbon dioxide concentrations over the past 60 million years. Nature, 406, 695-699.

Pekar, S., \& DeConto, R. (2006). High-Resolution Ice-Volume Estimates for the Early Miocene: Evidence for a Dynamic Ice Sheet in Antarctica. Palaeogeography, Palaeoclimatology, Palaeoecology, 231, 101-109.

Pierce, E., van de Flierdt, T., Williams, T., Hemming, S., Cook, C. P., \& Passchier, S. (2017). Evidence for a Dynamic East Antarctic Ice Sheet During the Mid-Miocene Climate Transition. Earth and Planetary Science Letters, 478, 1-13.

Plint, A. (1988). Sharp-Based Shoreface Sequences and Offshore Bars in the Cardium Formation of Alberta; Their Relationship to Relative Changes in Sea Level. (Vol. 42). SEPM Special Publication. 
Pollard, D., \& DeConto, R. (2009). Modelling West Antarctic Ice Sheet Growth and Collapse through the Past Five Million Years. Nature, 458(7236), 329-332.

Pollard, D., DeConto, R., \& Alley, R. (2015). Potential Antarctic Ice Sheet Retreat Driven by Hydrofracturing and Ice Cliff Failure. Earth and Planetary Science Letters, 412, 112-121.

Poole, I., Cantrill, D., \& Utescher, T. (2005). A Multi-Proxy Approach to Determine Antarctic Terrestrial Palaeoclimate During the Late Cretaceous and Early Tertiary. Palaeogeography, Palaeoclimatology, Palaeoecology, 222, 95-121.

Porter, S., \& Beget, J. (1981). Provenance and Depositional Environments of Late Cenozoic Sediments in Permafrost Cores from Lower Taylor Valley, Antarctica (Vol. 33).

Postma, G. (1986). Classification for Sediment Gravity-Flow Deposits Based on Flow Conditions During Sedimentation. Geology, 14(4), 291-294.

Prebble, J., Raine, J., PJ, B., \& MJ, H. (2006). Vegetation and Climate from Two Oligocene Glacioeustatic Sedimentary Cycles (31 and $24 \mathrm{Ma}$ ) Cored by the Cape Roberts Project, Victoria Land Basin, Antarctica. Palaeogeography, Palaeoclimatology, Palaeoecology, 231(1-2), 41-57.

Prebble, J., Reichgelt, T., Mildenhall, D., Greenwood, D., Raine, J., Kennedy, E., \& Seebeck, H. (2017). Terrestrial Climate Evolution in the Southwest Pacific over the Past 30 Million Years. Earth and Planetary Science Letters, 459, 136-144.

Prentice, M., \& Matthews, R. (1991). Tertiary Ice Sheet Dynamics: The Snow Gun Hypothesis. Journal of Geophysical Research: Solid Earth, 96(4), 6811-6827.

Prentice, M., Kleman, J., \& Stroeven, A. (1998). The Composite Glacial Erosional Landscape of the Northern McMurdo Dry Valleys: Implications for Antarctic Tertiary Glacial History. In J. Priscu (Ed.), Ecosystem Dynamics in a Polar Desert: The McMurdo Dry Valleys, Antarctica (pp. 1-38).

Pross, J., Contreras, L., Bijl, P., Greenwood, D., Bohaty, S., Schouten, S., Bendle, J., Rohl, U., Tauxe, L., Raine, I., Huck, C., van de Flierdt, T., Jamieson, S., Stickley, C., van de Schootbrugge, B., Escutia, C., Brinkhuis, H., \& Scientists, I. O. D. P. E. 3. (2012). Persistent near-tropical warmth on the Antarctic continent during the early Eocene epoch. Nature, 488, 73-77.

Raine, J. (1998). Terrestrial Palynomorphs from Cape Roberts Project Drillhole CRP-1, Ross Sea, Antarctica. Terra Antarctica, 5(3), 539-548.

Raitzsch, M., Bijma, J., Bickert, T., Schulz, M., Holbourn, A., \& Kučera, M. (2020, in review). Eccentricity-Paced Atmospheric Carbon-Dioxide Variations across the Middle Miocene Climate Transition. Climate of the Past, 1-22.

Raymo, M. (1991). Geochemical Evidence Supporting T. C. Chamberlin's Theory of Glaciation. Geology, 19(4), 344-347.

Raymo, M., \& Huybers, P. (2008). Unlocking the mysteries of the ice ages. Nature, 451, 284-285.

Raymo, M., \& Ruddiman, W. (1992). Tectonic Forcing of Late Cenozoic Climate. Nature, 359(6391), 117-122.

Retallack, G. (2009). Greenhouse Crises of the Past 300 Million Years. Geological Society of America Bulletin, 121, 1441-1455. 
Rimet, F., Feret, L., Bouchez, A., Dorioz, J., \& Dambrine, E. (2019). Factors Influencing the Heterogeneity of Benthic Diatom Communities Along the Shoreline of Natural Alpine Lakes. Hydrobiologia, 839(1), 103-118.

Roberto, A., Carlo, P., Rocchi, S., \& Panter, K. (2012). Early Miocene Volcanic Activity and Paleoenvironment Conditions Recorded in Tephra Layers of the AND-2A Core (Southern McMurdo Sound, Antarctica). Geosphere, 8(6), 1342-1355.

Roberts, A., Heslop, D., Zhao, X., \& Pike, C. (2014). Understanding Fine Magnetic Particle Systems through Use of First-Order Reversal Curve (Forc) Diagrams. Reviews of Geophysics, 52.

Roberts, A., Pike, C., \& Verosub, K. (2000). First-Order Reversal Curve Diagrams: A New Tool for Characterizing the Magnetic Properties of Natural Samples. Journal of Geophysical Research, 105, 28461-28476.

Roberts, A., Wilson, G., Harwood, D., \& Verosub, K. (2003). Glaciation across the OligoceneMiocene Boundary in Southern McMurdo Sound, Antarctica: New Chronology from the CIROS-1 Drill Hole. Palaeogeography, Palaeoclimatology, Palaeoecology, 198(12), 113-130.

Rott, H., Stuefer, M., Siegel, A., Skvarca, P., \& Eckstaller, A. (1998). Mass Fluxes and Dynamics of Moreno Glacier, Southern Patagonia Icefield. Geophysical Research Letters, 25(9), 1407-1410.

Royer, D., Berner, R., \& Beerling, D. (2001). Phanerozoic Atmospheric $\mathrm{CO}_{2}$ Change: Evaluating Geochemical and Paleobiological Approaches. Earth-Science Reviews, 54, 349-392.

Ruddiman, W. (2014). Earth's Climate Past and Future (3rd ed.). W.H. Freeman.

Sakai, A., Paton, D., \& Wardle, P. (1981). Freezing Resistance of Trees of the South Temperate Zone, Especially Subalpine Species of Australasia. Ecology, 62(3), 563-570.

Sangiorgi, F., Bijl, P., Passchier, S., Salzmann, U., Schouten, S., McKay, R., Cody, R., Pross, J., Flierdt, T., Bohaty, S., Levy, R., Williams, T., Escutia, C., \& Brinkhuis, H. (2018). Southern Ocean Warming and Wilkes Land Ice Sheet Retreat During the Mid-Miocene. Nature Communications, 9(317).

Scherer, R., DeConto, R., Pollard, D., \& Alley, R. (2016). Windblown Pliocene Diatoms and East Antarctic Ice Sheet Retreat. Nature Communications, 7(1), 12957.

Schnitker, D. (1980). North Atlantic Oceanography as Possible Cause of Antarctic Glaciation and Eutrophication. Nature, 284(5757), 615-616.

Shackleton, N., Berger, A., \& Peltier, W. (1990). An Alternative Astronomical Calibration of the Lower Pleistocene Timescale Based on ODP Site 677. Transactions of the Royal Society of Edinburgh: Earth Sciences, 81(4), 251-261.

Shackleton, N., Hall, M., \& Pate, D. (1995). Pliocene Stable Isotope Stratigraphy of Site 846. In N. Pisias, L. Mayer, T. Janecek, A. Palmer-Julson, \& T. van Andel (Eds.), Proceedings of the Ocean Drilling Program, Scientific Results (pp. 337-355).

Shanmugam, G. (1996). High-Density Turbidity Currents: Are They Sandy Debris Flows?: Perspectives. Journal of Sedimentary Research, 66.

Shevenell, A., Kennett, J., \& Lea, D. (2004). Middle Miocene Southern Ocean Cooling and Antarctic Cryosphere Expansion. Science, 305(5691), 1766-1770. 
Shevenell, A., Kennett, J., \& Lea, D. (2008). Middle Miocene Ice Sheet Dynamics, Deep-Sea Temperatures, and Carbon Cycling: A Southern Ocean Perspective. Geochemistry Geophysics Geosystems, 9.

Siegert, M., Carter, S., Tabacco, S., I ad Popov, \& Blankenship, D. (2005). A revised inventory of Antarctic subglacial lakes. Antarctic Science, 17(3), 453-460.

Sijp, W., England, M., \& Toggweiler, J. (2009). Effect of Ocean Gateway Changes under Greenhouse Warmth. Journal of Climate, 22(24), 6639-6652.

Smith, B., Fricker, H., Joughin, I., \& Tulaczyk, S. (2009). An inventory of active subglacial lakes in Antarctica detected by ICESat (2003-2008. Journal of Glaciology, 55(192), 573-593.

Smol, J., Wolfe, Birks, H., Douglas, M., Jones, V., Korhola, A., Pienitz, R., Rühland, K., Sorvari, S., Antoniades, D., Brooks, S., Fallu, M., Hughes, M., Keatley, B., Laing, T., Michelutti, N., Nazarova, L., Nyman, M., Paterson, A., ... Weckström, J. (2005). Climate-Driven Regime Shifts in the Biological Communities of Arctic Lakes. Proceedings of the National Academy of Sciences of the United States of America, 102(12), 4397-4402.

Sorlien, C., Luyendyk, B., Wilson, D., Decesari, R., Bartek, L., \& Diebold, J. (2007). Oligocene Development of the West Antarctic Ice Sheet Recorded in Eastern Ross Sea Strata. Geology, 35(5), 467-470.

Sosdian, S., Babila, T., Greenop, R., Foster, G., \& Lear, C. (2020). Ocean Carbon Storage across the Middle Miocene: A New Interpretation for the Monterey Event. Nature Communications, 11(1), 134.

Sosdian, S., Greenop, R., Hain, M., Foster, G., Pearson, P., \& Lear, C. (2018). Constraining the Evolution of Neogene Ocean Carbonate Chemistry Using the Boron Isotope $\mathrm{Ph}$ Proxy. Earth and Planetary Science Letters, 498, 362-376.

Stap, L., Sutter, J., Knorr, G., Stärz, M., \& Lohmann, G. (2019). Transient Variability of the Miocene Antarctic Ice Sheet Smaller Than Equilibrium Differences. Geophysical Research Letters, 46(8), 4288-4298.

Stearns, L., Smith, B., \& Hamilton, G. (2008). Increased flow speed on a large East Antarctic outlet glacier caused by subglacial floods. Nature Geoscience, 1, 827-831.

Stephens, B., \& Keeling, R. (2000). The Influence of Antarctic Sea Ice on Glacial-Interglacial $\mathrm{CO}_{2}$ Variations. Nature, 404(6774), 171-174.

Stern, T., \& Baxter, A. (2002). Glacial Erosion, Rock, and Peak Uplift within the Central Transantarctic Mountains (Vol. 34). Royal Society of New Zealand.

Stern, T., Baxter, A., \& Barrett, P. (2005). Isostatic Rebound Due to Glacial Erosion within the Transantarctic Mountains. Geology, 33(3), 221-224.

Stern, T., \& ten Brink, U. (1989). Fexural Uplift of the Transantarctic Mountains. Journal of Geophysical Research, 94, 10315-10330.

Stocker, T., Qin, D., Plattner, G., Tignor, M., Allen, S., Boschung, J., Nauels, A., Xia, Y., Bex, V., \& Midgley, P. (2013). Climate Change 2013: The Physical Science Basis. Contribution of working group I to the fifth assessment report of the intergovernmental panel on climate change, 1535. 
Stroeven, A., \& Prentice, M. (1997). A Case for Sirius Group Alpine Glaciation at Mount Fleming, South Victoria Land, Antarctica: A Case against Pliocene East Antarctic Ice Sheet Reduction. GSA Bulletin, 109(7), 825-840.

Sugden, D., \& Denton, G. (2004). Cenozoic Landscape Evolution of the Convoy Range to Mackay Glacier Area, Transantarctic Mountains: Onshore to Offshore Synthesis. Geological Society of America Bulletin, 116(7-8), 840-857.

Sugden, D., Denton, G., \& Marchant, D. (1991). Subglacial Meltwater Channel Systems and Ice Sheet Overriding, Asgard Range, Antarctica. Geografiska Annaler: Series A, Physical Geography, 73, 109-121.

Sugden, D., Marchant, D., Potter, N., Souchez, R., Denton, G., Swisher, C., \& Tison, J. (1995). Preservation of Miocene Glacier Ice in East Antarctica. Nature, 376, 412-414.

Sugden, D., Summerfield, M., Denton, G., Wilch, T., McIntosh, W., Marchant, D., \& Rutford, R. (1999). Landscape Development in the Royal Society Range, Southern Victoria Land, Antarctica: Stability since the Mid-Miocene. Geomorphology, 28(3), 181-200.

Super, J., Thomas, E., Pagani, M., Huber, M., O’Brien, C., \& Hull, P. (2018). North Atlantic Temperature and $p \mathrm{CO}_{2}$ Coupling in the Early-Middle Miocene. Geology, 46(6), 519522.

Swanger, K., Lamp, J., Winckler, G., Schaefer, J., \& Marchant, D. (2017). Glacier Advance During Marine Isotope Stage 11 in the McMurdo Dry Valleys of Antarctica. Scientific Reports, 7(1), 41433.

Talalay, P., \& Pyne, A. (2017). Geological drilling in McMurdo Dry Valleys and McMurdo Sound, Antarctica: Historical development. Cold Regions Science and Technology, 141, 131-162.

Talarico, F., Pace, D., \& Sandroni, S. (2011). Amphibole-Bearing Metamorphic Clasts in Andrill AND-2A Core: A Provenance Tool to Unravel the Miocene Glacial History in the Ross Embayment (Western Ross Sea, Antarctica). Geosphere, 7(4), 922-937.

Taylor, J., Siegert, M., Payne, A., Hambrey, M., O’Brien, P., Cooper, A., \& Leitchenkov, G. (2004). Topographic Controls on Post-Oligocene Changes in Ice-Sheet Dynamics, Prydz Bay Region, East Antarctica. Geology, 32(3), 197-200.

ten Brink, U., Bannister, S., Beaudoin, B., \& Stern, T. (1993). Geophysical Investigations of the Tectonic Boundary between East and West Antarctica. Science, 261, 45-50.

ten Brink, U., Hackney, R., Bannister, S., Stern, T., \& Makovsky, Y. (1997). Uplift of the Transantarctic Mountains and the Bedrock beneath the East Antarctic Ice Sheet. Journal of Geophysical Research: Solid Earth, 102(12), 27603-27621.

ten Brink, U., \& Stern, T. (1992). Rift Flank Uplifts and Hinterland Basins: Comparison of the Transantarctic Mountains with the Great Escarpment of Southern Africa. Journal of Geophysical Research: Solid Earth, 97(1), 569-585.

Thomas, G., Chiverrell, R., \& Huddart, D. (2004). Ice-Marginal Depositional Responses to Readvance Episodes in the Late Devensian Deglaciation of the Isle of Man. Quaternary Science Reviews, 23, 85-106.

Thompson, S., \& Pollard, D. (1997). Greenland and Antarctic Mass Balances for Present and Doubled Atmospheric $\mathrm{CO}_{2}$ from the Genesis Version-2 Global Climate Model. Journal of Climate, 10(5), 871-900. 
Timmermann, A., Friedrich, T., Timm, O., Chikamoto, M., Abe-Ouchi, A., \& Ganopolski, A. (2014). Modeling Obliquity and $\mathrm{CO}_{2}$ Effects on Southern Hemisphere Climate during the Past 408 ka. Journal of Climate, 27(4), 1863-1875.

Toggweiler, J. (1999). Variation of Atmospheric $\mathrm{CO}_{2}$ by Ventilation of the Ocean's Deepest Water. Paleoceanography, 14(5), 571-588.

Toggweiler, J., \& Russell, J. (2008). Ocean Circulation in a Warming Climate. Nature, 451(7176), 286-288.

Tye, B., \& Coleman, J. (1989). Depositional Processes and Stratigraphy of Fluvially Dominated Lacustrine Deltas: Mississippi Delta Plain. Journal of Sedimentary Petrology, 59, 973-996.

Urey, H. (1952). On the Early Chemical History of the Earth and the Origin of Life. Proceedings of the National Academy of Sciences, 38(4), 351-363.

Utescher, T., Bruch, A., Micheels, A., Mosbrugger, V., \& Popova, S. (2011). Cenozoic Climate Gradients in Eurasia - a Palaeo-Perspective on Future Climate Change? Palaeogeography, Palaeoclimatology, Palaeoecology, 304(3), 351-358.

Valletta, R., Willenbring, J., Lewis, A., Ashworth, A., \& Caffee, M. (2015). Extreme Decay of Meteoric Beryllium-10 as a Proxy for Persistent Aridity. Scientific Reports, 5, 17813.

Van der Putten, N., Verbruggen, C., Bjorck, S., Michel, E., Disnar, J., Chapron, E., Moine, B., \& de Beaulieu, J. (2015). The Last Termination in the South Indian Ocean: A unique terrestrial record from Kerguelen Islands (49S) situated within the Southern Hemisphere westerly belt. Quaternary Science Reviews, 122, 142-157.

van der Meer, J., \& Menzies, J. (2011). The Micromorphology of Unconsolidated Sediments. Sedimentary Geology, 238, 213-232.

van der Meer, J., Menzies, J., \& Rose, J. (2003). Subglacial Till: The Deforming Glacier Bed. Quaternary Science Reviews, 22, 1659-1685.

Van Tuyll, C., Wal, R., \& Oerlemans, J. (2007). The Response of a Simple Antarctic Ice-Flow Model to Temperature and Sea-Level Fluctuations over the Cenozoic Era. Annals of Glaciology, 46.

Verfaillie, D., Favier, V., Dumont, M., Jomelli, V., Gilbert, A., Brunstein, D., Gallee, H., Rinterknecht, V., Menegoz, M., \& Frenot, Y. (2015). Recent glacier decline in the Kerguelen Islands (49S, 69E) derived from modeling, field observations, and satellite data. JGR Earth Surface, 120(3), 637-654.

Villalba, R., Boninsegna, J., Veblen, T., Schmelter, A., \& Rubilis, S. (1997). Recent trends in tree-ring records from high elevation sites in the Andes of Northern Patagonia. Climatic Change, 36, 425-454.

Volk, T., \& Hoffert, M. (1985). Ocean Carbon Pumps: Analysis of Relative Strengths and Efficiencies in Ocean-Driven Atmospheric $\mathrm{CO}_{2}$ Changes. In E. Sundquist \& W. Broecker (Eds.), The Carbon Cycle and Atmospheric $\mathrm{CO}_{2}$ : Natural Variations Archean to Present (pp. 99-110).

Vucetich, C., \& Topping, W. (1972). A fiord origin for the Pecten deposits, Wright Valley, Antarctica. New Zealand Journal of Geology and Geophysics, 15(4), 660-673. 
Walker, J., Hays, P., \& Kasting, J. (1981). A Negative Feedback Mechanism for the LongTerm Stabilization of Earth's Surface Temperature. Journal of Geophysical Research: Oceans, 86(10), 9776-9782.

Walker, R., \& James, N. (1992). Facies Models: Response to Sea Level Change. (Vol. 409). Geological Association of Canada.

Warny, S., Askin, R., Hannah, M., Mohr, B., Raine, J., Fabio, F., Harwood, D., Levy, R., Acton, G., Atkins, C., Bassett, K., Berg, M., Bibby, T., Blair, S., Blank, L., Browne, P., Del Carlo, P., Dooley, J., Drew, S., \& Wonik, T. (2009). Palynomorphs from a Sediment Core Reveal a Sudden Remarkably Warm Antarctica During the Middle Miocene. Geology, 37, 955-958.

Webb, P., Harwood, D., Mabin, M., \& McKelvey, B. (1994). Late Neogene Uplift of the Transantarctic Mountains in the Beardmore Glacier Region. Terra Antartica, 1(7), 463-467.

Webb, P., Harwood, D., Mabin, M., \& McKelvey, B. (1996). A marine and terrestrial Sirius Group succession, middle Beardmore Glacier-Queen Alexandra Range, Transantarctic Mountains, Antarctica. Micropaleontology, 27(1-4), 273-297.

Webb, P., Harwood, D., McKelvey, B., Mercer, J., \& Stott, L. (1984). Cenozoic marine sedimentation and ice-volume variation on the East Antarctic craton. Geology, 12(5), 287-291.

White, J., Ager, T., Adam, D., Leopold, E., Liu, G., Jetté, H., \& Schweger, C. (1997). An 18 Million Year Record of Vegetation and Climate Change in Northwestern Canada and Alaska: Tectonic and Global Climatic Correlates. Palaeogeography, Palaeoclimatology, Palaeoecology, 130(1), 293-306.

Wilch, T., Denton, G., Lux, D., \& McIntosh, W. (1993). Limited Pliocene Glacier Extent and Surface Uplift in Middle Taylor Valley, Antarctica. Geografiska Annaler: Series A, Physical Geography, 75(4), 331-351.

Willeit, M., Ganopolski, A., Calov, R., Robinson, A., \& Maslin, M. (2015). The Role of $\mathrm{CO}_{2}$ Decline for the Onset of Northern Hemisphere Glaciation. Quaternary Science Reviews, 119, 22-34.

Williams, T., \& Handwerger, D. (2005). A High-Resolution Record of Early Miocene Antarctic Glacial History from Odp Site 1165, Prydz Bay. Paleoceanography, 20(2).

Wilson, D., Bertram, R., Needham, E., van de Flierdt, T., Welsh, K., McKay, R., Mazumder, A., Riesselman, C., Jimenez-Espejo, F., \& Escutia, C. (2018). Ice Loss from the East Antarctic Ice Sheet During Late Pleistocene Interglacials. Nature, 561(7723), 383-386.

Wilson, D., Jamieson, S., Barrett, P., Leitchenkov, G., Gohl, K., \& Larter, R. (2012). Antarctic Topography at the Eocene-Oligocene Boundary. Palaeogeography Palaeoclimatology Palaeoecology, 335, 24-34.

Wilson, D., Pollard, D., DeConto, R., Jamieson, S., \& Luyendyk, B. (2013). Initiation of the West Antarctic Ice Sheet and Estimates of Total Antarctic Ice Volume in the Earliest Oligocene. Geophysical Research Letters, 40(16), 4305-4309.

Wilson, G., Levy, R., Naish, T., Powell, R., Fabio, F., Ohneiser, C., Sagnotti, L., Winter, D., Cody, S., Henrys, S., Ross, J., Krissek, L., Niessen, F., Pompilio, M., Scherer, R., 
Alloway, B., Barrett, P., Brachfeld, S., Browne, G., \& Wise, S. (2012). Neogene Tectonic and Climatic Evolution of the Western Ross Sea, Antarctica - Chronology of Events from the AND-1B Drill Hole. Global and Planetary Change, 96-97, 189-203. Wilson, T. (1995). Cenozoic Transtension Along the Transantarctic Mountains-West Antarctic Rift Boundary, Southern Victoria Land, Antarctica. Tectonics, 14(2), 531-545.

Witkowski, C., Weijers, J., Blais, B., Schouten, S., \& Sinninghe Damsté, J. (2018). Molecular Fossils from Phytoplankton Reveal Secular $\mathrm{CCO}_{2}$ Trend over the Phanerozoic. Science Advances, 4(11), 4556.

You, Y., Huber, M., Müller, D., Poulsen, C., \& Ribbe, J. (2009). Simulation of the Middle Miocene Climate Optimum. Geophysical Research Letters, 36(4), 4702.

Young, D., Wright, A., Roberts, J., Warner, R., Young, N., Greenbaum, J., Schroeder, D., Holt, J., Sugden, D., Blankenship, D., van Ommen, T., \& Siegert, M. (2011). A Dynamic Early East Antarctic Ice Sheet Suggested by Ice-Covered Fjord Landscapes. Nature, 474(7349), 72-75.

Zachos, J., Breza, J., \& Wise, S. (1992). Early Oligocene Ice-Sheet Expansion on Antarctica: Stable Isotope and Sedimentological Evidence from Kerguelen Plateau, Southern Indian Ocean. Geology, 20, 569-573.

Zachos, J., Dickens, G., \& Zeebe, R. (2008). An Early Cenozoic Perspective on Greenhouse Warming and Carbon Cycle Dynamics. Nature, 451, 279-283.

Zachos, J., Mo, P., Sloan, L., Thomas, E., \& Billups, K. (2001). Trends, Rhythms, and Aberrations in Global Climate 65 Ma to Present. Science, 292, 686-693.

Zhang, Y., Pagani, M., Liu, Z., Bohaty, S., \& Deconto, R. (2013). A 40-Million-Year History of Atmospheric $\mathrm{CO}_{2}$. Philosophical transactions. Series A, Mathematical, Physical, and Engineering Sciences, 37, 1-20. 
